\title{
ACCELERATED FUEL QUALIFICATION (AFQ) WORKSHOP II SUMMARY REPORT
}

\author{
Prepared Under \\ Contract DE-NE0008819 \\ And \\ Contract DE-NE0008831 \\ Presented January 16, 2020 \\ Complied By \\ R. Faibish \\ General Atomics
}

\section{DISCLAIMER}

\begin{abstract}
This report contains some work sponsored by an agency of the United States Government. Neither the United States Government nor any agency thereof, nor any of their employees, makes any warranty, express or implied, or assumes any legal liability or responsibility for the accuracy, completeness, or usefulness of any information, apparatus, product, or process disclosed, or represents that its use would not infringe privately owned rights. Reference herein to any specific commercial product, process, or service by trade name, trademark, manufacturer, or otherwise, does not necessarily constitute or imply its endorsement, recommendation, or favoring by the United States Government or any agency thereof. The views and opinions of authors expressed herein do not necessarily state or reflect those of the United States Government or any agency thereof.
\end{abstract}

\section{GENERAL ATOMIC PROJECT 30543 NOVEMBER 2020}


TABLE OF CONTENTS

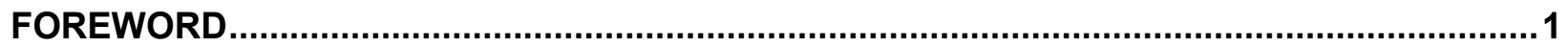

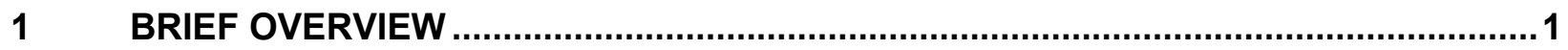

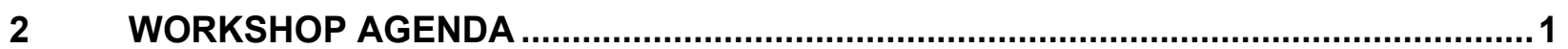

3 DISCUSSION AND KEY TAKEAWAYS ............................................................ 3

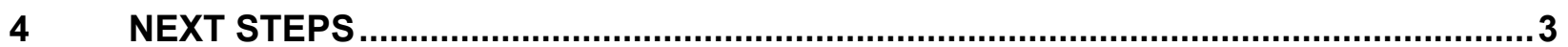

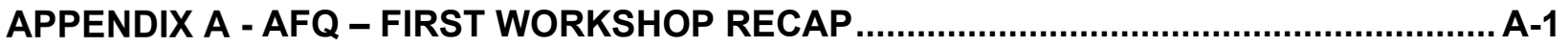

APPENDIX B - ROADMAP TO ACCELERATED FUEL QUALIFICATION............................ B-1

APPENDIX C - APPENDIX C: HIGH ENERGY HEAVY ION IRRADIATION FOR ACCELERATED TESTING ............................................................................. C-1

APPENDIX D - FISSION ACCELERATED STEADY-STATE TESTING (FAST) IN NUCLEAR

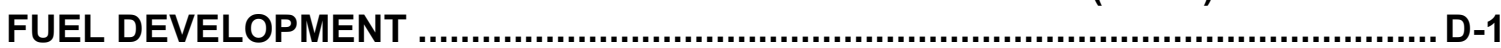

APPENDIX E - APPENDIX E: FUEL PERFORMANCE MODELING AND FUEL QUALIFICATION AT TERRAPOWER ................................................................... E-1

APPENDIX F - FUEL PERFORMANCE SIMULATIONS OF SWELLING, FISSION GAS RELEASE AND CREEP IN U $\mathrm{SI}_{2}$ INFORMED BY ATOMISTIC SIMULATIONS ..........F-1 APPENDIX G - TCR FUEL DESIGN AND DEVELOPMENT TOWARDS QUALIFICATION .. G-1 APPENDIX H - FELTUS AFQ WORKSHOP II JAN 2020 PRESENTATION ON TRISO FUEL MATERIAL PROPERTIES STUDY

APPENDIX I - ENERGY MULTIPLIER MODULE (EM²) ACCELERATED FUEL QUALIFICATION STRATEGY

APPENDIX J - ADVANCED FUEL QUALIFICATION METHODOLOGY REPORT ..................J-1

APPENDIX K - FUEL QUALIFICATION, NRC PERSPECTIVES ......................................... K-1

APPENDIX L - LOWER LENGTH SCALE MODELING EXAMPLES ...................................

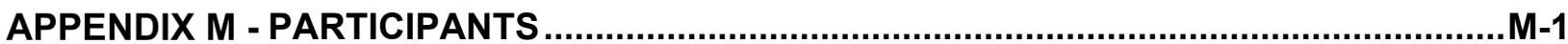




\section{FOREWORD}

The files contained in this report are the compilation of all materials pertaining to the second workshop on Accelerated Fuel Qualification (AFQ): AFQ Workshop II. The overall goal of the workshop was to discuss progress since the first workshop in May 2019 in developing the enabling computational and experimental AFQ building blocks, as well as to agree on next steps in advancing the AFQ methodology and its implementation.

\section{BRIEF OVERVIEW}

The second AFQ workshop, AFQ Workshop II, was held on Thursday, January 16, 2020, in Washington, DC, with 29 participants from industry (General Atomics, Framatome, Lightbridge, TerraPower, Westinghouse), national labs (ANL, INL, LANL, ORNL), DOE-NE, NRC, as well as two aerospace companies who are supporting NASA (Aerospace Corporation and Analytical Mechanics Associates). The main goal of the workshop was to discuss progress since the first workshop in May 2019 in developing the enabling computational and experimental AFQ building blocks and agree on next steps. A draft of the AFQ Working Group Charter was also reviewed and changes agreed to. There were 12 presentations given during the workshop, which included overview presentations, information on status of AFQ building computational and experimental building blocks, case studies, and a concluding presentation on NRC perspectives.

\section{WORKSHOP AGENDA}

\section{Morning Session:}

\begin{tabular}{|c|c|c|c|c|}
\hline Topic & Presenter & Start & End & Duration \\
\hline \multicolumn{5}{|c|}{ Welcome and Workshop Introduction } \\
\hline First AFQ Workshop Recap & $\begin{array}{l}\text { Ron Faibish } \\
\text { (General Atomics) }\end{array}$ & $\begin{array}{l}8: 30 \\
\mathrm{am}\end{array}$ & $\begin{array}{l}8: 45 \\
\text { am }\end{array}$ & $15 \min$ \\
\hline $\begin{array}{l}\text { Roadmap to Accelerated Fuel } \\
\text { Qualification }\end{array}$ & $\begin{array}{l}\text { Mark Adams } \\
\text { (General Atomics) }\end{array}$ & $\begin{array}{l}8: 45 \\
\text { am }\end{array}$ & $\begin{array}{l}9: 20 \\
\text { am }\end{array}$ & $35 \min$ \\
\hline \multicolumn{5}{|c|}{ Fundamental Computational, Experimental, and Theoretical Building Blocks } \\
\hline $\begin{array}{l}\text { High energy heavy ion irradiation } \\
\text { for accelerated testing }\end{array}$ & $\begin{array}{l}\text { Abdellatif Yacout } \\
\text { (ANL) }\end{array}$ & $\begin{array}{l}9: 20 \\
\text { am }\end{array}$ & $\begin{array}{l}9: 50 \\
\text { am }\end{array}$ & $30 \mathrm{~min}$ \\
\hline $\begin{array}{l}\text { Fission Accelerated Steady-state } \\
\text { Testing (FAST) in Nuclear Fuel } \\
\text { Development }\end{array}$ & $\begin{array}{l}\text { Matthew Kerr } \\
(\mathrm{INL})\end{array}$ & $\begin{array}{l}9: 50 \\
\text { am }\end{array}$ & $\begin{array}{l}10: 20 \\
\text { am }\end{array}$ & $30 \min$ \\
\hline \multicolumn{5}{|c|}{ BREAK (10:20 am - 10:45 am) } \\
\hline \multicolumn{5}{|c|}{ Integrating Building Blocks and Bridging Multi-Scale Phenomena } \\
\hline $\begin{array}{l}\text { Overview of a process to develop } \\
\text { and identify regulatory }\end{array}$ & $\begin{array}{l}\text { Pete Gaillard } \\
\text { (TerraPower) } \\
\end{array}$ & $\begin{array}{l}10: 45 \\
\text { am }\end{array}$ & $\begin{array}{l}11: 15 \\
\text { am }\end{array}$ & $30 \min$ \\
\hline
\end{tabular}




\begin{tabular}{|l|l|c|c|c|}
\hline Topic & Presenter & Start & End & Duration \\
\hline $\begin{array}{l}\text { requirements and design criteria } \\
\text { applicable to metallic fuel }\end{array}$ & & & \\
\hline \multicolumn{4}{|c|}{ Nuclear Fuel Applications and Case Studies } \\
\hline $\begin{array}{l}\text { Fuel performance simulations of } \\
\text { swelling, fission gas release and } \\
\text { creep in U3Si2 informed by } \\
\text { atomistic simulations }\end{array}$ & $\begin{array}{l}\text { David Andersson } \\
\text { (LANL) }\end{array}$ & $\begin{array}{c}11: 15 \\
\text { am }\end{array}$ & $\begin{array}{c}11: 45 \\
\text { am }\end{array}$ & 30 min \\
\hline $\begin{array}{l}\text { TCR fuel design and development } \\
\text { towards qualification }\end{array}$ & $\begin{array}{l}\text { Kurt Terrani } \\
\text { (ORNL) }\end{array}$ & $\begin{array}{c}11: 45 \\
\text { am }\end{array}$ & $\begin{array}{c}12: 15 \\
\text { pm }\end{array}$ & 30 min \\
\hline \multicolumn{4}{|l|}{ LUNCH (12:15 pm - 1:15 pm) } \\
\hline
\end{tabular}

\section{Afternoon Session:}

\begin{tabular}{|c|c|c|c|c|}
\hline Topic & Presenter & Start & End & Duration \\
\hline \multicolumn{5}{|c|}{ Nuclear Fuel Applications and Case Studies (Continued) } \\
\hline $\begin{array}{l}\text { Using statistical uncertainty } \\
\text { analyses to determine the } \\
\text { importance of irradiation effects on } \\
\text { TRISO fuel and materials } \\
\text { properties }\end{array}$ & $\begin{array}{l}\text { Madeline Feltus } \\
\text { (US DOE-NE) }\end{array}$ & $\begin{array}{l}1: 15 \\
\mathrm{pm}\end{array}$ & $\begin{array}{l}1: 45 \\
\mathrm{pm}\end{array}$ & $30 \mathrm{~min}$ \\
\hline $\begin{array}{l}\text { Case study illustrating how } \\
\text { building blocks are applied and } \\
\text { the direction TerraPower is } \\
\text { moving }\end{array}$ & $\begin{array}{l}\text { James Vollmer } \\
\text { (TerraPower) }\end{array}$ & $\begin{array}{l}1: 45 \\
\mathrm{pm}\end{array}$ & $\begin{array}{l}2: 15 \\
\mathrm{pm}\end{array}$ & $30 \min$ \\
\hline $\begin{array}{l}\text { Energy Multiplier Module }\left(\mathrm{EM}^{2}\right) \\
\text { accelerated fuel qualification } \\
\text { strategy }\end{array}$ & $\begin{array}{l}\text { John Bolin } \\
\text { (General Atomics) }\end{array}$ & $\begin{array}{l}2: 15 \\
\mathrm{pm}\end{array}$ & $\begin{array}{l}2: 45 \\
\mathrm{pm}\end{array}$ & $30 \min$ \\
\hline $\begin{array}{l}\text { Lower Length Scale Modeling } \\
\text { Examples }\end{array}$ & $\begin{array}{l}\text { Kallie Metzger } \\
\text { (Westinghouse) }\end{array}$ & $\begin{array}{l}2: 45 \\
\mathrm{pm}\end{array}$ & $\begin{array}{c}2: 55 \\
\mathrm{pm}\end{array}$ & $10 \mathrm{~min}$ \\
\hline \multicolumn{5}{|c|}{ BREAK (2:55 pm - 3:10 pm) } \\
\hline \multicolumn{5}{|c|}{ Regulatory Discussion } \\
\hline $\begin{array}{l}\text { NRC input and terminology } \\
\text { conversation }\end{array}$ & $\begin{array}{l}\text { Christopher Van Wert } \\
\text { (US NRC) }\end{array}$ & $\begin{array}{l}3: 10 \\
\mathrm{pm}\end{array}$ & $\begin{array}{l}3: 40 \\
\mathrm{pm}\end{array}$ & $30 \mathrm{~min}$ \\
\hline \multicolumn{5}{|c|}{ AFQ Technical Working Group Charter Discussion } \\
\hline Open Discussion & $\begin{array}{l}\text { Ron Faibish- } \\
\text { Moderator } \\
\text { (General Atomics) } \\
\end{array}$ & $\begin{array}{l}3: 40 \\
\mathrm{pm}\end{array}$ & $\begin{array}{l}4: 30 \\
\mathrm{pm}\end{array}$ & $50 \min$ \\
\hline \multicolumn{5}{|c|}{ Future Actions } \\
\hline Open Discussion & \begin{tabular}{|l|} 
Ron Faibish - \\
Moderator \\
(General Atomics) \\
\end{tabular} & $\begin{array}{l}4: 30 \\
\mathrm{pm}\end{array}$ & $\begin{array}{l}\text { 5:00 } \\
\mathrm{pm}\end{array}$ & $30 \min$ \\
\hline \multicolumn{5}{|c|}{ ADJOURN (5:00 pm) } \\
\hline
\end{tabular}


1. Participants of the AFQ Working Group (WG) agreed that the main premise of the AFQ methodology remains that modeling and experiments should be simultaneously exploited to reduce years of data that would otherwise be required for deployment of new nuclear fuels.

2. Case studies were presented that further demonstrated modeling and experimental tools development to advance and accelerated approach to fuel qualification by coupling the two.

3. The WG agreed that fuel qualification needs to be carried out with a specific reactor design and related safety case in mind.

4. The NRC is seeking input from the team, as part of the public in general, on a key fuel qualification-related congressional requirement in the Nuclear Energy Innovation and Modernization Act (NEIMA) (January 2019) legislation. The specific relevant ask in the bill is as follows:

"Report required. -Not later than 30 months after the date of enactment of this Act, the Commission shall submit to the appropriate congressional committees a report... for-- (B) ensuring that the Commission has adequate expertise, modeling, and simulation capabilities, or access to those capabilities, to support the evaluation of commercial advanced reactor license applications, including the qualification of advanced nuclear reactor fuel."

The NRC plans to submit the report to Congress by January 2021. The AFQ WG is planning to provide consolidated input to the NRC before their white paper is due to Congress.

\section{NEXT STEPS}

1. Plan for the third AFQ workshop (AFQ Workshop III) in the late fall 2020 timeframe, with an agenda aimed to follow up on items listed in the takeaways above and any new items as they arise leading to the third workshop.

2. Finalize the AFQ Working Group Charter.

3. Discuss AFQ White Paper outline and drafting assignments. 
APPENDIX A - AFQ - First Workshop Recap 


\section{Accelerated Fuel Qualification (AFQ): First Workshop Recap}

By

Ron S. Faibish, Ph.D.

Sr. Director of Business Development General Atomics

January 16, 2020

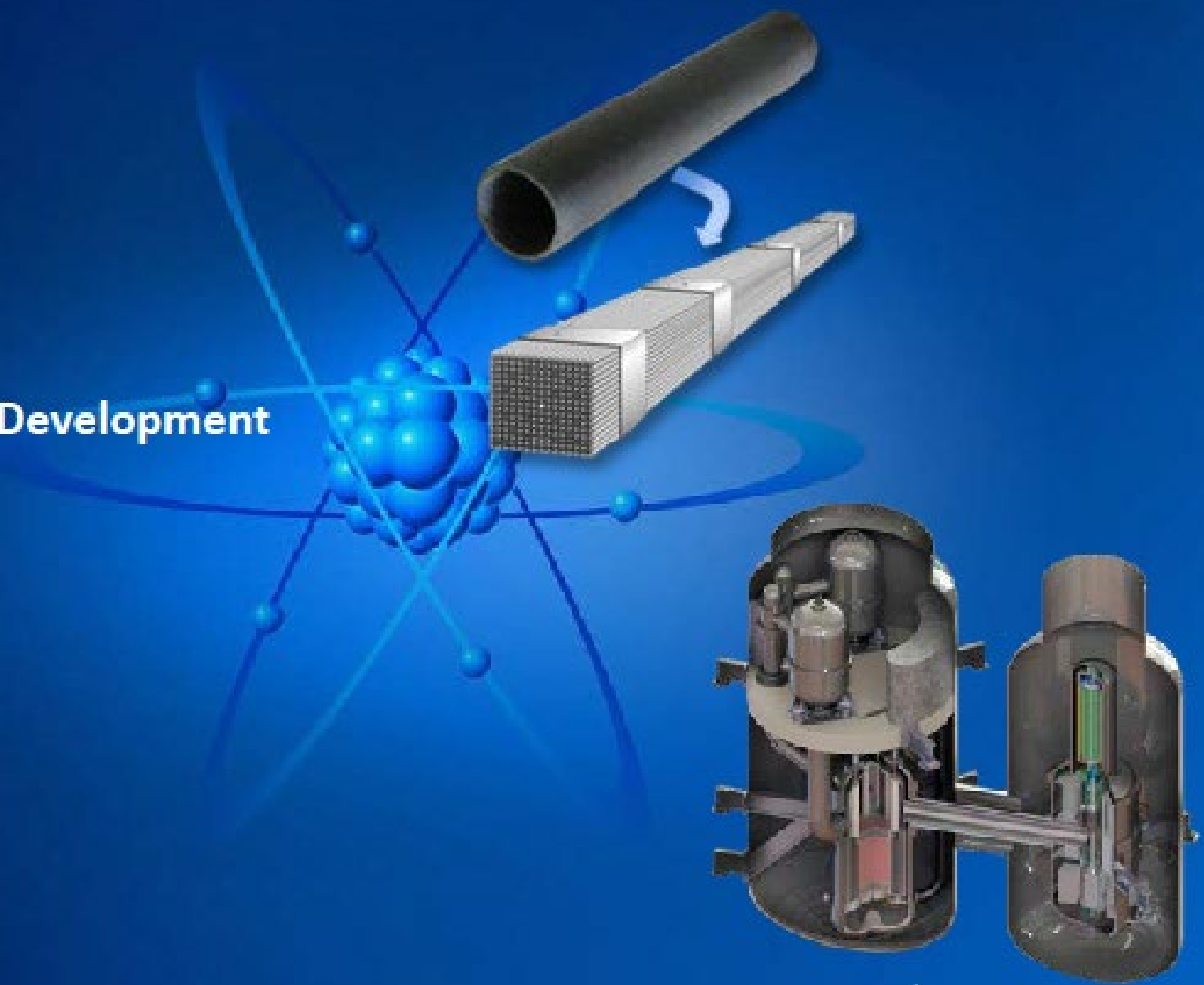

\& general atomies 


\section{The Proposition}

Modeling and experiments must be simultaneously exploited to markedly reduce the years of data that would otherwise be required for deployment of new nuclear fuels. 


\section{Conceptual Progression of AFQ Approach}

Data-Driven Approach

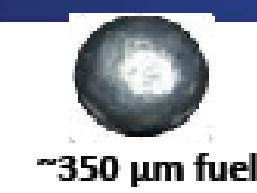

microsphere

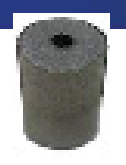

Pellet

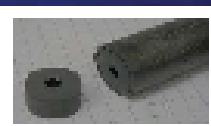

Fuel rod

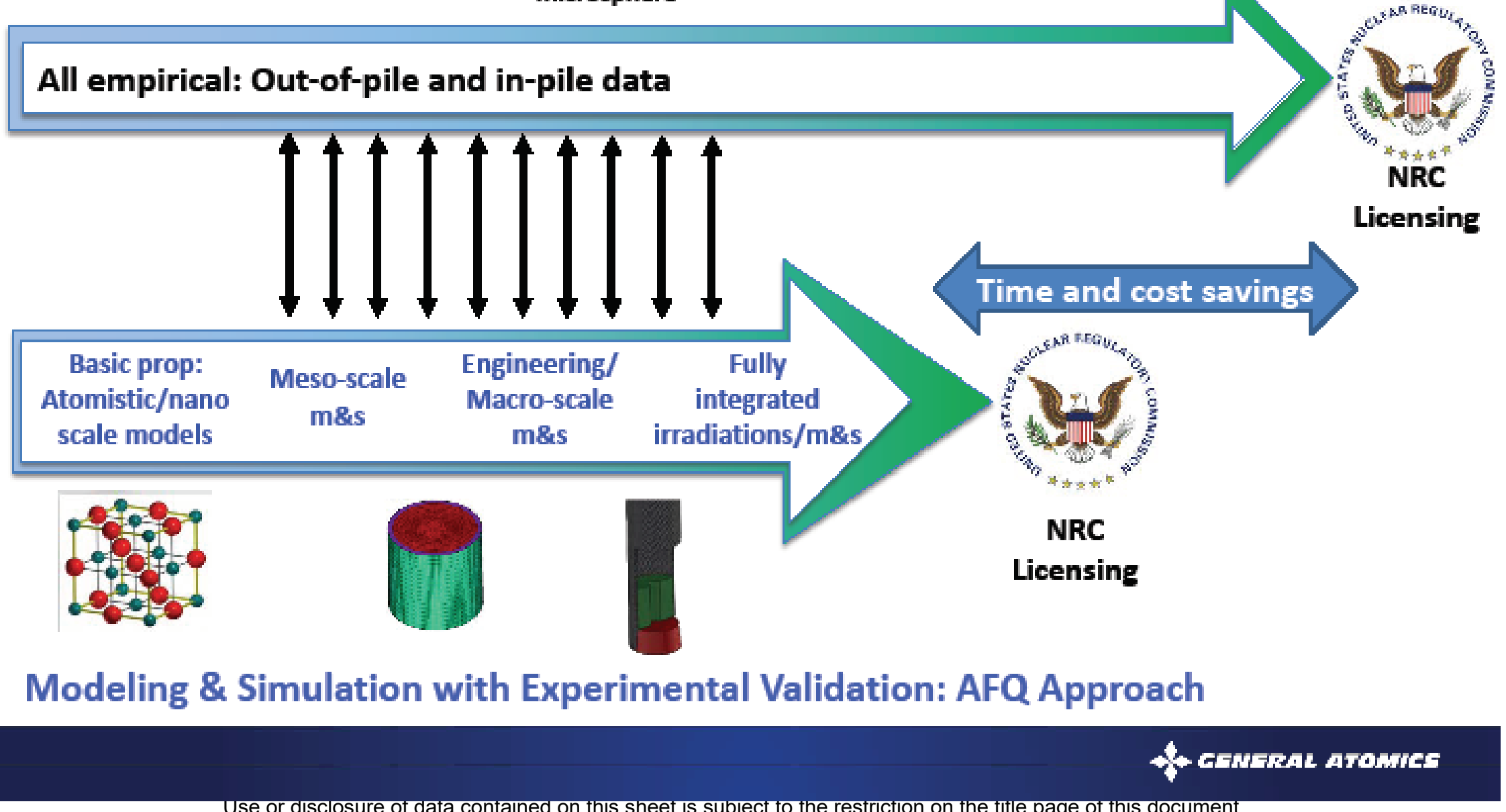

Use or disclosure of data contained on this sheet is subject to the restriction on the title page of this document 


\section{A Key Enabler: Accelerated Fuel Qualification (AFQ)}

\section{AFQ Defined:}

The combination of microstructurally-informed advanced nuclear fuel performance modeling and simulation (M\&S) tools with targeted irradiation and other select experimental data that can significantly reduce the cost and number of irradiation experiments and, ultimately, the cost and time associated with new fuel qualification.

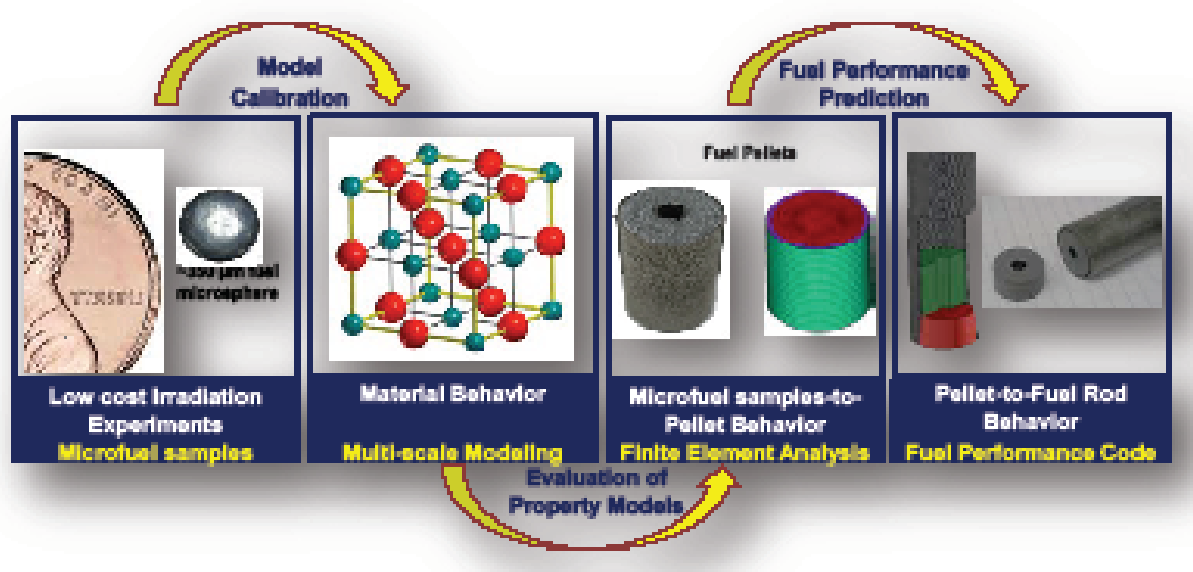




\section{AFQ Working Framework and Key Stakeholders: Making it All Happen}

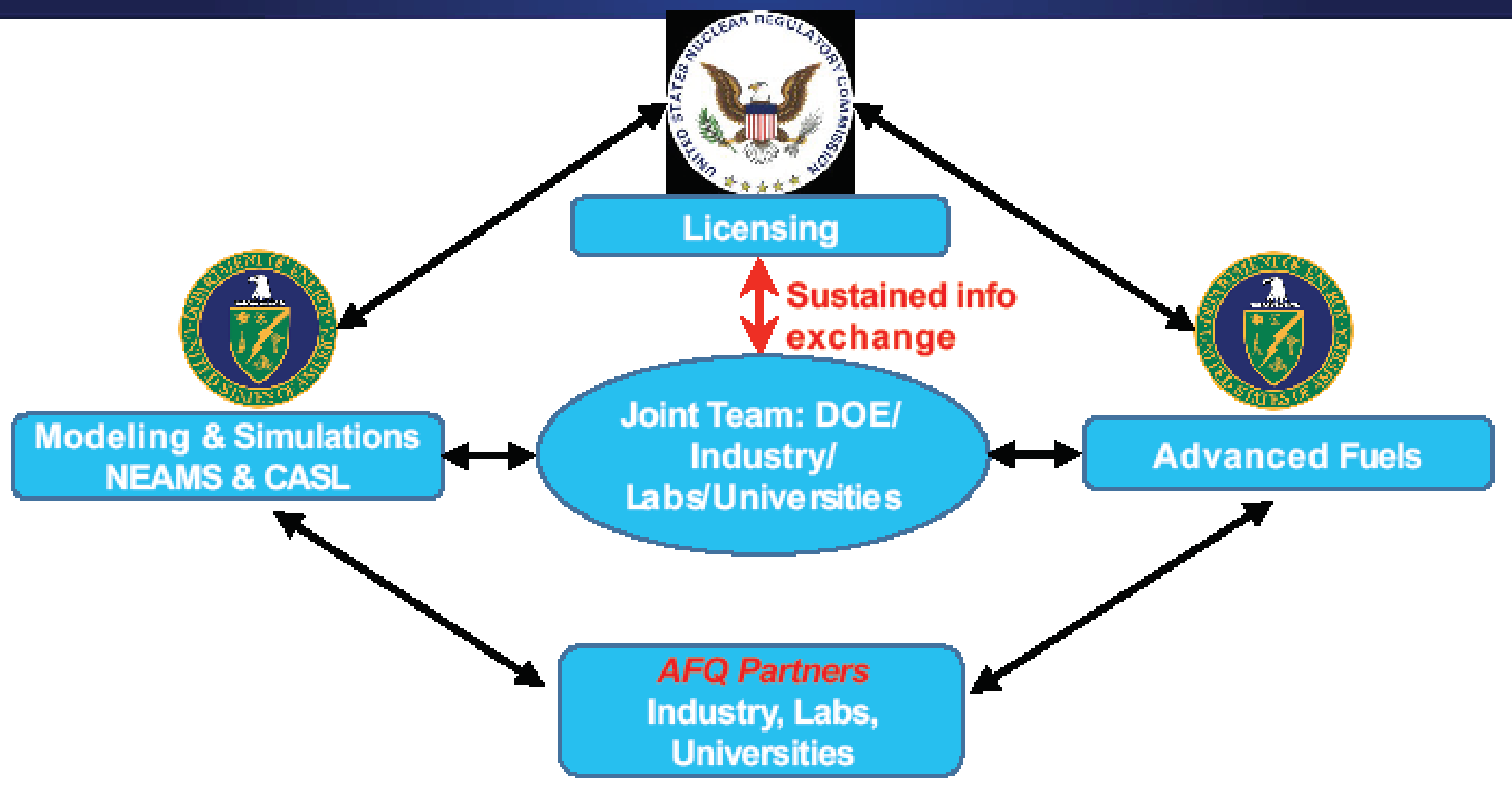

Building a coalition of partners with DOE's overall coordination 


\section{Key Take-Aways from First Workshop (I)}

- Significant advancements in computational power and tools in the recent years have enabled the increasingly accurate prediction of material properties and behavior from basic principles through complex meso and engineering scale phenomena.

- AFQ methodology has the potential to reduce the high number of new nuclear integral tests that are required to qualify new fuels while maintaining the highest safety standards and requirements.

- All participants strongly agree that the AFQ methodology in no way will substitute the need for integral fuel testing. 


\section{Key Take-Aways from First Workshop (II)}

- Uncertainties associated with any computational techniques to model or simulate material properties and/or behavior need to be quantified and their implications on validity of $m \& s$ results assessed.

- Technical Working Group (TWG) should be established that would be charged with furthering the development and applicability of the AFQ methodology.

- NRC recommended linking any AFQ-related fuel work to safety analysis activities of the reactor system as a whole (i.e., a holistic approach to safety analysis). 


\section{Summary and Next Steps}

Summary Statement: An agreed-to methodology provides guidance to industry on the path needed to qualify new materials and technologies in an expeditious way that incorporates modeling and simulation with experiments.

\section{Next Steps:}

- Plan for a follow up workshop in the fall 2019 timeframe.

- Establish the AFQ Technical Working Group. This could be discussed and agreed upon in the next workshop meeting. 


\section{Agenda: Morning Session}

\begin{tabular}{|c|c|c|c|c|}
\hline Topic & Presenter & Start & End & Duration \\
\hline \multicolumn{5}{|c|}{ Welcome and Workshop Introduction } \\
\hline First AFQ Workshop Recap & $\begin{array}{l}\text { Ron Faibish } \\
\text { (General Atomics) }\end{array}$ & $8: 30 \mathrm{am}$ & $8: 45$ am & $15 \mathrm{~min}$ \\
\hline $\begin{array}{l}\text { Roadmap to Accelerated Fuel } \\
\text { Qualification }\end{array}$ & $\begin{array}{l}\text { Mark Adams } \\
\text { (General Atomics) }\end{array}$ & $8: 45$ am & 9:20 am & $35 \mathrm{~min}$ \\
\hline \multicolumn{5}{|c|}{ Fundamental Computational, Experimental, and Theoretical Building Blocks } \\
\hline $\begin{array}{l}\text { High energy heavy ion irradiation for } \\
\text { accelerated testing }\end{array}$ & $\begin{array}{l}\text { Abdellatif Yacout } \\
\text { (ANL) }\end{array}$ & $9: 20 \mathrm{am}$ & 9:50 am & $30 \mathrm{~min}$ \\
\hline $\begin{array}{l}\text { Fission Accelerated Steady-state } \\
\text { Testing (FAST) in Nuclear Fuel } \\
\text { Development }\end{array}$ & $\begin{array}{l}\text { Geoffrey Beausoleil } \\
\text { (INL) }\end{array}$ & $9: 50 \mathrm{am}$ & $10: 20 \mathrm{am}$ & $30 \mathrm{~min}$ \\
\hline \multicolumn{5}{|c|}{ BREAK (10:20 am - 10:45 am) } \\
\hline \multicolumn{5}{|c|}{ Integrating Building Blocks and Bridging Multi-Scale Phenomena } \\
\hline $\begin{array}{l}\text { Overview of a process to develop and } \\
\text { identify regulatory requirements and } \\
\text { design criteria applicable to metallic } \\
\text { fuel }\end{array}$ & $\begin{array}{l}\text { Pete Gaillard } \\
\text { (TerraPower) }\end{array}$ & $10: 45 \mathrm{am}$ & $11: 15 \mathrm{am}$ & $30 \mathrm{~min}$ \\
\hline \multicolumn{5}{|c|}{ Nuclear Fuel Applications and Case Studies } \\
\hline $\begin{array}{l}\text { Fuel performance simulations of } \\
\text { swelling, fission gas release and } \\
\text { creep in U3Si2 informed by atomistic } \\
\text { simulations }\end{array}$ & $\begin{array}{l}\text { David Andersson } \\
\text { (LANL) }\end{array}$ & 11:15 am & $11: 45 \mathrm{am}$ & $30 \mathrm{~min}$ \\
\hline $\begin{array}{l}\text { TCR fuel design and development } \\
\text { towards qualification }\end{array}$ & $\begin{array}{l}\text { Kurt Terrani } \\
\text { (ORNL) }\end{array}$ & $11: 45 \mathrm{am}$ & $12: 15 \mathrm{pm}$ & $30 \mathrm{~min}$ \\
\hline
\end{tabular}




\section{Agenda: Afternoon Session}

\begin{tabular}{|c|c|c|c|c|}
\hline Topic & Presenter & Start & End & Duration \\
\hline \multicolumn{5}{|c|}{ Nuclear Fuel Applications and Case Studies (Continued) } \\
\hline $\begin{array}{l}\text { Using statistical uncertainty analyses } \\
\text { to determine the importance of } \\
\text { irradiation effects on TRISO fuel and } \\
\text { materials properties }\end{array}$ & $\begin{array}{l}\text { Madeline Feltus } \\
\text { (US DOE-NE) }\end{array}$ & $1: 15 \mathrm{pm}$ & $1: 45 \mathrm{pm}$ & $30 \mathrm{~min}$ \\
\hline $\begin{array}{l}\text { Case study illustrating how building } \\
\text { blocks are applied and the direction } \\
\text { TerraPower is moving }\end{array}$ & $\begin{array}{l}\text { James Vollmer } \\
\text { (TerraPower) }\end{array}$ & $1: 45 \mathrm{pm}$ & 2:15 pm & $30 \mathrm{~min}$ \\
\hline $\begin{array}{l}\text { Energy Multiplier Module }\left(E M^{2}\right) \\
\text { accelerated fuel qualification strategy }\end{array}$ & $\begin{array}{l}\text { John Bolin } \\
\text { (General Atomics) }\end{array}$ & $2: 15 \mathrm{pm}$ & $2: 45 \mathrm{pm}$ & $30 \mathrm{~min}$ \\
\hline \multicolumn{5}{|c|}{ BREAK (2:45 pm - 3:00 pm) } \\
\hline \multicolumn{5}{|c|}{ Regulatory Discussion } \\
\hline $\begin{array}{l}\text { NRC input and terminology } \\
\text { conversation }\end{array}$ & $\begin{array}{l}\text { Christopher Van Wert } \\
\text { (US NRC) }\end{array}$ & $3: 00$ pm & $3: 30 \mathrm{pm}$ & $30 \mathrm{~min}$ \\
\hline \multicolumn{5}{|c|}{ AFQ Technical Working Group Charter Discussion } \\
\hline Open Discussion & $\begin{array}{l}\text { Mark Adams - Moderator } \\
\text { (General Atomics) }\end{array}$ & $3: 30 \mathrm{pm}$ & $4: 15 \mathrm{pm}$ & $45 \mathrm{~min}$ \\
\hline \multicolumn{5}{|c|}{ Future Actions } \\
\hline Open Discussion & $\begin{array}{l}\text { Ron Faibish - Moderator } \\
\text { (General Atomics) }\end{array}$ & 4:15 pm & $4: 45 \mathrm{pm}$ & $30 \mathrm{~min}$ \\
\hline
\end{tabular}




\section{Transition of Advanced M\&S Capabilities into Usable Engineering Tools}

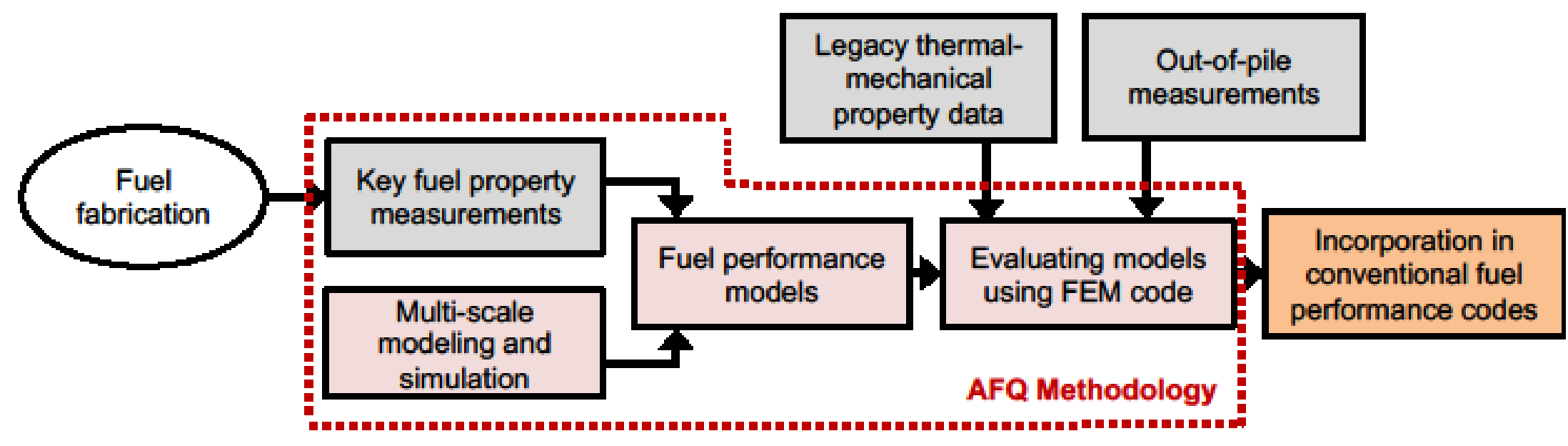


APPENDIX B - Roadmap to Accelerated Fuel Qualification 


\section{Roadmap to Accelerated Fuel Qualification}

By

Mark L. Adams, Ph.D.

Director of Special Programs

General Atomics

Presented at the

Accelerated

Fuel Qualification

Workshop 2

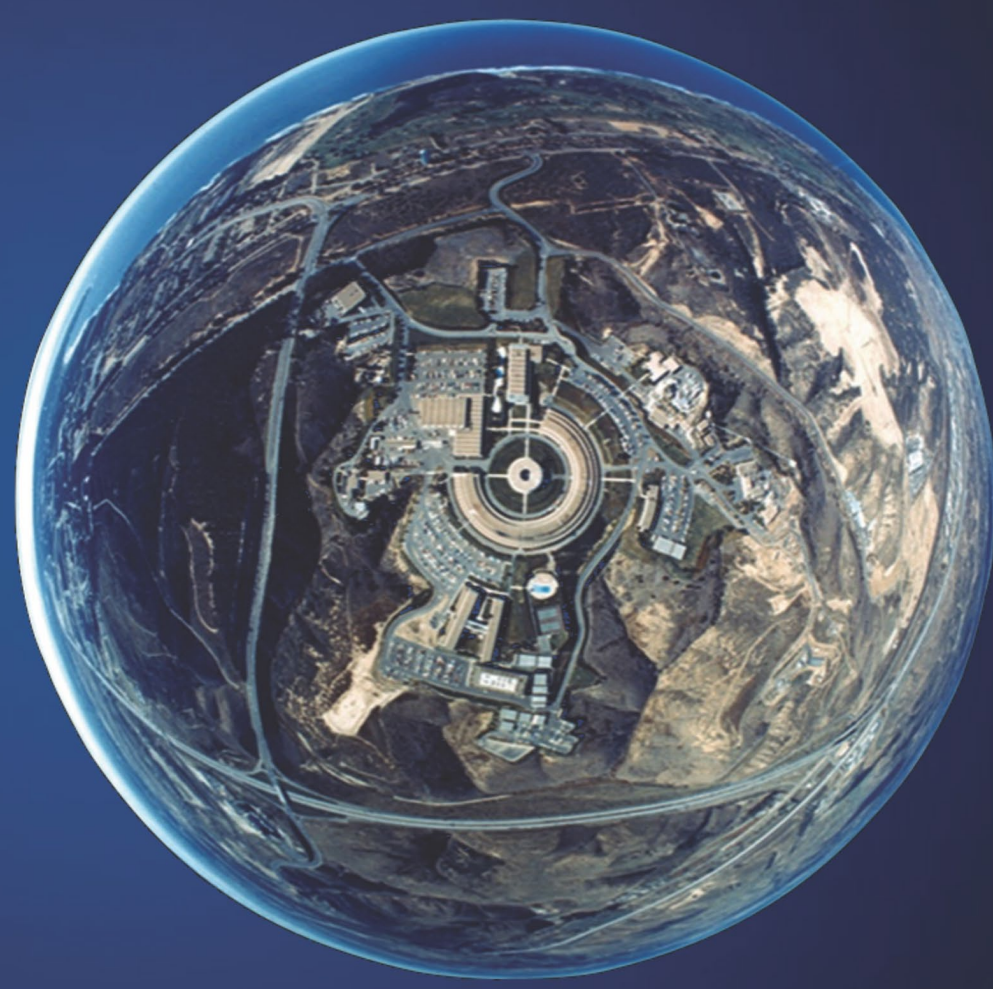

16 January 2020

\& general atomics 


\section{Roadmap to Accelerated Fuel Qualification}

- Build on the, "Conceptual Progression of AFQ Approach"

- Validated Predictive Capability

- Building blocks

- Coupling multi-physics phenomena

- Bridging multi-scale phenomena

- Performance Risk Management

- Systems Engineering

- Risk Analysis

- AFQ Workshop 2 Opening Comments and Agenda 


\section{Conceptual Progression of AFQ Approach Presented at the First AFQ Workshop}

\section{Data-Driven Approach}

\section{$\sim 350 \mu \mathrm{m}$ fuel}

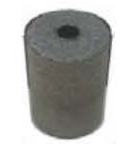

Pellet

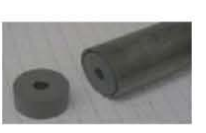

Fuel rod

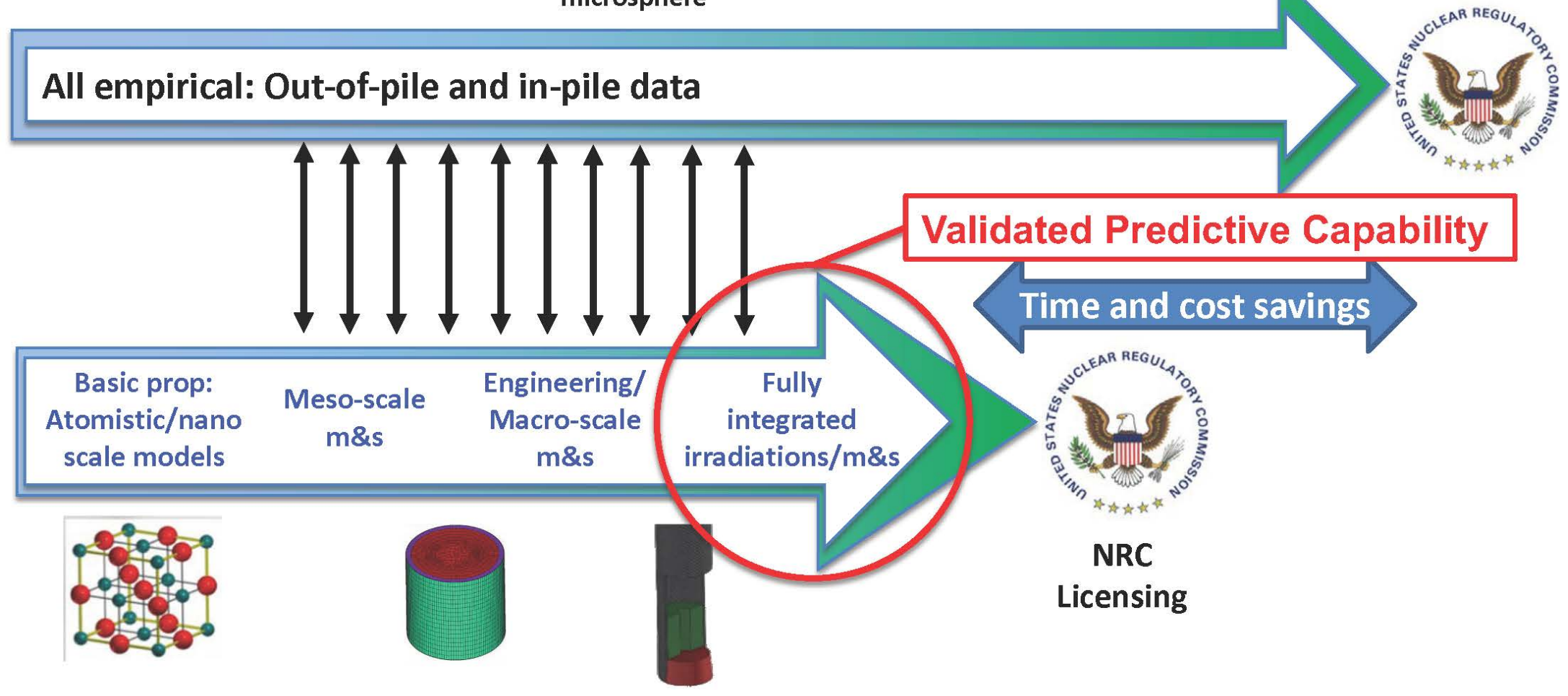

Modeling \& Simulation with Experimental Validation: AFQ Approach 


\section{Validated Predictive Capability Building Blocks}

\section{Theory}

- Explains nuclear fuel performance

- Multi-Physics \& Multi-Scale

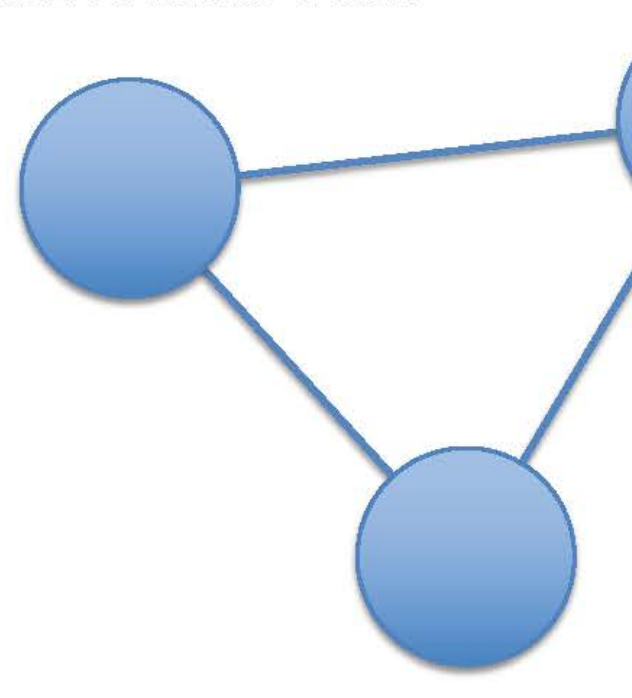

\section{Experiment}

- Validates theory

- Focused \& Integral

\section{Computation}

- Integrates knowledge

- Solves theoretical models \& processes experimental data 


\section{Coupling Multi-Physics Phenomena is a Validated Predictive Capability Challenge}

- Nuclear fuel performance involves multiple coupled physical processes, e.g., hydrodynamic energy equation includes $p$ (pressure from EOS) and $Q$ (heat generation form fission):

$$
\frac{\partial}{\partial t}\left(\rho u+\frac{1}{2} \rho v^{2}\right)+\nabla \cdot\left[\left(\rho u+\frac{1}{2} \rho v^{2}\right) v+p v\right]=\rho Q
$$

- Operator splitting can help multi-physics coupling

$$
\begin{aligned}
& \frac{d u}{d t}=(A+B) u \quad u(h)=e^{h(A+B)} u(0) \\
& e^{h(A+B)} \approx e^{h A} e^{h B} \quad \text { First Order } \\
& e^{h(A+B)} \approx e^{h A / 2} e^{h B} e^{h A / 2} \quad \text { Second Order }
\end{aligned}
$$

- Numerical analysis can help quantify uncertainty

- Accuracy Order of the Approximation

- Consistency Discretized Equation $\Leftrightarrow$ Differential Equation

- Stability Numerical Solution $\Leftrightarrow$ Exact Solution of Discretized Equation

- Convergence Numerical Solution $\Leftrightarrow$ Exact Solution of Differential Equation 


\section{Bridging Multi-Scale Phenomena is a Validated Predictive Capability Challenge}

- Nuclear fuel performance spans an enormous spatial and temporal range

Atoms [nm]

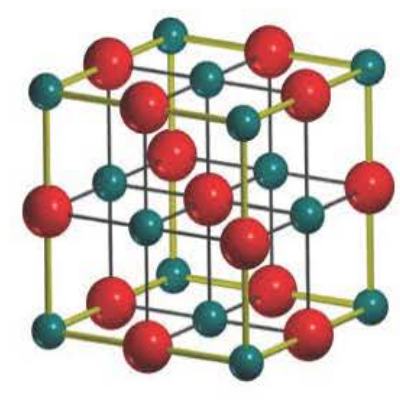

Kernel $[\mu \mathrm{m}]$

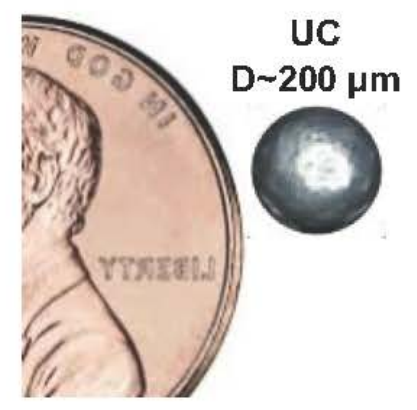

Pellet $[\mathrm{cm}]$

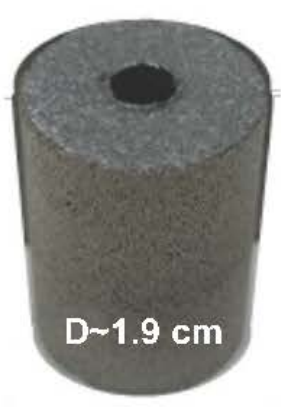

EM ${ }^{2}$ Fuel $[\mathrm{m}]$

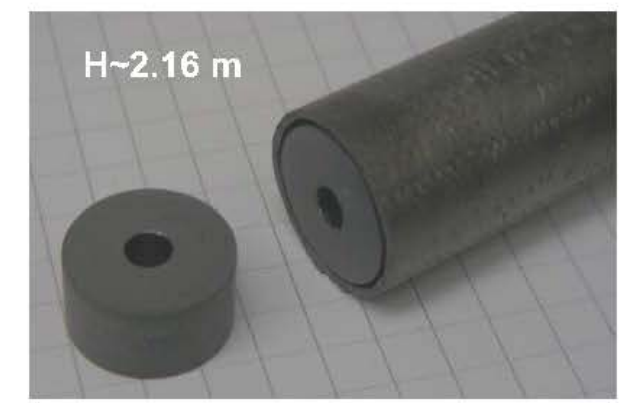

- Approaches to incorporate multi-scale information:

- Tables or empirical formulas

- Inline model with parameters 


\section{Statistical Mechanics Models can Connect Atomic Properties with Macroscopic Properties}

- Ornstein-Zernike and hypernetted-chain equations connect atomic interaction potential with macroscopic properties

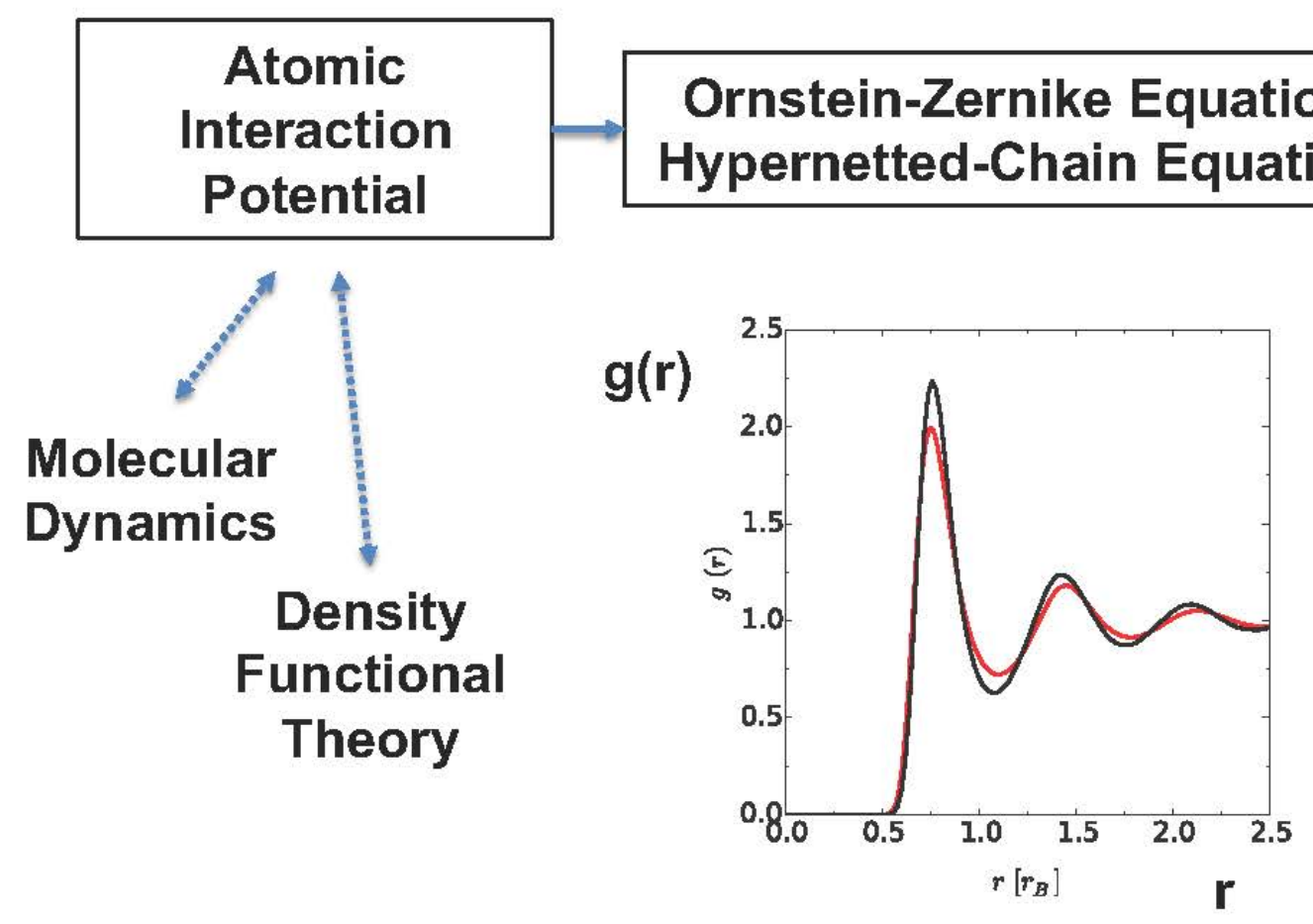

Thermodynamic Functions 


\section{Independent Multi-Scale Experimental Measurements can Reduce Uncertainty}

Microscopic Property Measurements

$S(k)$ is related to the Fourier transform of $\mathbf{g}(\mathbf{r})$

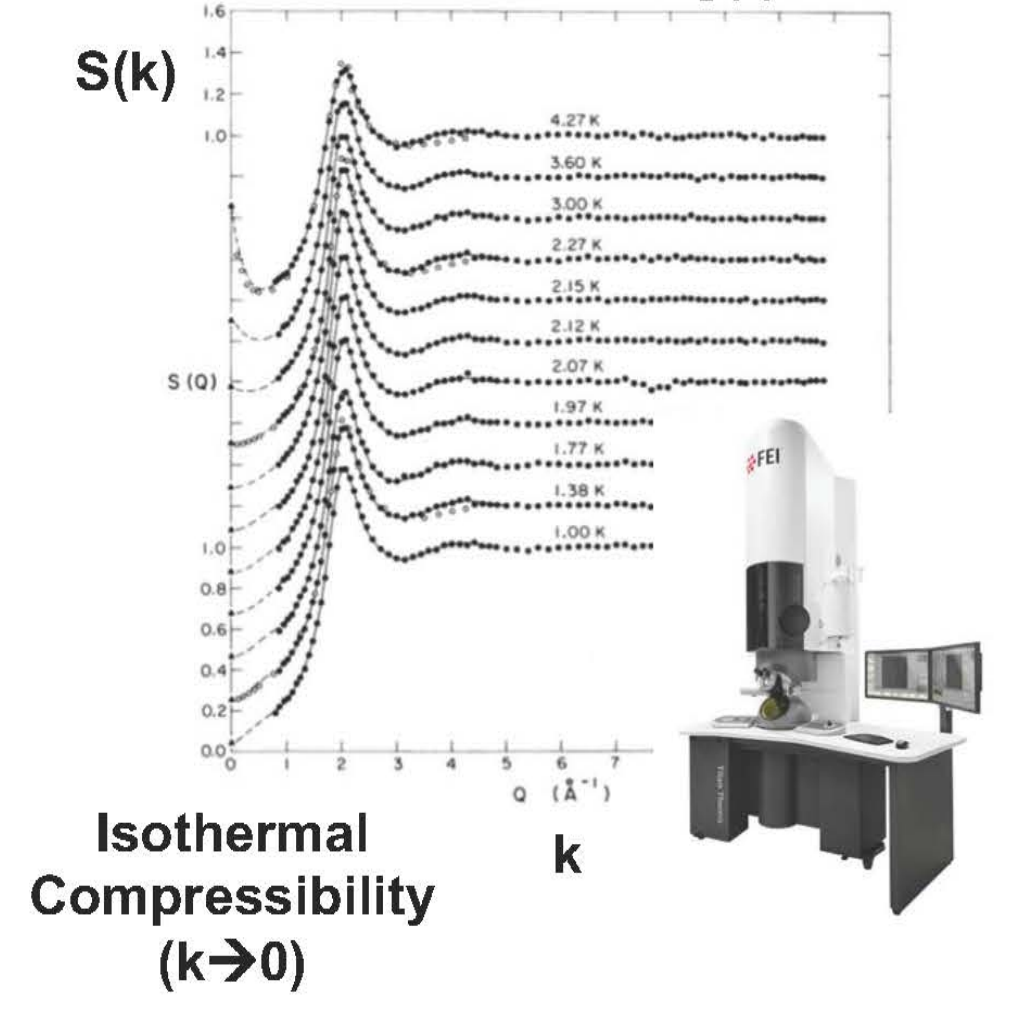

Macroscopic Property Measurements

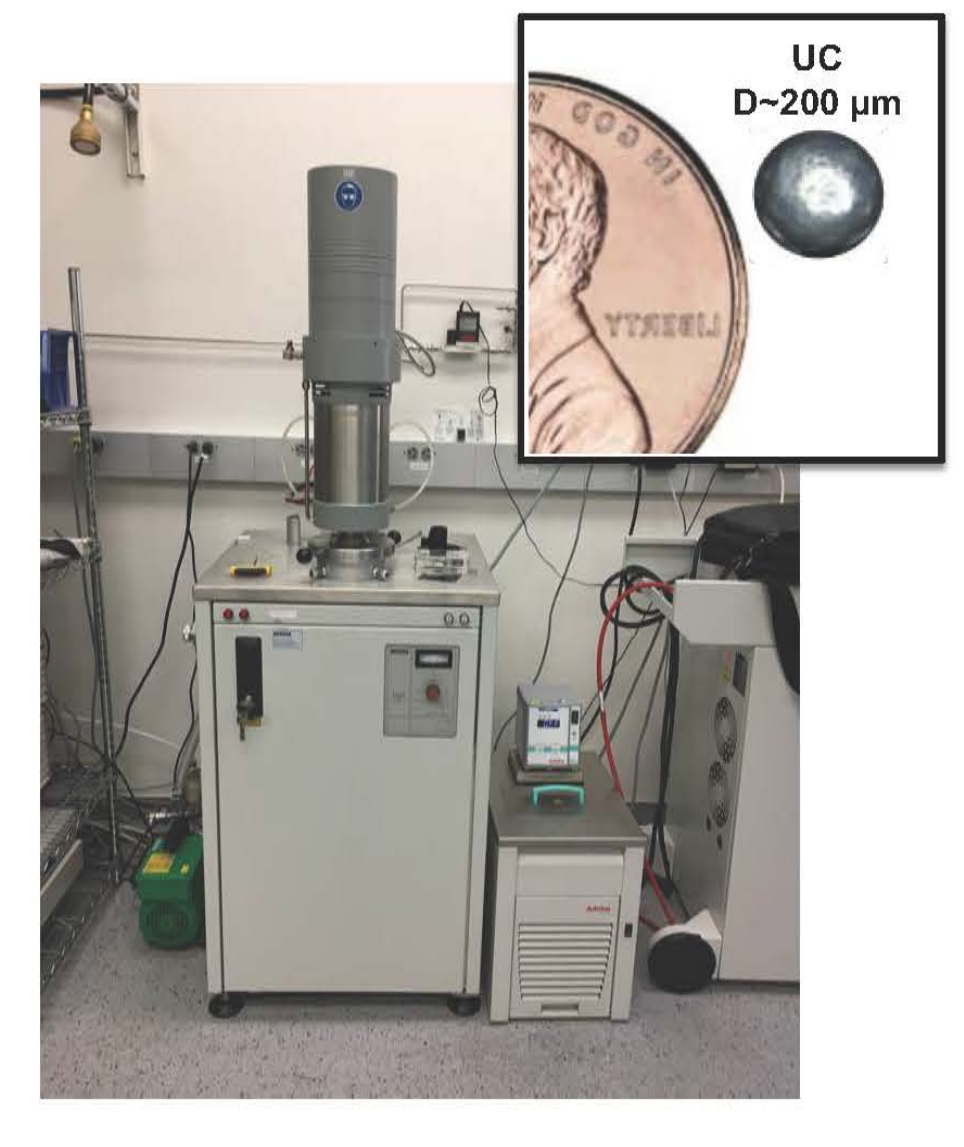




\section{Validated Predictive Capability Enables High-Quality Performance Risk Management}

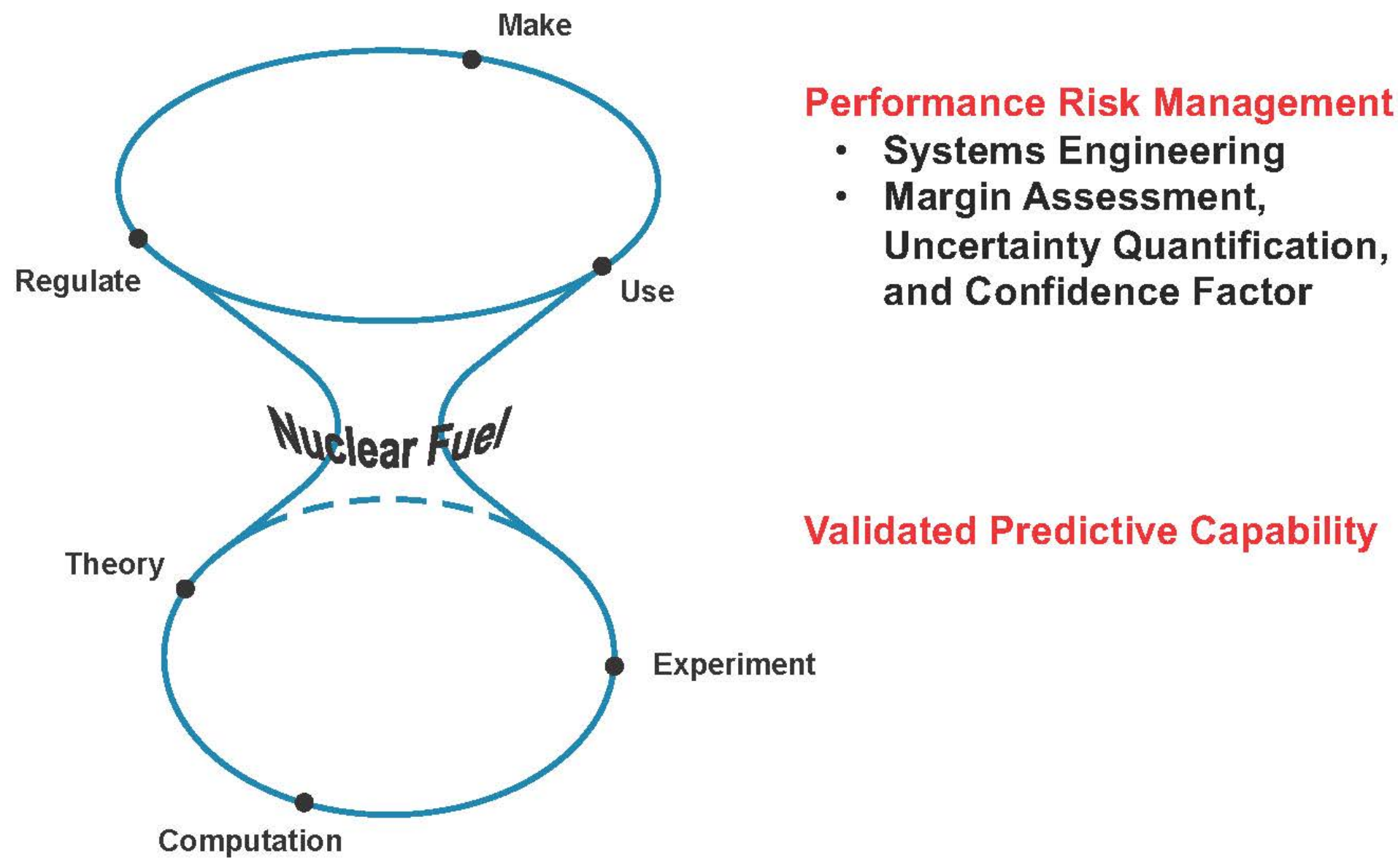




\section{Conceptual Progression of AFQ Approach Presented at the First AFQ Workshop}

\section{Data-Driven Approach}

$$
\begin{aligned}
& \begin{array}{c}
\sim 50 \mu \mathrm{m} \text { fuel } \\
\text { microsphere }
\end{array} \\
& \text { Data-Driven Approach }
\end{aligned}
$$

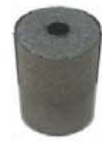

Pellet

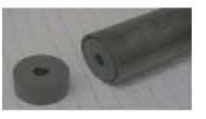

Fuel rod

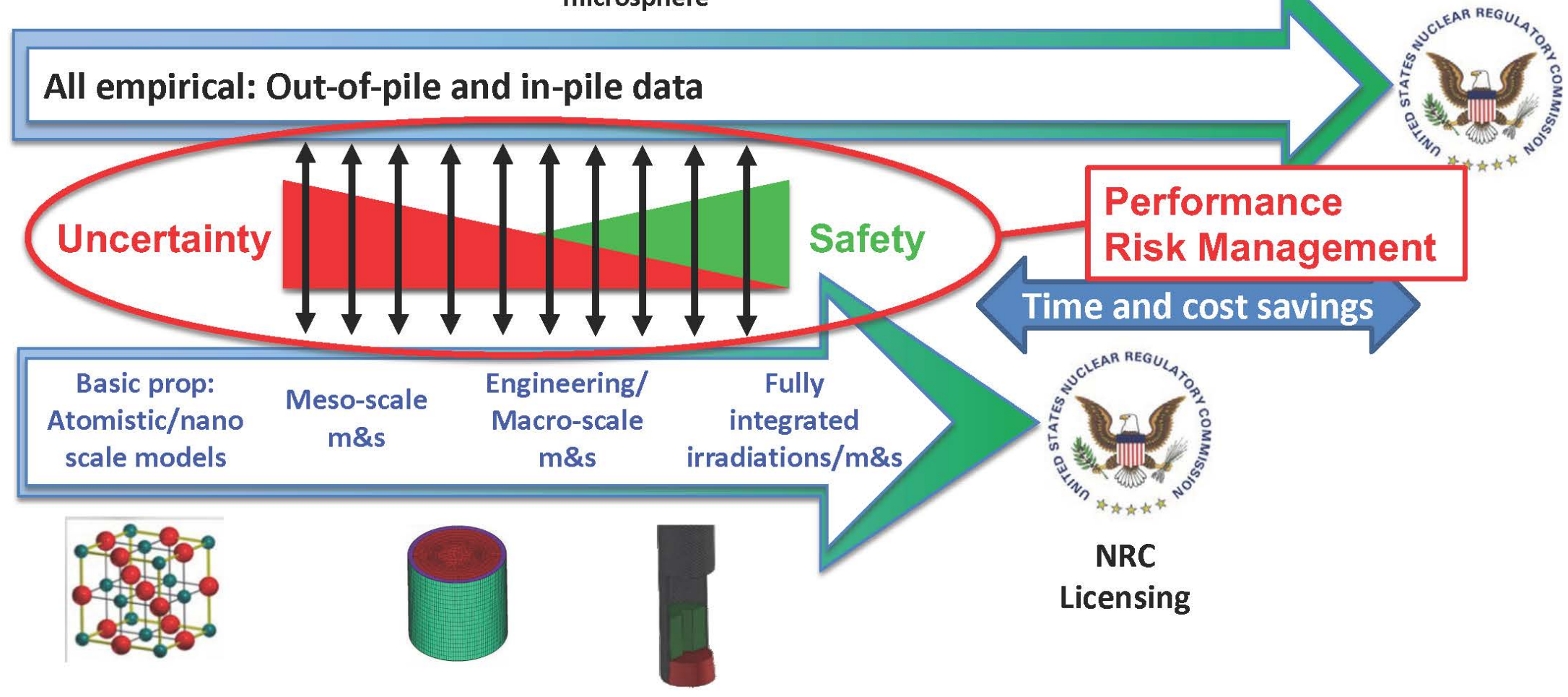

Modeling \& Simulation with Experimental Validation: AFQ Approach 


\title{
Systems Engineering Approach to Defining Nuclear Fuel Requirements
}

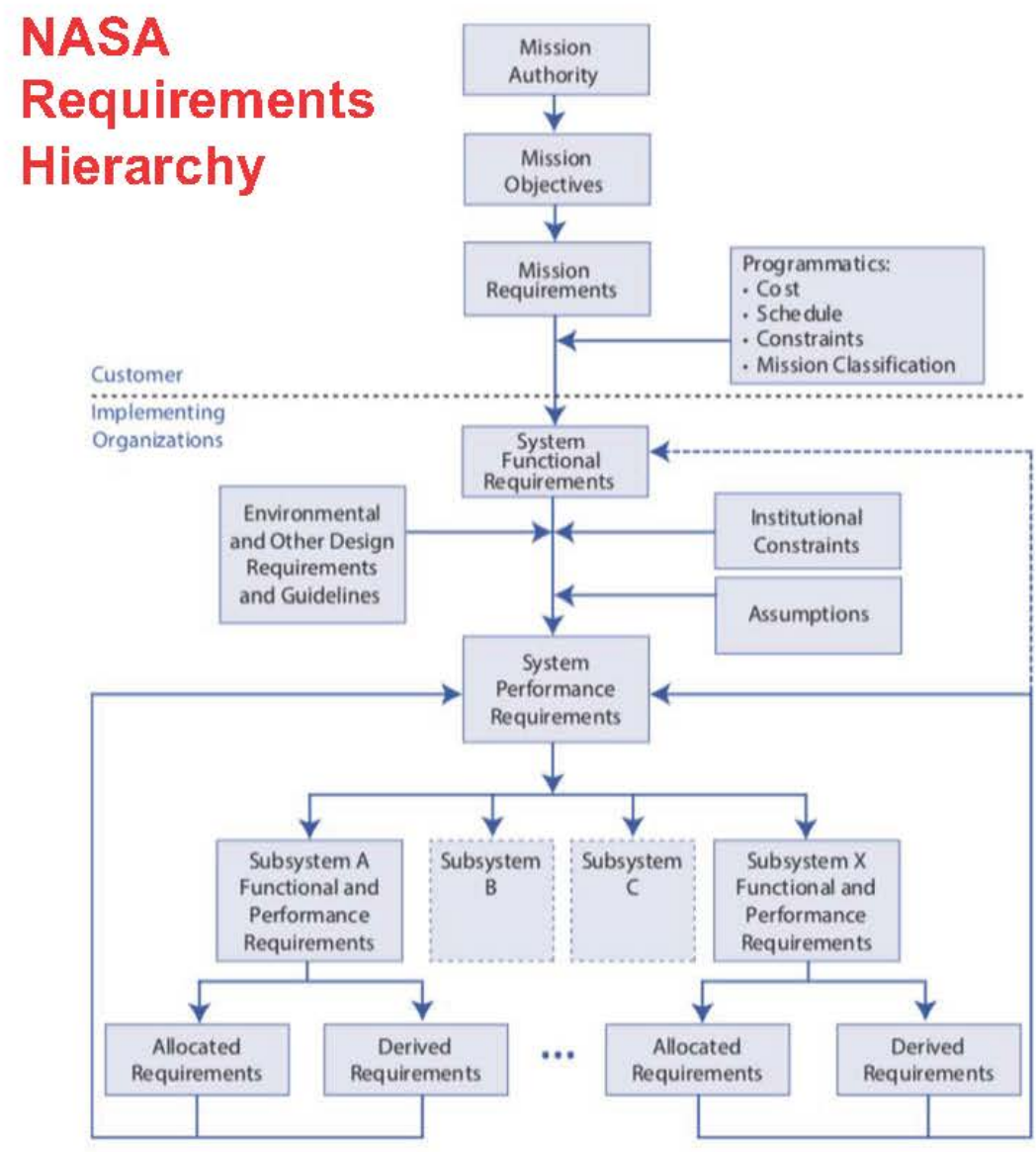

\author{
Customer Requirements
}

System Level Requirements

Subsystem Requirements

Nuclear Fuel Examples:

- Fuel T < Melting T

- Cladding Strain < 1\% 


\section{Performance Parameter Uncertainty Quantification \& Margin Assessment Improves Safety \& Reliability}

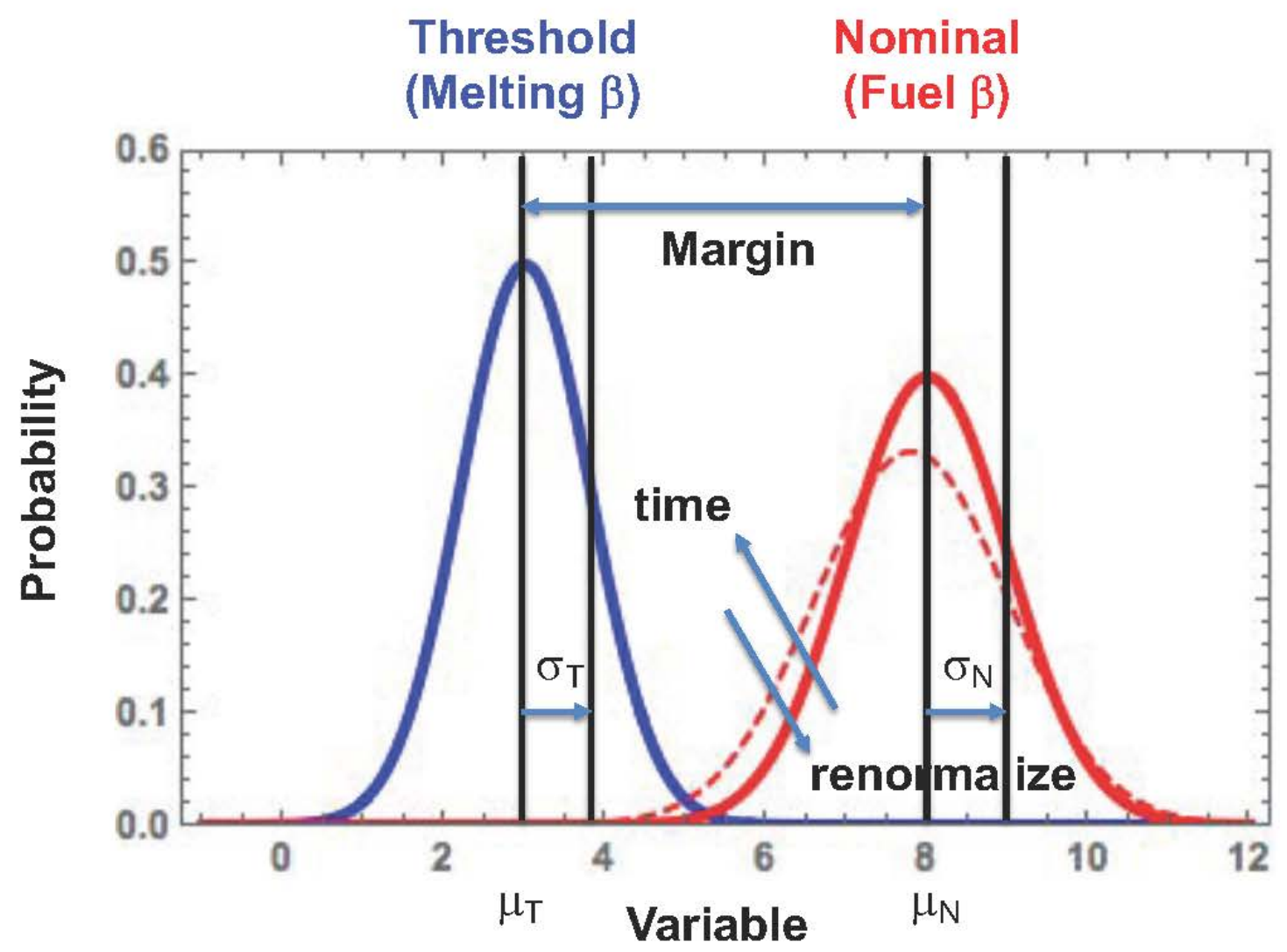

Margin

$$
M=\mu_{N}-\mu_{T}
$$

Uncertainty

$$
U=\sqrt{\sigma_{N}^{2}+\sigma_{T}^{2}}
$$

Confidence Factor

$$
C F=\frac{M}{U}
$$




\section{AFQ Workshop 2 Opening Comments}

- "When successfully demonstrated and applied, the AFQ approach will open a new horizon for exciting new nuclear fuels to strengthen the competitiveness of the US nuclear industry."

- This is the second workshop in a series that is intended to move AFQ forward

- Two high-level AFQ thrust areas are emerging:

- Validated Predictive Capability

- Performance Risk Management 


\section{AFQ Workshop 2 Agenda}

- Welcome and Workshop Introduction (3)

- Scienta (Science)

- Fundamental Computational, Experimental, and Theoretical Building Blocks (2)

- Integrating Building Blocks and Bridging Multi-Scale Phenomena (1)

- Ipsum (Engineering)

- Nuclear Fuel Applications and Case Studies (5)

- Regulatory Discussion

- AFQ Technical Working Group Charter Discussion

- Future Actions 
APPENDIX C - Appendix C: High Energy Heavy lon Irradiation for Accelerated Testing 


\section{High Energy Heavy lon Irradiation for Accelerated Testing}

\section{Abdellatif Yacout \\ Argonne National Laboratory}

$2^{\text {nd }}$ Accelerated Fuel Qualification Workshop

955 L'Enfant Plaza SW, Washington, DC

January $16^{\text {th }}, 2019$

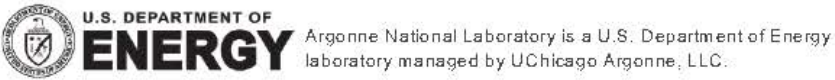

Argonne 


\section{CONTENT}

- Radiation Effects in Nuclear Materials

- Advantages of High Energy Heavy Ion Irradiation

- Argonne Tandem Linac Accelerator System (ATLAS)

- Accelerated Testing of Different Fuels with High Energy Heavy Ion Irradiation

- AMIS - ATLAS Materials Irradiation Station

- Summary 


\section{RADIATION EFFECTS IN NUCLEAR MATERIALS}

- Radiation Effects in Nuclear Fuels

- Major origin: fission fragments with 100 MeV

- Energy deposition of fission fragments

- Point defects accumulation (dislocations, voids, etc.)

- Amorphization and decomposition

- Grain subdivision

- Accumulation of stopped fission fragments

- Fission gas bubbles

- Secondary phases and solid solution (solid fission products)

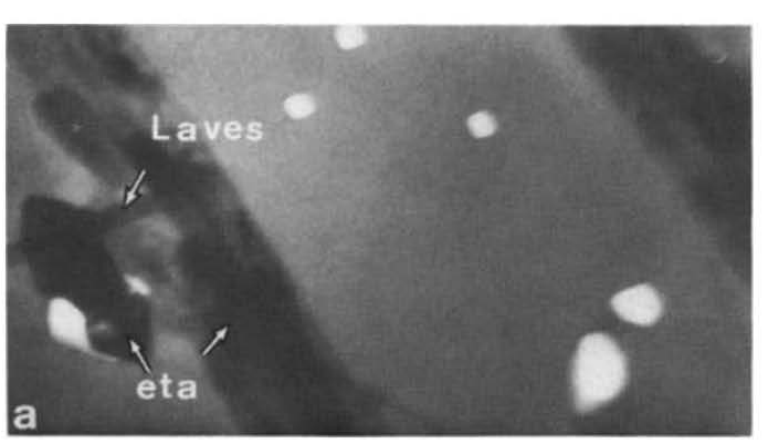

Secondary phases and He bubbles in in-pile irradiated SS316 [2]

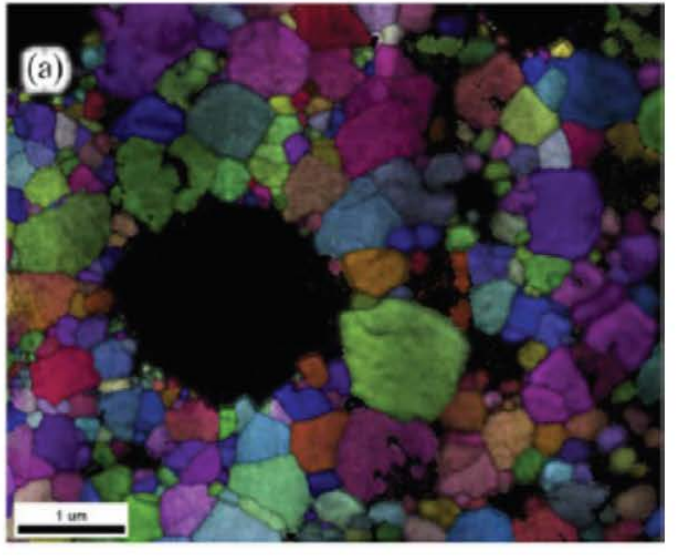

HBS in in-pile irradiated UO2 featuring nanocrystalline grains and micro-pores [1]
- Radiation Effects in Structural

\section{Materials}

- Major origin: neutrons

- Energy deposition of neutrons/secondary ions

- Point defects accumulation (dislocations, voids, etc.)

- Amorphization and decomposition

- Grain subdivision

- Neutron induced nuclear reactions

- He bubbles

[1] T.J. Gerczak et al, JNM, 2018 [2] P.J. Maziasz et al, JNM, 1981

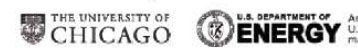




\section{ADVANTAGES OF HIGH-ENERGY IONS}

- Simulate Fission Fragment Damage (Fuels)

- Each fission reaction produces $\sim 200 \mathrm{MeV}$ energy

- 2 3 neutron: $\sim 4.8 \mathrm{MeV}$

- Prompt gamma: $\sim 7 \mathrm{MeV}$

- Delayed energy (decays): $\sim 19 \mathrm{MeV}$

- 2 Fission fragments: $\sim 169 \mathrm{MeV}$ (major source of radiation effects in fuels)

- High-energy ions can replicate fission fragments $(\sim 100 \mathrm{MeV})$

- Applicable to already neutron-irradiated fuel to achieve higher burnup level

- Implant gaseous/solid fission products

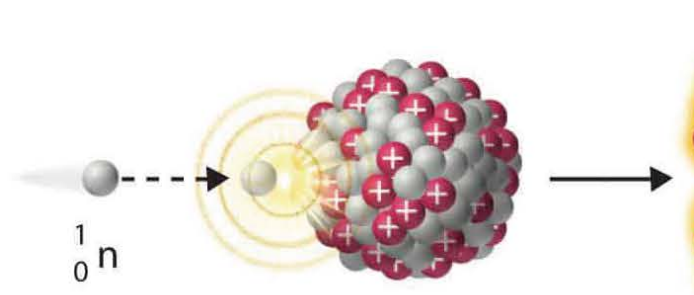

${ }_{92}^{235} \mathrm{U}$

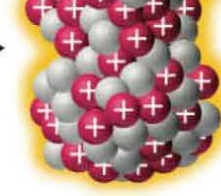

$$
{ }_{92}^{236} \mathrm{U}
$$

Unstable

nucleus

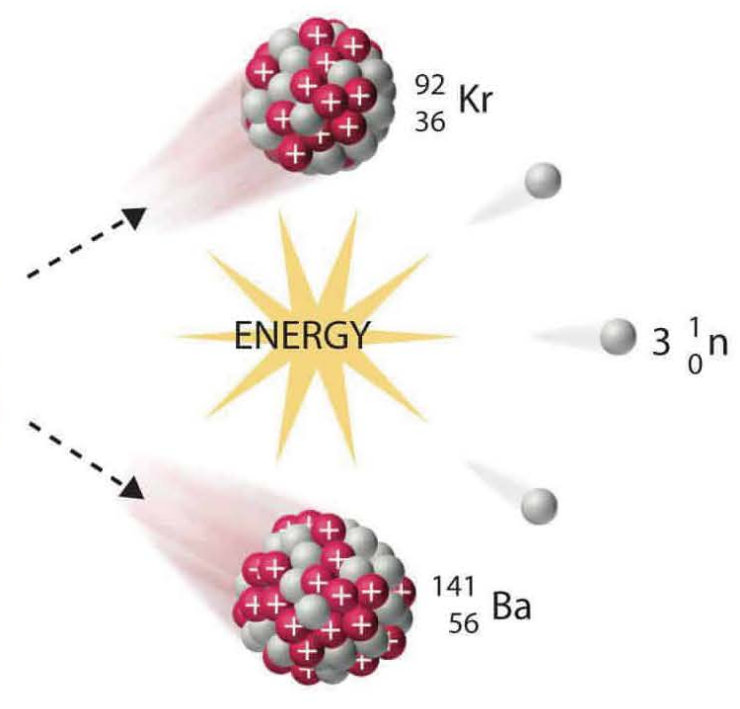




\section{ADVANTAGES OF HIGH ENERGY HEAVY ION IRRADIATION}

- Motivations:

- Fuel development: direct replication of high-energy

fission fragments: e.g. $100 \mathrm{MeV} \mathrm{Xe}$

- Extensive damage range within irradiated materials

- Uniqueness:

- Ultra high energy: $1 \mathrm{MeV} / \mathrm{amu}$ or higher

- Vast ion diversity (almost entire periodic table coverage)
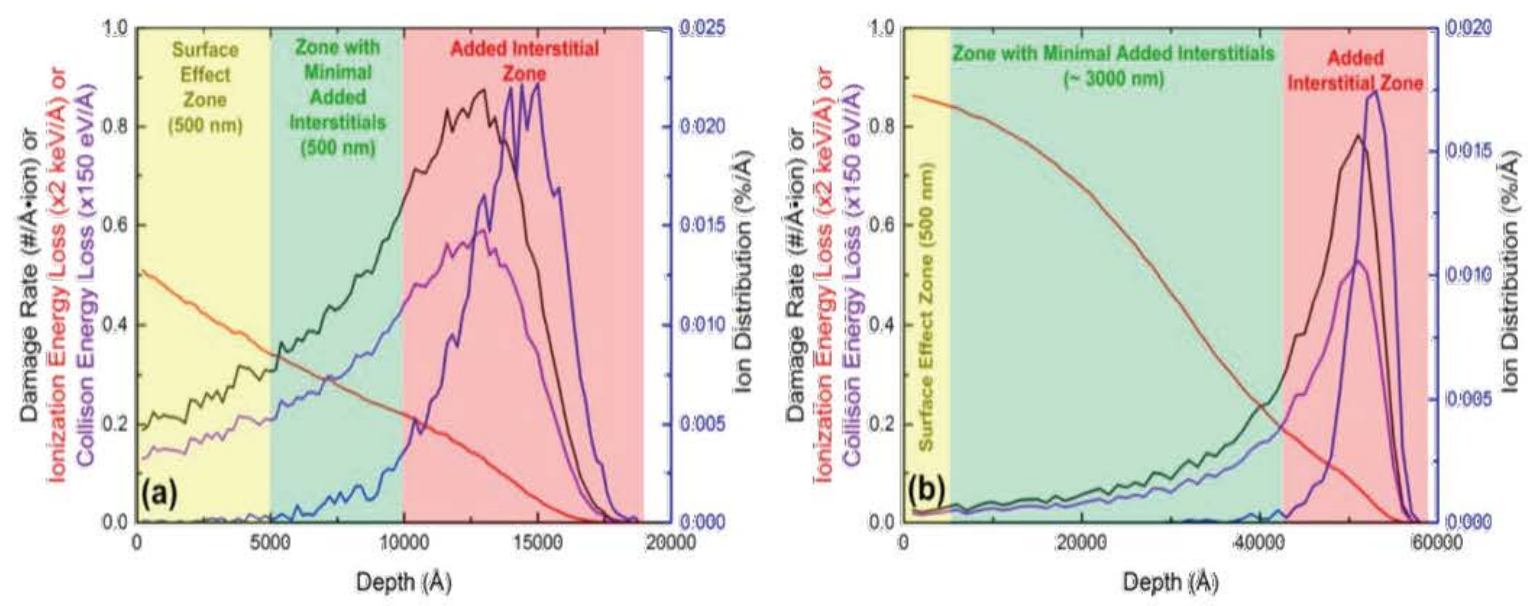

Damage Profiles Induced by $5 \mathrm{MeV}(\mathrm{L})$ and $54 \mathrm{MeV}(\mathrm{R})$ Fe ions in Steel (SRIM Simulation) 

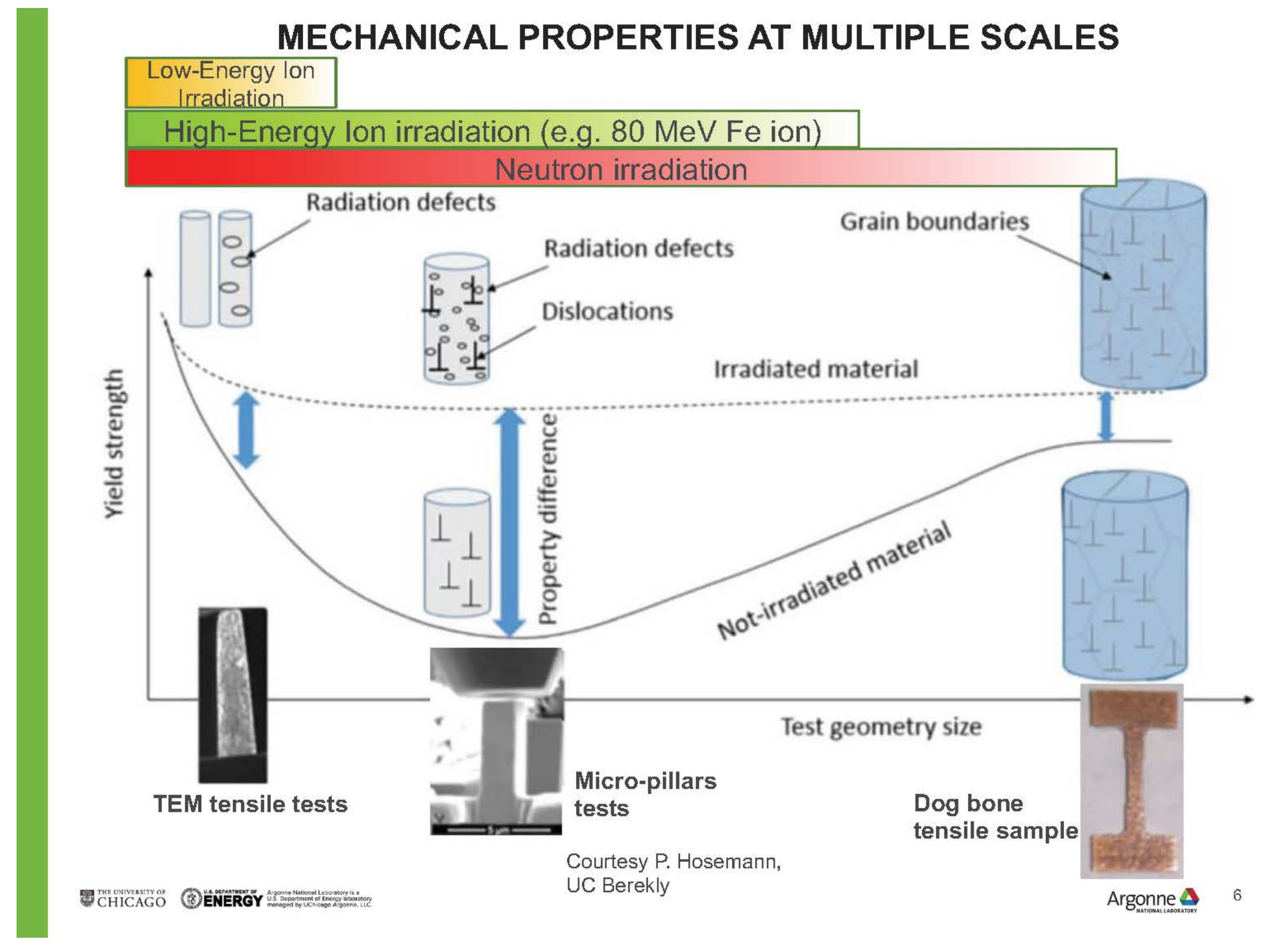


\section{ARGONNE TANDEM LINAC ACCELERATOR SYSTEM (ATLAS)}

- DOE office of science user facility

- ATLAS Capabilities

- Nuclear structure research facility

- Superconducting linear ion accelerator

- Energy: up to $17 \mathrm{MeV}$ per nucleon capability

- Available lons

- full range of all stable ions ATLAS

- Some radioactive ions

- From proton to uranium

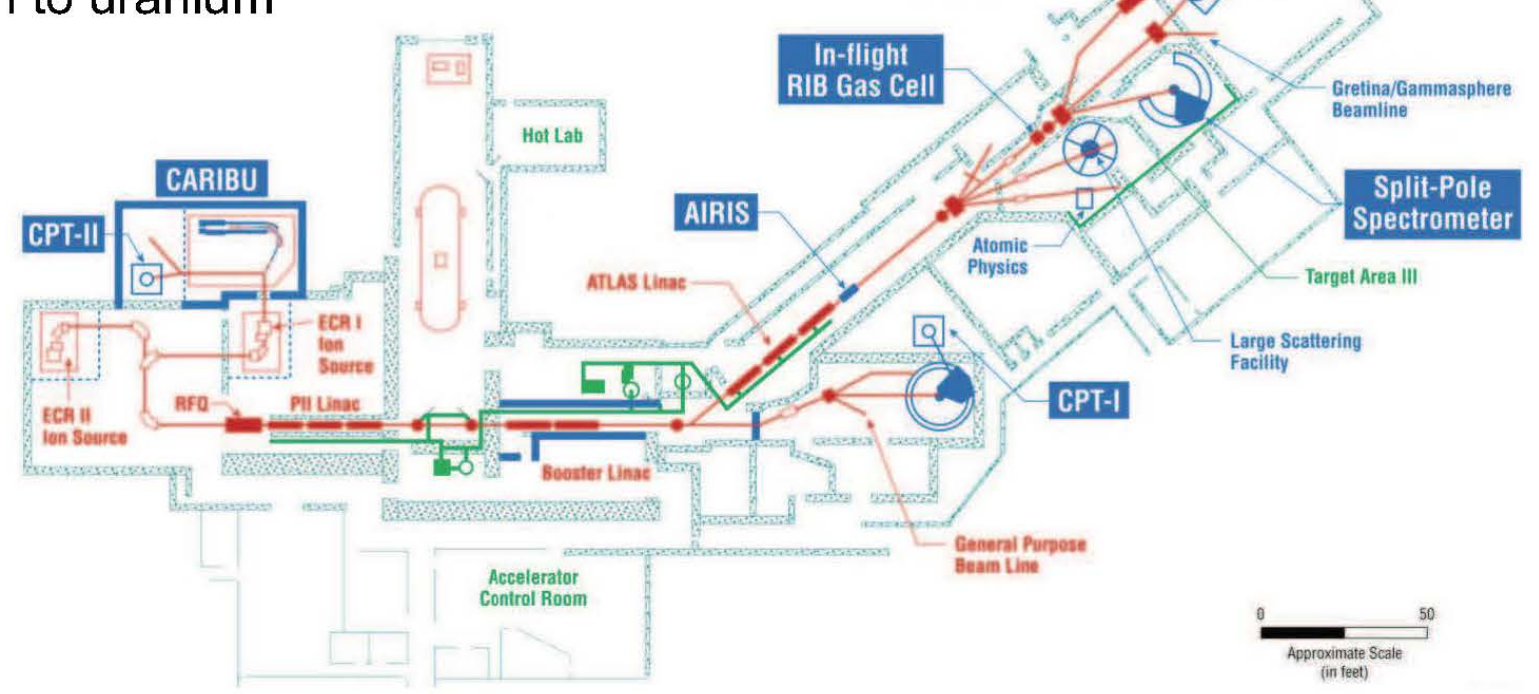




\section{ION IRRADIATION CHAMBER AT ATLAS}

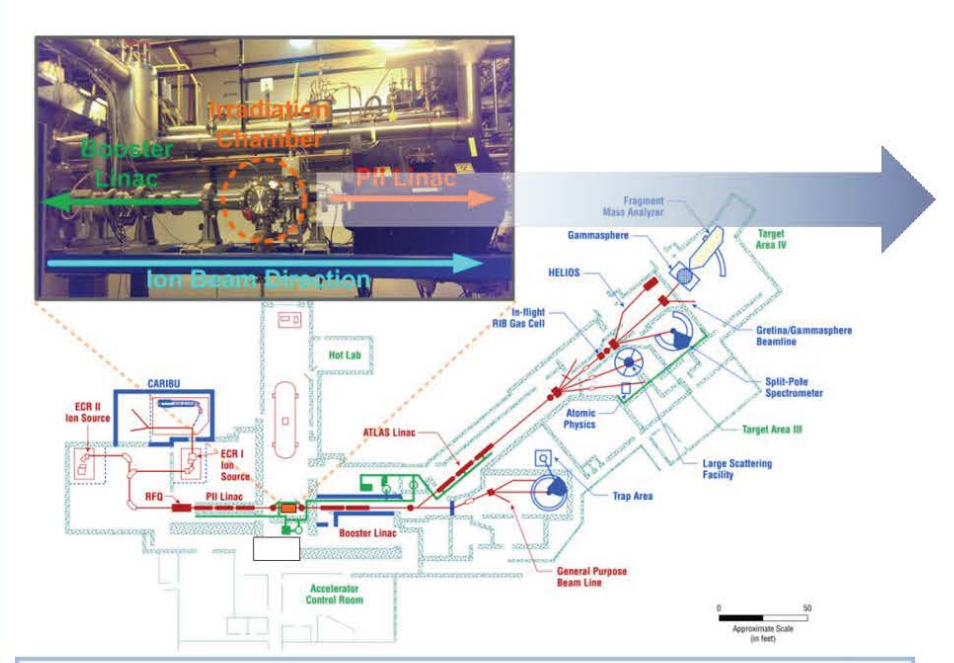

Ion Irradiation Chamber Established at ATLAS

- Features of the Chamber

- Between PII and Booster LINACs

- Up to $1.5 \mathrm{MeV}$ per nucleon

- Ion type: proton to uranium (e.g. $56 \mathrm{MeV} \mathrm{Fe}, 131 \mathrm{MeV} \mathrm{Xe}$, etc.)

- Up to $1 \mathrm{p} \mu \mathrm{A}$ ion current

- Multiple sample stages supporting irradiation temperature ranging from RT to $900 \mathrm{C}$.

STHCAGO

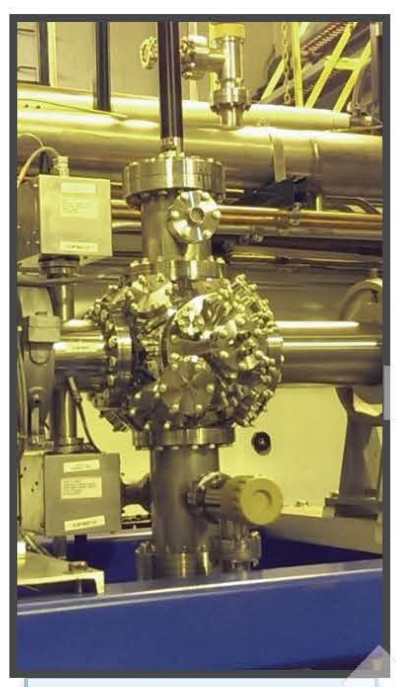

Irradiation Chamber
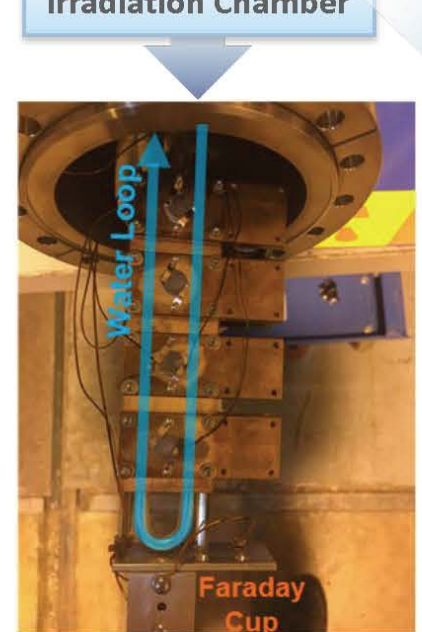

Active Cooling Sample Stage (RT to 300 C)

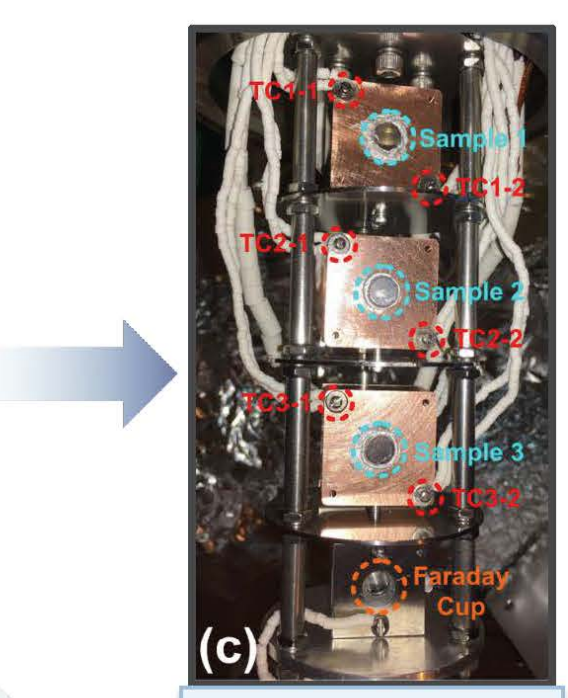

Hi-Temp Sample Stage (>300C)

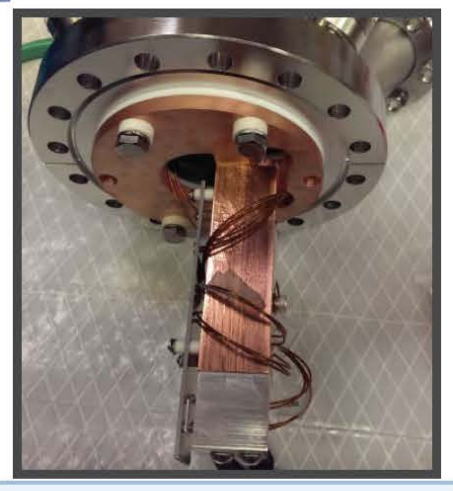

Passive Cooling Sample Stage AIgUIIIt 


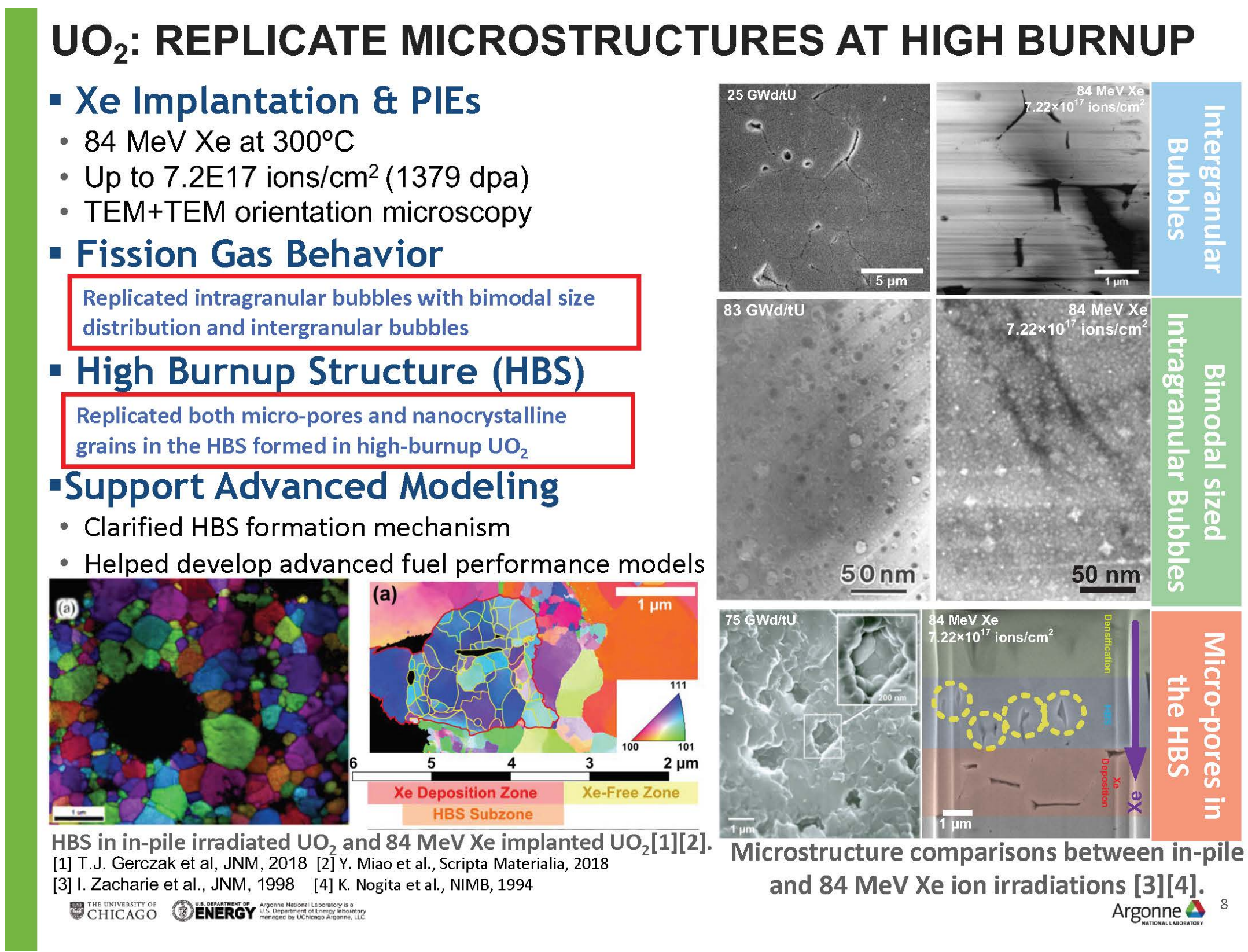




\section{U-MO: HIGH-DENSITY RESEARCH REACTORS FUELS}

- Xe Implantation \& PIEs

- $84 \mathrm{MeV}$ Xe at 50 300C

- Up to $2.9 \mathrm{E} 17 \mathrm{ions} / \mathrm{cm}^{2}$

- $\mathrm{TEM}+\mu \mathrm{XRD}+\mathrm{XTM}$

- Fission Gas Behavior

- Intra- and inter-aranular

Replicated size and number density of bubbles in in-pile irradiated U-Mo

- Phase Stability

- Radiation-induced recovery of $\mathrm{V}$-U-Mo within the $\mathrm{Xe}$ ion range

Replicated the $\gamma$-UMo phase stabilization by neutron irradiation

- Recrystallization

- Nano-grains formation

Consistent with in-pile irradiation

- Interaction Layer

- Amorphous IL $(T<200 \mathrm{C})$

Consistent with in-pile irradiation
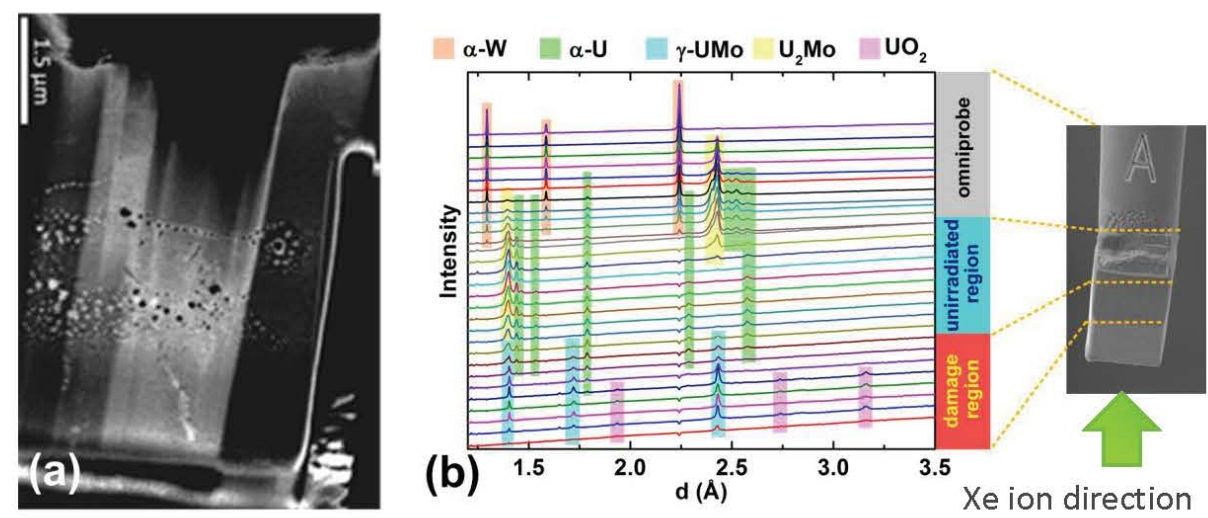

Synchrotron $\mu$ XRD showing the recovery of $\psi$-UMo from $\alpha-\nu^{\prime}$ mixture under Xe ion irradiation

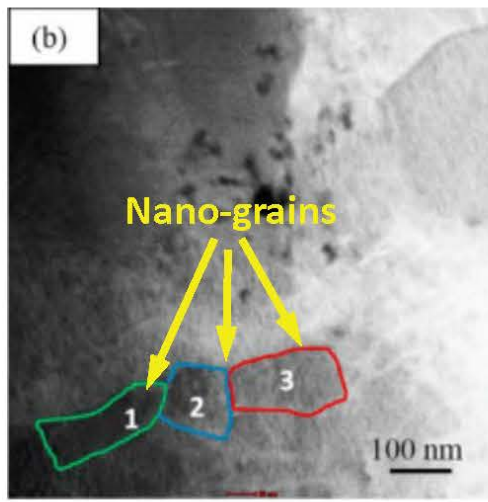

Recrystallization induced by $84 \mathrm{MeV}$ Xe irradiation
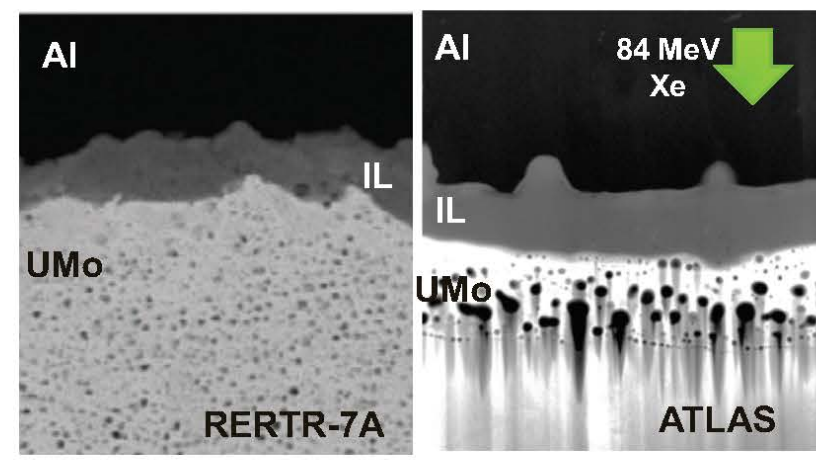

Al-UMo IL and Xe bubbles in in-pile (left) and Xe (right) irradiated fuels

[1] B. Ye et al., JNM, 2017 [2]D.D.Keiser et al., Nucl. Eng. Technol.

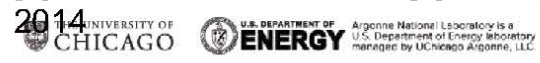




\section{$\mathrm{U}_{3} \mathrm{SI}_{2}:$ NEW FUEL WITH ENHANCED ACCIDENT TOLERANCE}

- Novel Fuel for LWRs

- Successful applications at low temperatures in research reactors (RERTR)

- Limited in-pile experience at high temperatures in LWRs

- Ion irradiation needed for accelerated fuel performance evaluation \& qualification

- Xe Implantation \& PIEs

- Exactly same $\mathrm{U}_{3} \mathrm{Si}_{2}$ batch as irradiated in ATR

- $84 \mathrm{MeV}$ Xe at 300/450/600C

- Up to $1.4 \mathrm{E} 17 \mathrm{ions} / \mathrm{cm}^{2}$

- TEM+ $\mu$ XRD

\section{- Fission Gas Behavior}

- Lo Temp $\rightarrow$ Monomodal intragranulr bubbles

- Hi Temp $\rightarrow$ Bimodal intragranular bubbles

- Intergranular bubbles with size dependent on the GB type

Consistent with preliminary PIE results of ATF-1 campaign (no prominent swelling at $\sim 20 \mathrm{GWd} / \mathrm{tU}$ )

[1] Y. Miao et al., JNM 2017 [2] Y. Miao et al., JNM 2018

[3] Y. Miao et al., JNM 2019

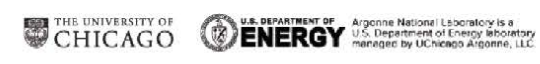
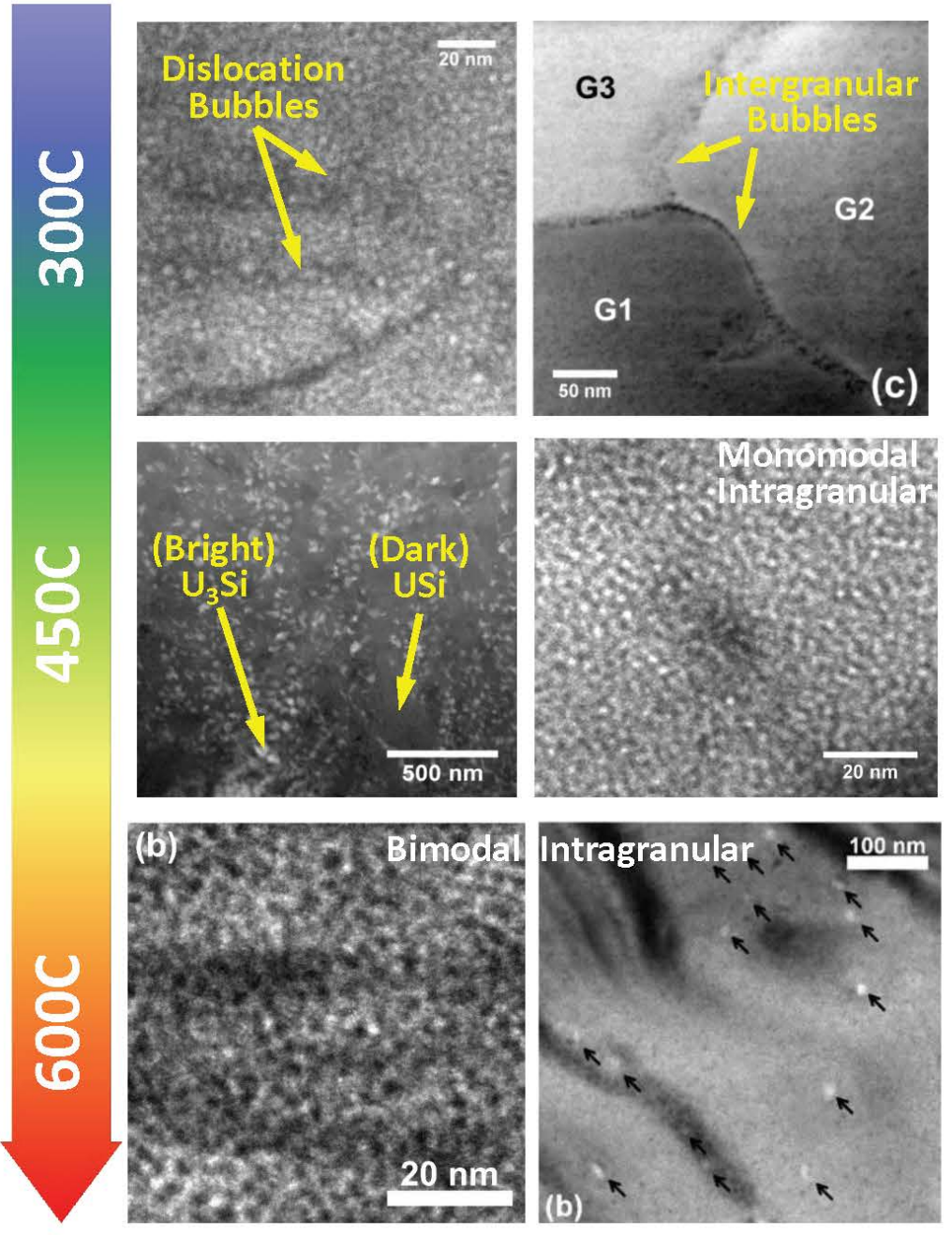

Radiation-induced microstructure modifications in $\mathrm{U}_{3} \mathrm{Si}_{2}$ implanted by $84 \mathrm{MeV}$ Xe at LWR temperatures 


\section{$\mathrm{U}_{3} \mathrm{SI}_{2}:$ NEW FUEL WITH ENHANCED ACCIDENT TOLERANCE}

- Xe Implantation \& PIEs

- $84 \mathrm{MeV}$ Xe at $450 \mathrm{C}$

- >200 dpa

- $\mathrm{TEM}+\mu \mathrm{XRD}$

- Phase Stability

- Phase decomposition at $450 \mathrm{C}$ (>200 dpa)

- Nanocrystalline USi matrix

- Amorphous U-enriched inclusions

Predicted the occurrence of phase decomposition under certain irradiation conditions

Need confirmation from in-pile irradiation \& PIE

- Bubbles in Decomposed $\mathrm{U}_{3} \mathrm{Si}_{2}$

- Intragranular/intergranular/phase boundary

- Limited swelling due to the nano-grains

- Support Model Development

- Reference for rate theory parameterization

- Fission gas correlation implemented into BISON

[1] Y. Miao et al., JNM 2019

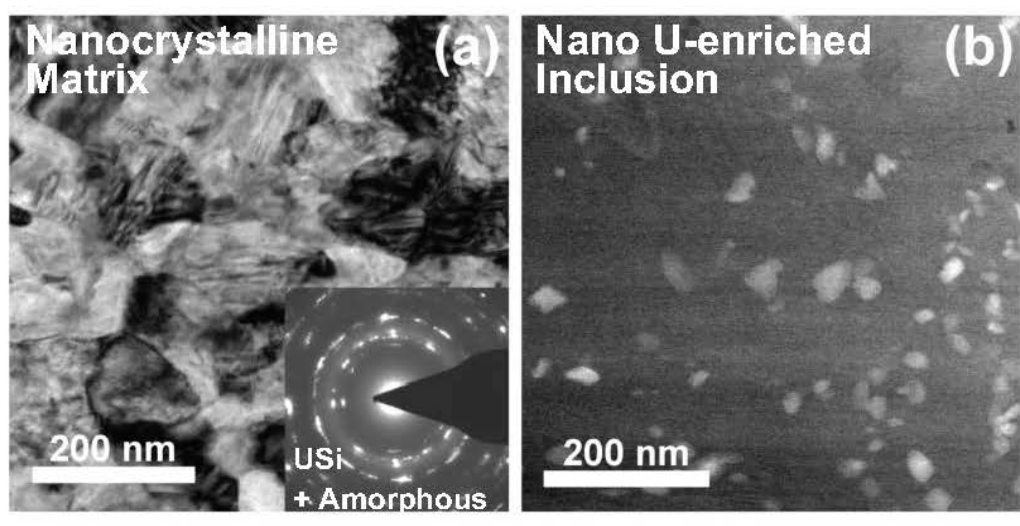

Phase decomposition of $\mathrm{U}_{3} \mathrm{Si}_{2}$ into a $\mathrm{U}$-enriched inclusion and a nanocrystalline USi matrix
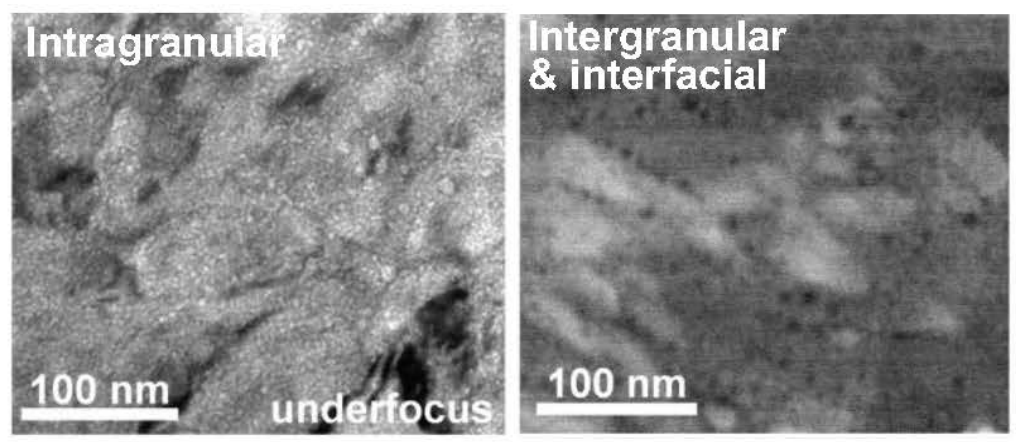

Xe bubbles in decomposed $\mathrm{U}_{3} \mathrm{Si}_{2}$

פ⿹勹巳 


\section{U-10ZR: BINARY FAST REACTOR FUEL}

- Xe Implantation \& PIEs

- $84 \mathrm{MeV}$ Xe at $700 \mathrm{C}$ ( $\sim$ centerline temp)

- Up to $2.19 \mathrm{E} 17$ ions $/ \mathrm{cm}^{2}$

- TEM

- U-Zr Phases

- Irradiated at $\gamma_{1}+\gamma_{2}$ phase field

- Mainly $\gamma_{1} \rightarrow \alpha ; \gamma_{2} \rightarrow \omega / \delta$ during cooling

Consistent with phase diagram

\section{-Fission Gas Behavior}

- U-enriched $\gamma_{1}$

- Bimodal bubble size distribution

- Large bubbles on dislocations

- Lower bubble density

- Zr-enriched $\gamma_{2}$

- Monomodal bubble size distribution

- Small bubbles, high density

Dissimilar fission gas behavior in different phases

- Support Model Development

- Help develop/validate fission gas models for separate U-Zr phases.

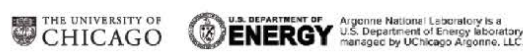
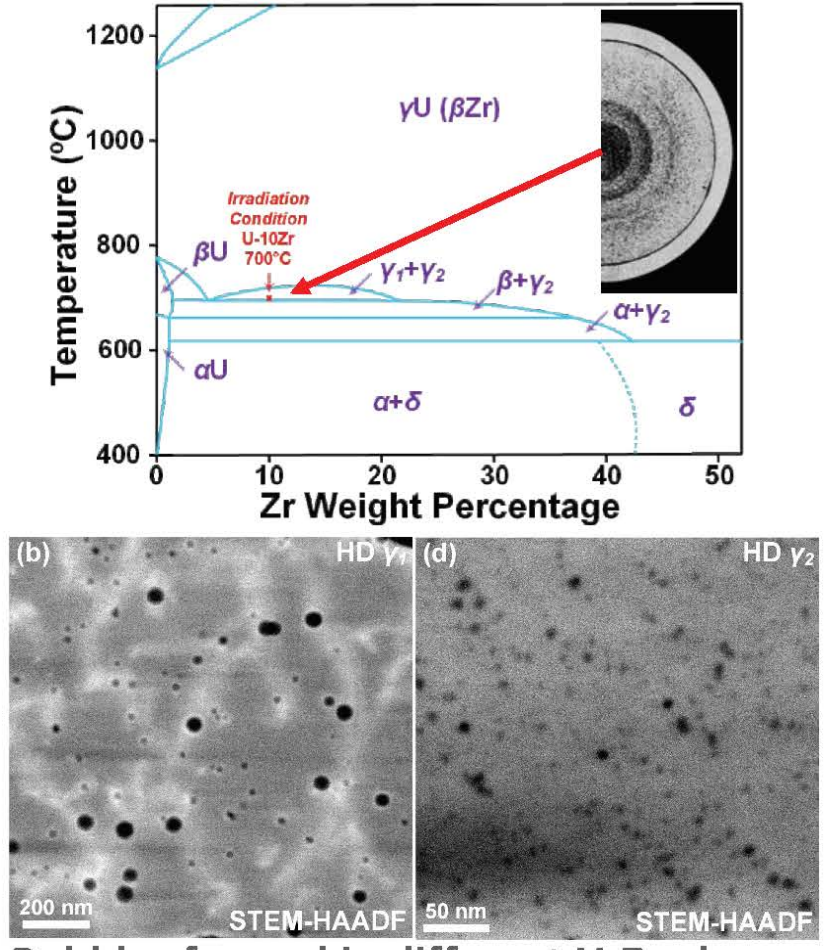

Bubbles formed in different $\mathrm{U}-\mathrm{Zr}$ phases
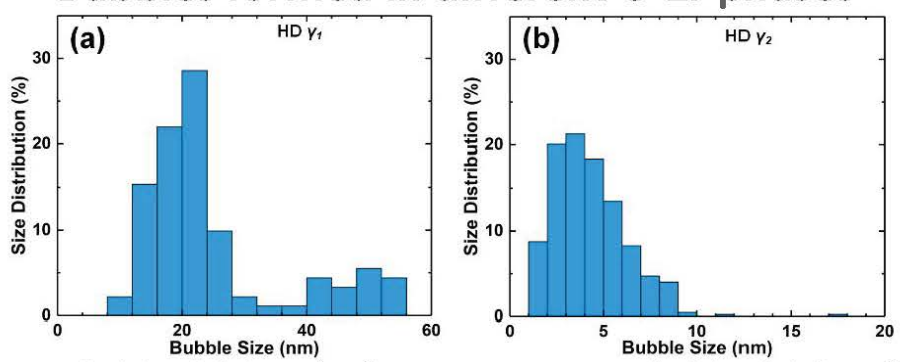

Bimodal bubbles $\left(\gamma_{1}\right)$ vs. monomodal bubbles $\left(\gamma_{2}\right)_{13}$

Argonne $\mathbf{A}$ 


\section{SUMMARY: HEAVY ION IRRADIATION USING A LINAC (ATLAS) FOR SUPPORT OF AFQ}

High-energy ion irradiation produced by LINACs is capable of

- replicating a series of microstructural modifications observed in in-pile irradiated materials to help understand the mechanisms;

- Fission gas bubbles in $\mathrm{UO}_{2}$ and U-Mo

- Al-ZrN IL in U-Mo dispersion fuel with ZrN coated particles

- Radiation-induced dislocations in steels

- providing microstructural modifications data of new nuclear materials before in-pile data are available;

- Bubble morphology and phase stability data of $\mathrm{U}_{3} \mathrm{Si}_{2}$

- creating a deep radiation damage profile that enables the application of advanced characterization techniques;

- Phase stability in U-Mo and $U_{3} \mathrm{Si}_{2}$ ( $\mu$ XRD)

- Dislocations effect on mechanical properties (in situ synchrotron tensile test)

Key Issue: ATLAS is a DOE Science user facility with limited availability for other users. How to allow for more beam time at ATLAS for accelerated fuel materials testing ? 


\section{ATLAS MATERIALS IRRADIATION STATION (AMIS)}

- A beam switching capability which alternate between an intense stable ion beam (to be used for materials research) and a radioactive ion beam (CARIBU - used by DOE office of nuclear physics users - ONP) or vice versa (for tracer studies)

- Utilize the pulsed time structure of the recent ATLAS upgrade, CARIBU, which delivers accelerated beams of radioactive fission fragments from a spontaneous fission source of $252 \mathrm{Cf}$ (only pulsed $3 \%$ of beam time)

- The materials irradiation beam will be pulsed in between the CARIBU pulses, so it will not interrupt the main mission of the ONP facility

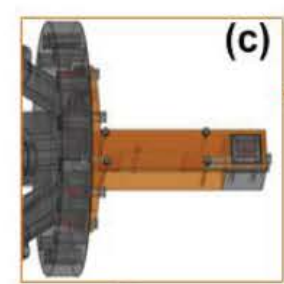

(c)
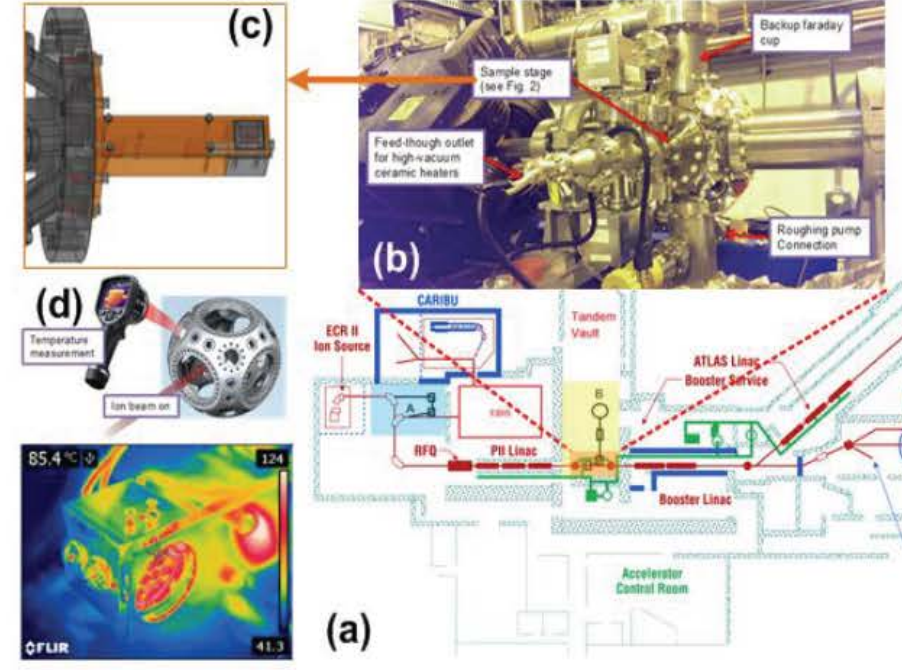

(a)
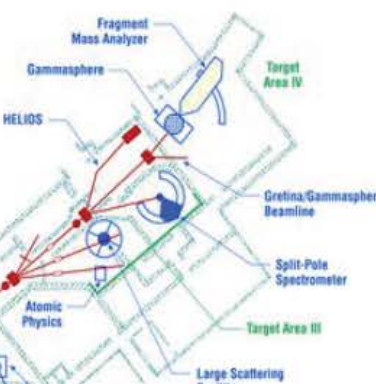

raserility

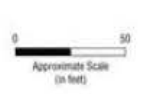

Upgrade plan of establishing AMIS at ATLAS: (a) floor plan of ATLAS after CARIBU and AMIS upgrade; red region is the current irradiation chamber used to validate the feasibility of AMIS; blue(A) and yellow $(B)$ regions indicate the upgrade needed for AMIS. (b) current irradiation chamber operating during maintenance period. (c) sample stage of the current irradiation chamber. (d) temperature control of the current irradiation chamber.

G 


\section{UPGRADE PLAN OF AMIS: OVERVIEW}

- AMIS Beam Extraction (Region B)

- In Tandem Vault after the Injector LINAC

- Ions have $1 \mathrm{MeV} / \mathrm{amu}$ or higher energy

- Pulsed extraction of AMIS ion pulses (97\%)

- CARIBU Upgrade

- $\quad$ CARIBU pulses continues to be accelerated by following LINACs

- Californium Rare Isotope Breeder Upgrade

- Recently funded upgrade plan

- CARIBU only uses $3 \%$ pulses
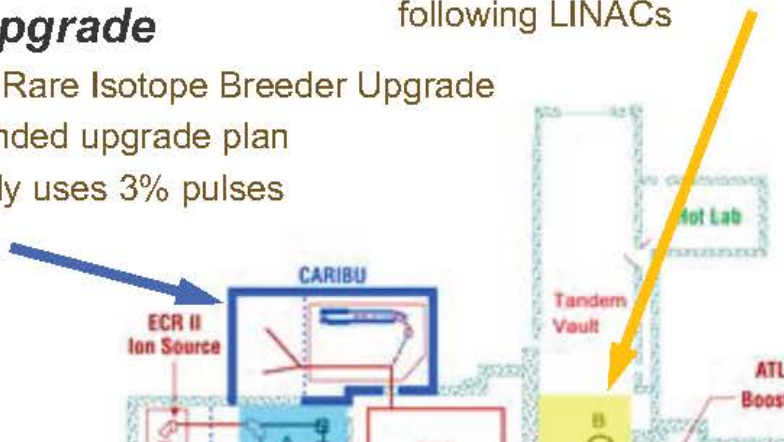

\section{Beam Combiner (Region A)}

- Combining CARIBU and AMIS ion sources

- Time allocation: $97 \%$ AMIS and 3\% CARIBU

- Both beams share ATLAS acceleration capability simultaneously 


\section{AMIS (ATLAS MATERIALS IRRADIATION STATION)}

\section{- Advantages:}

- Accelerated testing of fuel materials to support down-selection of fuel material over a short period of time (1 to 2 years time frame)

- Will enhance already existing inter-laboratory and university collaborations on heavy ion irradiation

- Moderate investment to gain extended access to a unique world class facility

- Leverage already existing office of science investment in ATLAS

- Potential for becoming a NSUF user facility for the nuclear materials community providing more access time for national labs and universities 


\section{AMIS STATION LAYOUT}

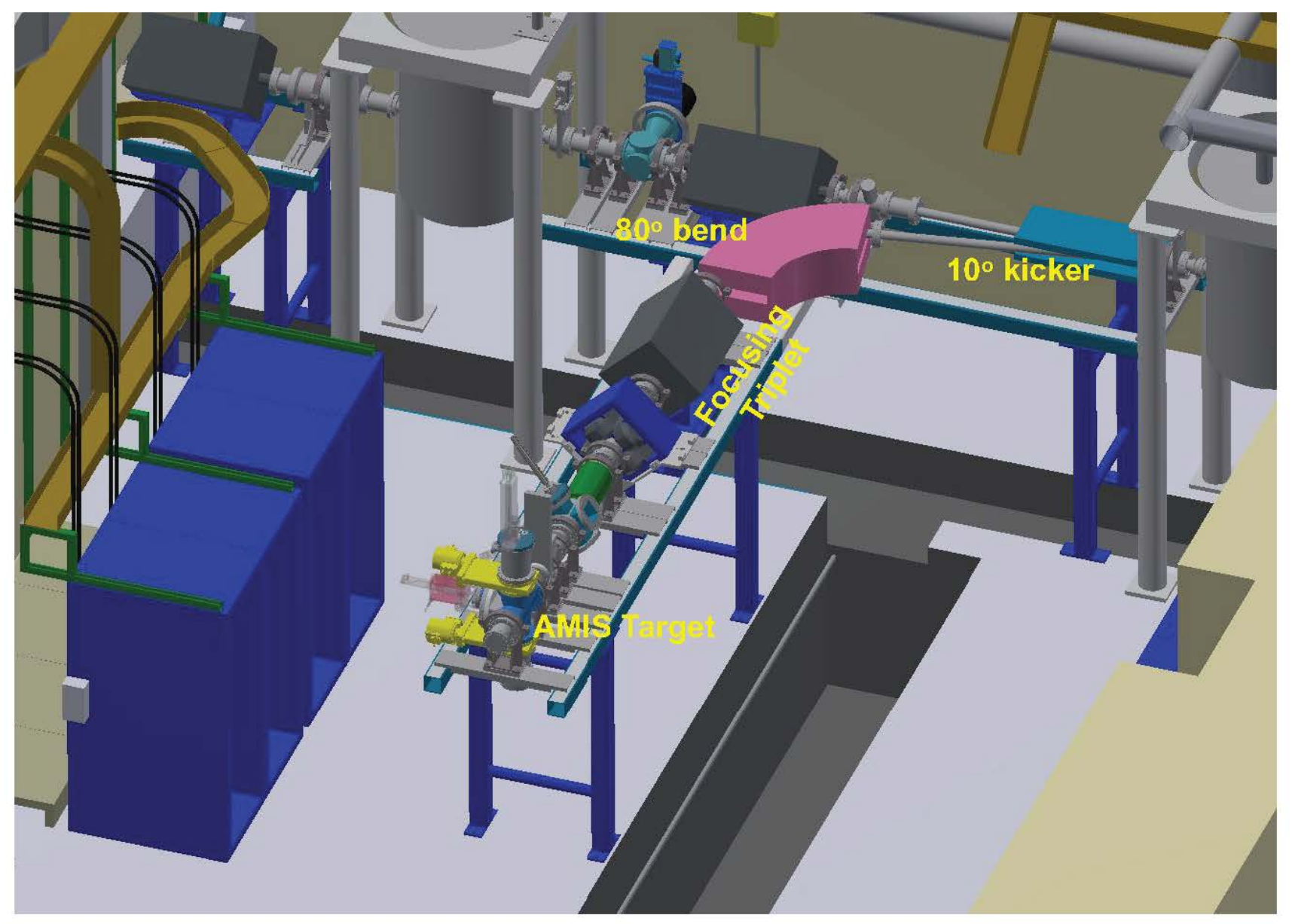

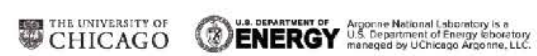

Argonne $\mathbf{A} 18$

Use or disclosure of data contained on this sheet is subject to the restriction on the title page of this document C-19 


\section{AMIS STATION LAYOUT}

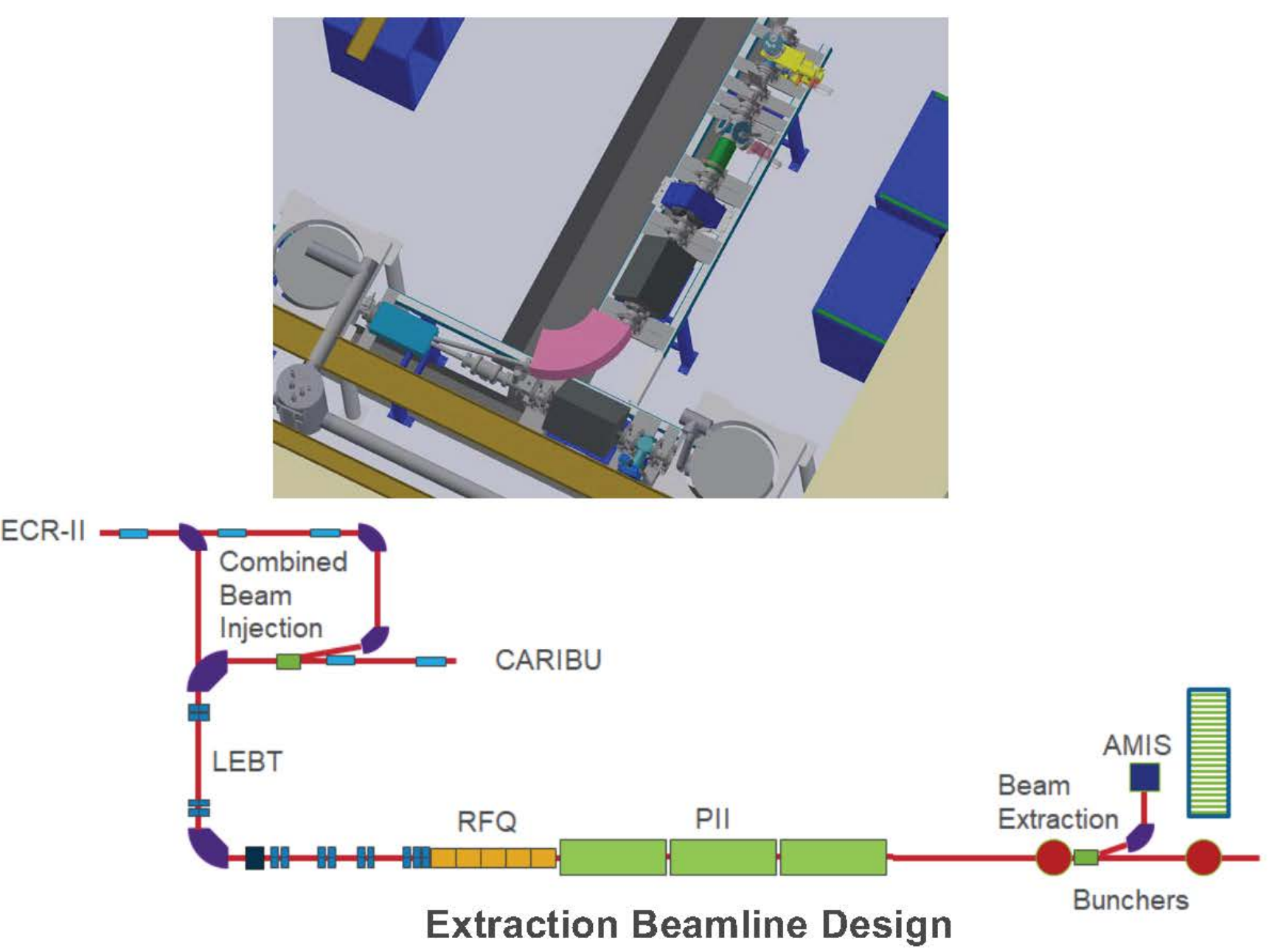




\section{SUMMARY}

- $100 \mathrm{MeV}$ fission fragments produced during fission are responsible for majority of damage and changes in fuel microstructure during irradiation

- High Energy Heavy Ion Irradiation with key fission fragments types and energies can simulate those fission products

- High burnup \&1000's of dpa in fuel materials can be simulated

- Accelerated testing was performed at ATLAS accelerator on different fuel materials at different operating conditions (U-Mo, UO2, U3Si2, U10-Zr) and structural materials

- Accelerated testing using high energy heavy ions can support the accelerated fuel qualification approach, based on the positive results of testing on different fuel materials

- A dedicated materials irradiation station (AMIS) at ATLAS will provide extended access to the facility (more beam time) 


\section{BACKUP}




\section{PROPOSAL - EXTREME MATERIALS BEAMLINE (XMAT)}

A new beamline at the Advanced Photon Source (APS) for in situ studies of materials under irradiation, temperature, stress, environmental, etc.

XMAT will provide $\mathrm{x}$-ray probes for in-situ study of materials in simulated extreme radiation environments, enabling rapid evaluation of materials performance under extreme service conditions including structural materials and in particular for nuclear fuels.

XMAT is made possible by combining the technology of Argonne's unique capabilities:

1.Energetic, Heavy lon Beams (ATLAS)

2.Focusable, High Energy X-Rays (APS)

3.Multi-modal Imaging (APS)

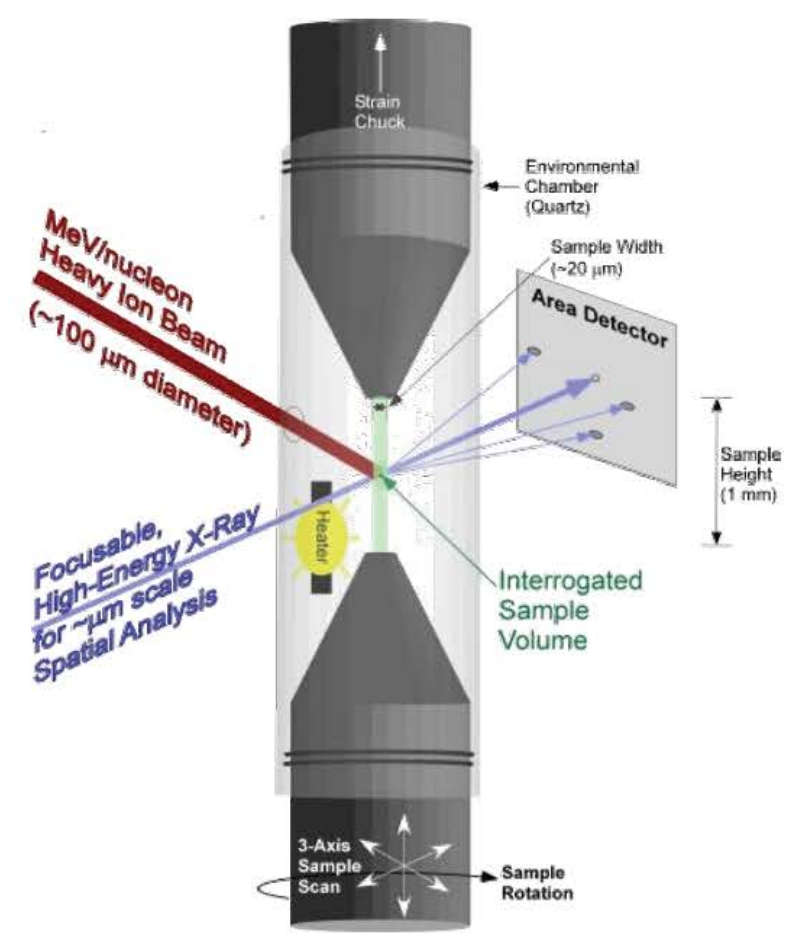

In-situ monitoring the changes in mechanical properties, and microstructures during ion irradiations

Opportunity Window -> APS/ATLAS Upgrades

: 


\section{RANKING OF XMAT IN RELATION TO OTHER ION IRRADIATION FACILITIES IN THE US}

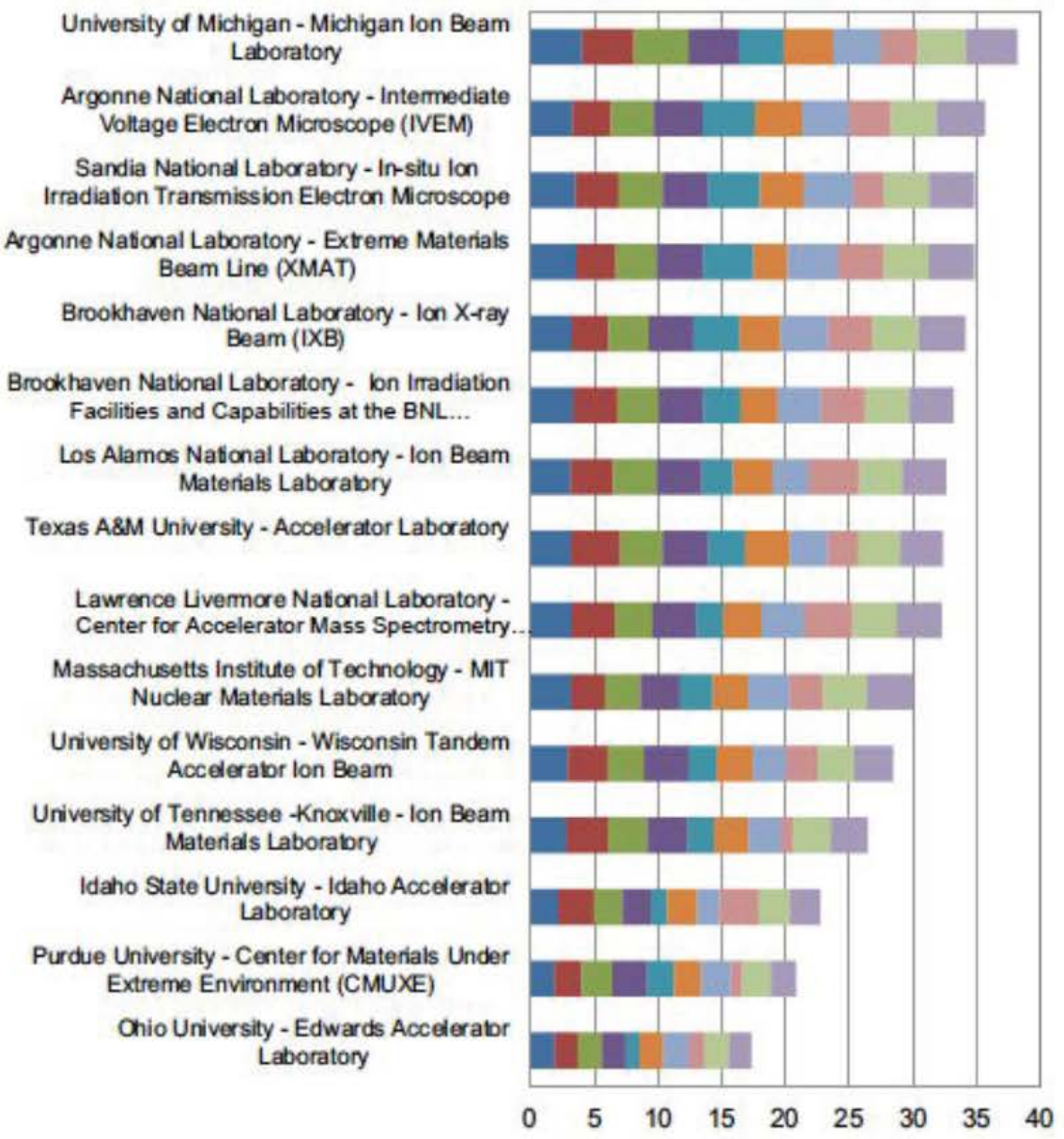

Overall score and ranking of the ion beam facilities, "NSUF ION BEAM

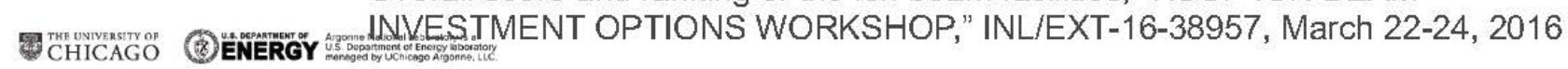
conditions (neutrons or fission fragments).
WC1: Viability for the capability to extend our understanding towards accurately simulating nuclear irradiation

IC2: Ability of the facility b provide a variety of ion irradiations (lion types, energies, multiple beams, etc.).

C3: Ability of the facility to provide a variety of wellcontrolled target environments and conditions.

-C4: Ability of the facility b collect and analyze materials propertes andior perform microstructural characterization

C5: Ability of the facility to collect and analyze materials properbes andior perform microstructural characterization

C6: Current or potential productivity of the facility $(\mathrm{e} g$. fewer high-impact experiments or high-volume sampl

C7: Unique capabilifes of the facility including any new a dose technological

C8: Ability of the facility to handle radioactive materials (structural materials and/or fuels) in the beams and elsewhere onsite.

C9: Ability of the tacility to produce quality-level data that can support licensing as well as verification and vaidabion of modeling and simulation.

C10: Ability of the facility bo produce results that meet the needs of the DOE - Office of Nuclear Energy (including cross-cutting programs) and the nuclear energy industry. 


\section{TIMELINE OF XMAT}

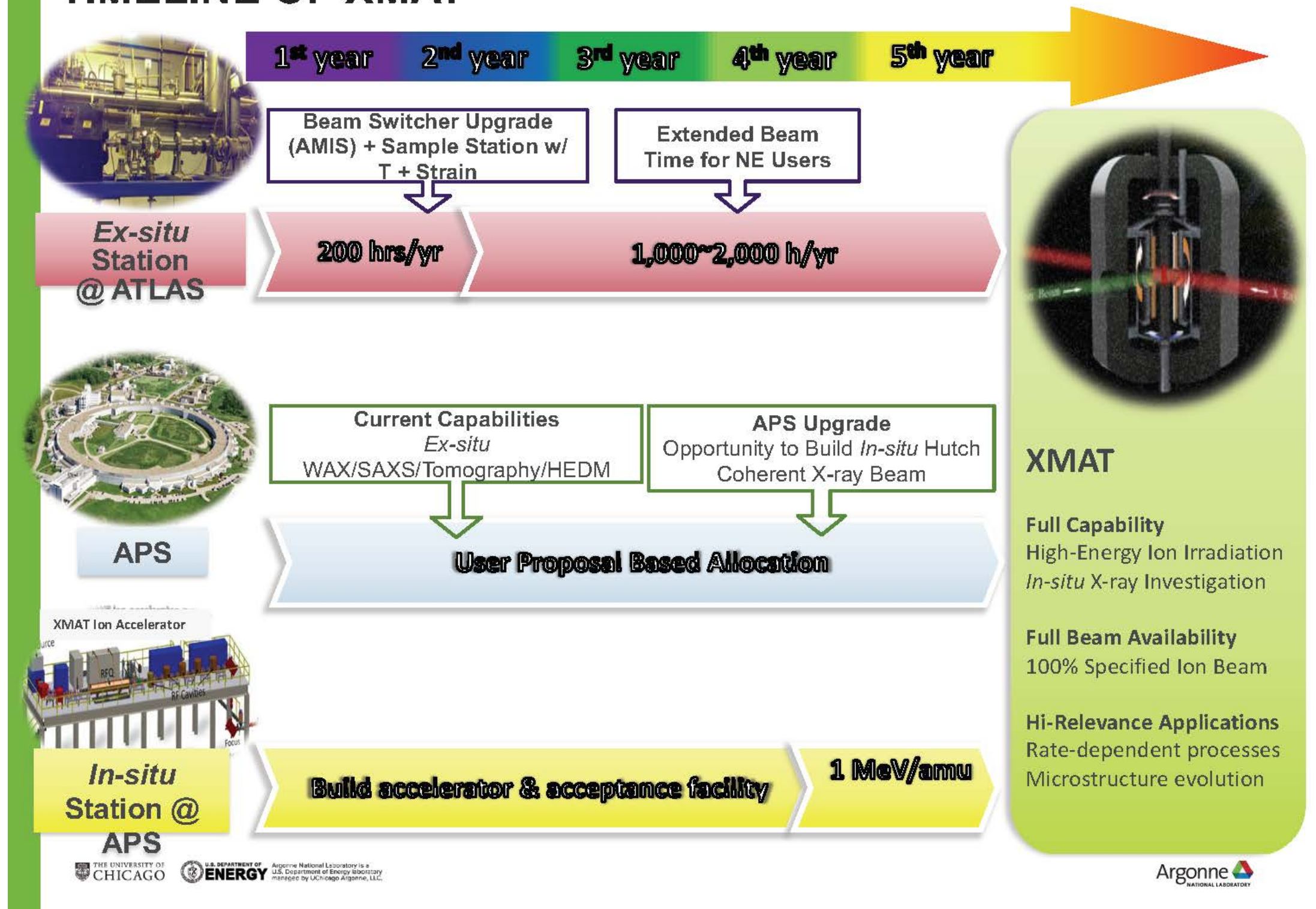

Use or disclosure of data contained on this sheet is subject to the restriction on the title page of this document 


\section{KEY XMAT ADVANCES}

In comparison to most existing ion irradiation capabilities, the XMAT ion energies and currents are $\sim 100$ times higher. The increased ion irradiation energy (e.g., $133 \mathrm{MeV}$ for xenon) enables several critical advances:

- It provides a unique opportunity to simulate the effects of fission fragments in nuclear fuels, where ions of all elements can be accelerated to fission fragment energies, while being characterized in situ.

- For cladding and structural materials, the increased penetration depth of energetic ions allows the "bulk behavior" to be examined, eliminating surface-sink effects, and allows understanding of individual physics of ion damage including electronic, collisional, \& added interstitial

- The in situ penetrating ability of the APS focusable hard x-rays, applied during ion irradiation, is another key advancement of XMAT that allows the interrogation of individual grains within solid material samples during irradiation.

- With this information and related computational modeling, the differences between ion and neutron irradiation as well as the impact of fission products damage become much more understandable.

XMAT can close the design loop for the entire nuclear materials community in two ways: 1)It provides accelerated testing for hundreds to thousands of samples $(24 ; 7)$

2)It reveals the key "single" physics dependences required for accurate computational modelling 
APPENDIX D - Fission Accelerated Steady-State Testing (FAST) in Nuclear Fuel Development 


\section{Nuclear Energy}

\section{Fission Accelerated Steady-State Testing (FAST) in Nuclear Fuel Development}

Geoffrey (Boone) Beausoleil, Kyle Paaren, Matthew Kerr, and Steve Hayes Nuclear Fuels and Materials Division, Idaho National Laboratory 


\section{Current Nuclear Development Cycle}

Nuclear Energy

Post Irradiation Exam and Performance Assessment ( 3 to 5 years)

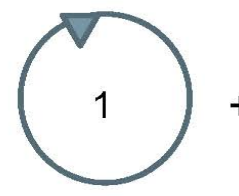

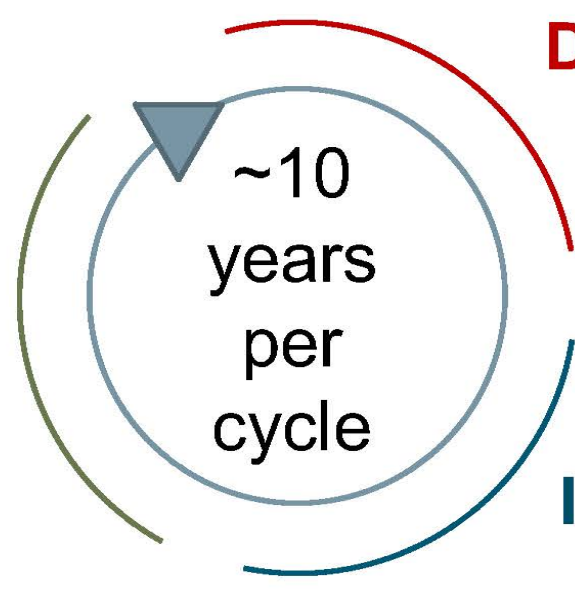

Design, Fabrication, and Characterization

(3 to 4 years)

Irradiation ( 3 to $5+$ years)

20 to 30 year development cycle Example: TRISO, HPRR, Metal fuel, advanced claddings, 


\section{Nuclear Energy}

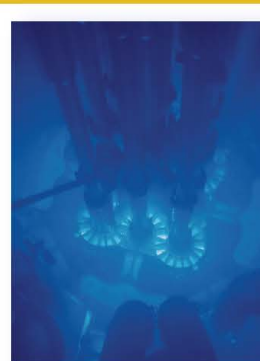

ATR:

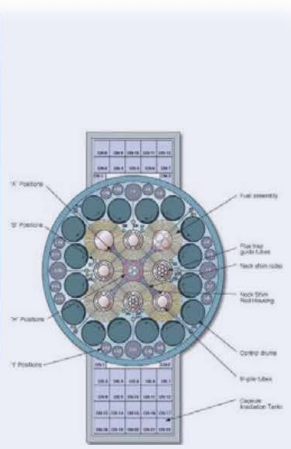

- Water-cooled plate-type MTR started 1967, still one of the newest and
most advanced MTRs today

- Serpentine driver core creates nine flux traps and numerous other test positions

- High flux, large useable test geometries (1.2 m long core), and high capacity factor (for an MTR $\sim 200$ day/yr

- Rich history of burnup accumulation in capsules, instrumented lead outs, \& pressurized water loops

- Transient power-cycling via 1. 1 dvanced Fuels campaign insertion/removal device
HFIR:

Water-cooled plate-type MTR started 1965

- Two involute plate rings create very high flux in center trap and other reflector positions

- Unrivalled isotope production and neutron beamline capabilities

- Unique material/fuel irradiation capabilities for properties evolution, separate effects, and model validation
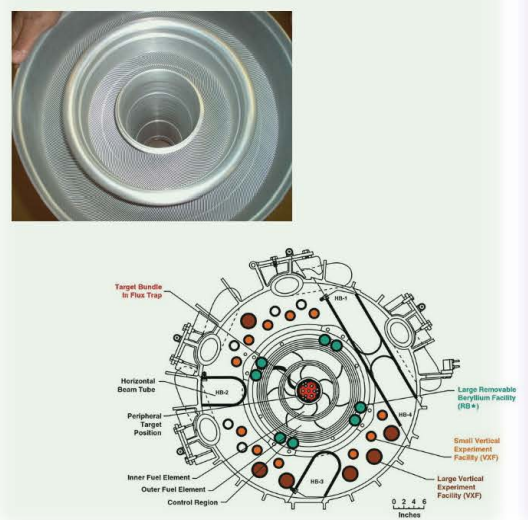

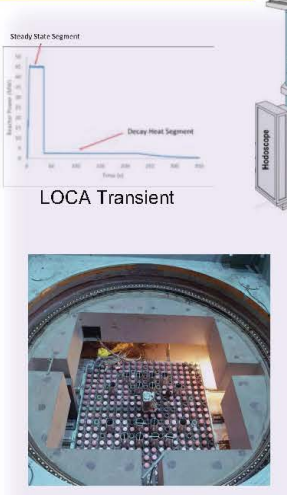

TREAT:

Graphite-based transien

reactor started in 1959

- Unparalleled transient shaping capability (milliseconds to minutes)

- Operated until 1994 focused largely on SFR testing

- Restarted 2018, demonstrated transient capabilities for LWR (RIA \& LOCA)

- First fueled water capsule irradiated just weeks ago 


\section{Approach to Accelerated Integral Fuel Testing} (Fission Accelerated Steady-state Testing)

Nuclear Energy

- Revised Capsule Design Objectives:

1) Increase burnup rate for fuel experiments: reduce time to achieve high burnup

2) Improve experiment reliability: reduced sensitivity to fabrication tolerances and capsule/pin eccentricity

3) Double capsule design allows experiment tenability to variety of prototypic conditions and fuel forms
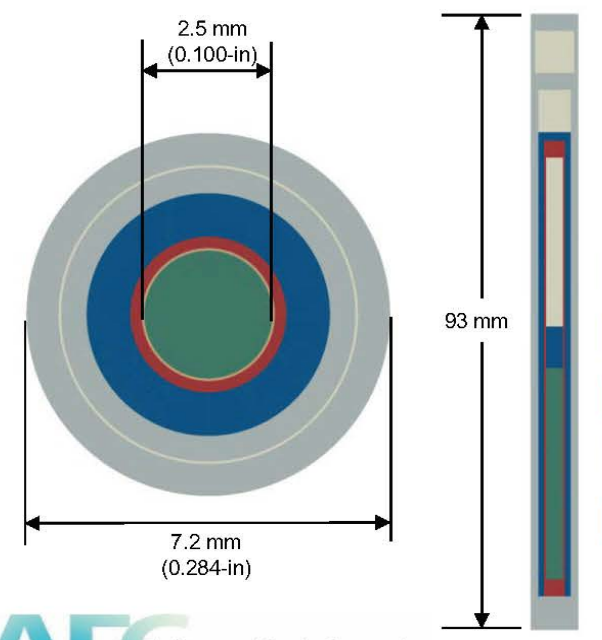

\begin{tabular}{|c|c|c|c|c|}
\hline $\begin{array}{l}\text { Capsule } \\
\text { Design }\end{array}$ & Cases & $\begin{array}{l}\text { Max. Inner } \\
\text { Clad Temp } \\
\text { (C) }\end{array}$ & $\begin{array}{l}\text { Min. Inner } \\
\text { Clad Temp } \\
\text { (C) }\end{array}$ & $\begin{array}{l}\text { Peak Fuel } \\
\text { Temp } \\
\text { (C) }\end{array}$ \\
\hline \multirow{3}{*}{$\begin{array}{c}\text { Standard } \\
365 \mathrm{~W} / \mathrm{cm} \\
50 \mu \mathrm{m} \text { gap }\end{array}$} & $0 \mu \mathrm{m}$ offset & 572 & 572 & 709 \\
\hline & $25 \mu \mathrm{m}$ offset & 605 & 483 & 695 \\
\hline & Difference & +33 & -89 & -14 \\
\hline \multirow{3}{*}{$\begin{array}{l}\text { Double- } \\
\text { Encapsulated } \\
300 \mathrm{~W} / \mathrm{cm} \\
50 \mu \mathrm{m} \text { gap }\end{array}$} & $0 \mu \mathrm{m}$ offset & 570 & 570 & 684 \\
\hline & $25 \mu \mathrm{m}$ offset & 567 & 523 & 664 \\
\hline & Difference & -3 & -47 & -20 \\
\hline \multirow{3}{*}{$\begin{array}{l}\text { Double- } \\
\text { Encapsulated } \\
180 \mathrm{~W} / \mathrm{cm} \\
100 \mu \mathrm{m} \mathrm{gap}\end{array}$} & $0 \mu \mathrm{m}$ offset & 566 & 566 & 637 \\
\hline & $25 \mu \mathrm{m}$ offset & 566 & 556 & 629 \\
\hline & Difference & 0 & -10 & -8 \\
\hline
\end{tabular}
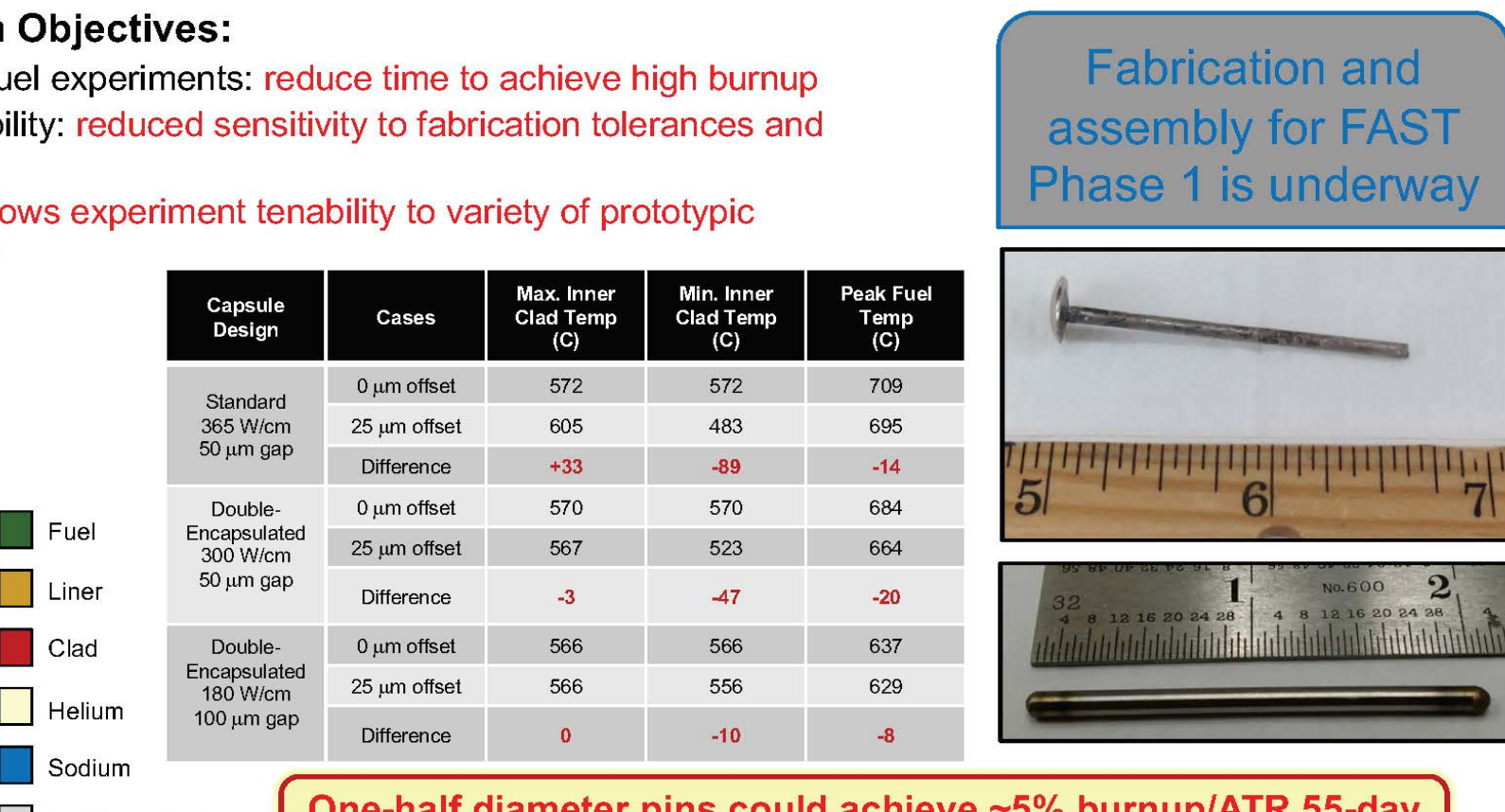

Stainless Steel

One-half diameter pins could achieve $\sim 5 \%$ burnup/ATR 55 -day cycle and reach $30 \%$ burnup in less than 3 years. 


\section{TREAT-THOR Testing}

Nuclear Energy

Temperature Heat-sink Over-power Response (THOR) capsule

- Thick wall heat sink capsule with liquid metal bond (sodium) to specimen

- Easy way to get heat transfer without the cost of a full loop

- Concerted with TREAT transient power shaping to created desired temperature response (milliseconds to minutes)

AFC, JAEA, and NSUF efforts underway for FY21 testing

- SFR fuel temperature response during early stages of overpower transients

- Phase-based radial thermal conductivity measurement (oscillating transient)

- Power to melt studies for SFR fuel

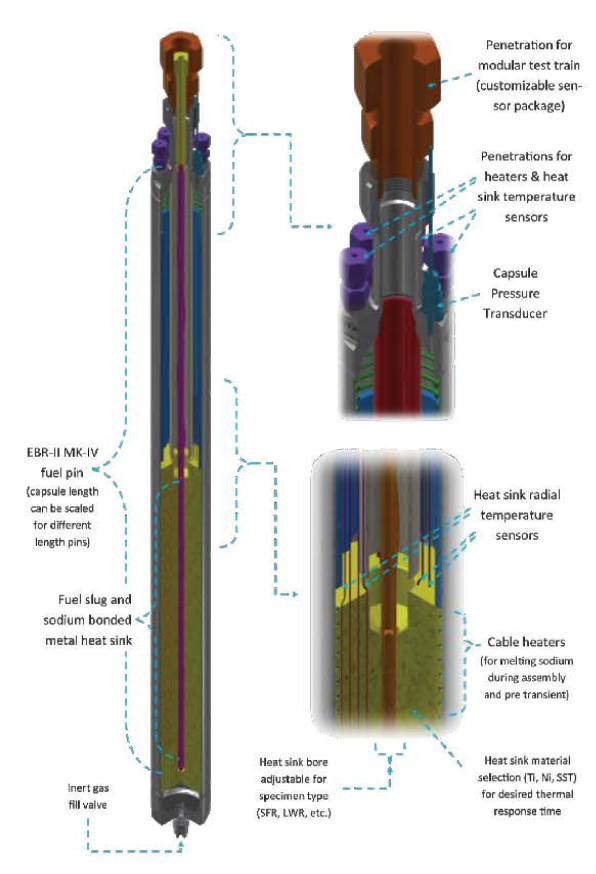




\section{U.S. DEPARTMENT OF}

\section{HFIR: MiniFuel Testing Capabilities}

Nuclear Energy

- Recently commissioned MiniFuel Capability

- Burnup accumulation of small specimens ( $1 \mathrm{~mm}$ particle and disc scale)

- More for microscopists than engineers, clever way to produce specimens for small-scale phenomena PIE

- Specimen to "filler" hardware volume ratio yields $\sim$ constant temperature irradiations relatively independent of fission rate

- Gamma-heated filler design can affect different target temperatures, life avg measured in PIE by passive SiC thermometry

- Current efforts already underway

- First UN irradiations recently performed

- AFC U-Zr irradiations presently under preparation

- Value potential to be evaluated

- RUSL experiments can give the first look at fresh fuel phase stability vs. temp/fission-rate

- MiniFuel can add the fission damage effect
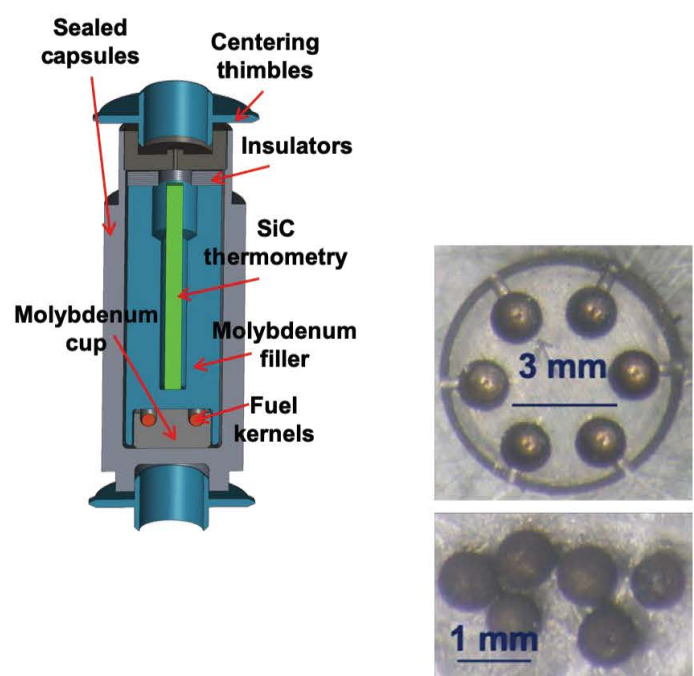

MiniFuel capsule (left) and PIE of UN fuel kernels irradiated to $\sim 10 \mathrm{MWd} / \mathrm{kg} \cup$ (right)

Images courtesy of $\mathrm{C}$. Petri 
Nuclear Energy

NSUF project that can be adopted into ATR

- Separate effects irradiation test at BR-2 in Belgium

- PIE planned at INL

- DISECT vehicle allows for customization of sample holder to meet the needs of the experiment

- Two approaches are being used for this irradiation

- U-Zr foils are placed in a zirconium housing with customized internal volume to accommodate swelling and act as a plenum for fission gasses.

- U-Mo 3mm diameter TEM punches are placed in an aluminum holder.

- Can be tailored to meet other fuel form objectives

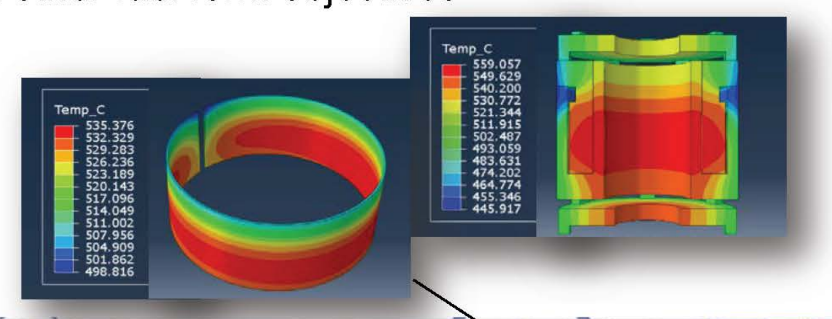

DISECT sample holders.

Top) Illustration of U-Mo TEM punches in aluminum housing Bottom) $\mathrm{U}-\mathrm{Zr}$ foil in zirconium housing
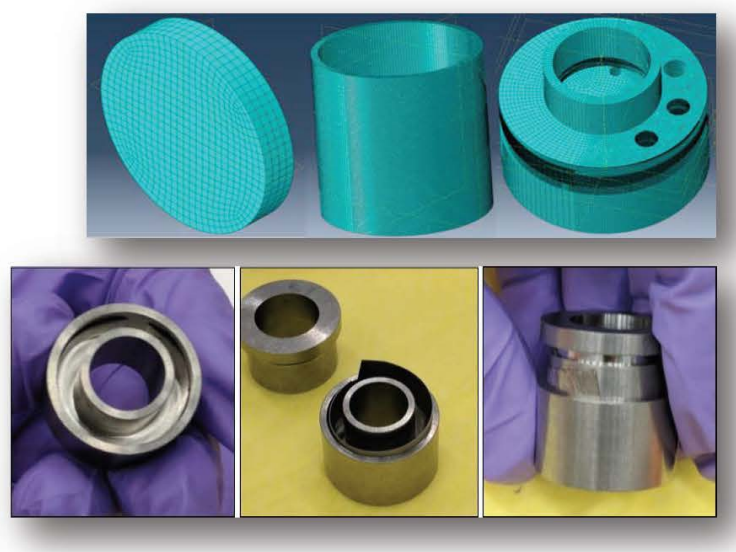

Abaqus thermal rendering of $\mathrm{U}-\mathrm{Zr}$ housing (Top) and U-Zr foil (Bottom) 


\section{PIRT Analysis and Prioritized Strategy}

Nuclear Energy

- INL stood up an accelerated testing working group that spans multiple laboratories and programs

- Contributors from across INL, LANL, \& ORNL as well as AFC and NEAMS

- Phenomenon Identification and Ranking Table analysis was performed

- Identified key focus areas for modelling and simulation needs

- Provided guidance for experimental objectives and data acquisition

- Coordinated AFC-NEAMS milestones based on results

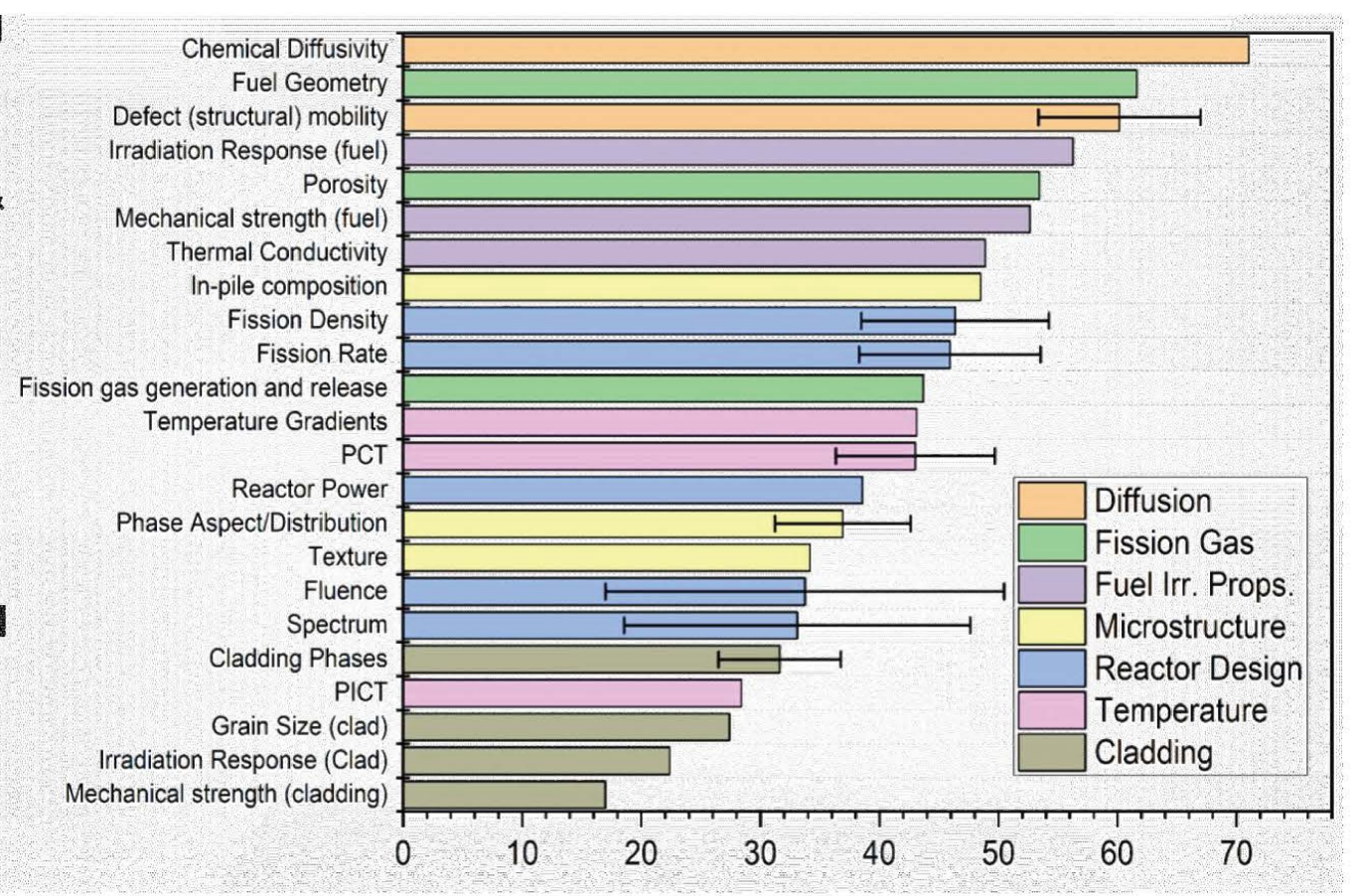




\section{Experiment \& Model-Simulation Synergy}

Nuclear Energy

- Coupling a wide range of reactor conditions with model conditions across a variety of length, time, and temperature scales allows for optimized R\&D

- Utilize BISON and MOOSE stgeady State A experiments prior to irradiation

- Perform bounding studies on key a Ramp phenomenon of interest; e.g. a hlo medium-low study of fuel plasticity power

- Utilize Raven for uncertainty quantification and representativity
analysis

- Able to quantify how realistic min the experiment is and the impaet of uncertainties to the results

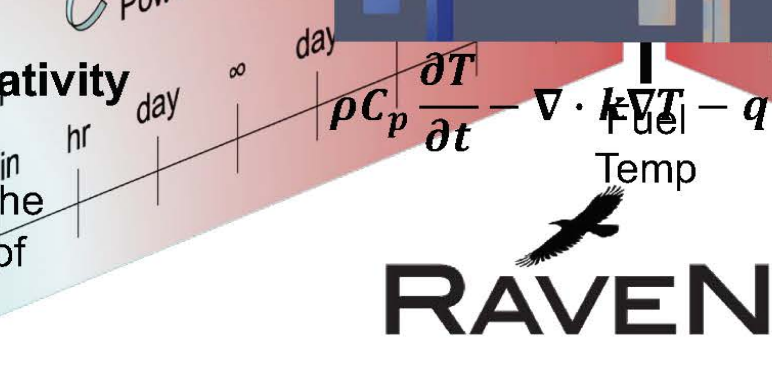
$+$

.

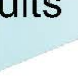




\section{U.S. DEPARTMENT OF}

\section{ENERGY}

\section{Accelerated Testing within AFC}

Nuclear Energy

AFC-ATWG relationship between experimental programs and modelling/simulation

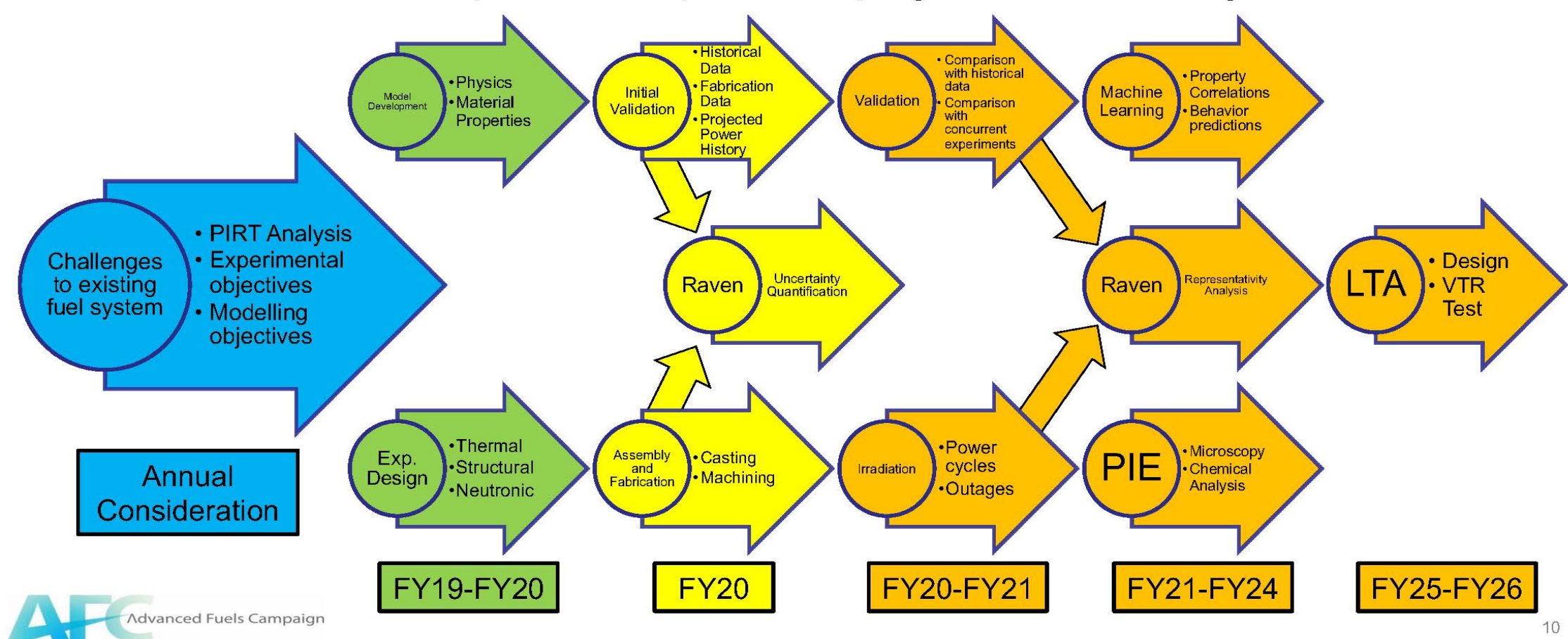


- Amereror

\section{Experiment Schedule Strategy for Metal Fuels}

Nuclear Energy

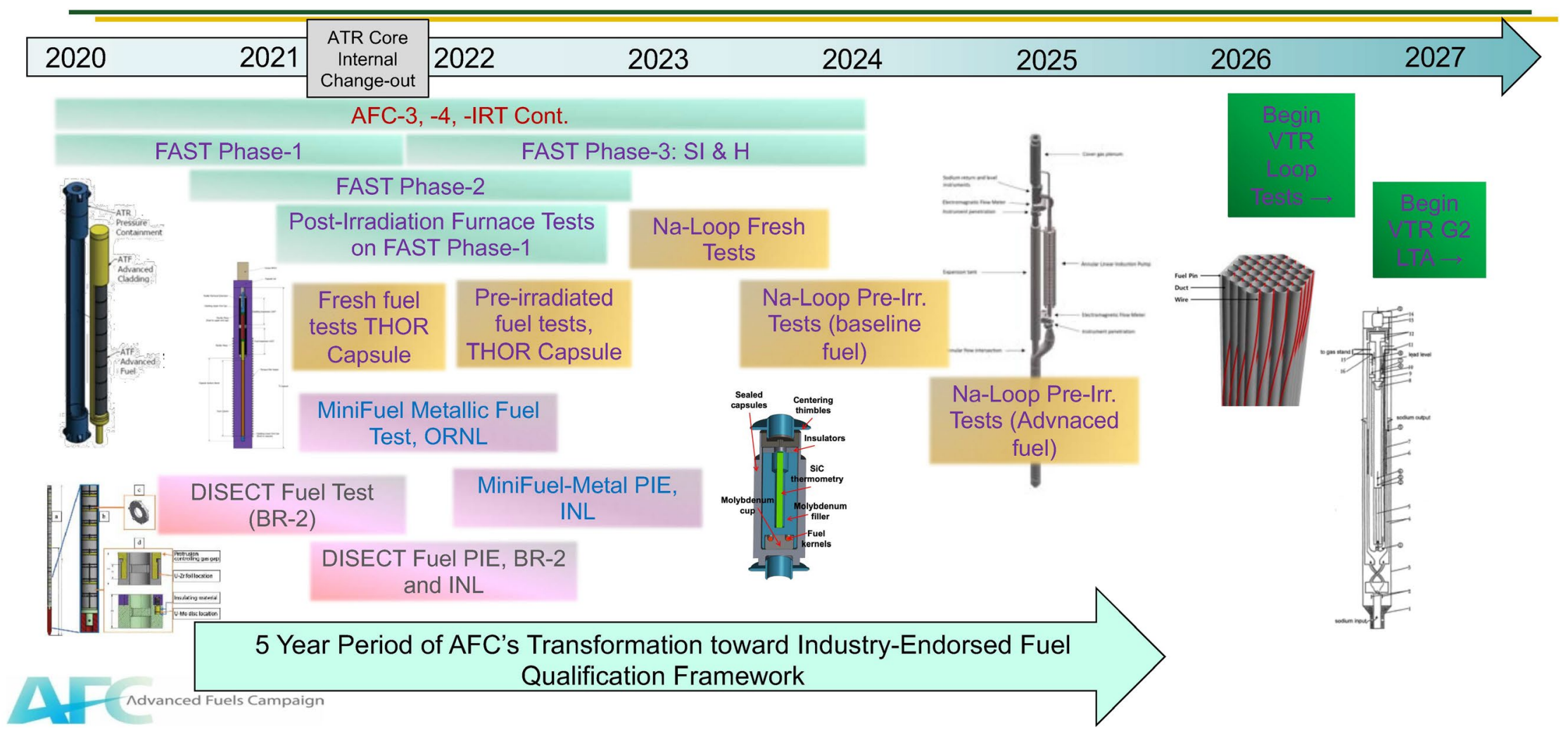




\section{FAST is Beyond Metal Fuel...}

Nuclear Energy

- FAST is performing extensive metal fuel irradiations

- But FAST was originated to support more than just SFR metal fuel development

Vendor Support

- Being adopted for UC irradiations with GA via LDRD

- Scoping studies for supporting Oklo fuel concepts

- Supporting pre-irradiation of novel LWR fuel concepts from LANL for TREAT testing

adopted as irradiation platform for the NNSA Advanced LEU concepts
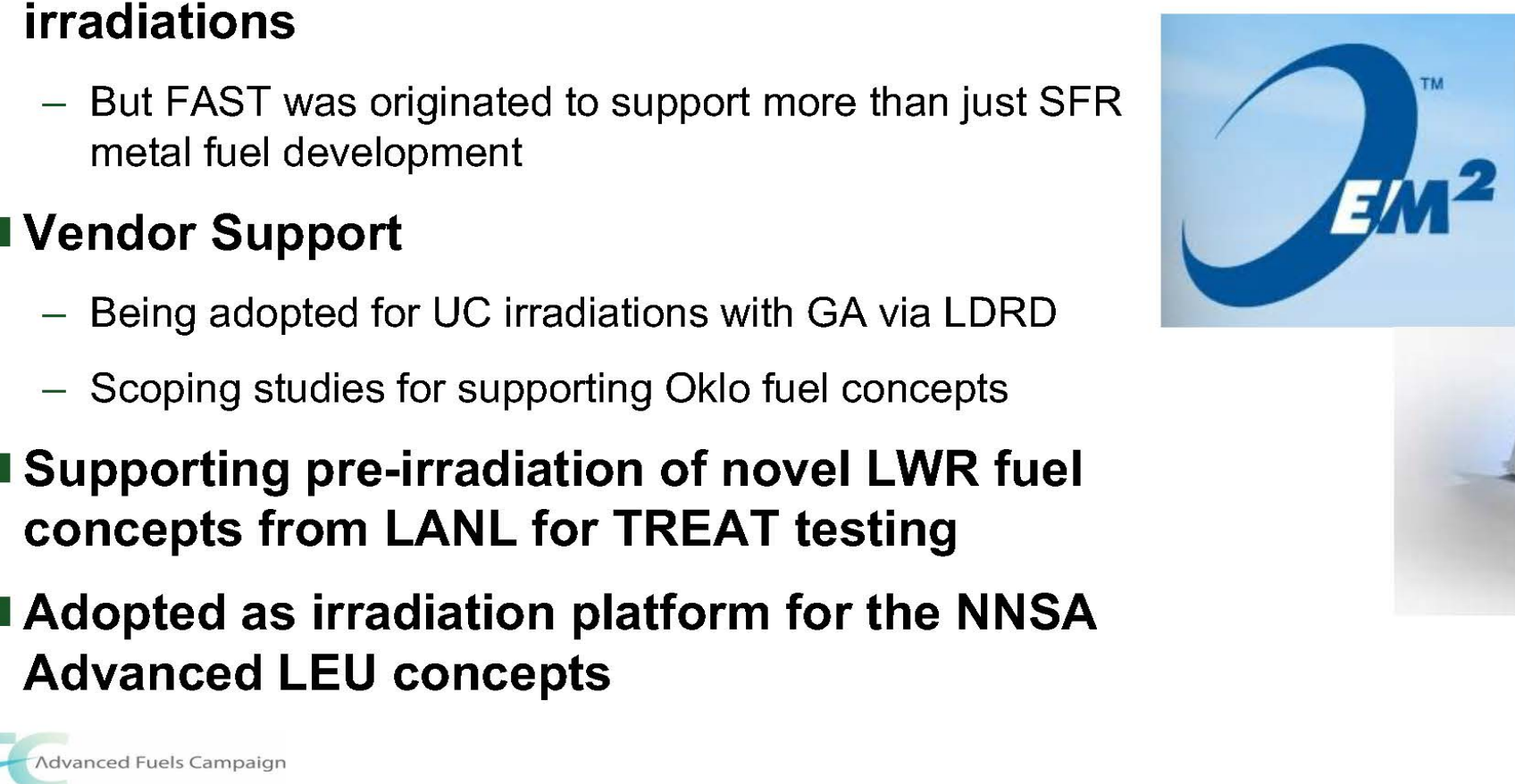


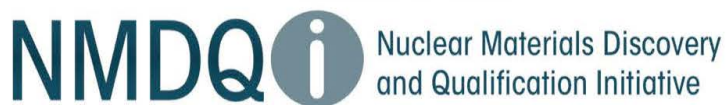

Qualification Requirements
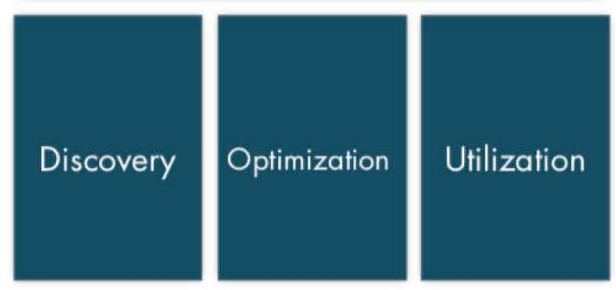

Computational Materials Design

Data Analytics

Physics Based Modeling

High Throughput Infrastructure

Advanced Manufacturing

Nuclear Materials and Fuels Testing

National Programs

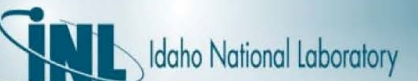

NMDQj takes a Grand Challenge approach to accelerate development

and qualification of new nuclear materials and fuels for future advanced reactor technologjes.

\section{Enabling Technologies and Capabilities:}

- Physics-based M\&S for materials discovery and optimization.

- Data analytics for machine and deep learning.

- High-throughput material fabrication/characterization applying advanced manufacturing principles.

- Nuclear material testing over a wide range of conditions, including accelerated irradiation testing. 
APPENDIX E - Appendix E: Fuel Performance Modeling and Fuel Qualification at TerraPower 


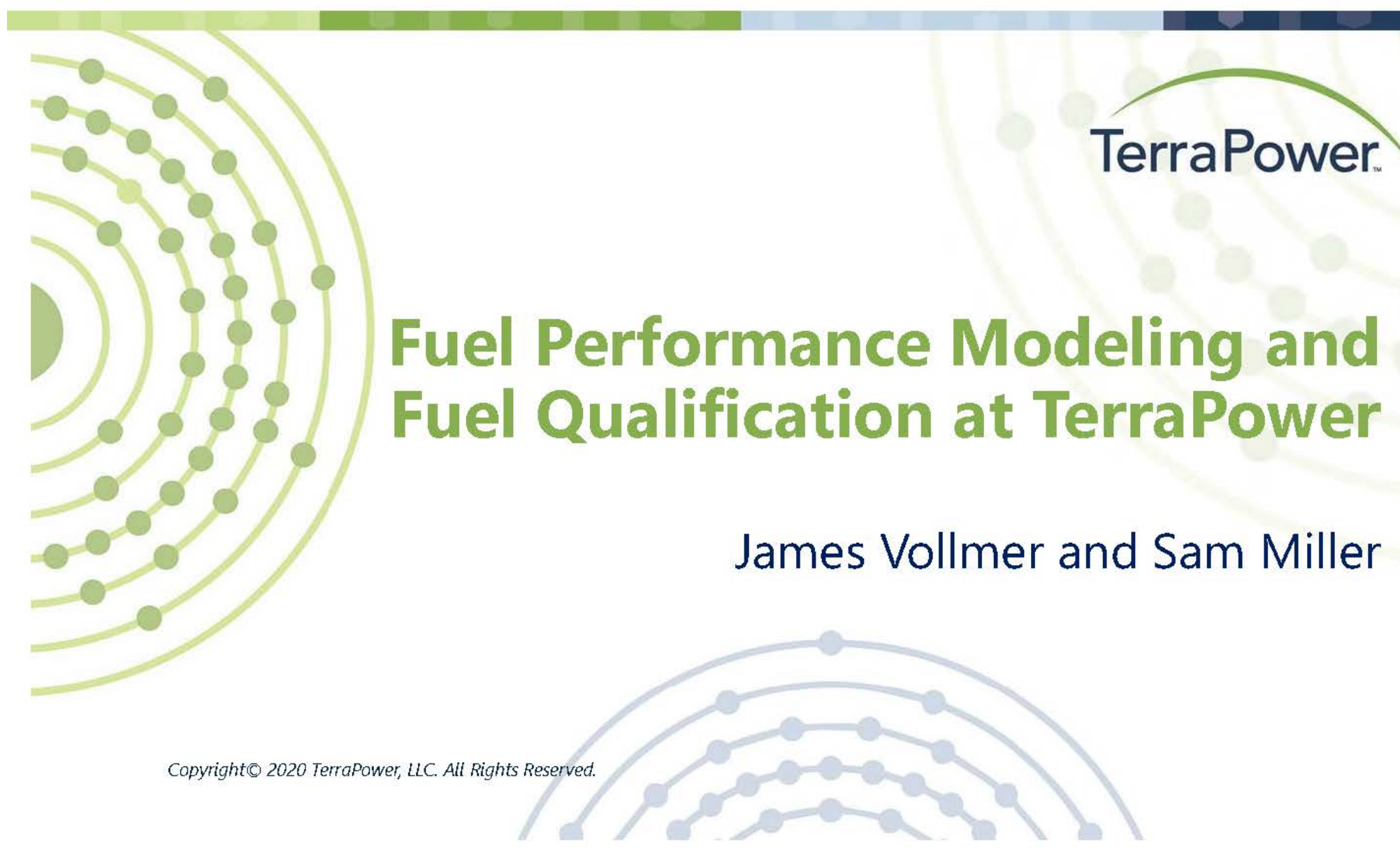




\section{Tight Integration Between Testing and Modeling}

- One of TerraPower's strengths has been the tight integration between modeling and testing activities

- Often a necessity due to aggressive performance and schedule targets

- Pushing the envelope for fuel burnup, lifetime, and fast fluence

- Need to make design decisions with limited information

- Needed to start testing early to achieve targets

- Small teams forced integration of activities

- Fuel performance model development

- Fuel performance assessments to support core design

- Fuel and material fabrication development

- Fuel and material testing (in-pile and out-of-pile)

- Overall support of fuel qualification 


\section{Flow Down of Requirements}

- Established fuel regulatory acceptance criteria that correspond to what is covered in the Standard Review Plan, making revisions as necessary to cover sodium fast reactors

- Revised fuel design criteria/bases to assure one-to-one coverage of the established fuel regulatory acceptance criteria

- Fuel Qualification Plans prepared to assess testing and analysis activities required to justify and assess compliance with fuel design criteria 


\section{Fuel Qualification Plans}

- Fuel qualification plans prepared to identify activities needed to:

- Justify fuel system damage criteria

- Justify fuel pin failure criteria

- Justify fuel coolability criteria

- Justify control rod insertability criteria

- Establish fuel system description

- Establish and validate methods for fuel system design evaluation 


\section{Fuel Qualification Plans (cont.)}

- Establish testing and inspection plans/specifications for new fuel

- Establish methods and programs for online fuel system monitoring

- Establish post irradiation surveillance plans/programs 


\section{Justifying Fuel Design Limits \& Evaluation Methods Have Been Main Priority}

- Evaluated and summarized available data to set and justify initial fuel design limits

-Wherever practical identify additional testing to verify acceptability of established limits using TerraPower materials

- Develop correlations and computational methods to analyze designs to verify limits are met

- Correlations/methods to cover high impact phenomena

- Identify validation needs for phenomena correlations and methods 


\section{Phenomena Identification Ranking Tables (PIRTs) Help Guide the Process}

For each design limit and targeted condition list all phenomena required to assess performance.

Rank importance and knowledge for each phenomenon.

\begin{tabular}{|c|l|}
\hline $\begin{array}{c}\text { Importance } \\
\text { Rank }\end{array}$ & \multicolumn{1}{c|}{ Definition } \\
\hline Low (L) & $\begin{array}{l}\text { Variation of parameter has minimal impact } \\
\text { on assessment of design criterion }\end{array}$ \\
\hline Medium (M) & $\begin{array}{l}\text { Variation of parameter has moderate impact } \\
\text { on assessment of design criterion }\end{array}$ \\
\hline High (H) & $\begin{array}{l}\text { Variation of parameter has significant impact } \\
\text { on assessment of design criterion }\end{array}$ \\
\hline
\end{tabular}

\begin{tabular}{|c|c|}
\hline $\begin{array}{c}\text { Knowledge } \\
\text { Level }\end{array}$ & Definition \\
\hline High $(\mathrm{H})$ & Known \\
\hline Medium (M) & Partially Known \\
\hline Low (L) & Unknown \\
\hline
\end{tabular}

PIRT process ensures that key fuel phenomena are identified and understood 


\section{PIRT Evaluation Identifies Key Fuel Phenomena}

\begin{tabular}{|c|c|c|}
\hline Design Criteria (Limits) & Purpose of Limit & Key Parameters that Influence Criteria \\
\hline $\begin{array}{l}\text { Thermal Creep Strain in } \\
\text { Cladding }\end{array}$ & $\begin{array}{l}\text { Prevent cladding rupture or coolant } \\
\text { flow blockage }\end{array}$ & $\begin{array}{l}\text { - HT9 Properties/Constituent Model } \\
\text { - FCCI Clad Wastage } \\
\text { - Fission Gas Release }\end{array}$ \\
\hline $\begin{array}{l}\text { Total Strain (Thermal plus } \\
\text { Irradiation Enhanced } \\
\text { Creep and Swelling) }\end{array}$ & $\begin{array}{l}\text { Prevent mechanical interaction and } \\
\text { coolant flow blockage }\end{array}$ & $\begin{array}{l}\text { - Fission Gas Release } \\
\text { - HT9 Properties/Constituent Model }\end{array}$ \\
\hline Peak Fuel Temperature & Prevent fuel melting & $\begin{array}{l}\text { - Fuel Thermal Conductivity } \\
\text { - Axial Growth }\end{array}$ \\
\hline $\begin{array}{l}\text { Peak Cladding } \\
\text { Temperature }\end{array}$ & $\begin{array}{l}\text { Prevent cladding failure due to fuel- } \\
\text { clad eutectic reactions }\end{array}$ & - Coolant Temperature \\
\hline Cladding Wastage & $\begin{array}{l}\text { Prevent cladding rupture or coolant } \\
\text { flow blockage }\end{array}$ & - FCCI Clad Wastage \\
\hline
\end{tabular}




\section{Fuel Performance Tools at TerraPower}

Crucible - Fast, integrated with ARMI ${ }^{\circledR}$, aimed at key design criteria during normal operation for all assemblies:

- Sodium-bond transport

- Fission gas release transport

- Fuel axial growth

- Cladding wastage

- Temperatures

- Cladding Strain

\section{ALCHEMY ${ }^{\circledR}$ - FEA model for high-fidelity} calculations

- Steady-state and transient behavior

- High-fidelity strain and temperatures

- Cladding damage models

- Capsule models for ATR/MITR/TREAT testing

- Absorber pin models $\left(B_{4} C\right)$

- "Structural" material models are used elsewhere

- OXBOW

- Pin attachment hardware (pin rails, endcaps, etc.)
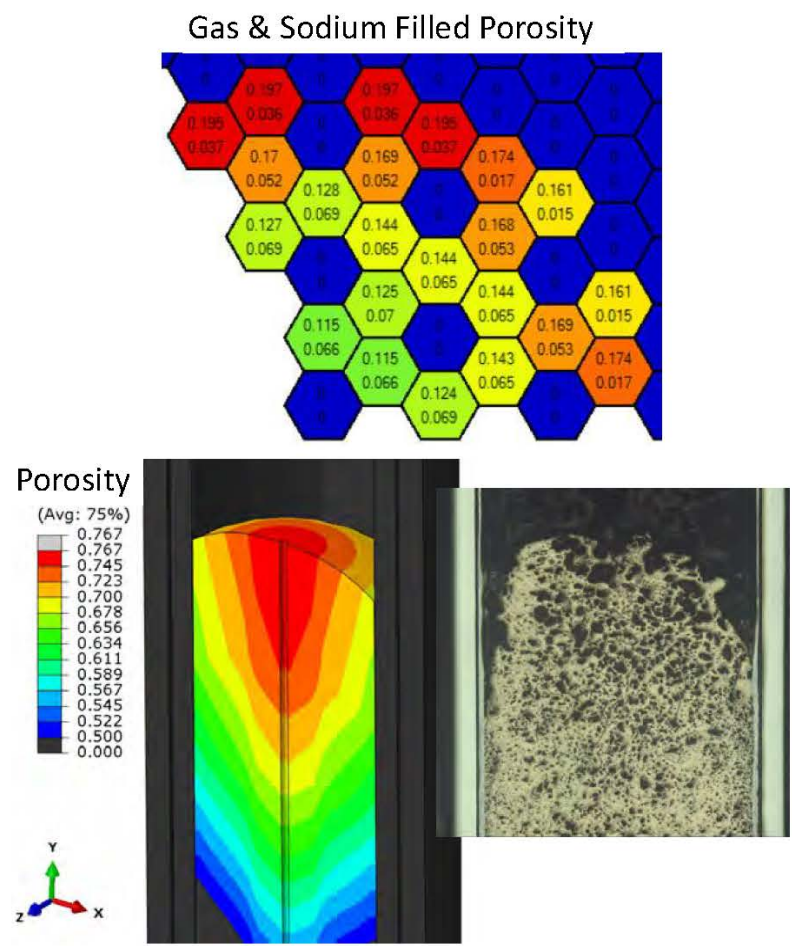
Focus:

\section{Fuel Performance Model Philosophy}

- Modeling key criteria necessary for design and licensing

- Collecting and analyzing experimental data

- Automation and efficiency of tools

Use fundamental equations and models where appropriate:

- General thermo-mechanical FEA models (ALCHEMY®)

- Structural materials creep and swelling models

- Fuel deformation

Use empirically-based models and avoid overly complex models: (minimize number of unknown model constants)

- Gas release model

- FCCI model

- Creep damage model

- Axial growth model

- Fuel conductivity change due to irradiation 


\section{ALCHEMY ${ }^{\circledR}$ Verification: Separate $\&$ Mixed Effects Testing}

Constitutive Model Benchmark Tests:

- Model tests use a variety of 2D and 3D element types and geometries, under various loading conditions

- Structural material models

- Thermal \& Irradiation Creep

- Stress-free and Stress-Enhanced Swelling

- Irradiation Hardening

- Fuel constitutive models

- Porous Plasticity \& Creep

- Fission Gas Behavior

- Thermal Behaviors

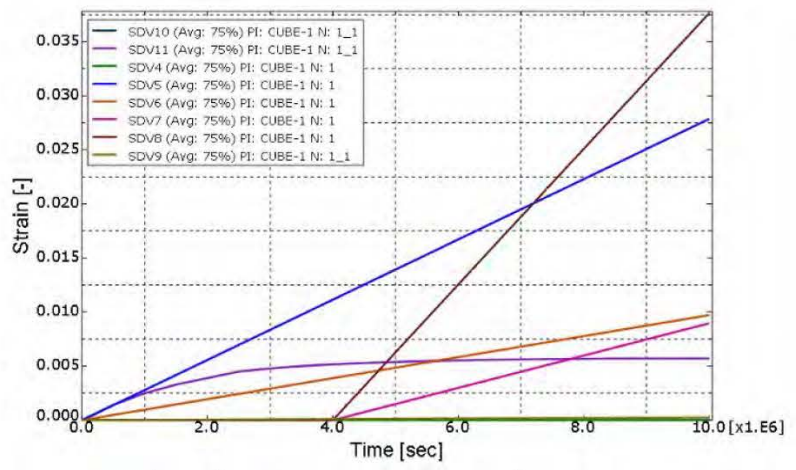

Plot of an integration test showing the complex HT9 strain behavior

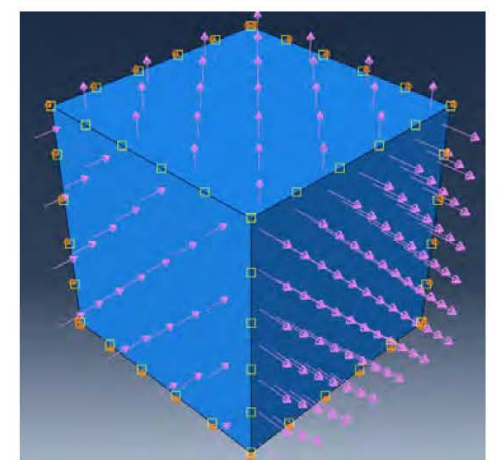

3D Triaxial Load Creep Integration Test 


\section{Claddling Deformation Mechanisms}

\section{Models for HT9 (multiple), SS316, D9, other steels \& materials}

8 mechanisms of deformation:

- Stress-Free Swelling

- Stress-Enhanced Swelling

- Linear Irradiation Creep

- Non-linear Irradiation Creep

- Primary Thermal Creep

- Diffusional Thermal Creep

- Power-Law Thermal Creep

- Visco-Plasticity

$$
\begin{aligned}
& f(d p a, T) \\
& f(d p a, T, \sigma) \\
& f(d p a, \sigma) \\
& f(d p a, T, \sigma) \\
& f(T, \sigma, \varepsilon) \\
& f(T, \sigma) \\
& f(T, \sigma) \\
& f(T, \sigma)
\end{aligned}
$$

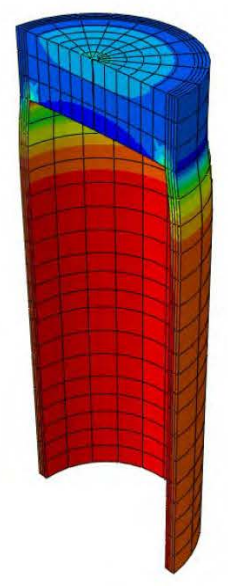

* Each of these mechanisms has an effective regime where the mechanism has a strong effect. * Models informed by recent TerraPower testing

* During steady-state operation, Power-Law Thermal Creep and Visco-Plasticity should not be dominant mechanisms $(\sigma<<$ Yield Strength) 


\section{Sample Fuel Pin Clad Strain Profile Predictions}
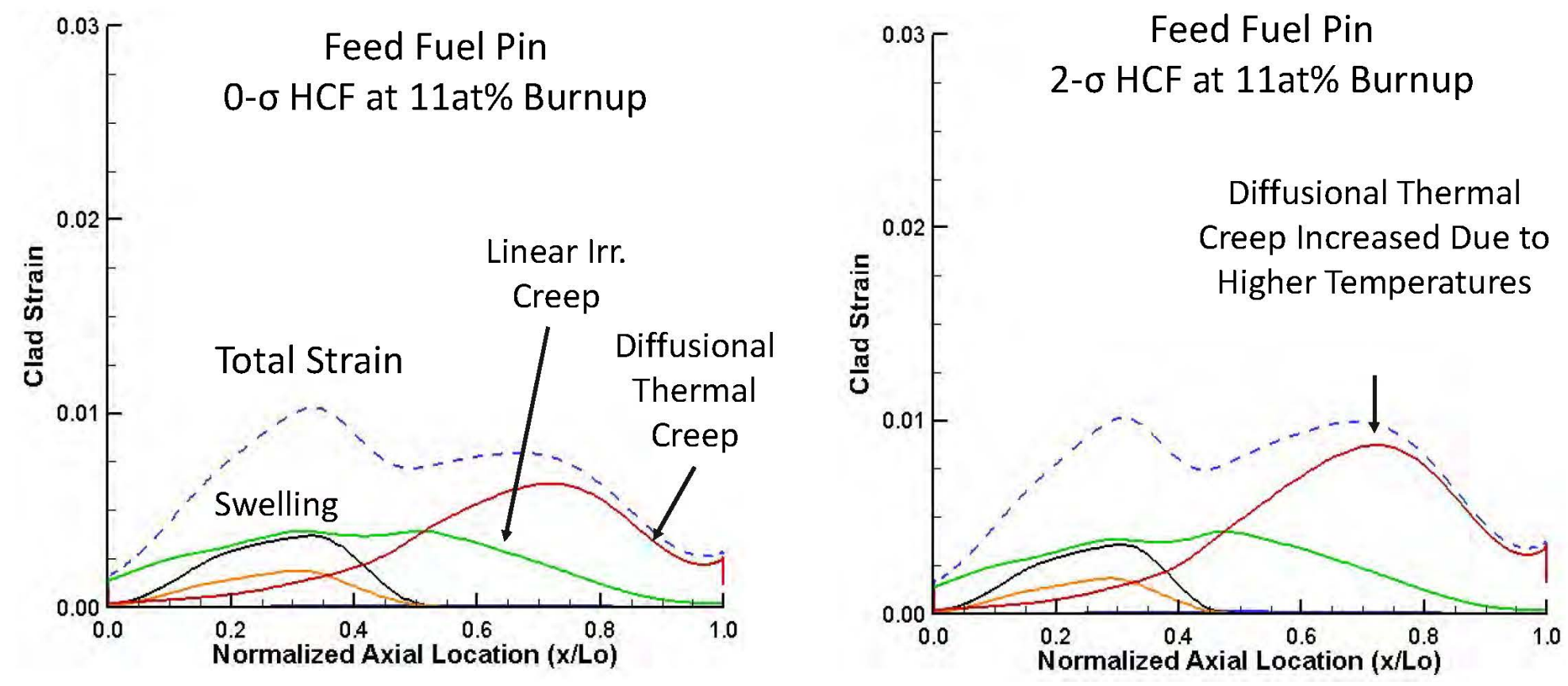

13 Copyright: 2020 TerraPower, LLC. All Rights Reserved.

TerraPower. 


\section{ALCHEMY ${ }^{\circledR}$ Validation Hierarchy \& Phases}

\section{Levels of Validation Hierarchy}

- Component

- Subsystem

- Complete system

\section{Validation Phases}

- Phase 1: Demonstrate general adequacy for modeling sodiumbonded metallic fuel (in this phase)

- Phase 2: Qualify ALCHEMY ${ }^{\oplus}$ for licensing SFR sodium-bonded fuel

- Phase 3: Qualify ALCHEMY® for licensing advanced TWR fuel systems (with additional testing)
A. Complete System Model Validation (steady-state and transient for each)

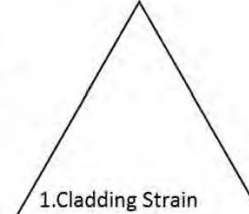

1.Cladding Strain
2.Fuel Temperatures

3.Time-to-cladding failure 4.Advanced Fuel Systems

B. Subsystem

Model

Validation

C. Component Validation

1. Fuel Behaviors 2. Cladding Behaviors a) Thermal Expansion

b) Yield Strength

$\begin{array}{ll}\text { Fuel Swelling b) Yield Streng } \\ \text { b) Gas Release } & \text { c) Swelling }\end{array}$

c) Constituent d) Creep Damage

Redistribution e) Sodium Wastage

e) Sodium Wastage

g) Fatigue

h) Thermal Aging 


\section{Historic Fuel Reports and Database Effort to Support Validation}

- Dedicated effort to compile, digitize, and analyze metallic fuel data from EBR-II and FFTF to create a fuel performance database to support ALCHEMY ${ }^{\circledR}$ validation

- Phased approach to progressively expand the number of benchmark cases as we develop and improve ALCHEMY's functionality

- Primary focus has been HT9-clad pins, but we do have 316 and D9 pins in our plans to validate applicability to other cladding materials

- Topical reports of fuel phenomena have also been prepared to support correlation development and sub-model validation

- Axial growth, fission gas release, $\mathrm{FCCl}$, eutectic interactions 


\section{Status of Historic HT9-Clad Fuel Pin Reports}

\begin{tabular}{|c|c|c|c|c|c|}
\hline Assembly & Fuel Type & $\begin{array}{l}\text { As-Built } \\
\text { Report }\end{array}$ & $\begin{array}{l}\text { Irradiation } \\
\text { History Report }\end{array}$ & $\begin{array}{l}\text { Profilometry } \\
\text { Report }\end{array}$ & $\begin{array}{l}\text { Additional } \\
\text { PIE Results }\end{array}$ \\
\hline$\times 425$ & U-10Zr, U-8Pu-10Zr, U-19Pu-10Zr & $x$ & $x$ & $\mathrm{x}$ & $x$ \\
\hline$\times 430$ & $\begin{array}{c}\text { U-10Zr, } \\
\text { U-19Pu-10Zr, U-22Pu-10Zr, U-26Pu-10Zr }\end{array}$ & $X$ & $x$ & $x$ & $x$ \\
\hline$\times 431$ & $\mathrm{U}-2 \mathrm{Zr}, \mathrm{U}-6 \mathrm{Zr}, \mathrm{U}-10 \mathrm{Zr}$ & & & $x$ & $x$ \\
\hline$\times 432$ & U-2Zr,U-6Zr,U-10Zr & & & $\mathrm{X}$ & $\mathrm{X}$ \\
\hline$\times 441$ & U-19Pu-6Zr, U-19Pu-10Zr, U-19Pu-12Zr & $X$ & $\mathrm{X}$ & $x$ & $X$ \\
\hline$\times 447$ & U-10Zr & $x$ & $x$ & $x$ & $x$ \\
\hline$\times 496$ & $\mathrm{U}-10 \mathrm{Zr}$ & & & & 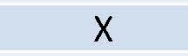 \\
\hline MFF-2 & $\mathrm{U}-10 \mathrm{Zr}$ & $x$ & $x$ & $x$ & $x$ \\
\hline MFF-3 & $\mathrm{U}-10 \mathrm{Zr}$ & $x$ & $x$ & $x$ & $x$ \\
\hline MFF-5 & $\mathrm{U}-10 \mathrm{Zr}$ & $x$ & $x$ & $x$ & $X$ \\
\hline MFF-6 & U-10Zr & $x$ & $x$ & $x$ & $x$ \\
\hline$\times 448$ & U-10Zr & & & & $x$ \\
\hline$\times 451$ & $\mathrm{U}-10 \mathrm{Zr}$ & & & & $x$ \\
\hline
\end{tabular}




\section{Uncertainty Propagation - Core Assessment}

Probability distributions developed for key model inputs/parameters

- Coolant temperature distribution

- FCCl wastage

- Fission Gas Release

Parameters sampled stochastically to determine prediction intervals for key design criteria
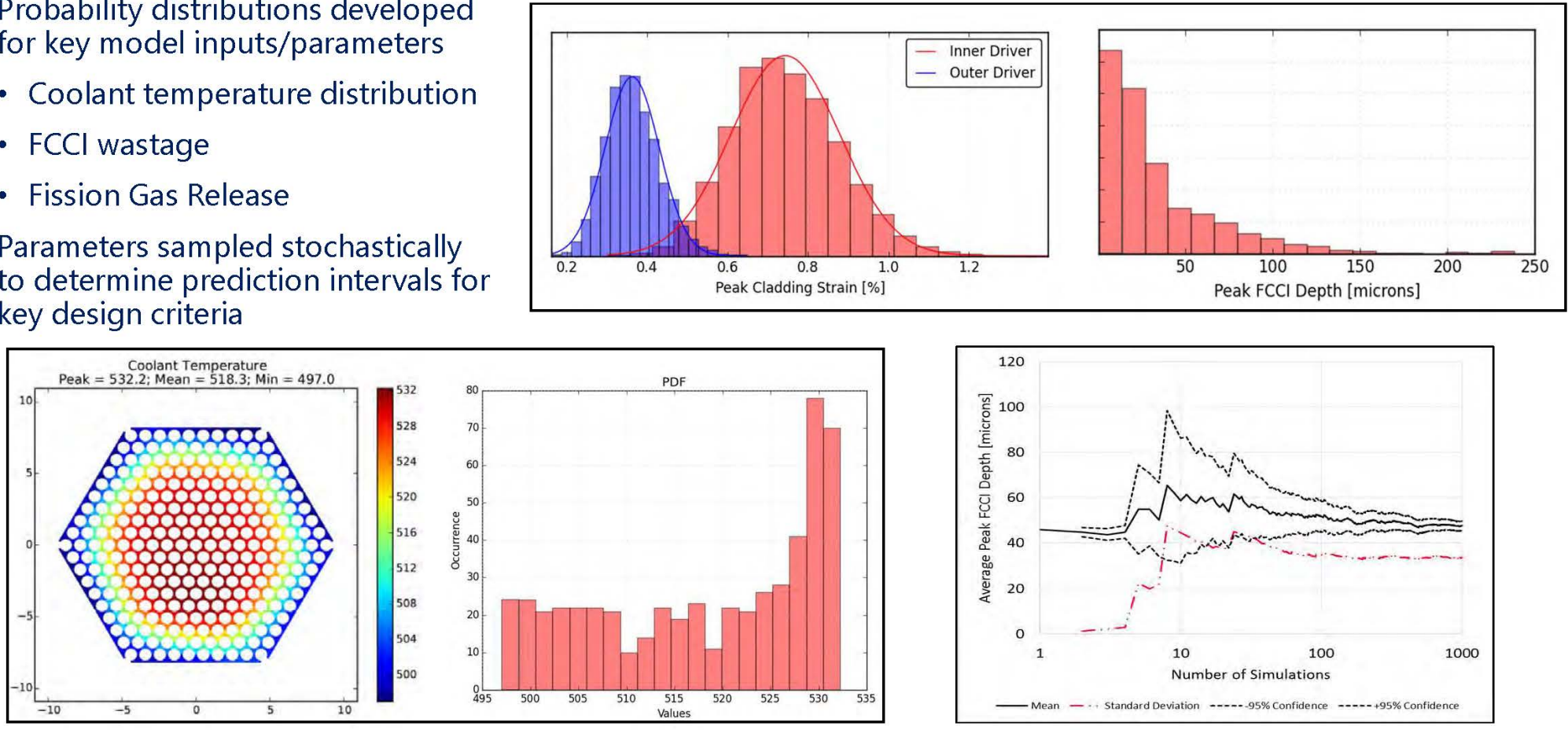

17 Copyright 2020 TerraPower, LLC. All Rights Reserved.

TerraPower. 


\section{Conclusions}

- Rely heavily on PIRT process to prioritize testing and modeling needs to provide high confidence in overall fuel performance

- Using a phased approach for fuel performance validation, including validation of sub-models for key phenomena

- Account for all key phenomena in fuel performance

- Quantify uncertainties for these sub-models

- Uncertainty propagation methodology allows us to assess the impacts of these uncertainties and tailor the fuel/core design, test program, and/or planned surveillance program to best address the uncertainties 
APPENDIX F - Fuel performance simulations of swelling, fission gas release and creep in $\mathrm{U}_{3} \mathrm{Si}_{2}$ informed by atomistic simulations 


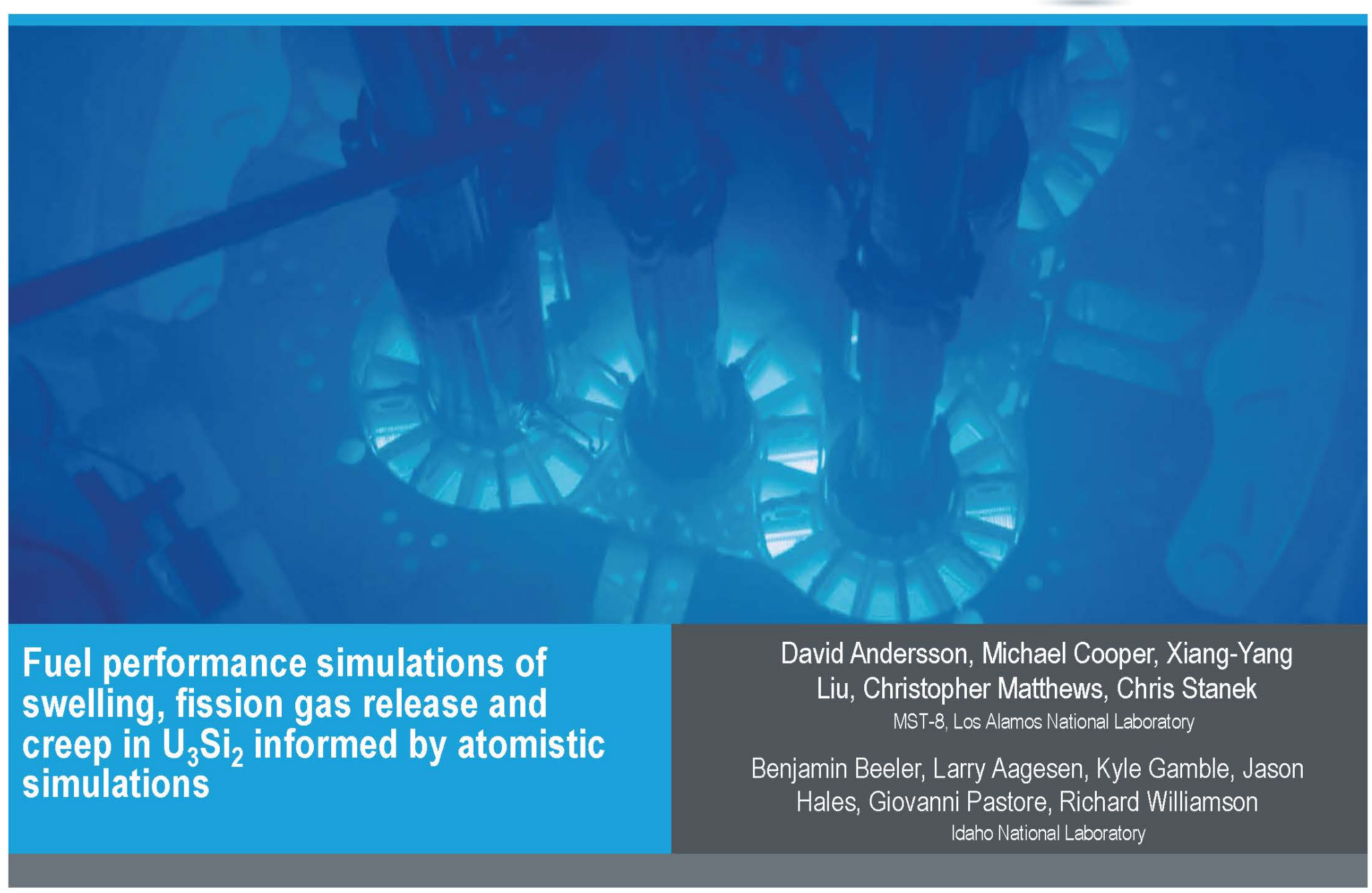




\section{Acknowledgements, goal and outline}

- Acknowledgements: Work funded under the NEAMS ATF HIP project and CASL (NRC pilot) - collaboration with WEC - still ongoing (but being wrapped up) under the Joint Modeling and Simulation program.

- Goal of presentation: Demonstrate how lower length scale (LLS) simulations can be used to fill data gaps for new fuels and be applied in qualification relevant fuel performance simulations validated against irradiation tests.

- Exemplified for $\mathrm{U}_{3} \mathrm{Si}_{2}$, but much of the methodology and most associated challenges extend to other fuels as well, including metal fuel, UN, UC, etc.

\section{- Outline of presentation:}

- Background and problem overview.

- DFT calculations of $\mathrm{U}_{3} \mathrm{Si}_{2}$ thermodynamics and intrinsic $\mathrm{Xe}, \mathrm{U}$ and $\mathrm{Si}$ diffusion.

- MD simulations of species transport due to irradiation induced ballistic mixing.

- Cluster dynamics simulations of irradiation-enhanced thermally activated diffusion informed by DFT and MD.

- Phase-field simulations of bubble percolation threshold.

- Bison implementation of LLS models.

- Application to $\mathrm{U}_{3} \mathrm{Si}_{2}$ ATR irradiation tests.

- Conclusions and lessons learned. 


\section{Accelerated fuel qualification and multi-scale fuel performance}

- Multi-scale fuel performs modeling and simulation refers to engineering scale fuel analysis performed with models and model parameters derived from a combination of experiments and lower length scale modeling.

- Experiments and modeling are used as complementary tools to improve understanding, model accuracy and ability to use models for extrapolation (predictability) throughout the design and qualification process.

- Opportunities also exist in discovery and screening space.

- Modeling should be used to derive maximum value; apply to problems where experiments are hard/expensive or where the additional understanding helps qualification.

- Integral testing for validation is still going to be critical, but multi-scale fuel performance may help develop a smaller test matrix. 


\section{$\mathrm{U}_{3} \mathrm{Si}_{2}$ as ATF for LWRs}

- $\mathrm{U}_{3} \mathrm{Si}_{2}$ is one of the concepts proposed as Accident Tolerant or Advanced Technology Fuel in response to the Fukushima accident and economic drivers (WEC).

- High thermal conductivity reduces temperature of pellet - less energy stored and increased coping time during an accident possibly lower fission gas diffusion.

- Higher U density gives economic benefits.

- Oxidation is a concern upon cladding breach.

- The simulation approach would be similar for other fuels.

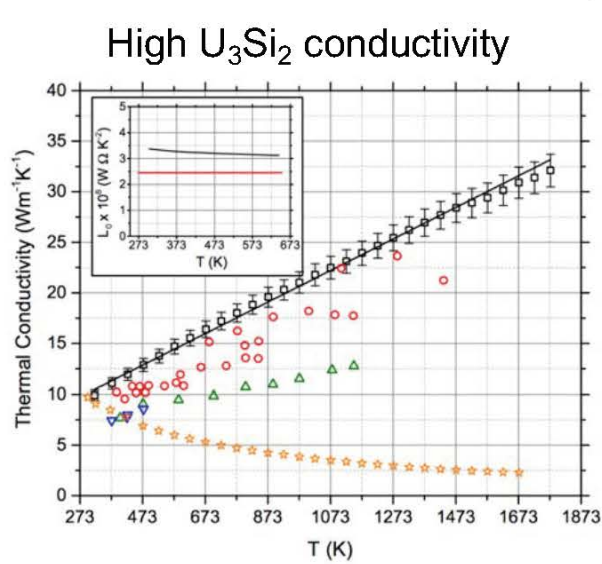

$\mathrm{U}_{3} \mathrm{Si}_{2}$ phase diagram

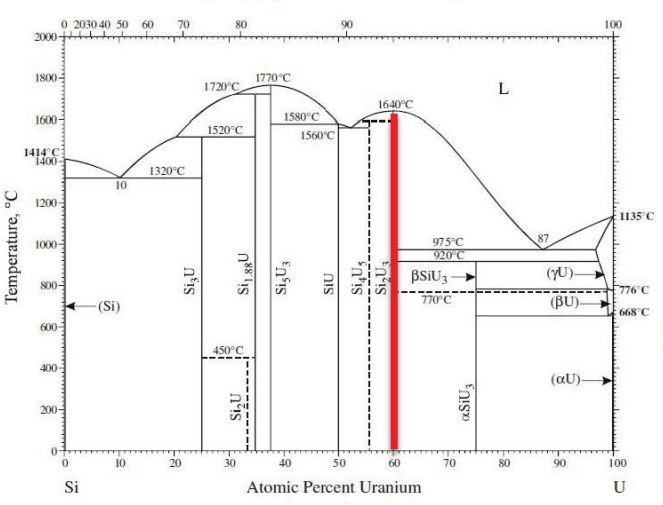

$\mathrm{U}_{3} \mathrm{Si}_{2}$ crystal structure 


\section{Development of atomistic models for $\mathrm{U}_{3} \mathrm{Si}_{2}$}

- A data poor fuel:

- Less operational experience than doped $\mathrm{UO}_{2}$.

- More material properties will be different relative to standard fuel

- Study of self-diffusion, point defect mobility, and fission gas diffusion has relevance to:

- fission gas release,

- swelling,

- and creep models for $\mathrm{U}_{3} \mathrm{Si}_{2}$.

- $\quad$ Like $\mathrm{UO}_{2}$ bulk diffusion in $\mathrm{U}_{3} \mathrm{Si}_{2}$ has three regimes $\left(\mathrm{D}_{1}, \mathrm{D}_{2}\right.$, and $\left.\mathrm{D}_{3}\right)$

- The same methods that work for $\mathrm{UO}_{2}$ are being extended to $\mathrm{U}_{3} \mathrm{Si}_{2}$.

- Investigation of grain boundary diffusion as input to creep and swelling models.

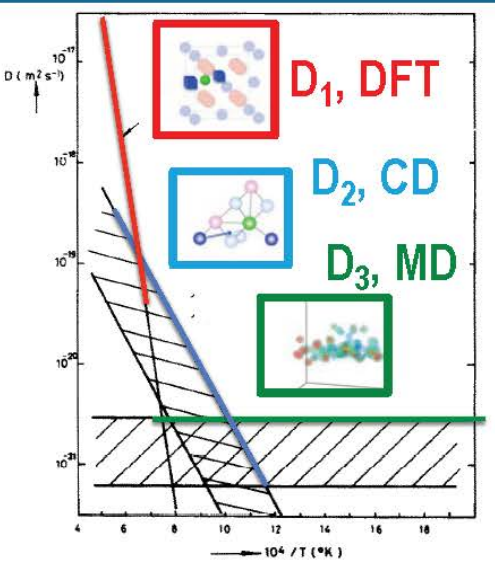

- Results inform engineering scale fuel performance models in Bison.
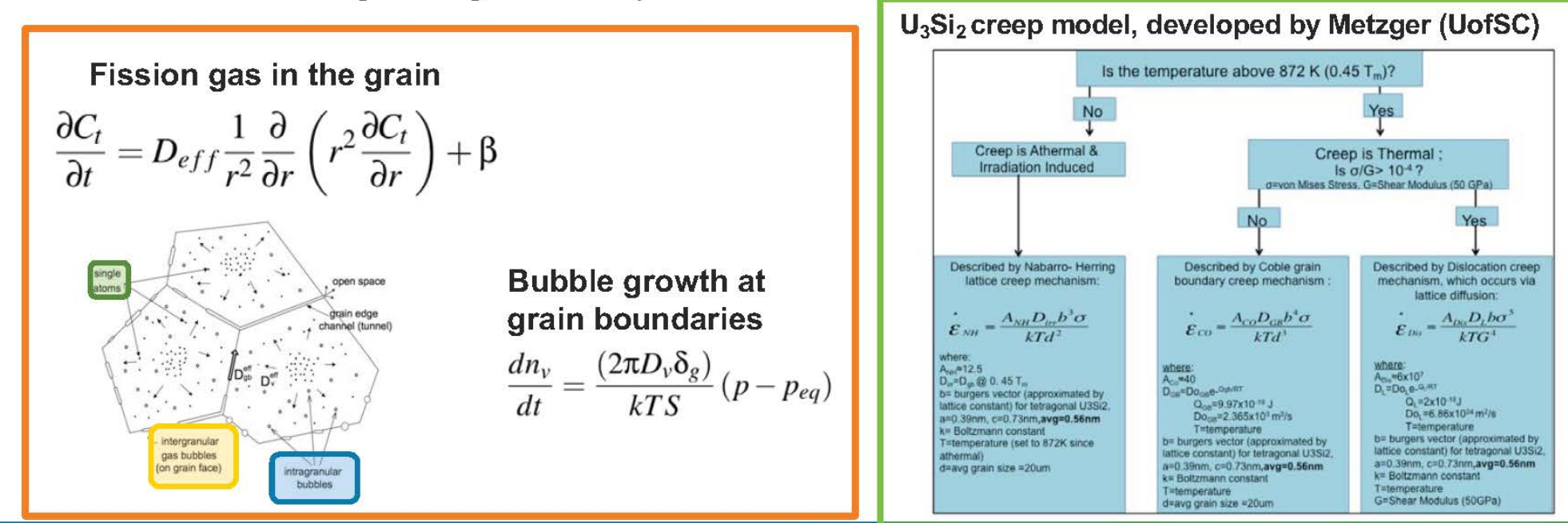


\section{Modeling point defects, self- diffusion and Xe diffusion}

- DFT to calculate defect formation and migration energies.

- $2 \times 2 \times 3$ supercell, $G G A+U$ to stabilize the $U_{3} \mathrm{Si}_{2}$ crystal structure.

For details: D. A. Andersson, et al.,

"Density functional theory calculations

of self-and Xe diffusion in $\mathrm{U}_{3} \mathrm{Si}_{2} ", \mathrm{~J}$.

DFT to calculate phonon spectra and defect entropies.

of self-and Xe diffusion in $\mathrm{U}_{3} \mathrm{Si}_{2}$ ",
Nucl. Mater. 515, 312-325 (2019).

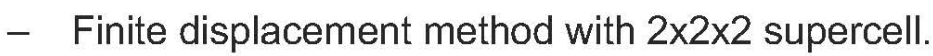

- Only the most important attempt frequencies for diffusion were calculated.

- The tetragonal crystal structure of $\mathrm{U}_{3} \mathrm{Si}_{2}$ means that the diffusivity is a tensor property.

Defect concentrations from formation energies and entropies (dilute limit):

$$
E_{A_{B}, f}=E\left(A_{B}, N \pm 1\right) \mp e_{B}-E(N)
$$

? $S_{A_{B}, f}=S\left(A_{B}, N \pm 1\right) \mp s_{B}-S(N)$

$$
c_{A_{B}}=z_{A_{B}} \exp \left(-\frac{F_{A_{B}, f}}{k_{B} T}\right)
$$

- Xe trap incorporation energies, vacancy-trap site binding energies and barriers for interstitial and vacancy assisted migration mechanisms calculated from DFT.

- Entropies from DFT following the approach for point defects.
The components of the self-diffusion tenso calculated by summing over all possible pathways:

$$
D_{B}^{R}=\sum_{A_{B}} u_{A_{B}} D_{A_{B}, 0}^{R} \exp \left(-\frac{E_{A_{B}, m}^{R}}{k_{B} T}\right)
$$
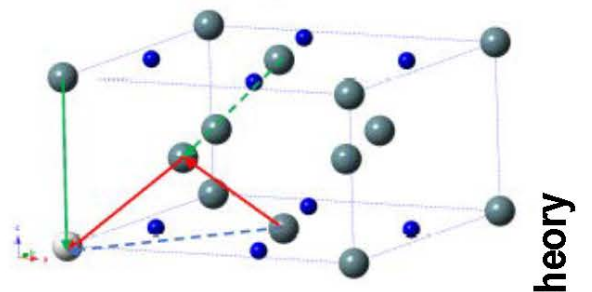

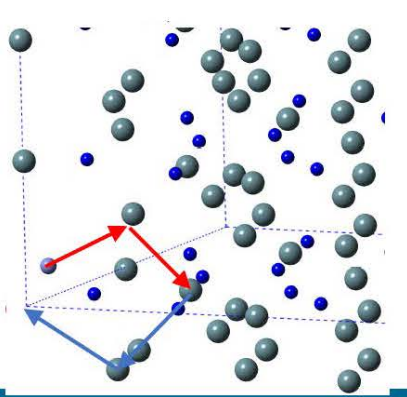




\section{Defect concentrations from DFT}

\section{Experiments}

- High concentration of Si interstitials predicted from DFT (energy+entropy) ${ }^{1}$, even higher non-stoichiometry than in Middleburgh et al. ${ }^{2}$

- Non-stoichiometry disagrees with the available phase diagram, but recently confirmed by neutron diffraction experiments on $\mathrm{U}_{3} \mathrm{Si}_{2.01}{ }^{3}$.

- Non-stoichiometry of $\mathrm{U}_{3} \mathrm{Si}_{2+\mathrm{x}}$ matters, because of burnup evolution.
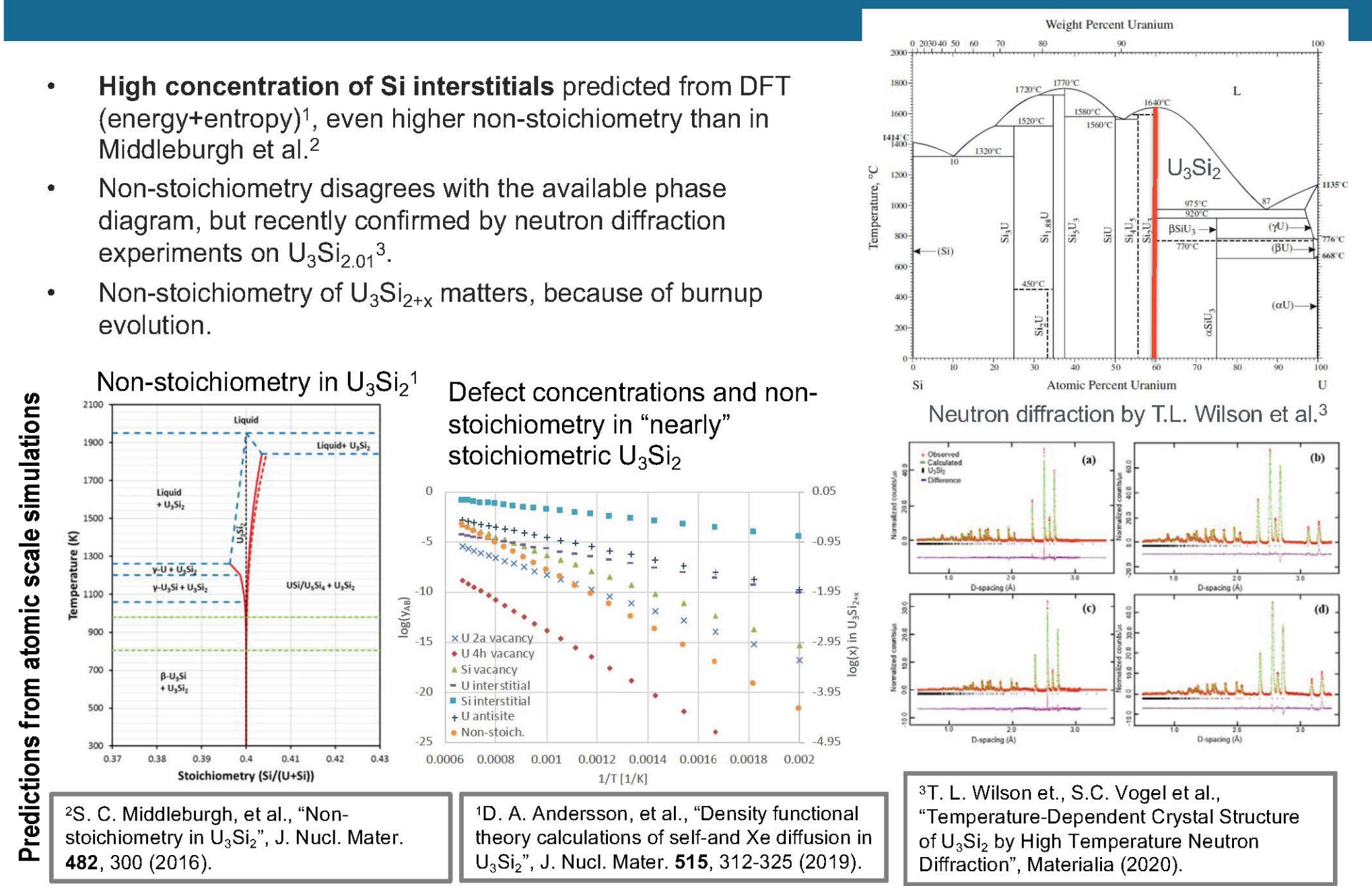

${ }^{3}$ T. L. Wilson et., S.C. Vogel et al.,

"Temperature-Dependent Crystal Structure

of $\mathrm{U}_{3} \mathrm{Si}_{2}$ by High Temperature Neutron

Diffraction", Materialia (2020). 


\section{Intrinsic $X e$ and self-diffusion from DFT $\left(D_{1}\right)$}

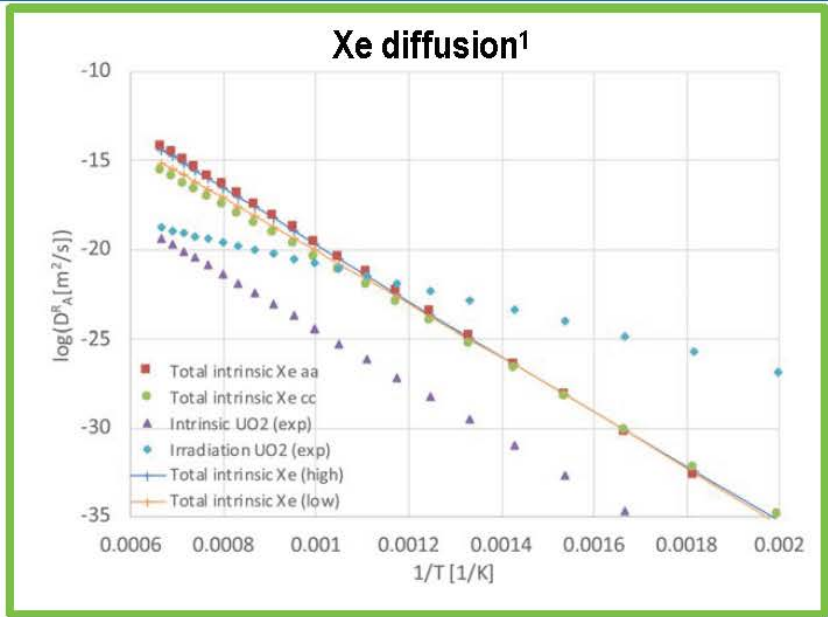

$8 \cdot x^{2} 8^{2} \cdot 8^{2} \cdot 3$

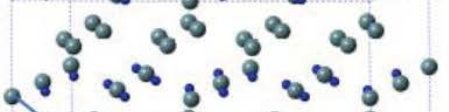

$3^{2} 5^{\circ} 8^{\circ} 3^{\circ}$

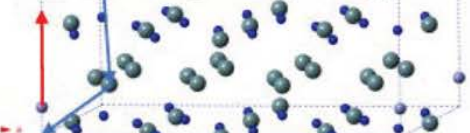

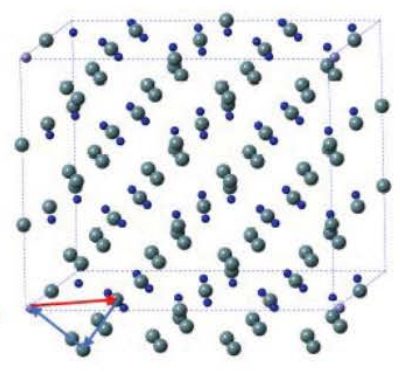

- Xe diffusion in c direction is $U$ vacancy assisted.

- Xe diffusion in a-b plane is Si vacancy assisted.

- Intrinsic Xe diffusion is higher than in $\mathrm{UO}_{2}$.

'D. A. Andersson, et al., "Density functional theory calculations of self-and

Xe diffusion in $\mathrm{U}_{3} \mathrm{Si}_{2}$ ", J. Nud. Mater. 515, 312-325 (2019).

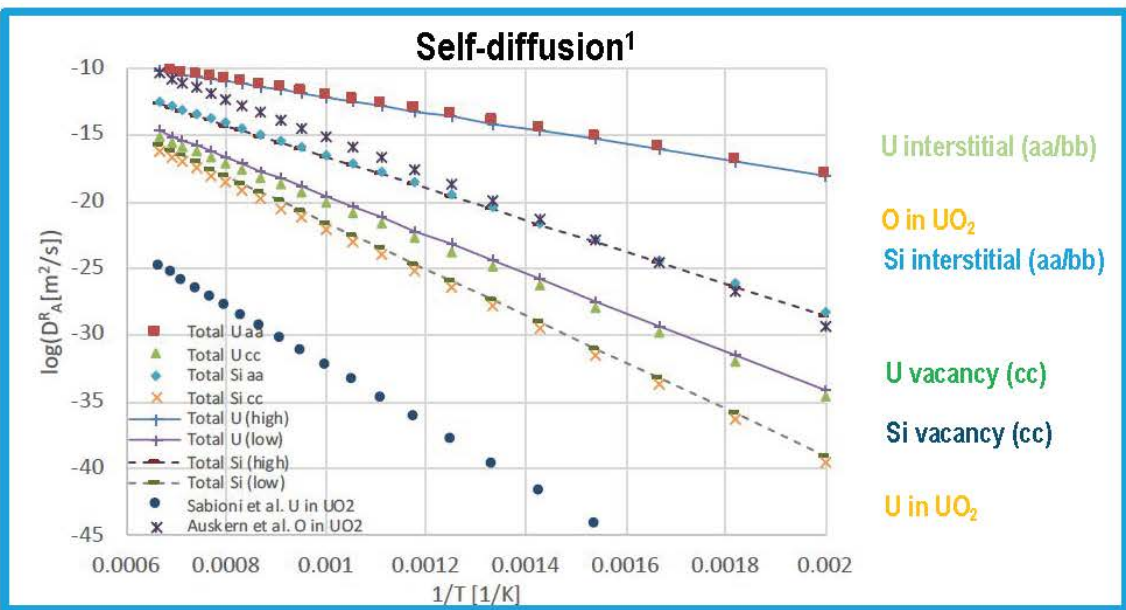

$\mathrm{Si}_{1} \mathrm{aa} / \mathrm{bb}$
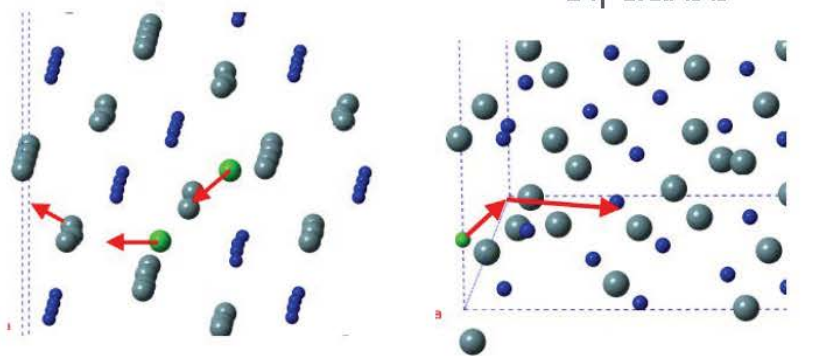

Self-diffusion due to highly anisotropic interstitial mechanisms.

- Very low barrier for $\mathrm{U}_{1}$.

- High concentration for $\mathrm{Si}_{1}$ 


\section{Athermal diffusion in $\mathrm{U}_{3} \mathrm{Si}_{2}$ from $\mathrm{MD}\left(\mathrm{D}_{3}\right)$}

Electronic excluded for $\mathrm{U}_{3} \mathrm{Si}_{2}$ Important for $\mathrm{UO}_{2}$

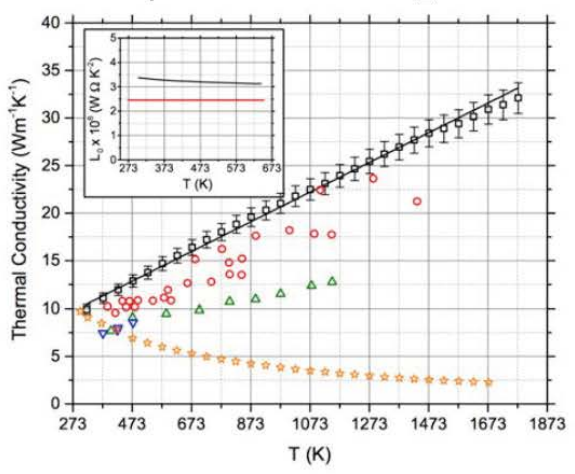

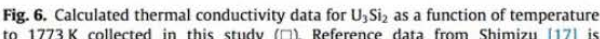

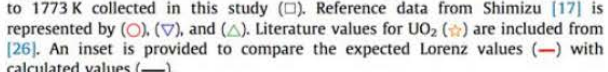
[26]. An inset is provides
calculated values $(-)$
Ballistic included for $\mathrm{U}_{3} \mathrm{Si}_{2}$
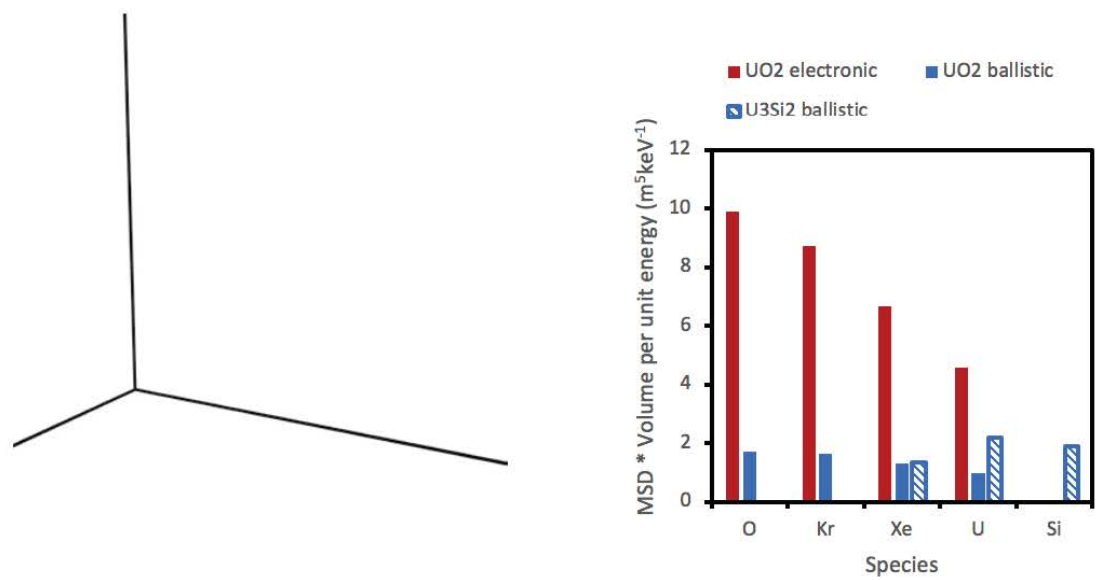

White et al., J. Nucl. Mater. 464 275-280 (2015)

" High thermal conductivity in $\mathrm{U}_{3} \mathrm{Si}_{2}$ means that heat deposited electronically is dissipated before it can melt the lattice $-90 \%$ of the energy fission is removed in this way.

- All atomic mixing is assumed to come from ballistic stopping ( $10 \%$ of fission energy)

- The ballistic part is similar to the same contribution in $\mathrm{UO}_{2}$, but much lower than transport due to electronic stopping (thermal spikes).

[2] Beeler, Baskes, Andersson, Cooper, Zhang, J. Nucl. Mater., 495 (2017) 267-276 


\section{Cluster dynamics model for irradiation enhanced diffusion $\left(D_{2}\right)$}

- Using the same FECD framework developed by Matthews et al. ${ }^{1}$ for cluster dynamics on $\mathrm{UO}_{2}$, a $\mathrm{CD}$ model is developed for $\mathrm{U}_{3} \mathrm{Si}_{2}$.

- Parameterized using the DFT data from Andersson.

- Assumptions:

- Given that the two $U$ vacancies have the same migration saddle point they are both described using only the more stable 2a vacancy.

- Anisotropy in diffusion is treated by taking the fastest direction and modifying the number of dimensions in pre-exponential of diffusion coefficient.

- Anti-sites have been omitted to reduced the number of solved defects and coupled ODEs.

Solved point defects: $U_{i}, V_{U}, S i_{i}, V_{S i}, X e_{i}$ Solved clusters: $X e_{U}, X e_{S i}, X e_{2 U}, X e_{2 S i}, X e_{U S i}$ Dependents: $U_{U}, S i_{S i}$

${ }^{1}$ C. Matthews et al., "Cluster Dynamics Simulation of Uranium Selfdiusion During Irradiation in $\mathrm{UO}_{2}$ ", J. Nucl. Mater. (2019).

\begin{tabular}{|c|c|}
\hline $\operatorname{sink}+U_{i} \leftrightarrow \operatorname{sink}+V_{i}$ & $(1)$ \\
$\operatorname{sink}+S i_{i} \leftrightarrow \operatorname{sink}+V_{i}$ & $(2)$ \\
$\operatorname{sink}+V_{U} \leftrightarrow \operatorname{sink}+U_{U}$ & $(3)$ \\
$\operatorname{sink}+V_{S} i \leftrightarrow \operatorname{sink}+S i_{S i}$ & $(4)$ \\
\hline$U_{i}+V_{U} \leftrightarrow U_{U}+V_{i}$ & $(5)$ \\
$S i_{i}+V_{S i} \leftrightarrow S i_{S i}+V_{i}$ & $(6)$ \\
\hline$U_{i}+X e_{U} \leftrightarrow X e_{i}+U_{U}$ & $(7)$ \\
\hline$V_{i}+X e_{U} \leftrightarrow X e_{i}+V_{U}$ & $(8)$ \\
\hline$U_{i}+X e_{2 U} \leftrightarrow X e_{U}+U_{U}+V_{i}$ & $(9)$ \\
\hline$X e_{2 U} \leftrightarrow X e_{U}+V_{U}$ & $(10)$ \\
\hline \hline$S i_{i}+X e_{S i} \leftrightarrow X e_{i}+S i_{S i}$ & $(11)$ \\
\hline$V_{i}+X e_{S i} \leftrightarrow X e_{i}+V_{S i}$ & $(12)$ \\
\hline$S i_{i}+X e_{2 S i} \leftrightarrow X e_{S i}+S i_{S i}+V_{i}$ & $(13)$ \\
\hline$X e_{2 S i} \leftrightarrow X e_{S i}+V_{S i}$ & $(14)$ \\
$X e_{U S i} \leftrightarrow X e_{S i}+V_{U}$ & $(15)$ \\
$X e_{U S i} \leftrightarrow X e_{U}+V_{S i}$ & $(16)$ \\
\hline \hline$S i_{i}+X e_{U S i} \leftrightarrow X e_{U}+S i_{S i}+V_{i}$ & $(17)$ \\
$U_{i}+X e_{U S i} \leftrightarrow X e_{S i}+U_{U}+V_{i}$ & $(18)$ \\
\hline
\end{tabular}




\section{Irradiation enhanced self-diffusion $\left(D_{2}\right)$}

\section{Concentrations of $\mathrm{U}$ and $\mathrm{Si}$ defects:}

- No enhancement of $U$ or Si interstitial concentrations - still high at thermal equilibrium.

- Enhancement of $V_{S i}$ and $V_{U}$ at low $T$.

- Very high $\mathrm{V}_{\mathrm{Si}}$ concentration as approaches expt. critical amorphization $\mathrm{T}$.

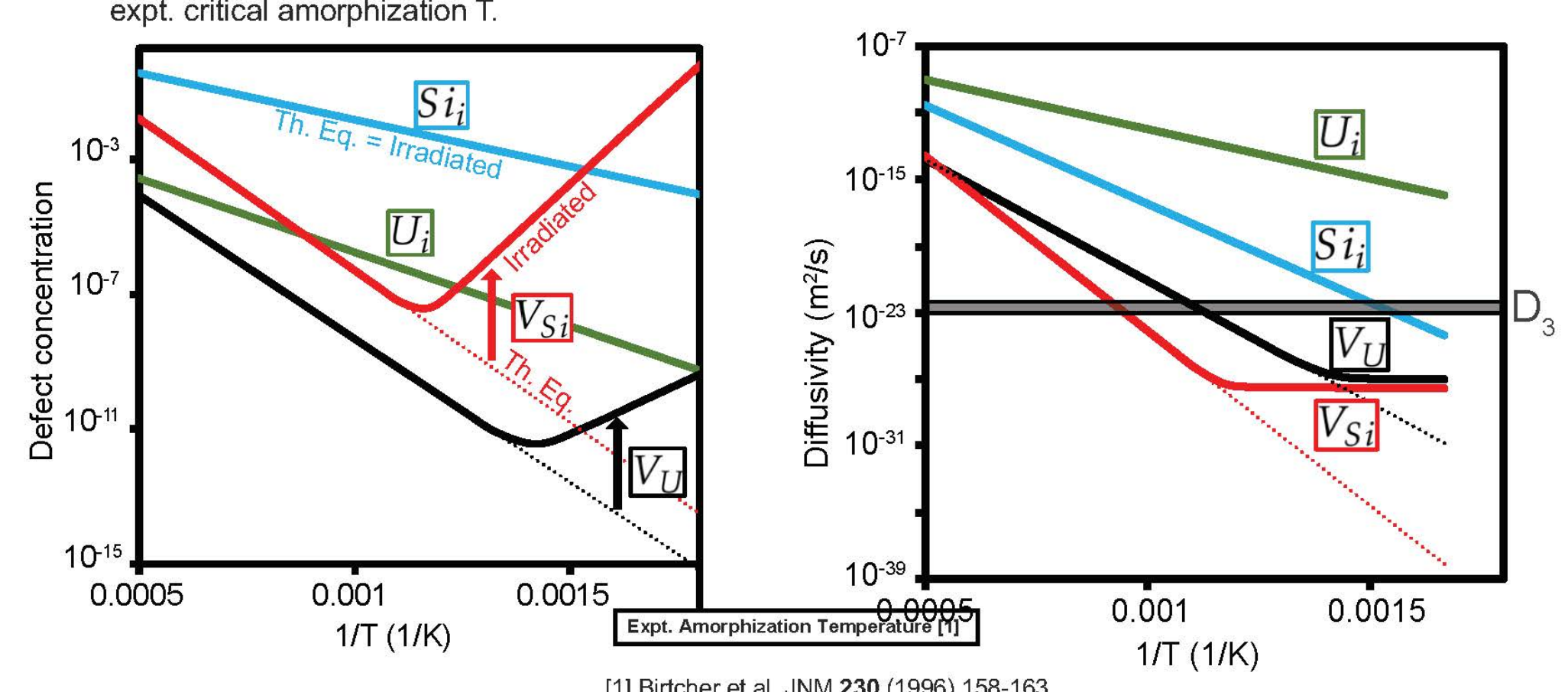

\section{Self-diffusion:}

- No enhancement of $U$ or Si interstitial diffusivity: - Highly mobile $U$ interstitials are now fastest.

- Enhancement of $V_{S i}$ and $V_{U}$ at low $T$.

- All self-diffusion coefficients are wiped out by athermal $D_{3}$ 


\section{Irradiation enhanced $\mathrm{Xe}$ diffusion $\left(\mathrm{D}_{2}\right)$}

\section{Xe concentrations (normalized):}

- $\mathrm{Xe}_{2 \mathrm{Si}}$ defect concentration enhanced due to higher $\mathrm{V}_{\mathrm{si}}$ concentration at low $\mathrm{T}$.

- All other defects are unaffected by irradiation.

- Fast interstitial defects are thought to recombine with $\mathrm{Xe}_{\cup \mathrm{Si}}$ and $\mathrm{Xe}_{2 \cup}$ driving them back to equilibrium despite enhanced $V_{\mathrm{si}}$.

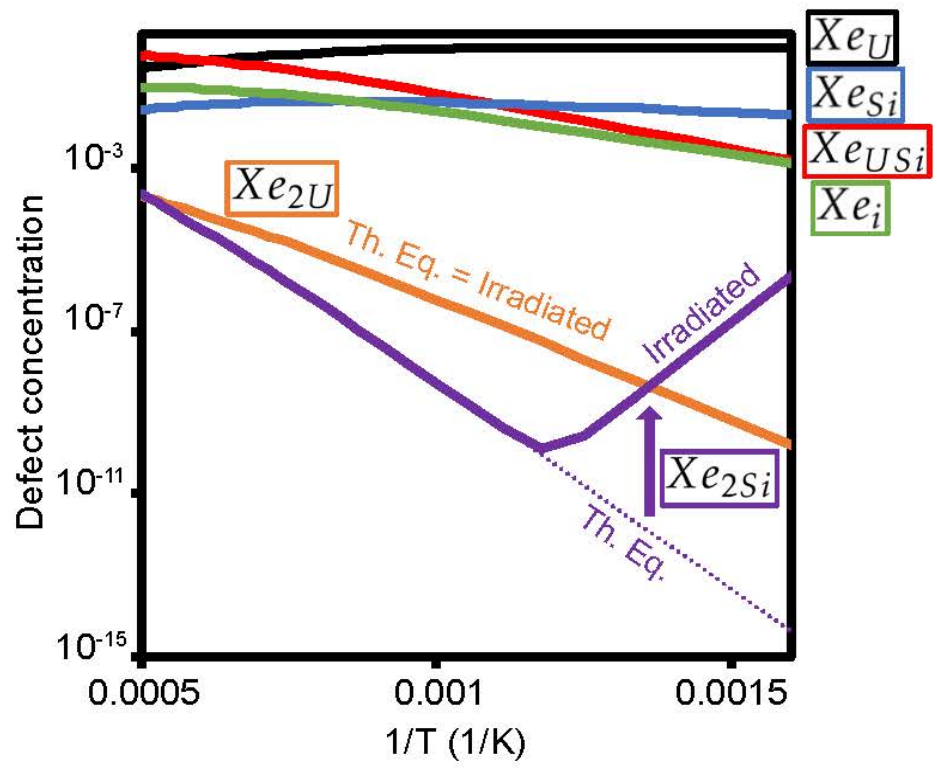

\section{Xe diffusivity:}

- As before only $\mathrm{Xe}_{2 \mathrm{Si}}$ diffusion is enhanced.

- However, is much lower diffusivity than for $\mathrm{Xe}_{2 \cup}$ or $\mathrm{Xe}_{U S i}$ which are at equilibrium.

- Furthermore, athermal $D_{3}$ diffusion dominates over $\mathrm{D}_{2}$.

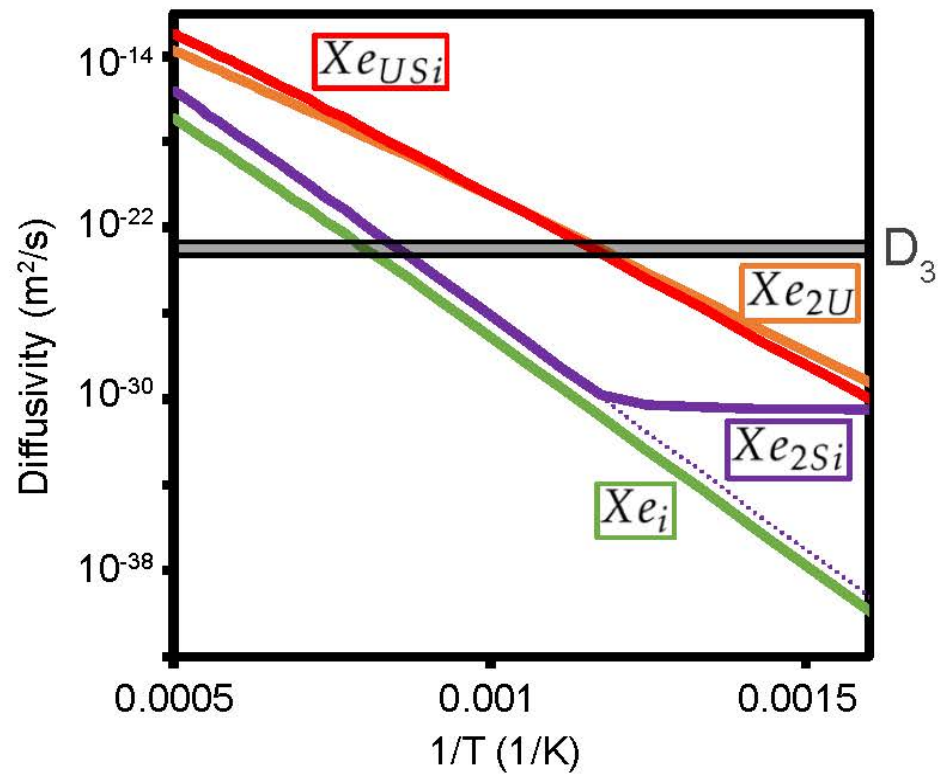




\section{Bison implementation of gas and self-diffusion in $\mathrm{U}_{3} \mathrm{Si}_{2}$}

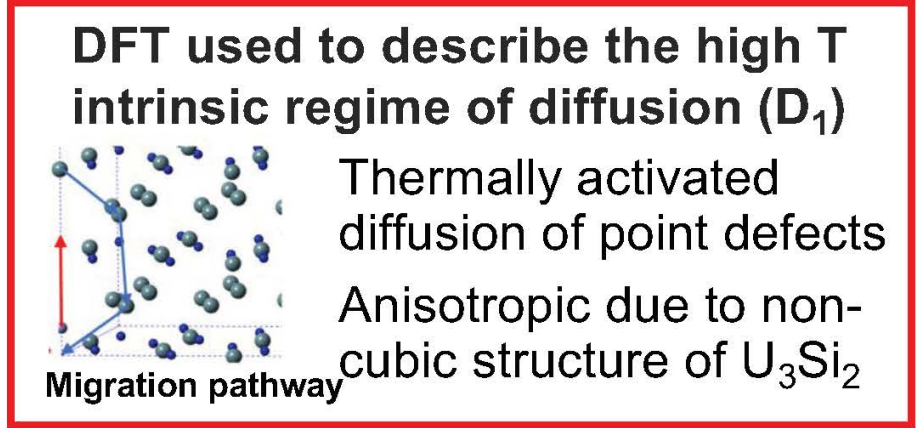

Andersson, Liu, Beeler, Middleburgh, Claisse, Stanek, J. Nucl, Mater, 337 271-278 (2018)
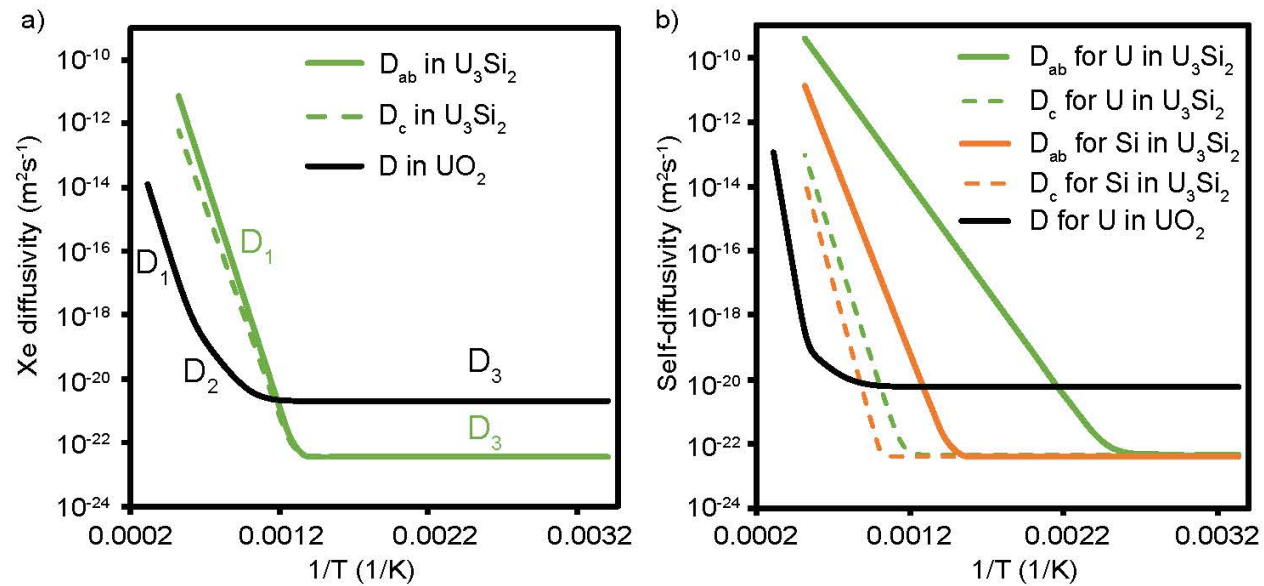

Predicted fission gas diffusion and self-diffusion coefficients for $\mathrm{U}_{3} \mathrm{Si}_{2}$ (comparison is made with $\left.\mathrm{UO}_{2}\right)$.

Significant anisotropy for selfdiffusion.

Analytical expressions for implementation in Bison for $\mathrm{Xe}$ and Si vacancy diffusion.

$$
D_{U_{3} S i_{2}}=2.95 \times 10^{-4} \exp \left(\frac{-2.92}{k_{B} T}\right)+3.58 \times 10^{-42} \dot{F}
$$

$$
D=9.40 \times 10^{-4} \cdot \exp \left(\frac{-4.17}{k_{B} T}\right)+3.01 \times 10^{-47} \cdot \dot{F}
$$




\section{Mesoscale simulations for $\mathrm{U}_{3} \mathrm{Si}_{2}$ (L. Aagesen, INL)}

- Fission gas bubble dihedral angle, $\mathrm{U}_{3} \mathrm{Si}_{2} /$ gas surface energy determined from MD calculations of surface and grain-boundary energies (B. Beeler, M. Baskes, D. Andersson, M. Cooper, Y. Zhang, JNM 514, 290, 2019).

- Used Marmot simulations to calculate grain boundary coverage at saturation $\left(\mathrm{F}_{\mathrm{c}, \text { sat }}\right)$ :

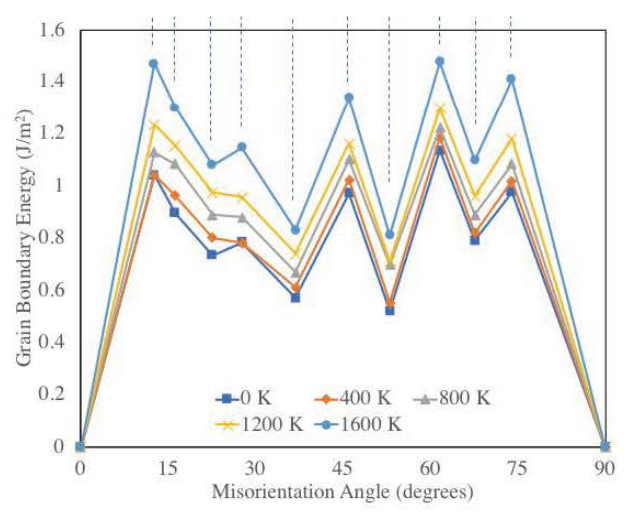

- $F_{c, \text { sat }}=0.54$, much closer to observed experimental value for $\mathrm{UO}_{2}(0.5)$ than theoretical value that was previously used $(\pi / 4)$.

- Considered effect of minimum spacing between bubbles and other parameters by sensitivity analysis.

- All implemented in the Bison fission gas model

- Large impact on Bison fission gas release and gaseous swelling predictions.

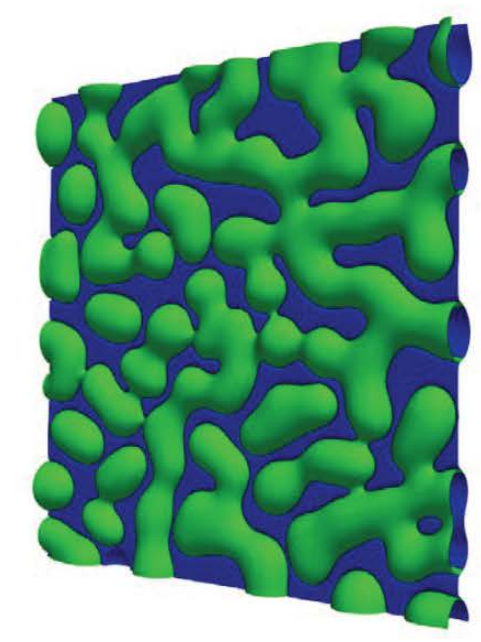




\section{Grain boundary self-diffusion}

\section{$\mathrm{U}$ diffusion at grain boundaries}

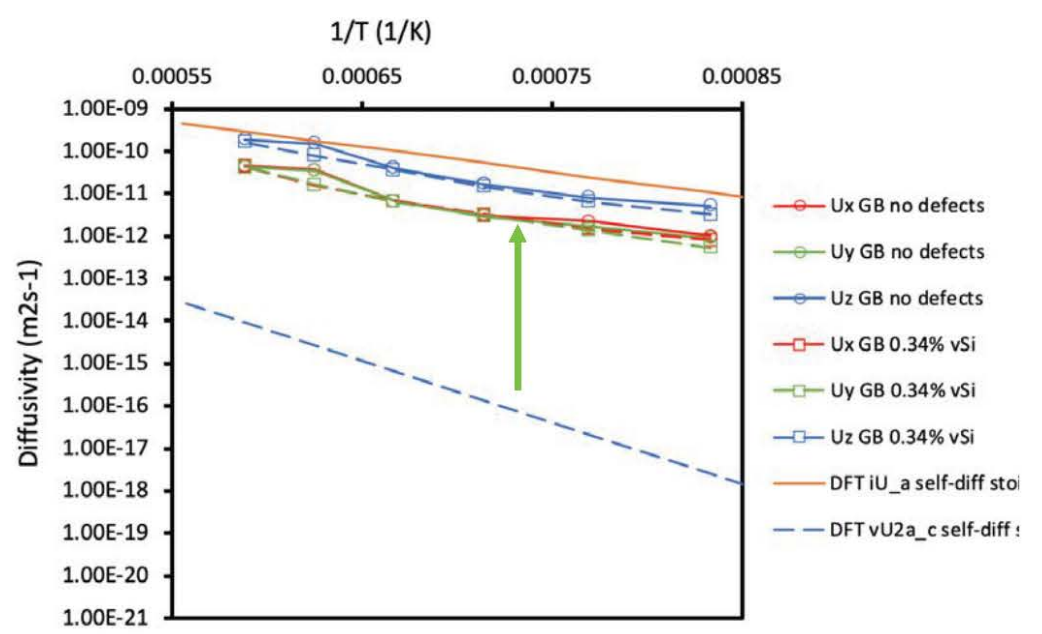

- Classical MD simulation of diffusion at a 530 tilt grain boundary.

- Slightly higher diffusion for $\mathrm{U}$ at grain boundaries than for $\mathrm{Si}$.

- Diffusion at grain boundaries is approx. 6 orders of magnitude higher than vacancy diffusion in the bulk lattice, although with weaker temperature dependence - this validates current assumption in BISON.

- The addition of vacancies to the grain boundary was predicted to have negligible effect on the diffusivity.

\section{Si diffusion at grain boundaries}

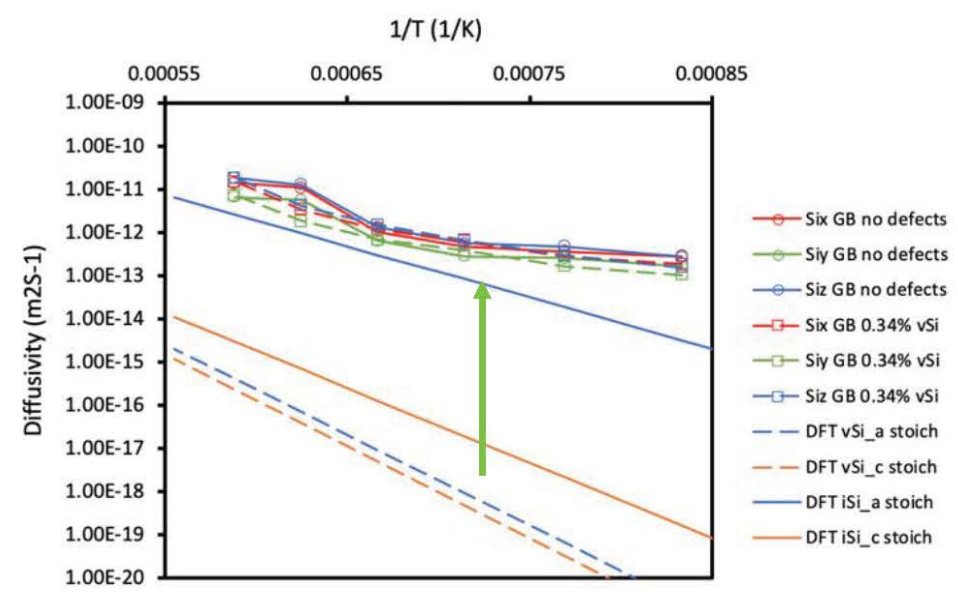

\section{Lines show atomic displacement}

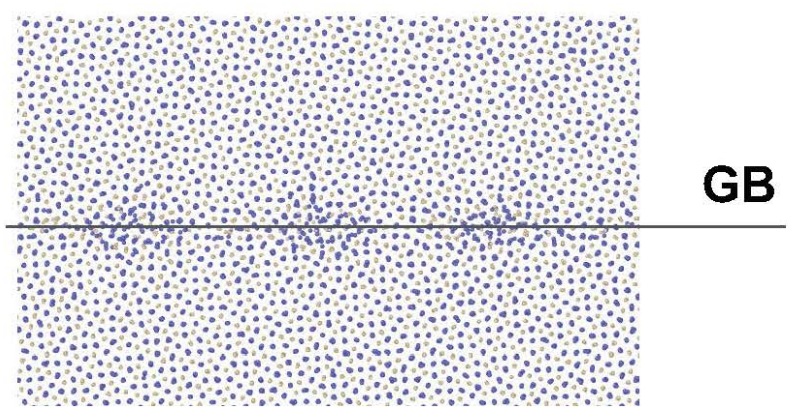




\section{Atomic scale diffusional $\mathrm{U}_{3} \mathrm{Si}_{2}$ creep model}

\section{Nabarro-Herring creep}

- Using the bulk diffusivity of Si interstitials (faster than $\mathrm{Si}$ vacancies but slower than $U$ defects) the Nabarro-Herring creep rate is predicted using the following equation:

$$
\dot{\epsilon}=\frac{42 \sigma_{s} \Omega}{k_{B} T d^{2}} D
$$

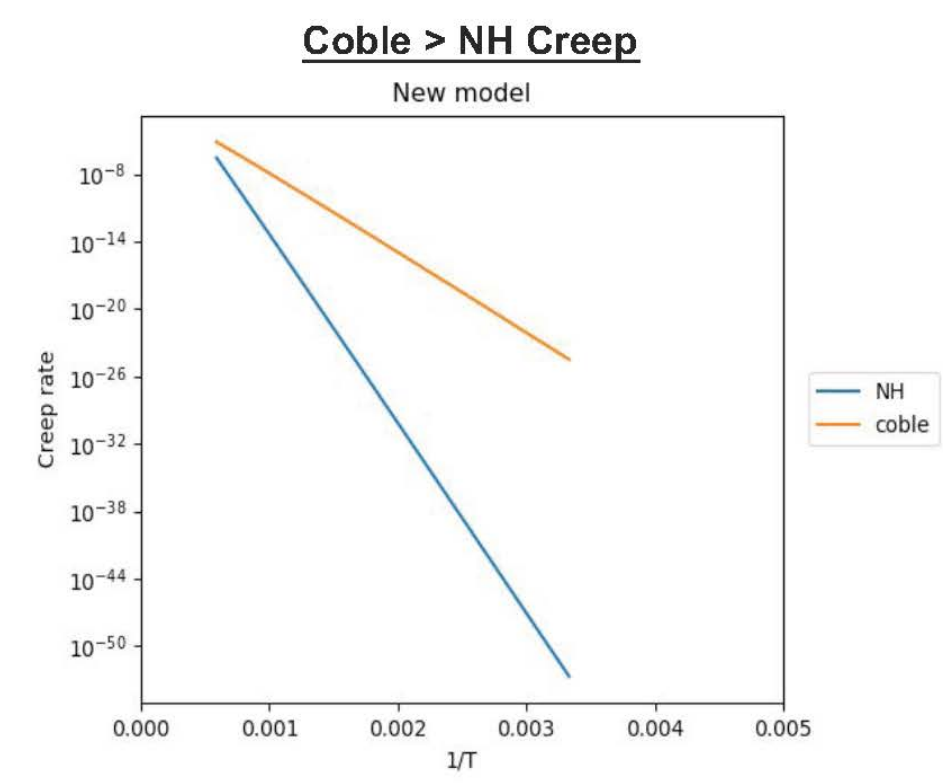

\section{Coble creep}

- Using the grain boundary diffusivity from classical MD the Coble creep rate is predicted using the following equation:

$$
\dot{\epsilon}=\frac{42 \sigma_{s} \Omega \delta}{k_{B} T d^{3}} D
$$

Similar approach to Metzger but with atomic scale diffusivities gives significant improvement compared to Expt. from USC

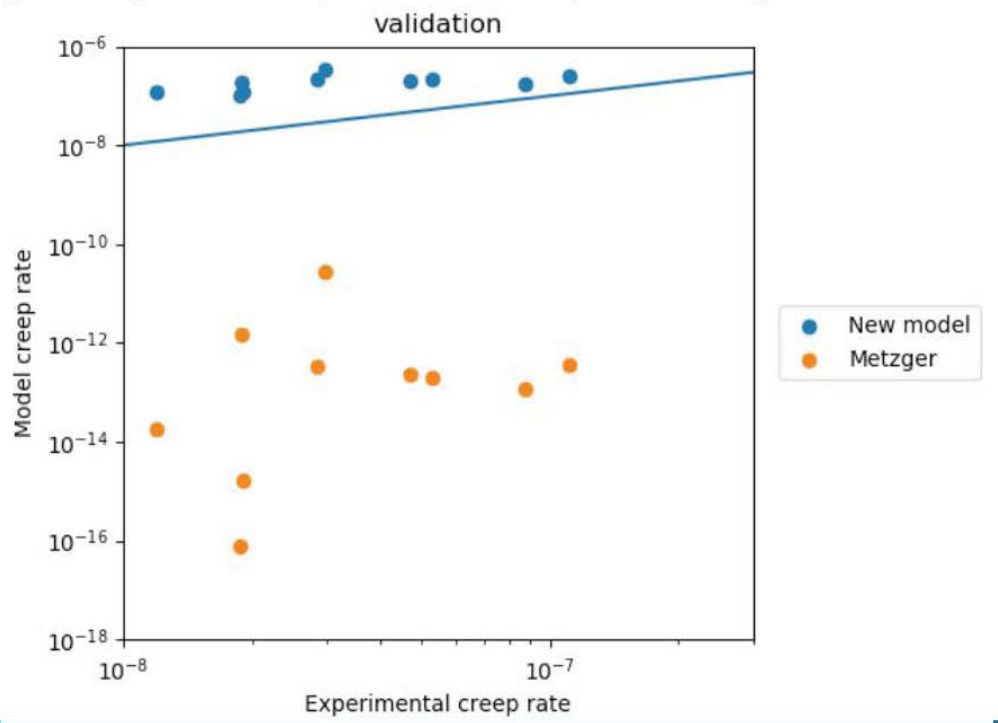




\section{$\mathrm{U}_{3} \mathrm{Si}_{2}$ material and behavioral models in Bison ( $\mathrm{K}$. Gamble, INL)}

- Bison contains the following material and behavioral models for $\mathrm{U}_{3} \mathrm{Si}_{2}$ (from best available source, experiments or modeling):

- Thermal Properties

- Thermal Conductivity (4 options + degradation)

- Specific Heat (2 options)

- Elasticity

- Porosity dependent Young's Shear moduli
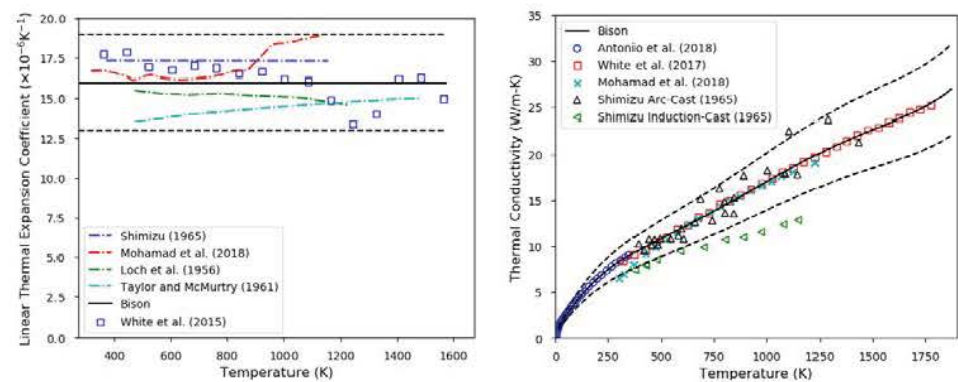

- Thermal and Irradiation Creep (2 options)

- Thermal Expansion

- Gaseous Swelling (3 options)

- Solid Swelling

- Densification

- Fission Gas Release

- Stoichiometric and Si-rich

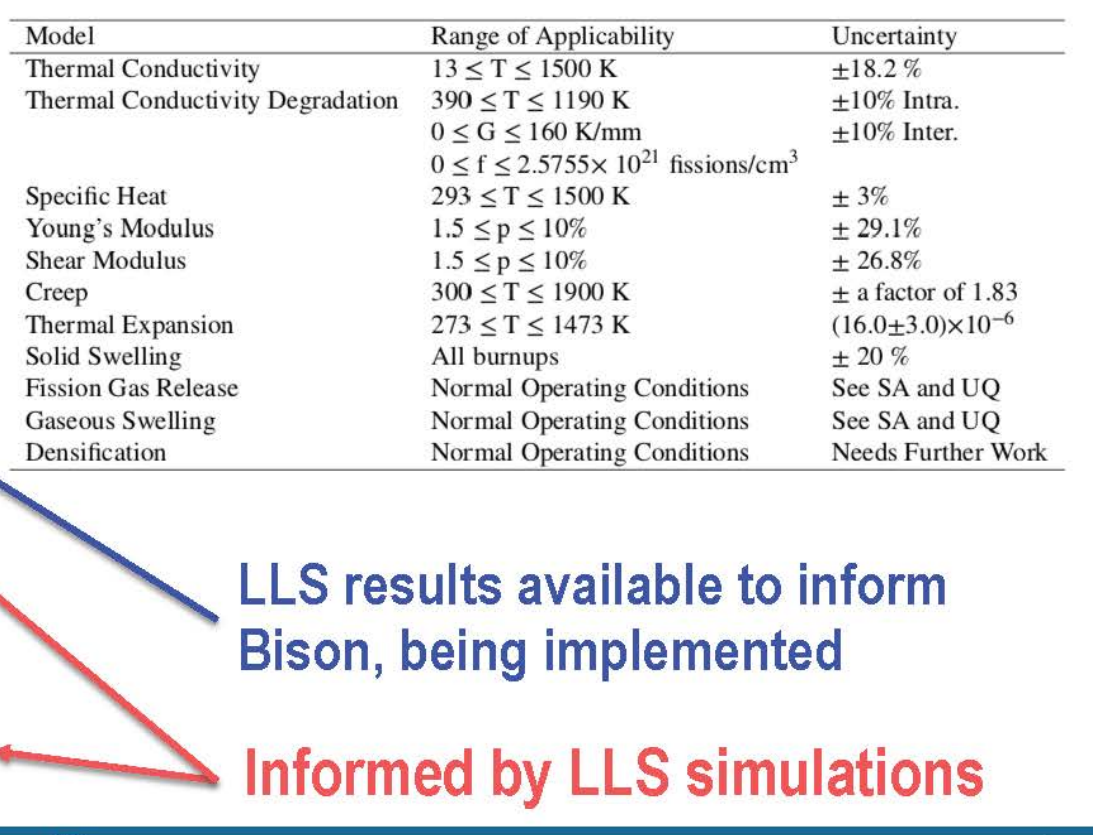




\section{Validation of Bison $\left(\mathrm{U}_{3} \mathrm{Si}_{2}\right)$ against ATR experiments}

- Two $\mathrm{U}_{3} \mathrm{Si}_{2}$ fueled experiments with ZIRLOTM (WEC)

- ATF-13 R4 filled with helium

- ATF-15 R6 filled with helium/argon mixture

- Available data includes:

- Fission Gas Release

- Fuel axial elongation (inferred from neutron radiographs)

- Clad profilometry
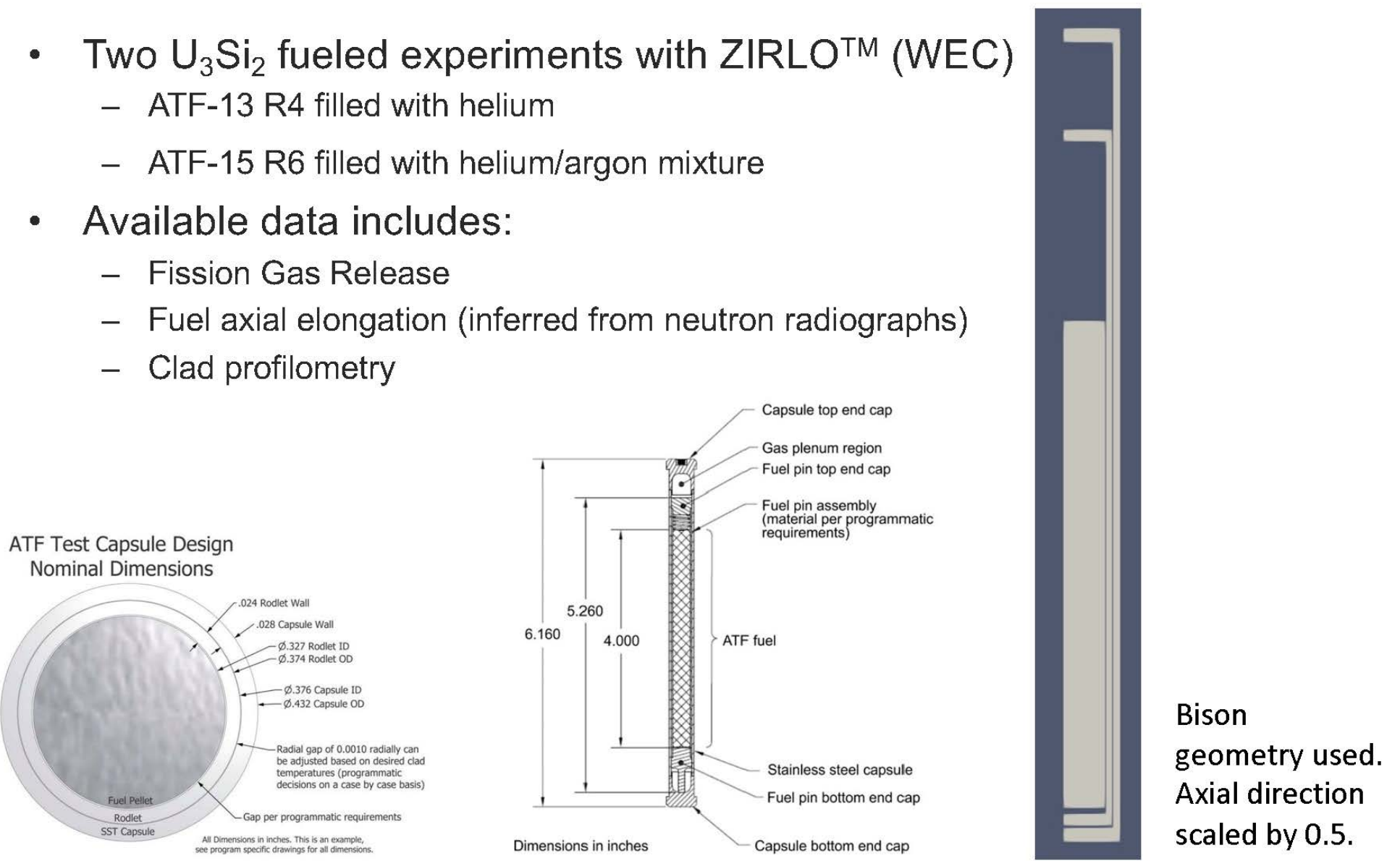


\section{Validation results}

- Using the nominal models Bison underpredicts swelling for R4 and overpredicts for R6.

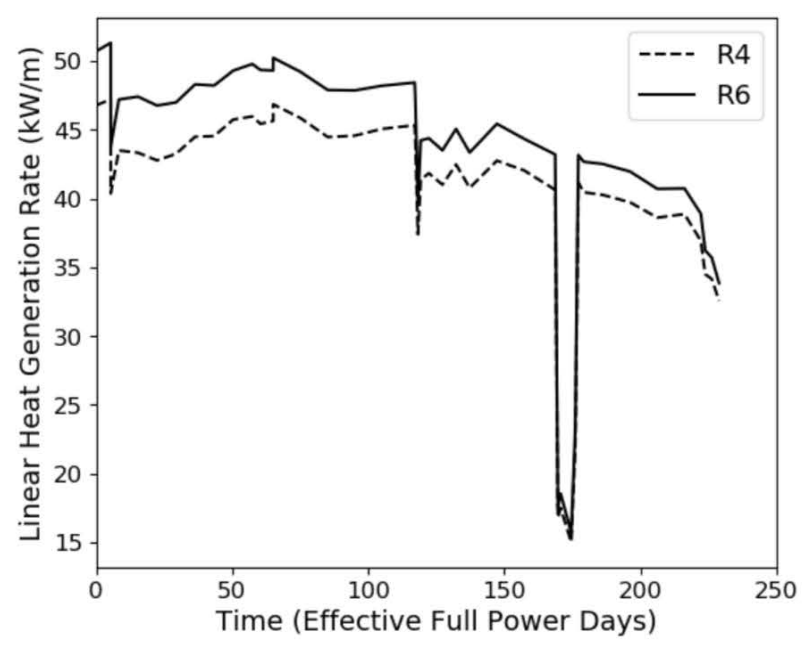

Swelling predictions for different gas diffusion models

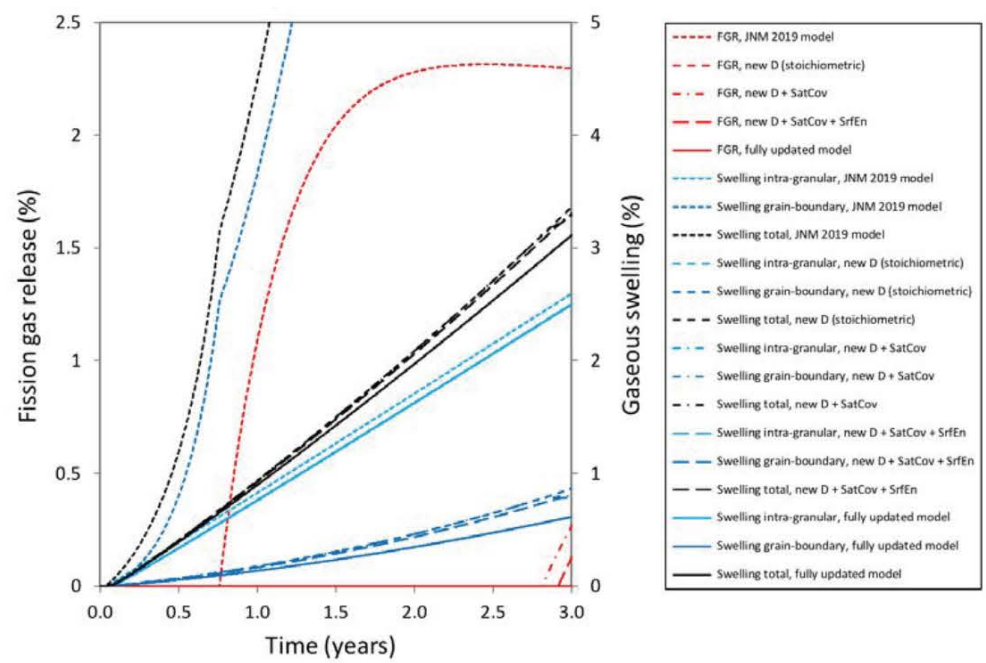

Bison comparisons to ATF-13 R4 and ATF-15 R6 PIE data

\begin{tabular}{lcccc}
\hline & Bison R4 & Experiment R4 & Bison R6 & Experiment R6 \\
\hline Fuel Elongation (mm) & -0.0784 & 0.0 & 0.0128 & 0.0 \\
Fission Gas Release (\%) & 0.0 & 0.06 & 0.19 & 0.06 \\
\hline
\end{tabular}




\section{Sensitivity analysis and uncertainty quantification (K. Gamble, INL)}

- Using the uncertainty defined in the individual material models, perform an SA and UQ analysis on the ATF-13 R4 case.

Parameters varied in the sensitivity analysis and uncertainty quantification

\begin{tabular}{|c|c|c|c|}
\hline Parameter & Nominal value & Scaling factor range & Distribution \\
\hline Thermal conductivity $\left(\mathrm{W} \cdot \mathrm{m}^{-1} \mathrm{~K}^{-1}\right)$ & See Equation 29 & {$[0.82 ; 1.18]$} & Normal \\
\hline Coefficient of thermal expansion $\left(\mathrm{K}^{-1}\right)$ & $16.0 \times 10^{-6}$ & {$[0.8125 ; 1.1875]$} & Normal \\
\hline Young's modulus (GPa) & See Equation $\longdiv { 3 9 }$ & {$[0.709 ; 1.291]$} & Normal \\
\hline Shear modulus (GPa) & See Equation $\overline{40}$ & {$[0.732 ; 1.268]$} & Normal \\
\hline Solid swelling (/) & See Equation $\overline{\overline{68}}$ & {$[0.8 ; 1.2]$} & Normal \\
\hline Nucleation factor of intra-granular bubbles (/) & $10^{-6}$ & {$\left[10^{-3} ; 10^{4}\right]$} & Uniform \\
\hline Re-solution rate of intra-granular bubbles $\left(\mathrm{s}^{-1}\right)$ & $2.80 \cdot 10^{-25}\left(5 \cdot 10^{-10} / R_{i g}\right)^{0.23} \cdot \dot{F}$ & {$[0.1 ; 10]$} & Uniform \\
\hline $\mathrm{U}_{3} \mathrm{Si}_{2}$ /gas specific surface energy $\left(\mathrm{J} \cdot \mathrm{m}^{-2}\right)$ & 1.7 & {$[0.5 ; 1.5]$} & Uniform \\
\hline Inter-granular diffusion coefficient of vacancies $\left(\mathrm{m} \cdot \mathrm{s}^{-2}\right)$ & $10^{6} \cdot D_{i g}^{v}$ & {$\left[10^{-2} ; 10^{2}\right]$} & Uniform \\
\hline Initial number density of inter-granular bubbles $\left(\mathrm{bbl} \cdot \mathrm{m}^{-2}\right)$ & $2 \cdot 10^{12^{\lg }}$ & {$\left[10^{-3} ; 10^{3}\right]$} & Uniform \\
\hline Semi-dihedral angle of inter-granular bubbles (deg) & 72.9 & {$[0.5 ; 1]$} & Uniform \\
\hline Saturation coverage of grain boundaries $(/)$ & 0.5 & {$[1 ; \pi / 2]$} & Uniform \\
\hline
\end{tabular}

Bison comparisons to ATF-13 R4 PIE data including $\pm 2 \sigma$

\begin{tabular}{lccc}
\hline & Bison Stoichiometric & Bison Si-Rich & Experiment \\
\hline Fuel Elongation (mm) & -0.135 to 0.132 & -0.1305 to 0.0567 & 0 \\
Fission Gas Release (\%) & 0.0 to 1.412 & 0.0 to 0.902 & 0.06 \\
\hline
\end{tabular}




\section{Doped $\mathrm{UO}_{2}$ fission gas diffusivity model}

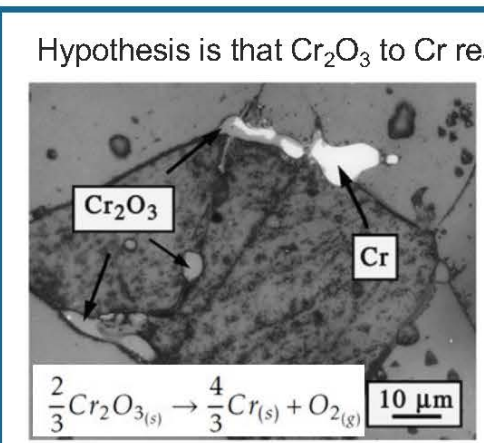

Bourgeois et al., J. Nucl. Mater., 297 (2001) 313-326

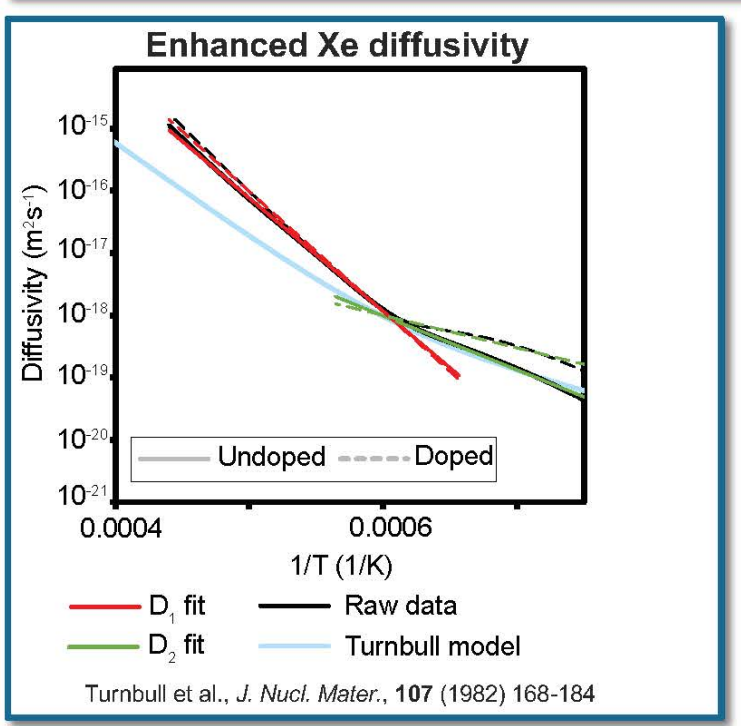

Turnbull et al., J. Nucl. Mater, 107 (1982) 168-184

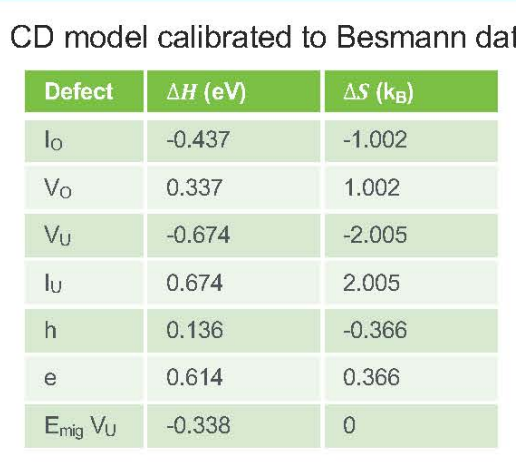

Temperature (K)

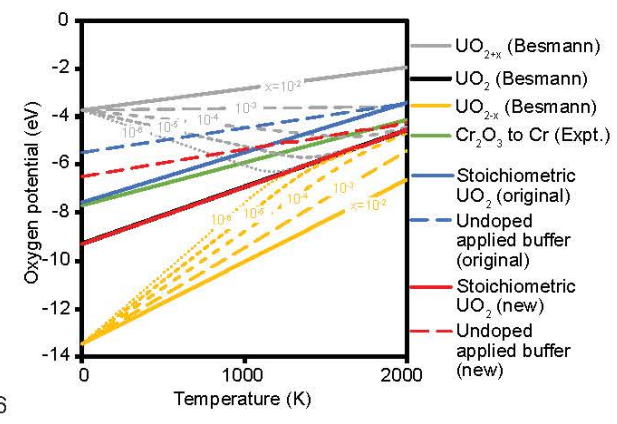

New enhanced diffusivity equation for use in Bison FGR model

$D^{\text {doped }}=\exp \left(-\frac{\Delta H_{1}}{k_{B}}\left[\frac{1}{T}-\frac{1}{T_{1}}\right]\right) D_{1}^{\text {undoped }}+\exp \left(-\frac{\Delta H_{2}}{k_{B}}\left[\frac{1}{T}-\frac{1}{T_{2}}\right]\right) D_{2}^{\text {undoped }}+D_{3}^{\text {undoped }}$

where $T_{1}=T_{2}=1673 \mathrm{~K}, \Delta H_{1}=0.316 \mathrm{eV}$, and $\Delta H_{2}=-0.684 \mathrm{eV}$.

Model

made available to MIT IRP team $(\mathrm{K}$. Shirvan) for additional testing. 


\section{Summary and conclusions}

- Demonstrated application of a hierarchical multi-scale simulation approach for $\mathrm{U}_{3} \mathrm{Si}_{2}$ :

- Relied on DFT calculations, MD simulations, cluster dynamics and phase field simulations.

- Informed engineering scale gas release, swelling and creep models in BISON (hierarchical information exchange, no concurrent coupling).

- LLS informed models are combined with empirical models derived from experiments to complete a Bison $\mathrm{U}_{3} \mathrm{Si}_{2}$ simulation capability.

- Bison simulations of ATR $U_{3} \mathrm{Si}_{2}$ irradiations compare well with experimental data.

- UQ and SA are important tools for guiding development and assessing results in a qualification context.

- Although exemplified for $\mathrm{U}_{3} \mathrm{Si}_{2}$, methodology, challenges and lessonslearned are expected to extend to other fuel types as well.

- Multi-scale modeling and simulations are a valuable tool to develop material models where experimental data is missing and difficult/expensive to acquire - provides valuable understanding.

- M\&S work must be performed in parallel with experiments for both "finecalibration" and validation based on rigorous UQ. 
APPENDIX G - TCR fuel design and development towards qualification 


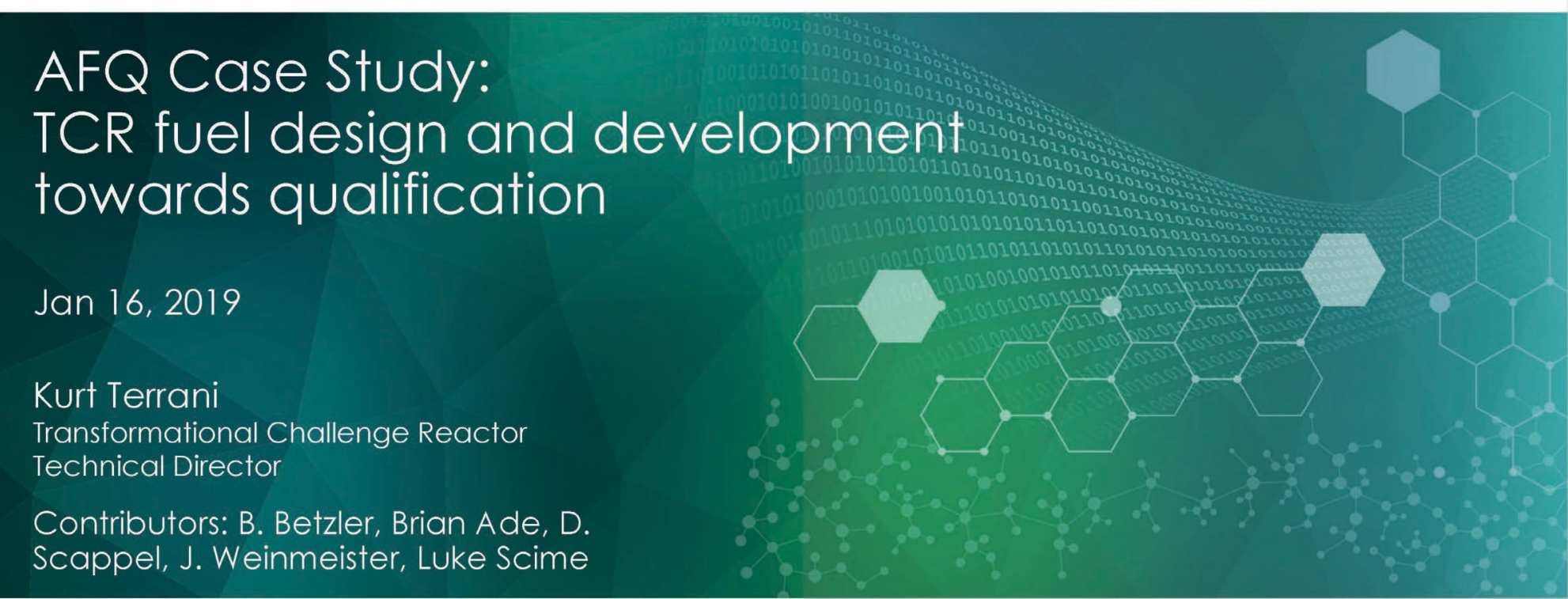

ORNL is managed by UT-Battelle, LLC for the US Department of Energy 


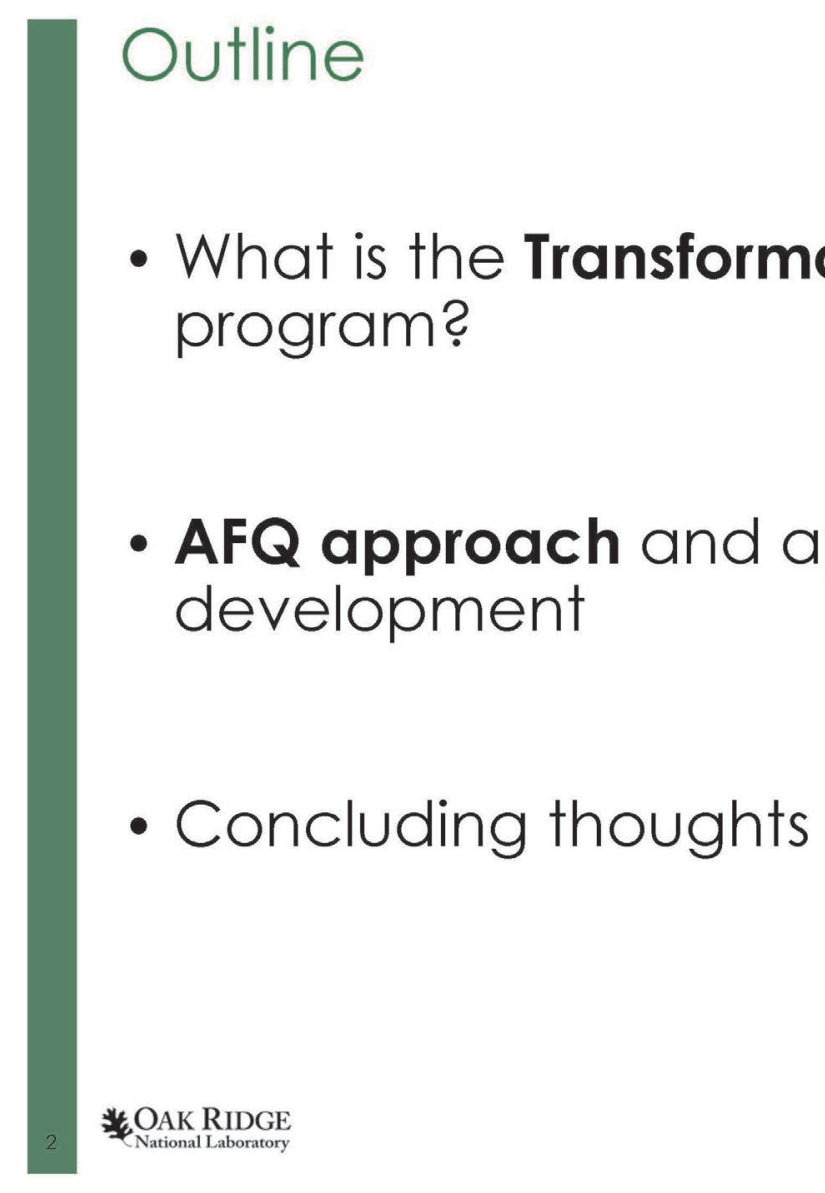




\section{What is TCR?}




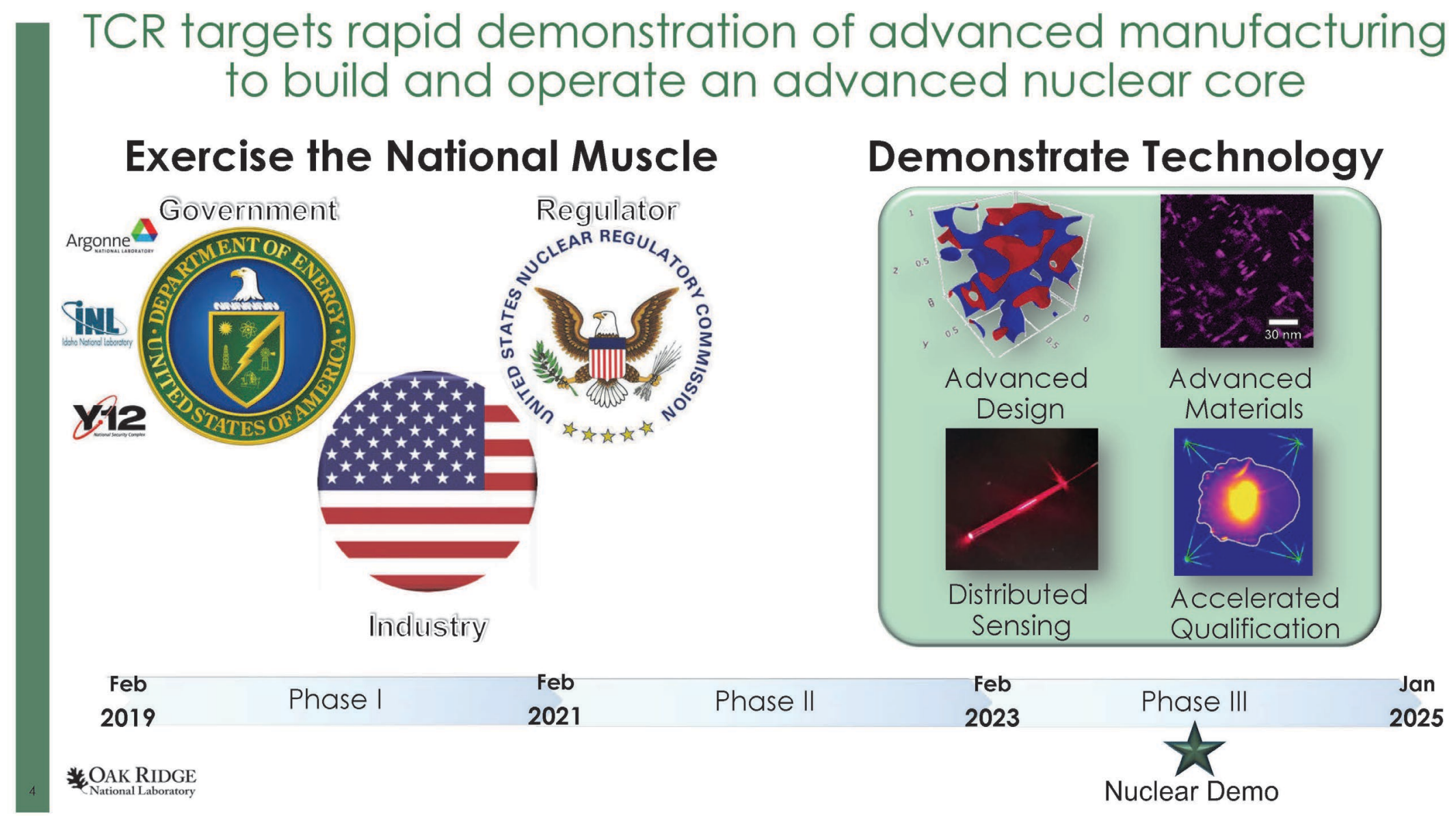




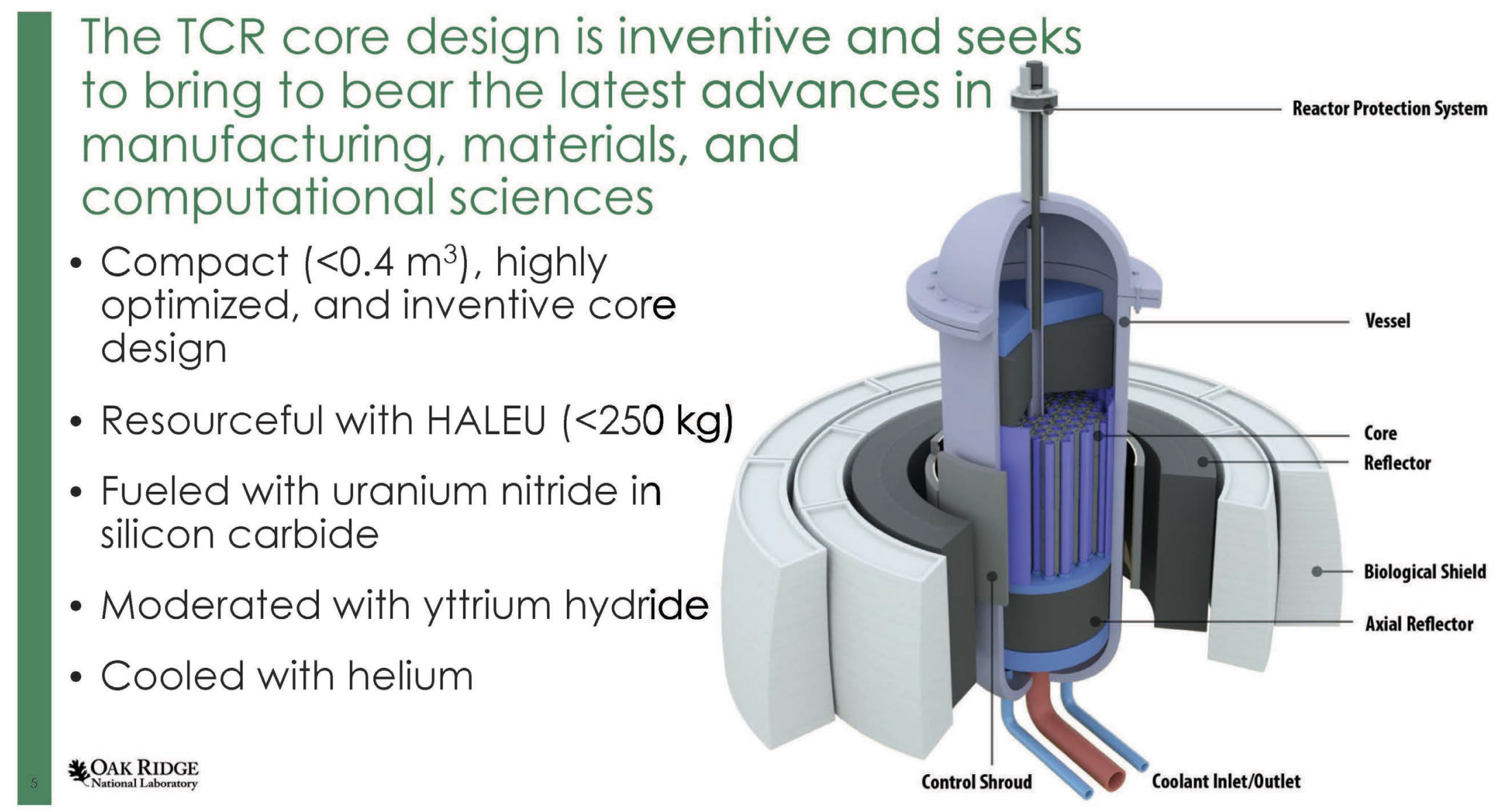




\section{AFQ approach applied to TCR core development}




\section{An accelerated scheme for nuclear fuel (core) development and qualification}

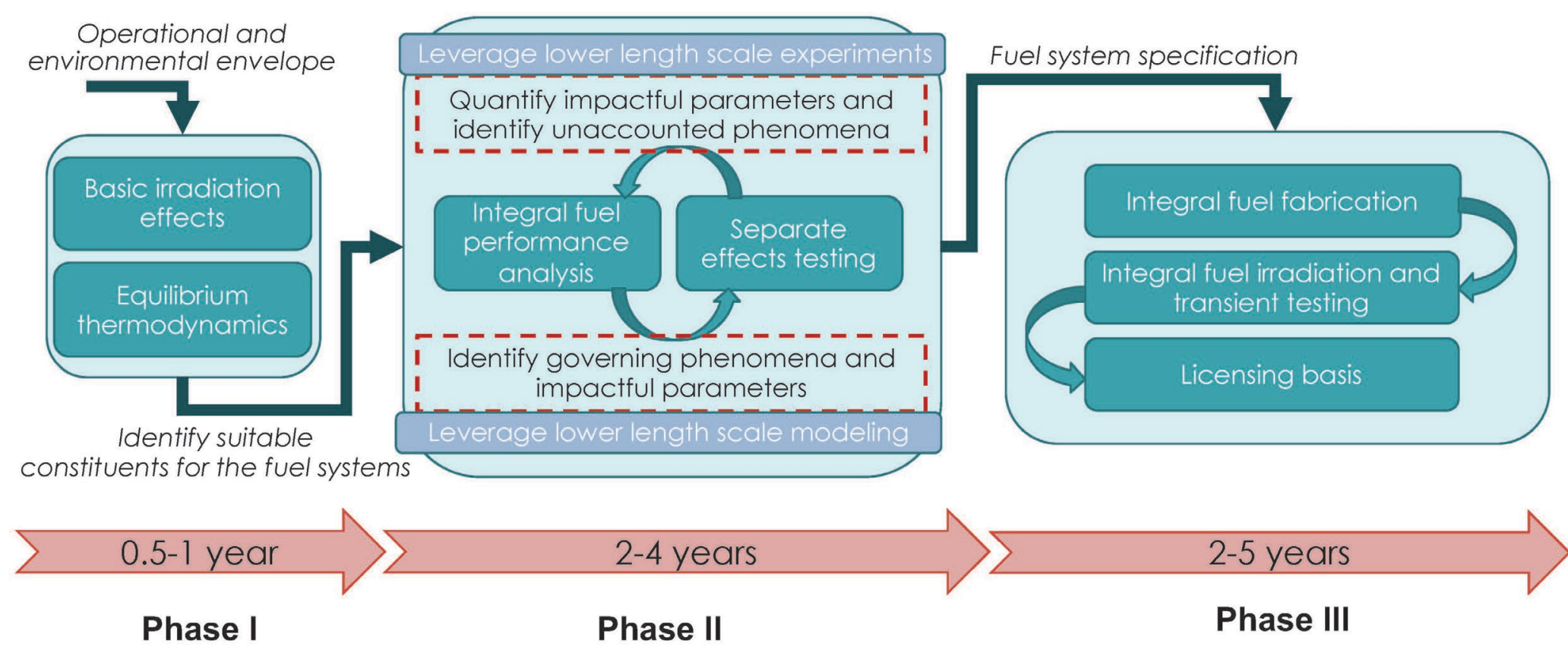
$\begin{array}{ll}\text { KA.A. Terrani, N.A. Capps, M.J. Kerr, C. Back, A.T. Nelson, B.D. Wirth, S.L. Hayes, C.R. Stanek, "Accelerating Nuclear Fuel Development and } \\ \text { National Laboratory } & \text { Qualification: Engineering-Scale Modeling and Simulation Integrated with Separate Effects Testing," J. Nucl. Mater., submitted (2020) }\end{array}$ 


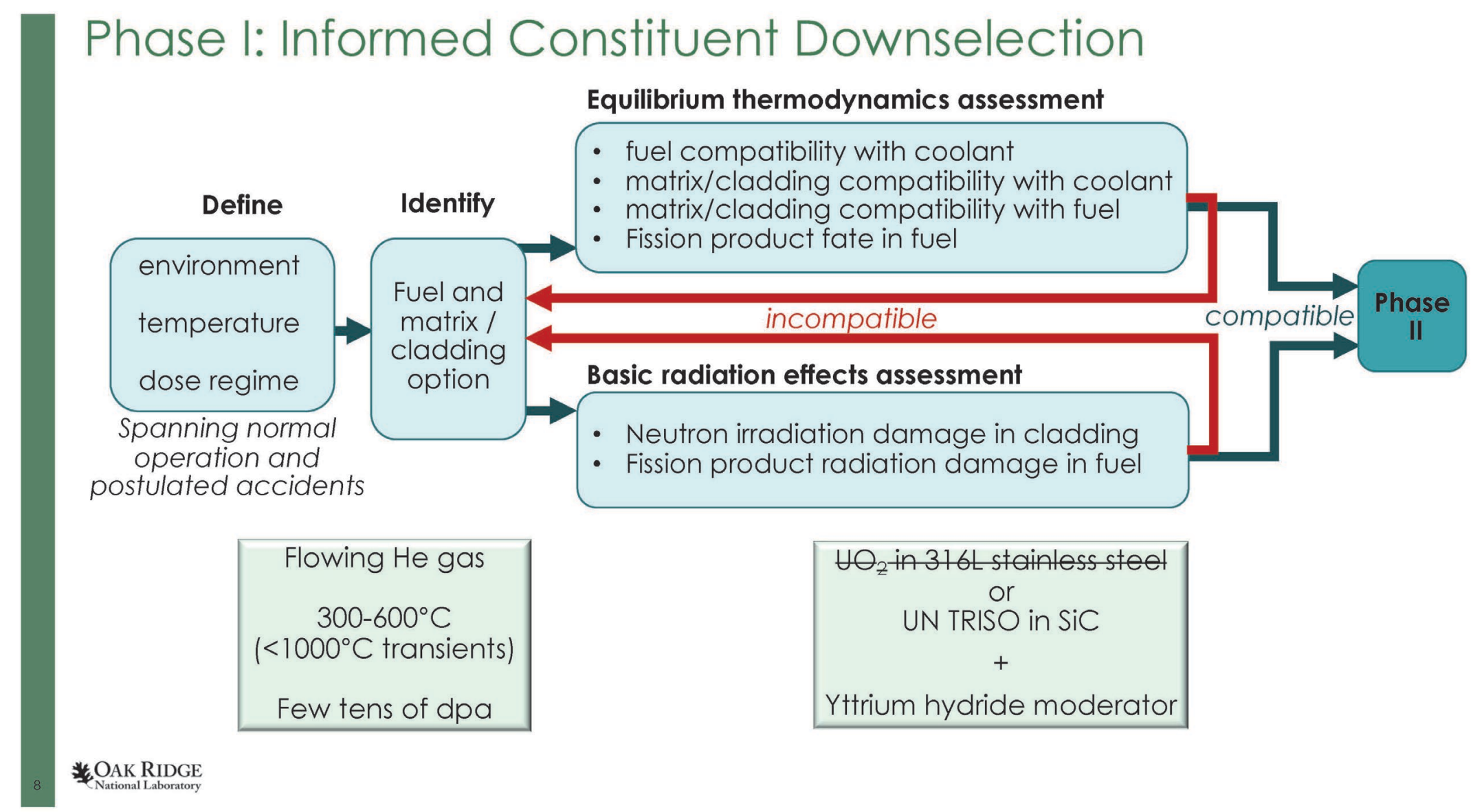




\section{Phase I: Informed Constituent Downselection}

- Fuel/matrix/cladding compatibility with coolant

- Matrix/cladding compatibility with fuel

- Fission product fate in fuel

- Neutron irradiation damage in cladding

- Fission product radiation damage in fuel

$$
\text { Temperature }\left[{ }^{\circ} \mathrm{C}\right]
$$
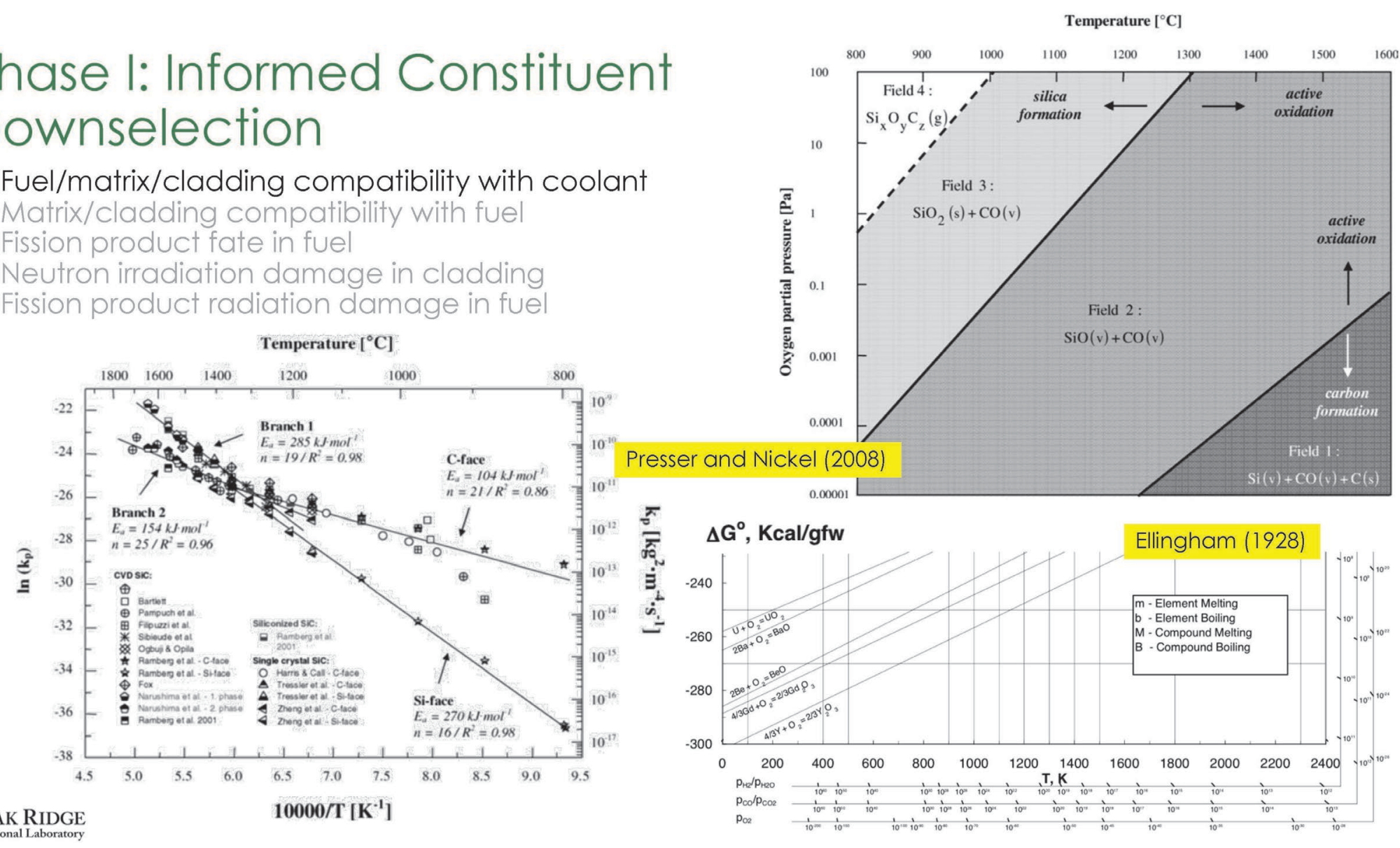


\section{Phase I: Informed Constituent Downselection}

- Fuel/matrix/cladding compatibility with coolant

- Matrix/cladding compatibility with fuel

- Fission product fate in fuel

- Neutron irradiation damage

- Fission product radiation damage in fuel

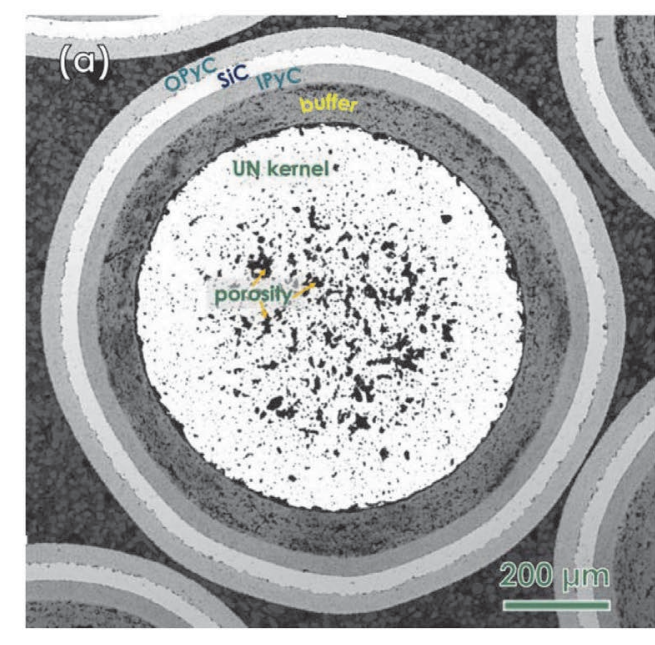

OAK RIDGE

\section{HFIR Irradiated}

$\sim 460^{\circ} \mathrm{C}, \sim 0.7 \%$ FIMA

fast fluence $(E>0.1 \mathrm{MeV}): 3.2 \times 10^{20} \mathrm{n} / \mathrm{cm}^{2}$ power-per-particle 120-545 mW power density $450-2030 \mathrm{~W} / \mathrm{cm}^{3}$

\section{Terrani et al. (2020)}
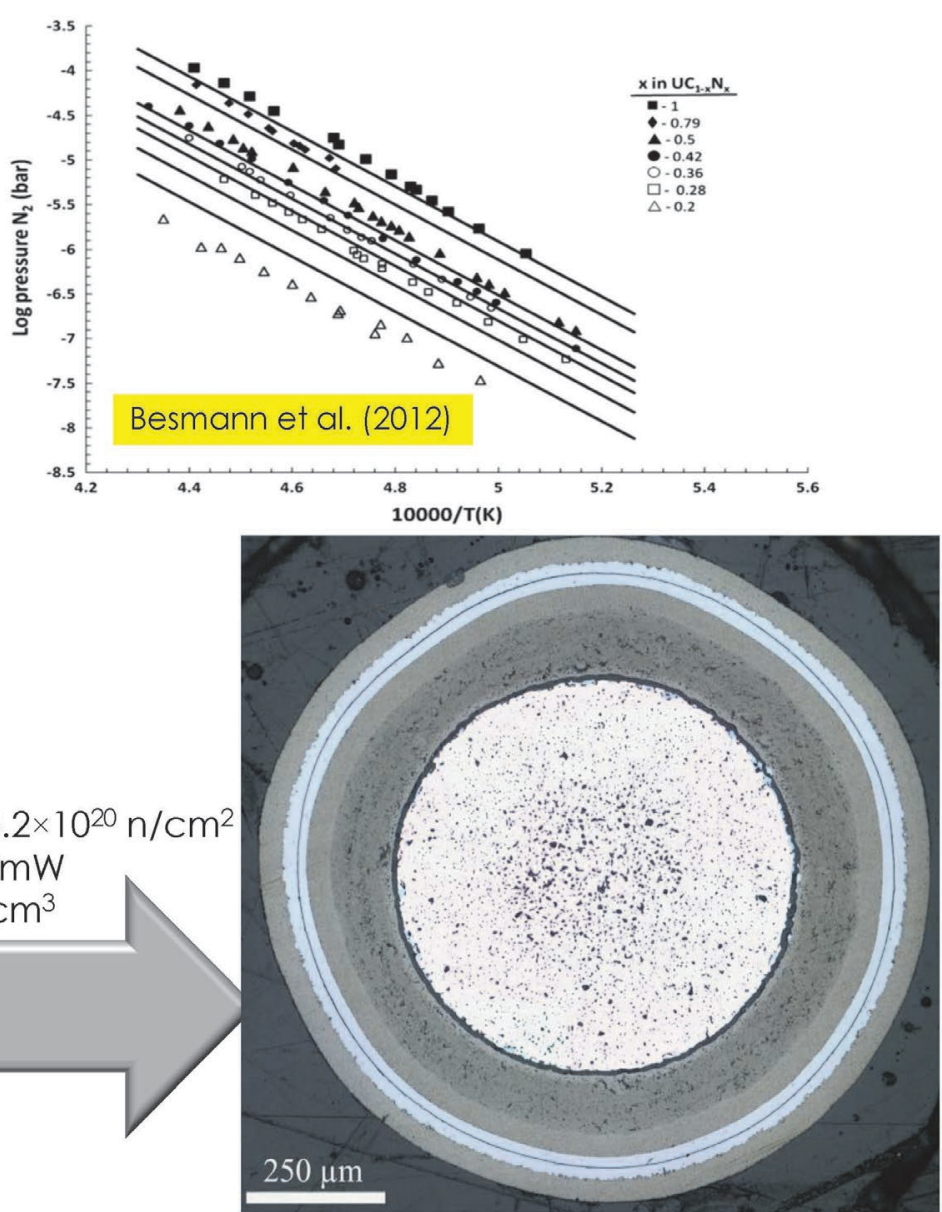


\section{Phase I: Informed Constituent Downselection}

- Fuel/matrix/cladding compatibility with coolant

- Matrix/cladding compatibility with fuel

- Fission product fate in fuel

- Neutron irradiation damage

- Fission product radiation damage in fuel
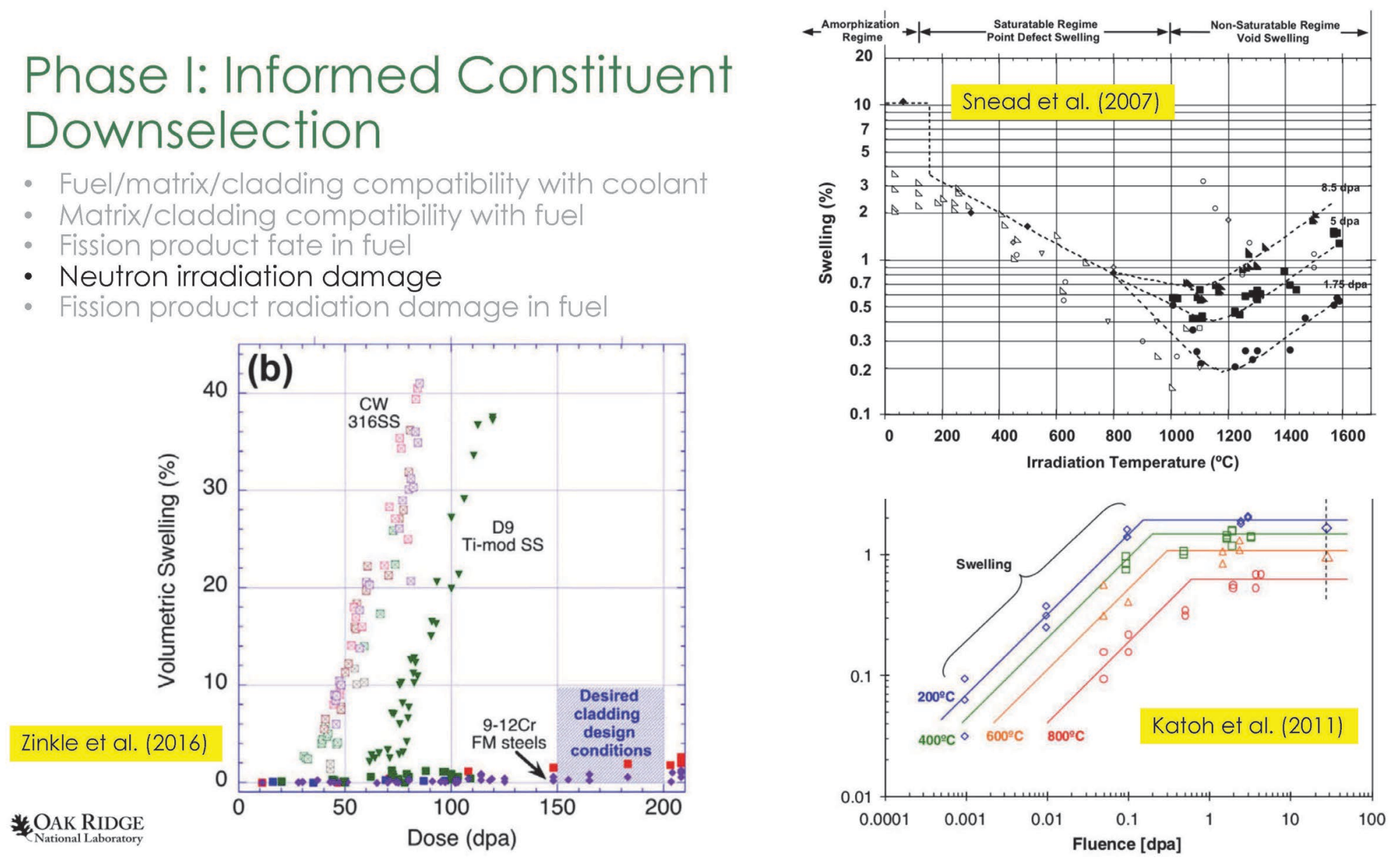


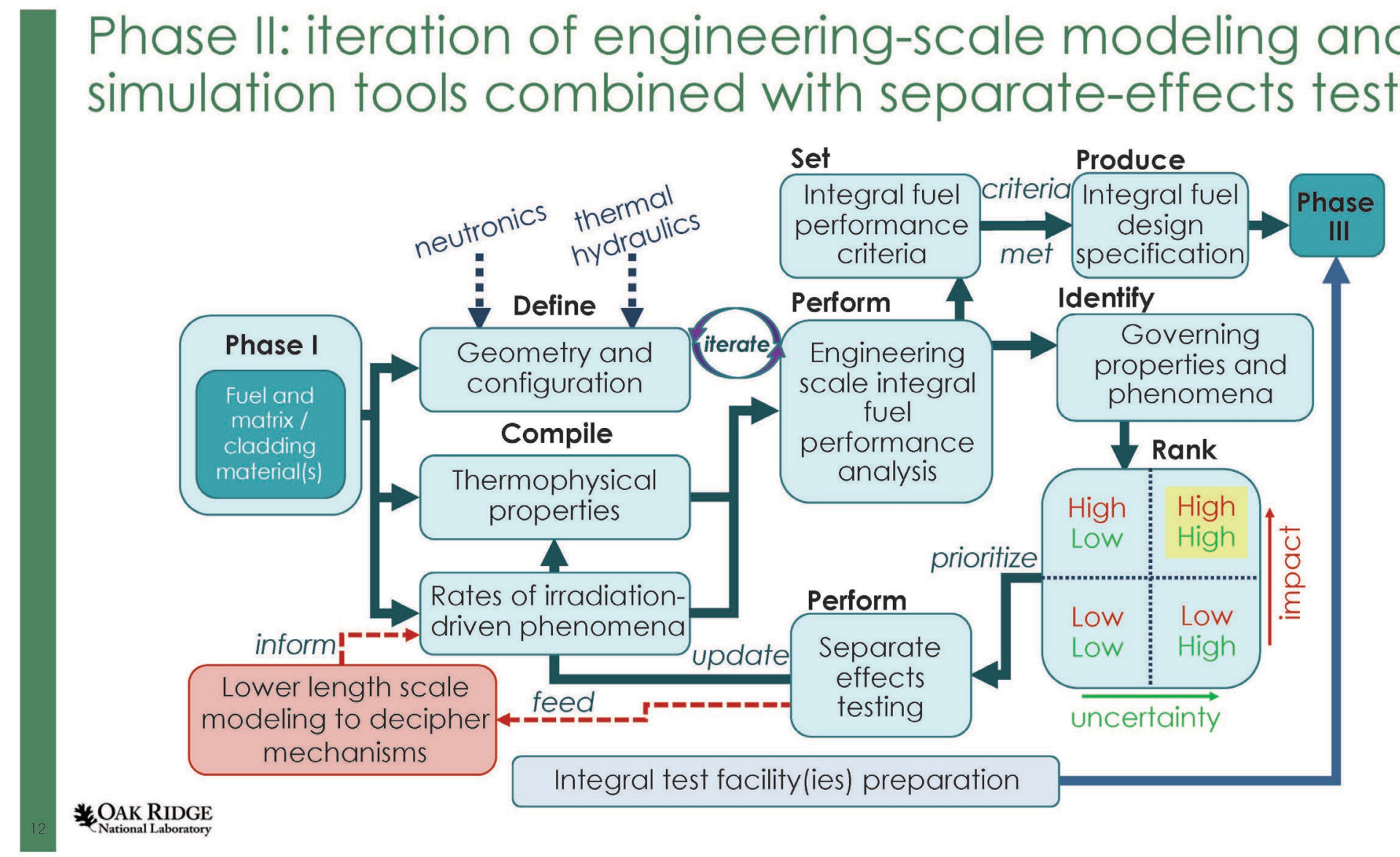




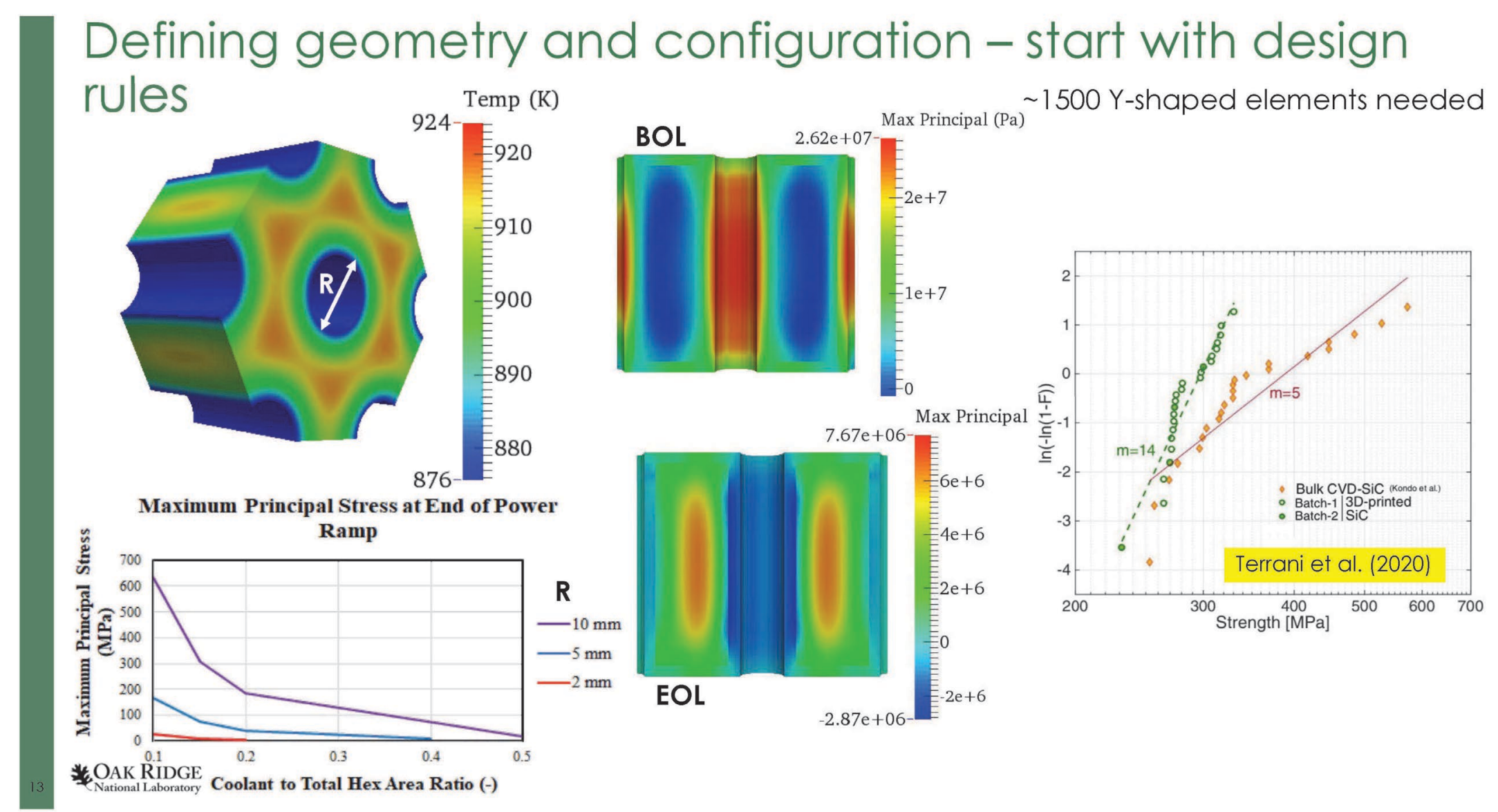




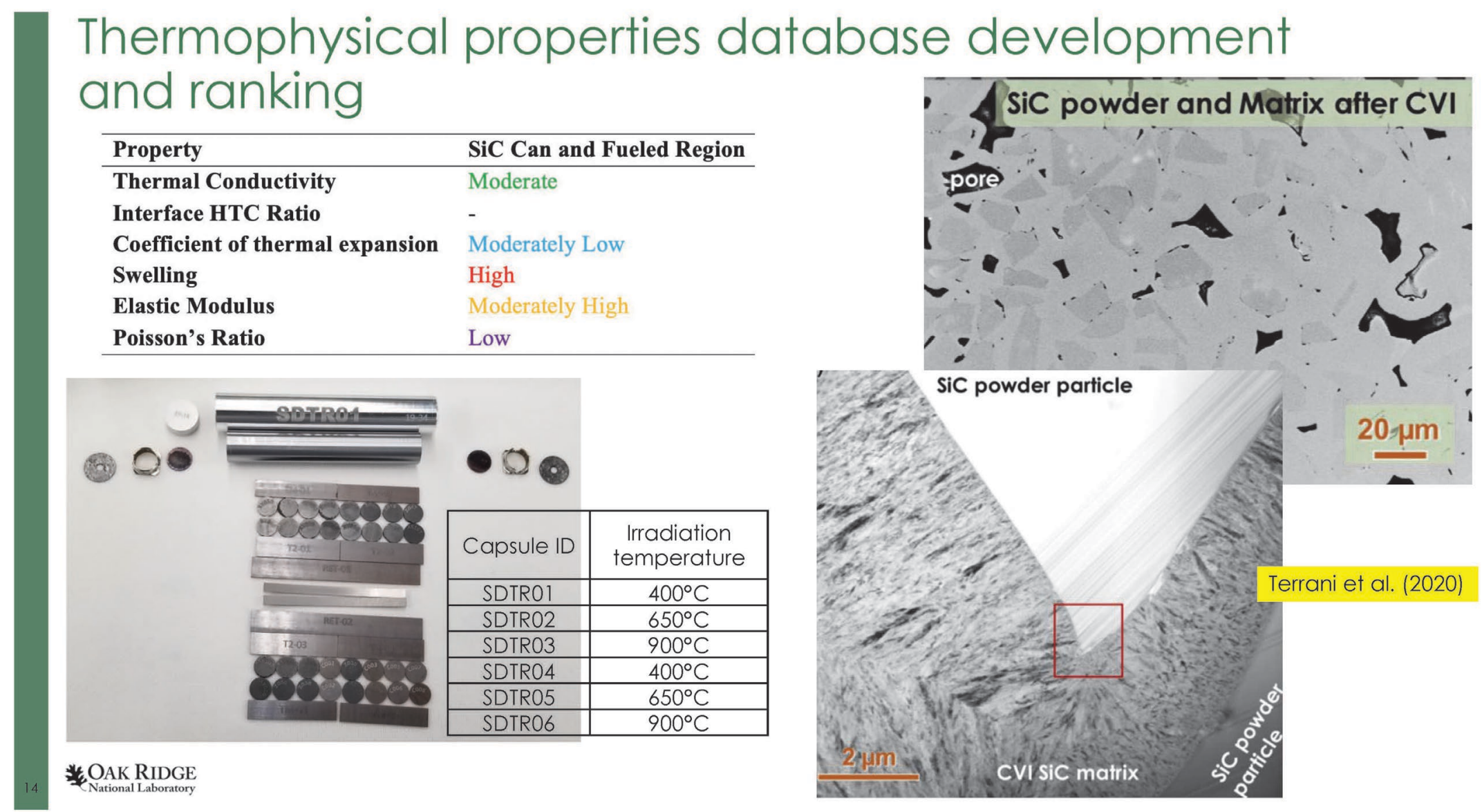




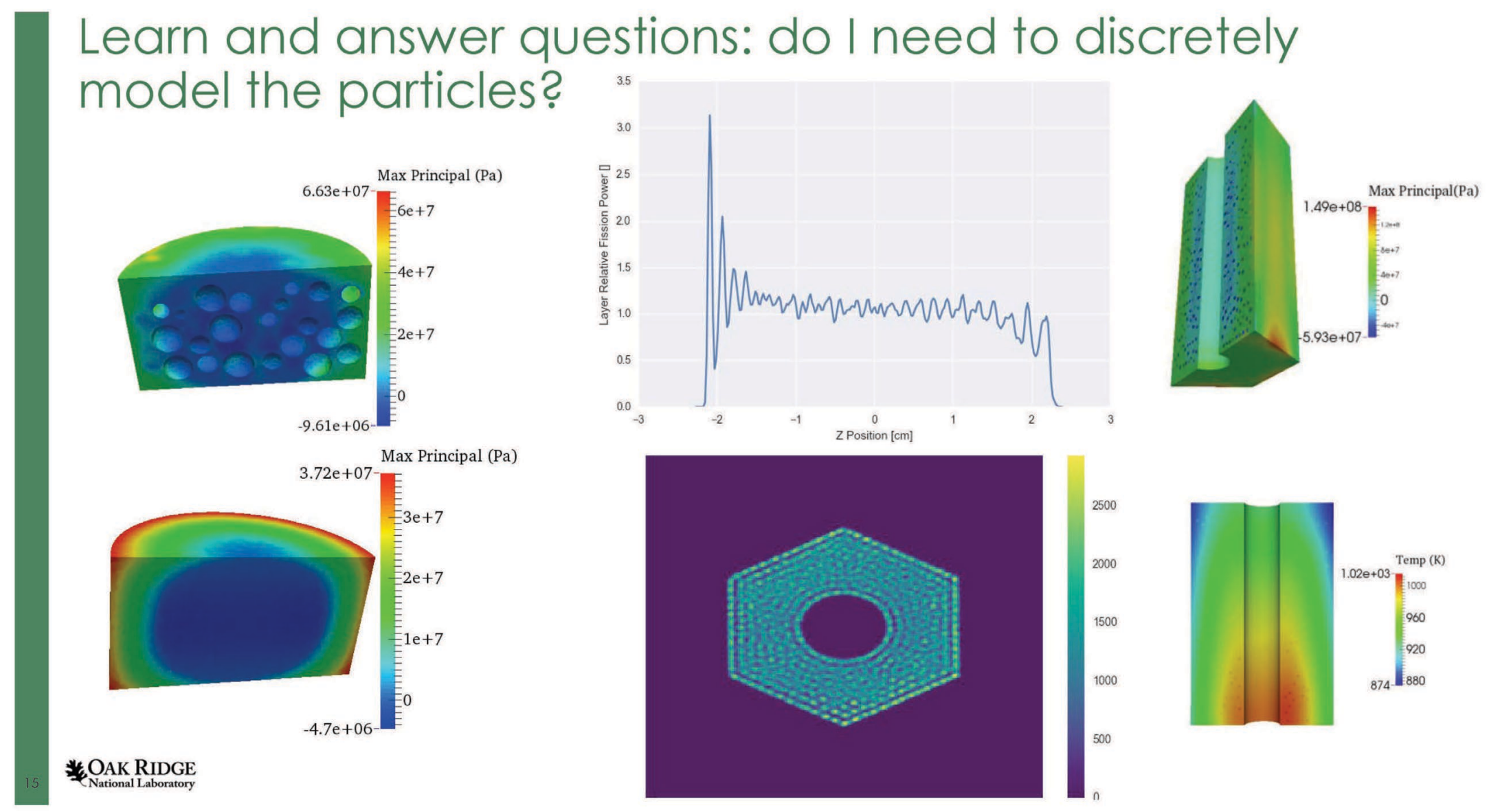




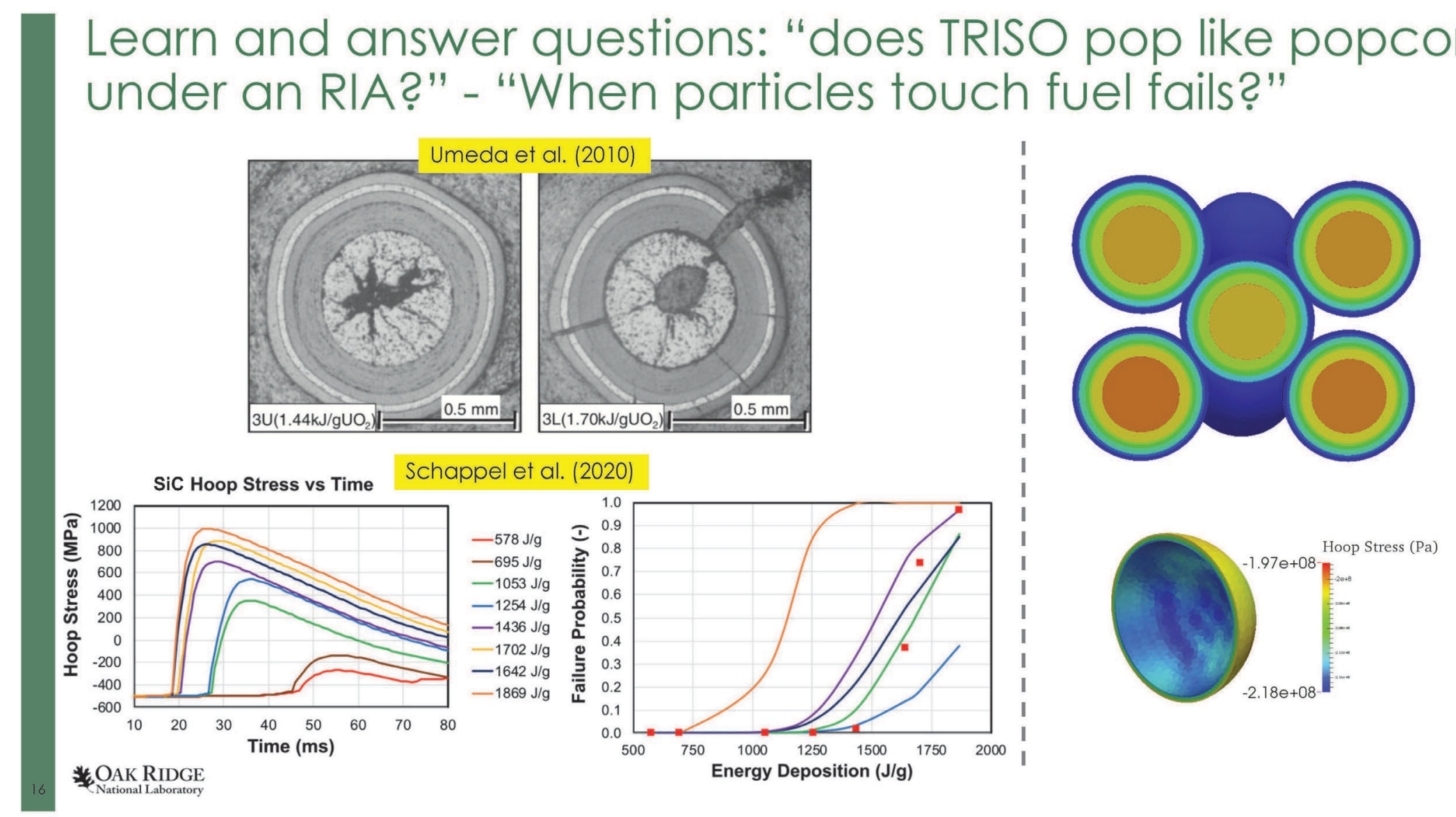




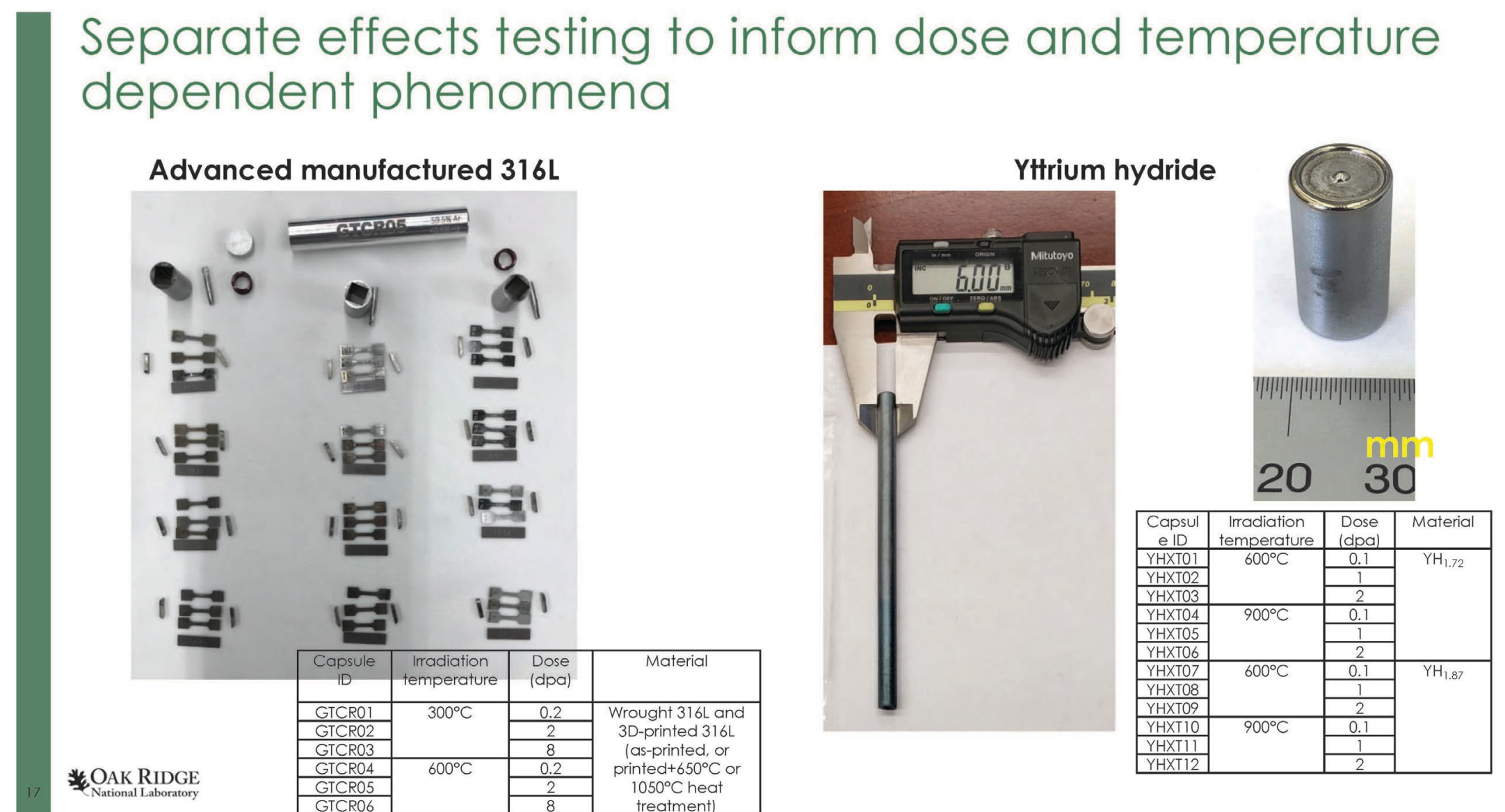


High quality property handbooks are key in informing modeling tools and enabling licensing and deployment
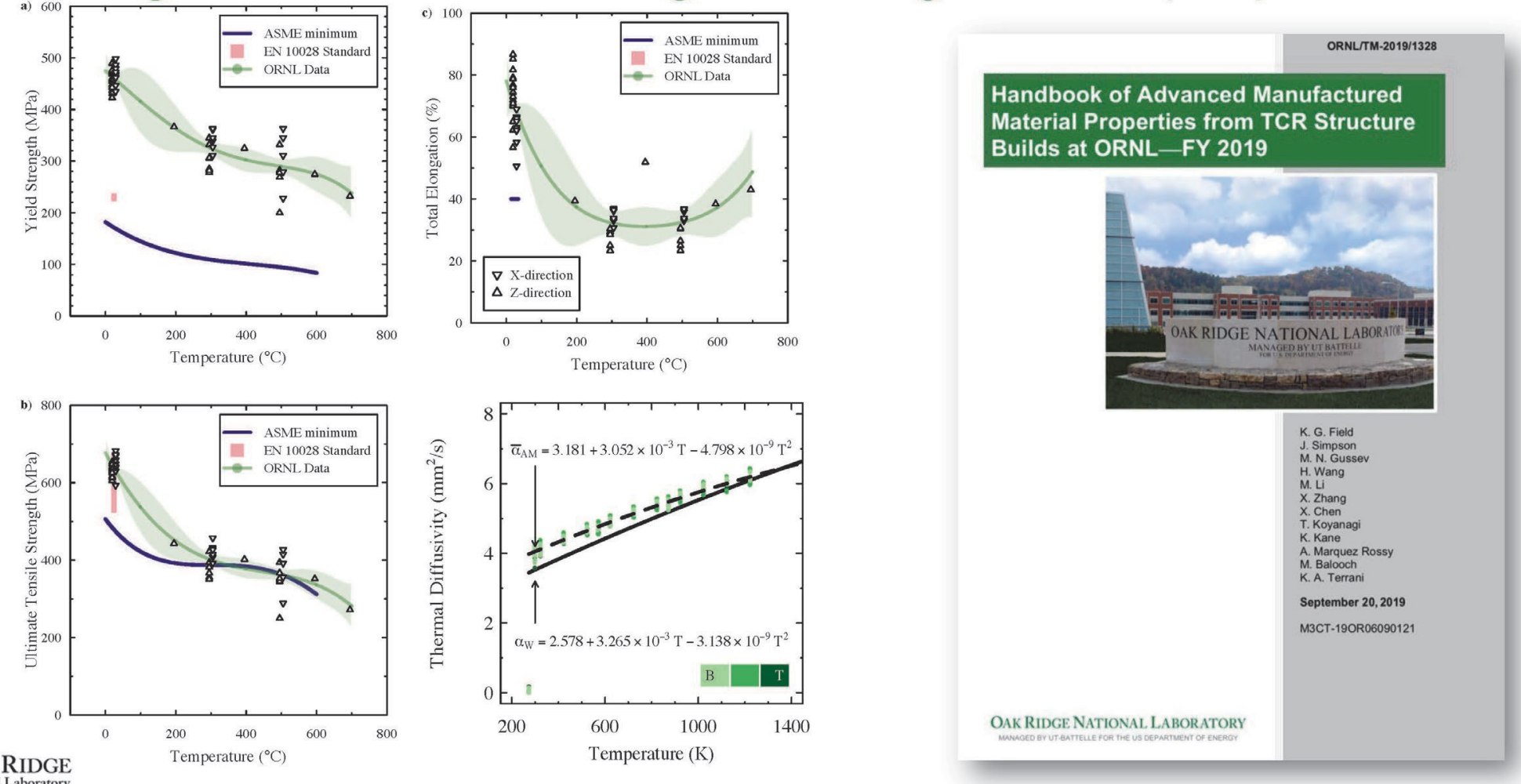


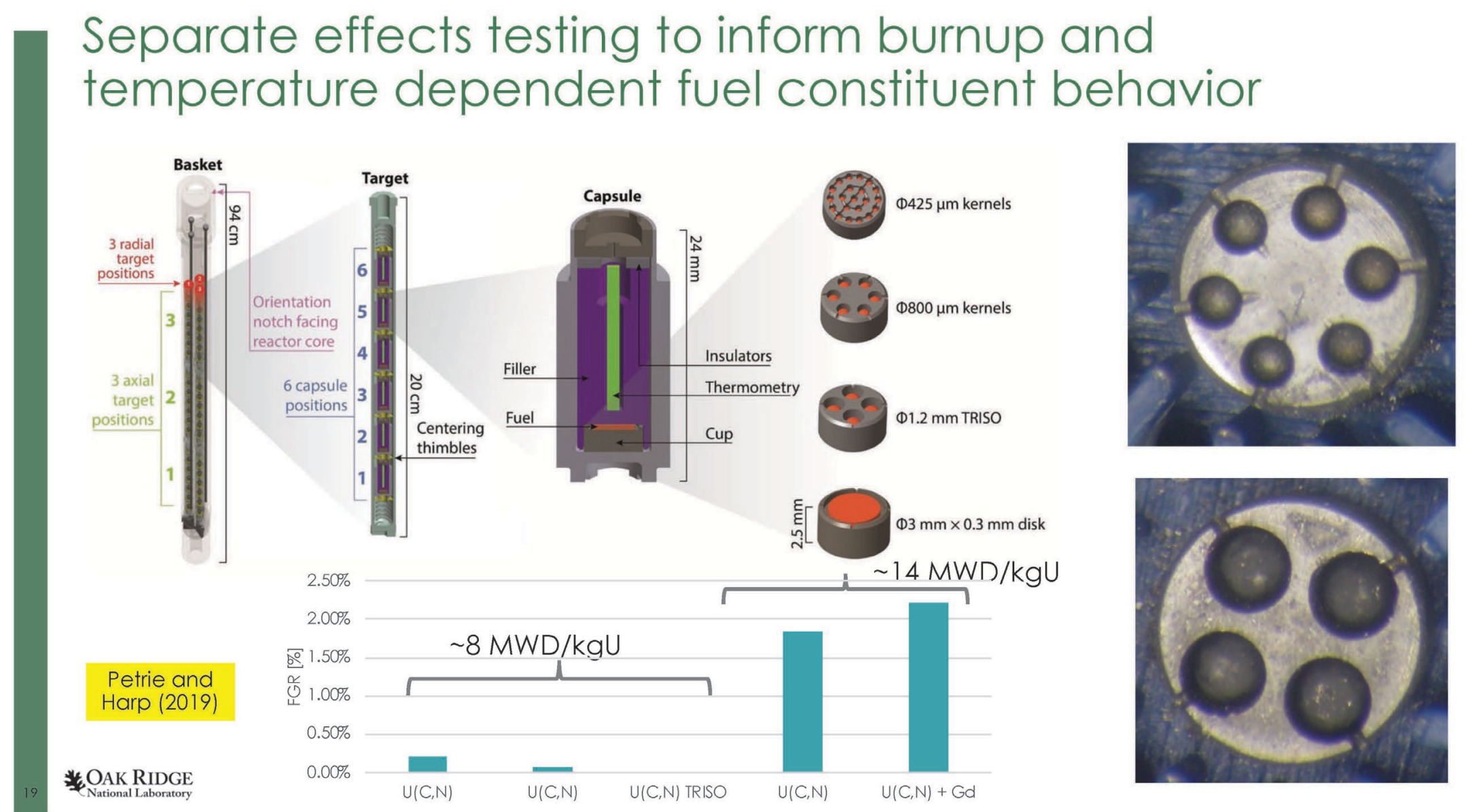




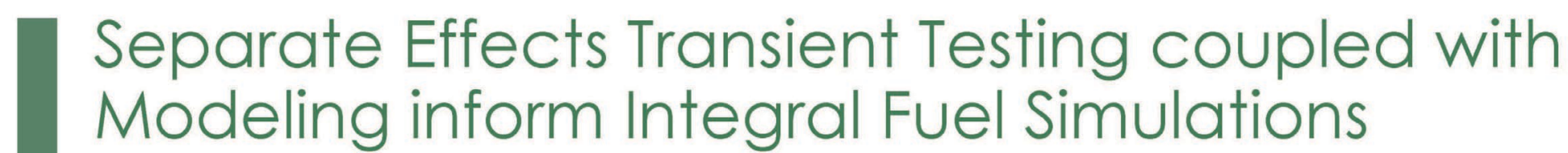

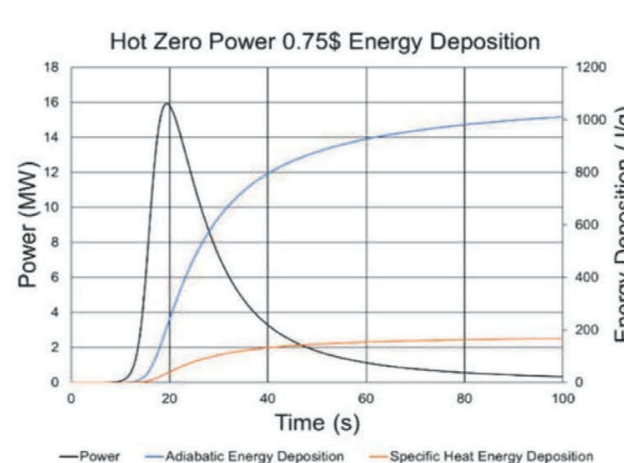

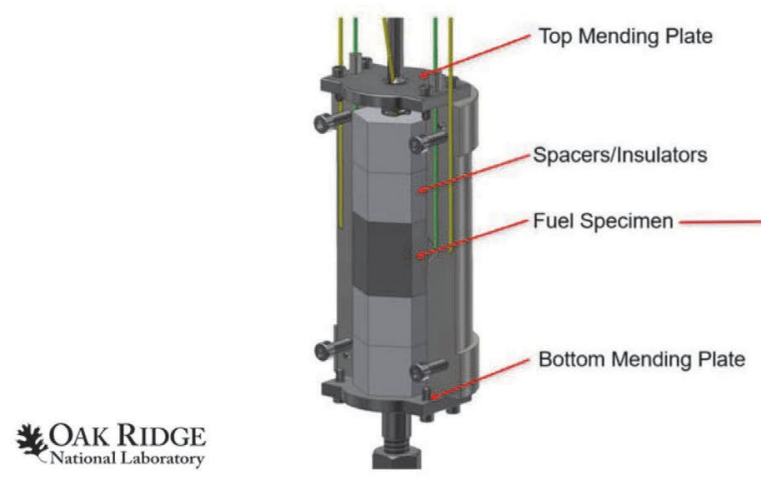

HZP $0.75 \$$ Fuel Temperatures
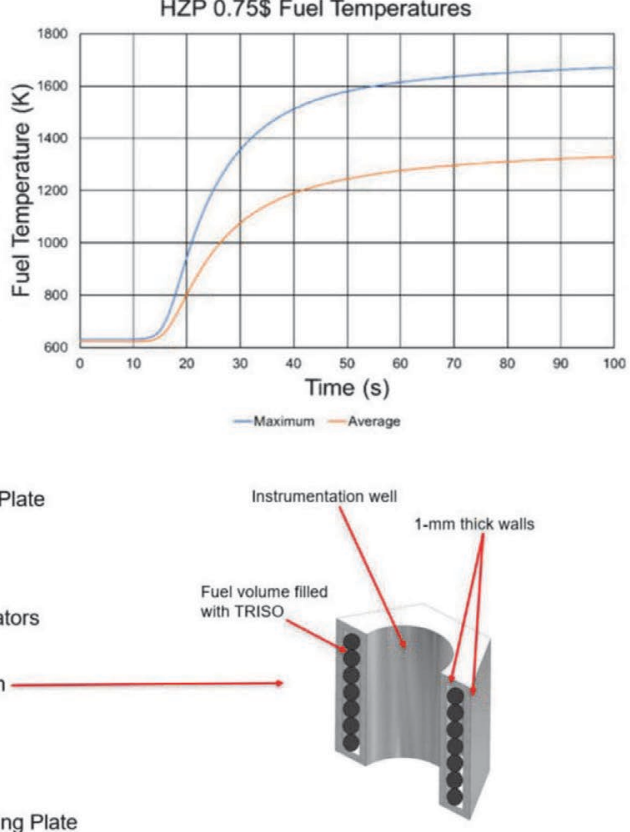

SiC Hoop Stress
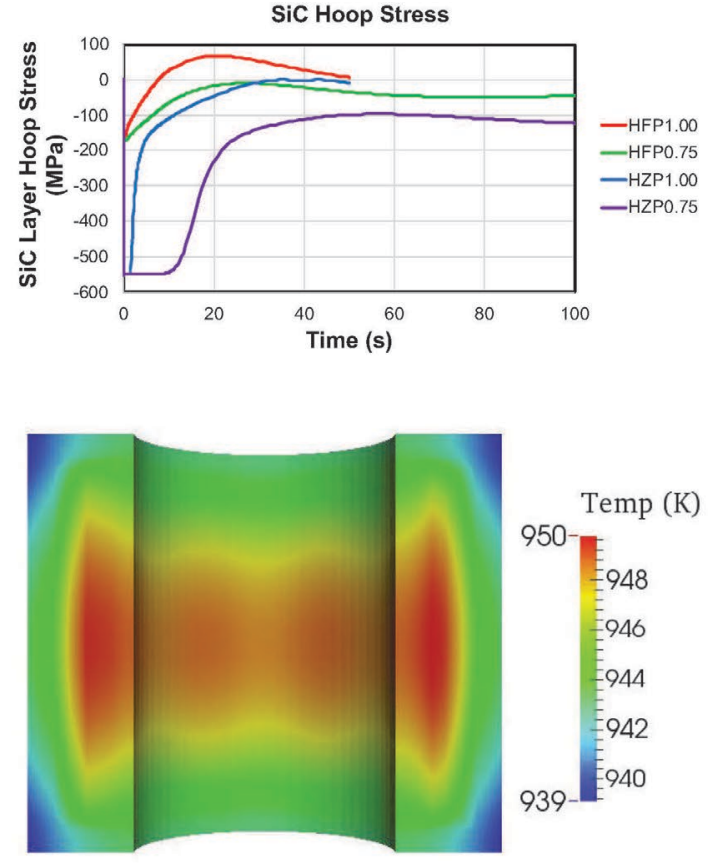


\section{Phase III: minimal integral fuel testing to verify models and capture (if any) unaccounted integral effects}

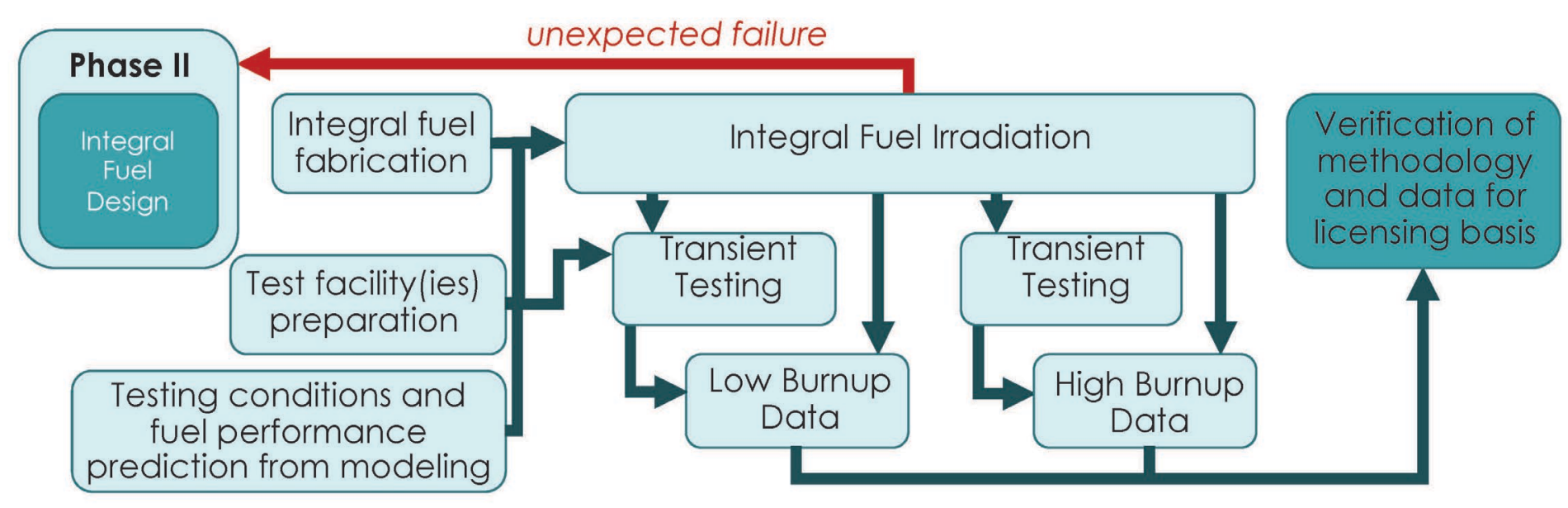

* OAK RIDGE 


\section{Concluding thoughts}

National Raboratory 


\section{Engineering-Scale Modeling and Simulation Informed by and Integrated with Separate-Effects Testing will Greatly accelerate Fuel Development and Qualification}

- TCR is building on the full breadth of the national capability and complex to deliver on its mission

- Modeling tools (e.g. NEAMS) are mature and knowledge of fuels and materials behavior (e.g. AFC/AGR/ART) are ample to facilitate an informed AFQ process (methodology + data)

- TCR demonstration will benefit the entire community and deliver new technologies and approaches for industrial adoption

tcr.ornl.gov

NaAK RIDGE 
APPENDIX H - Feltus AFQ Workshop II Jan 2020 Presentation

on TRISO Fuel Material Properties Study 


\section{Evaluating the importance of TRISO Fuel Materials Properties for Irradiated Fuel Performance Analysis}

Dr. Madeline Anne Feltus

Office of Advanced Fuel Technologies, NE-42

AFQ Workshop II Jan. 16, 2020 


\section{Importance of TRISO Fuel Materials Properties for Irradiated Fuel Performance Analysis}

\section{Overview}

- Identify the material properties that have the largest impact on the failure probability of tristructural isotropic (TRISO)-coated fuel particles under irradiation.

- Most material constitutive properties were obtained from historical TRISO experimental data, some with large variability.

- The NE AGR TRISO Fuel program is evaluating the adequacy of the historical material properties data, and need to generate new data.

- The PARFUME TRISO fuel performance code was used to assess the importance of material properties on the probability of silicon carbide (SiC) layer failure.

- Although many $(20+)$ material properties are used in PARFUME, only a few of them have a significant impact on the SiC failure probability.

- The most important properties are Pyrolytic Carbon (PyC) irradiation induced creep and strain (shrinkage, dimensional change).

References:

- Skerjank, W., B. Collin, INL/EXT-18-44631, Rev. 0, Aug. 2018.

- Skerjank, W. F., J. T. Maki, B. P. Collin, D. A. Petti, Evaluation of design parameters for TRISO-coated fuel particles to establish manufacturing critical limits using PARFUME, J. Nuclear Materials, vol. 469 (2016) pp. 99-105. 
Importance of TRISO Fuel Materials Properties for Irradiated Fuel Performance Analysis

\section{TRi-structural ISOtropic (TRISO) Coated Particle Fuel}

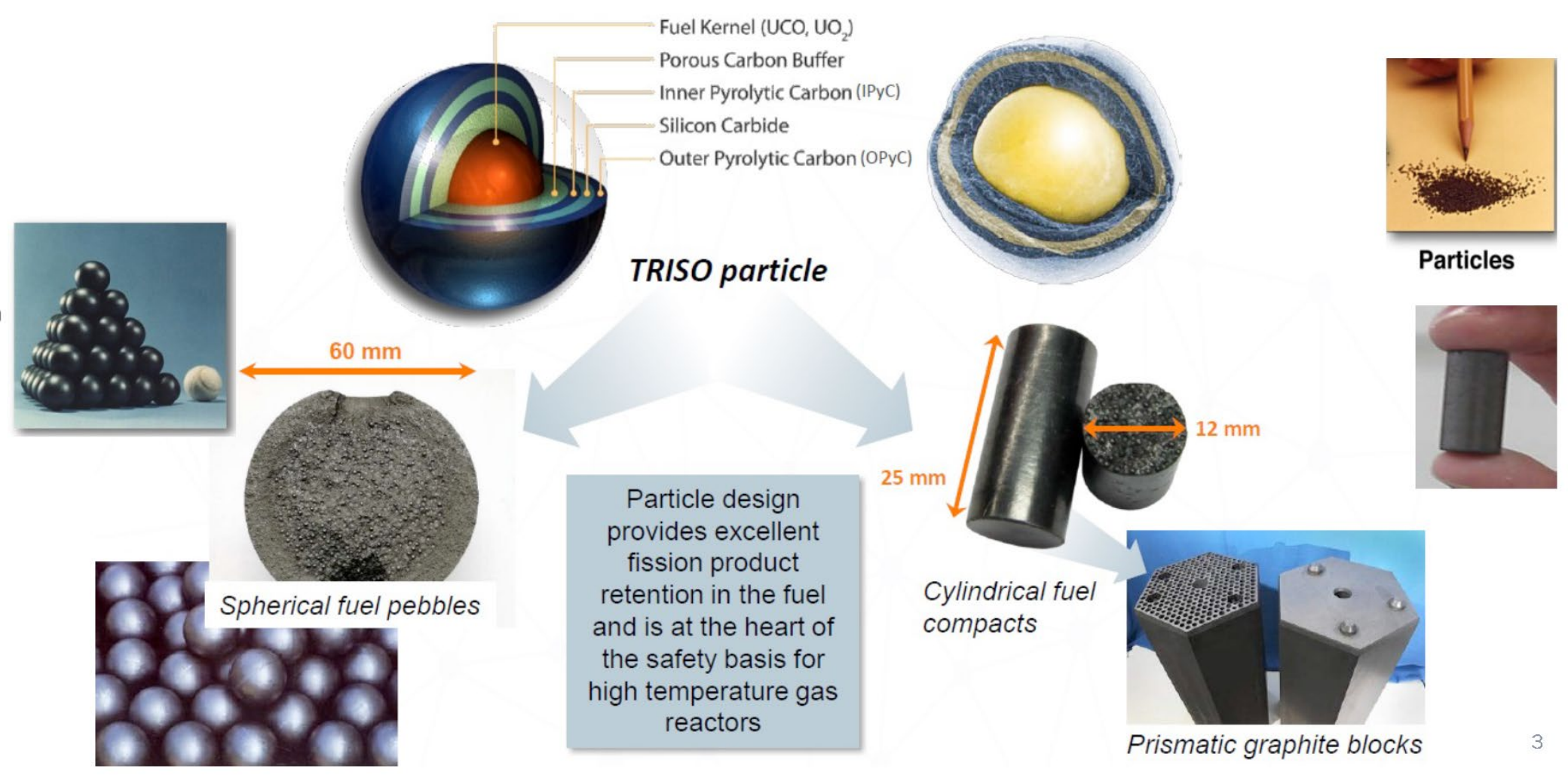




\section{Importance of TRISO Fuel Materials Properties for Irradiated Fuel Performance Analysis}

\section{PARFUME TRISO Fuel Performance Code}

- Integrated mechanistic model of thermal, mechanical and physiochemical behavior of TRISO particles

- Calculates TRISO particle failure probability given the particle-to-particle statistical variation in physical dimensions and material properties under irradiation and postulated accident conditions

- Calculates fission product transport and diffusion through the coating layers into the fuel matrix and coolant

- Gaussian distribution for fuel design parameters

- Weibull statistical distribution for layer strengths and modulus

- PARFUME calculates inter-layer stresses and strains using:

- Kernel diameter, 4 layer thicknesses

- Pyrocarbon (PyC) layers and SiC densities

- Degree of PyC anisotropy (Bacon Anisotropy Factor, BAF)

- PyC creep coefficients

- Poisson's ratio in PyC creep

- Bond strength between IPyC and SiC layers

- TRISO particle asphericity, measured by aspect ratio
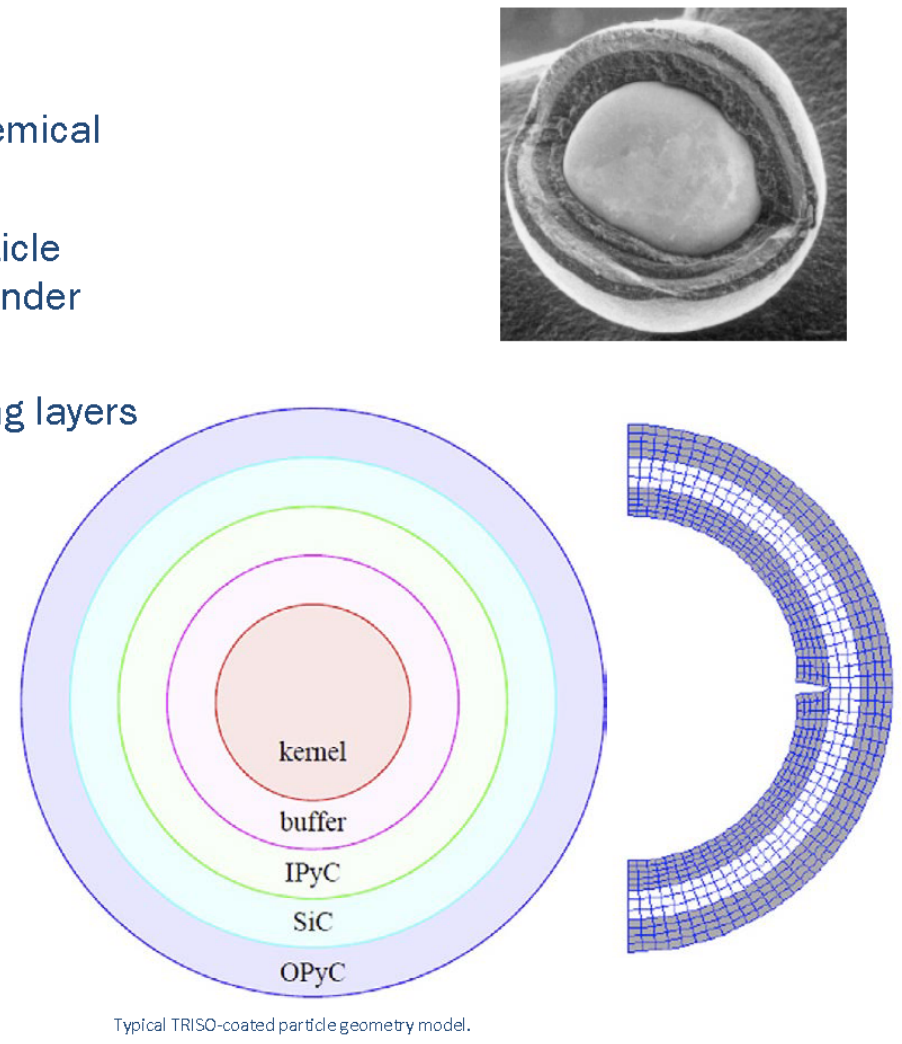


\section{Importance of TRISO Fuel Materials Properties for Irradiated Fuel Performance Analysis}

\section{TRISO Fuel Particle Failure Mechanisms}

- Irradiation-induced shrinkage of IPyC and OPyC layers put the SiC layer into compression.

- Shrinkage/swelling response of PyC layers is highly anisotropic, depends on irradiation temperature, degree of anisotropy (BAF)

- Irradiation-induced shrinkage of IPyC layer can cause partial debonding of IPyC from SiC layer and IPyC cracking caused by high tensile stress,

- Increasing internal gaseous fission product pressure produces tensile component to the hoop stress in the SiC layer, and increases tangential stress in $\mathrm{SiC}$ beyond $\mathrm{SiC}$ fracture strength. Uranium Oxycarbide (UCO) fuel limits $\mathrm{CO}$ production seen in $\mathrm{UO}_{2}$ fuel.

- Kernel migration (amoeba effect) where large temperature gradient causes equilibrium $\mathrm{CO}$ gas imbalance. Uranium Oxycarbide (UCO) fuel limits $\mathrm{CO}$ production seen in $\mathrm{UO}_{2}$ fuel

- Mechanical interaction between kernel/buffer with PyC, SiC layers (rarely observed in irradiations, since gap stays open as buffer stays bonded to kernel during densification)

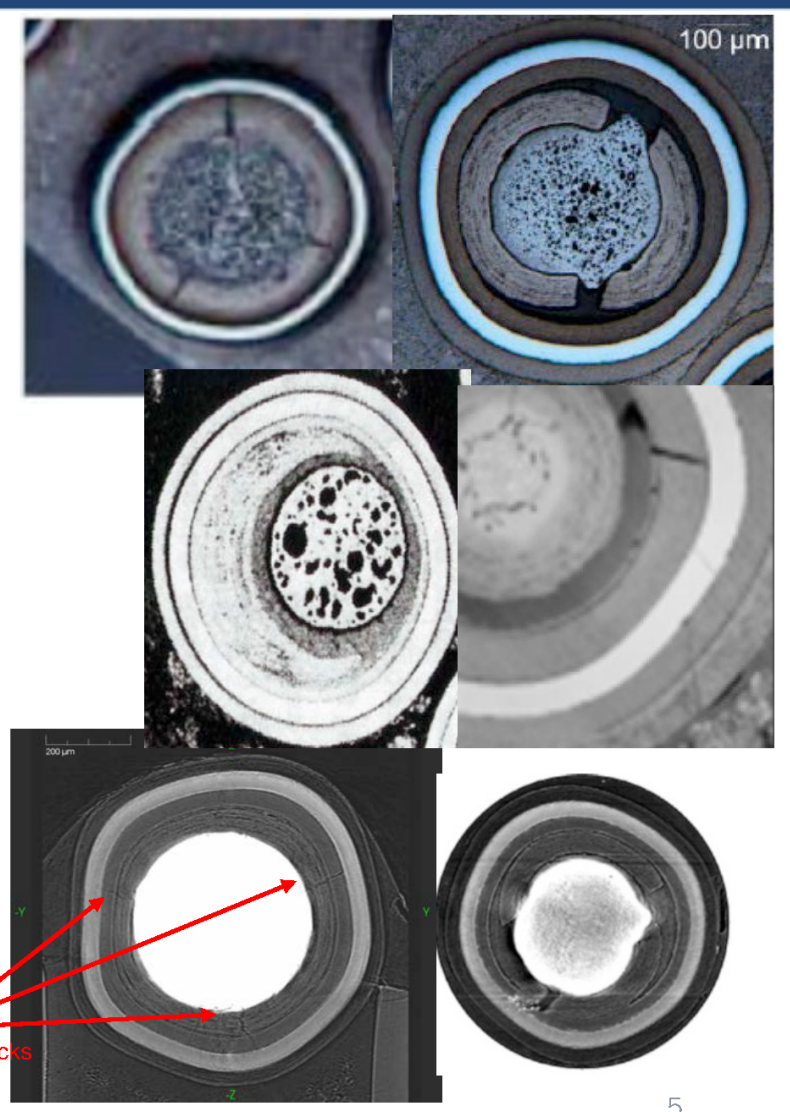


Importance of TRISO Fuel Materials Properties for Irradiated Fuel Performance Analysis

\section{Sensitivity, Importance Evaluation Methodology}

- Use parametric variations of each material property to calculate stress levels in each particle layer

- Calculate resultant failure probability under various irradiation temperature conditions

- Determine importance of each material property by using sensitivity multiplication factors (SMF) varied around nominal property value and by comparing calculated failure probabilities

- Use AGR-5/6/7 fuel specification values and average irradiation conditions

Table 1. Irradiation conditions. AGR-5/6/7 qualification experiment average values

\begin{tabular}{|c|c|c|c|c|}
\hline Condition & EFPD & Burnup (\%FIMA) & $\begin{array}{c}\text { Fast fluence } \\
\left(\times \mathbf{1 0}^{\mathbf{2 5}} \mathbf{\mathbf { n }} \mathbf{m}^{\mathbf{2}} \mathbf{\mathbf { E }} \mathbf{\mathbf { 0 . 1 8 }} \mathbf{~ M e V}\right)\end{array}$ & $\begin{array}{c}\text { Irradiation } \\
\text { Temperature }\left({ }^{\circ} \mathbf{C}\right)\end{array}$ \\
\hline 1 & 500 & 13.5 & 5 & 700 \\
\hline 2 & 500 & 13.5 & 5 & 1000 \\
\hline 3 & 500 & 13.5 & 5 & 1300 \\
\hline
\end{tabular}




\section{Importance of TRISO Fuel Materials Properties for Irradiated Fuel Performance Analysis}

Table 2. Fuel parameters used in PARFUME modeling.

\begin{tabular}{|l|l|c|}
\hline Category & Parameter & $\begin{array}{c}\text { Nominal Value } \\
\pm \text { Standard Deviation }\end{array}$ \\
\hline \multirow{5}{*}{ Fuel characteristics } & Carbon/uranium (atomic ratio) & 15.5 \\
& Oxygen/uranium (atomic ratio) & 0.4 \\
& Uranium contamination fraction & 1.5 \\
& Kernel diameter $(\mu \mathrm{m})$ & 0 \\
\hline \multirow{5}{*}{ Particle geometry } & $425 \pm 10$ \\
& Buffer thickness $(\mu \mathrm{m})$ & $100 \pm 10$ \\
& IPyC / OPyC thickness $(\mu \mathrm{m})$ & $40 \pm 3$ \\
& SiC thickness $(\mu \mathrm{m})$ & $35 \pm 2$ \\
& Particle asphericity $(\mathrm{SiC}$ aspect ratio) & 1.040 \\
\hline \multirow{5}{*}{ Fuel properties } & Kernel density $\left(\mathrm{g} / \mathrm{cm}^{3}\right)$ & 11.0 \\
& Kernel theoretical density $\left(\mathrm{g} / \mathrm{cm}^{3}\right)$ & 11.4 \\
& Buffer density $\left(\mathrm{g} / \mathrm{cm}^{3}\right)$ & 1.05 \\
& Buffer theoretical density $\left(\mathrm{g} / \mathrm{cm}^{3}\right)$ & 2.25 \\
& IPyC density $\left(\mathrm{g} / \mathrm{cm}^{3}\right)$ & $1.90 \pm 0.02$ \\
& OPyC density $\left(\mathrm{g} / \mathrm{cm}^{3}\right)$ & $1.90 \pm 0.02$ \\
& IPyC/OPyC $(\mathrm{post} \mathrm{compact} \mathrm{anneal)} \mathrm{BAF}$ & $1.05 \pm 0.005$ \\
\hline
\end{tabular}

AGR-5/6/7 fuel specification parameter average values

Skerjank, W., B. Collin, INL/EXT-18-44631 Rev. 0, Aug. 2018. 


\section{Importance of TRISO Fuel Materials Properties for Irradiated Fuel Performance Analysis}

Inner SiC Tangential Stress

PARFUME uses these SiC layer material properties:

- Weibull characteristic strength $\sigma_{0}$

- Weibull modulus $\mathrm{m}$ variability in measured strength.

- Elastic moduli, Poisson's ratio

- Thermal conductivity and expansion

Table 3. Failure probability in the nominal conditions.

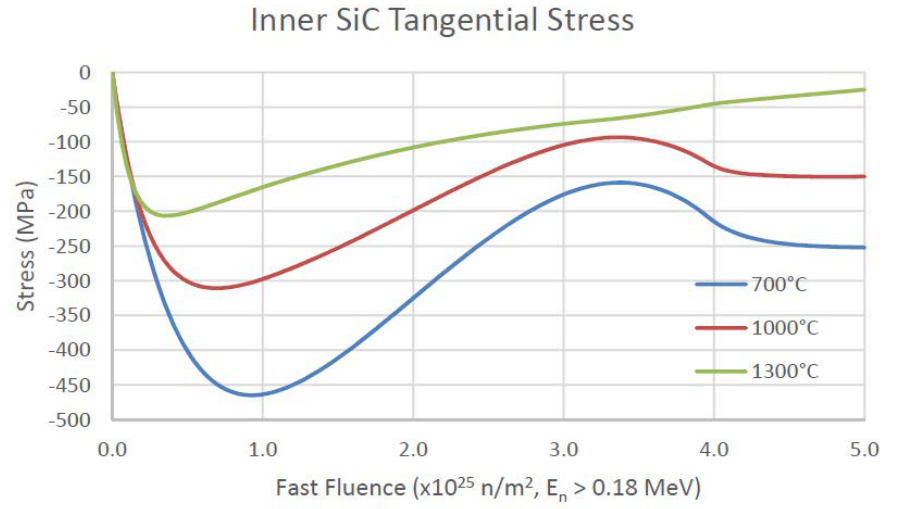

\begin{tabular}{|c|c|c|c|c|}
\hline \multirow{2}{*}{ Condition } & \multicolumn{3}{|c|}{ Probability of SiC failure } & Probability of \\
\cline { 2 - 5 } & Total & $\begin{array}{c}\text { Contribution from } \\
\text { IPyC Cracking }\end{array}$ & $\begin{array}{c}\text { Contribution from } \\
\text { Pressure }\end{array}$ & $\begin{array}{c}\text { IPyC cracking } \\
\text { IPyc }\end{array}$ \\
\hline 1 & $4.03 \times 10^{-4}$ & $4.03 \times 10^{-4}$ & $0^{*}$ & $8.94 \times 10^{-1}$ \\
\hline 2 & $2.52 \times 10^{-6}$ & $2.52 \times 10^{-6}$ & 0 & $5.48 \times 10^{-2}$ \\
\hline 3 & $2.21 \times 10^{-9}$ & $2.21 \times 10^{-9}$ & $2.82 \times 10^{-13}$ & $1.16 \times 10^{-3}$ \\
\hline
\end{tabular}

Weibull theory, coating layer failure probability: $\mathrm{P}_{\mathrm{f}}=1-\int_{\mathrm{V}}\left(\frac{\sigma}{\sigma_{\mathrm{o}}}\right)^{\mathrm{m}} \mathrm{dV}$ using tensile stress $(\sigma)$

* uCO fuel internal gas pressure too low to cause fuel failure 


\section{Importance of TRISO Fuel Materials Properties for Irradiated Fuel Performance Analysis}

Table 15. Failure probability: PyC irradiation-induced creep.

\begin{tabular}{|c|c|c|c|}
\hline Condition & $\begin{array}{c}\text { Sensitivity } \\
\text { Multiplication Factor }\end{array}$ & $\begin{array}{l}\text { Probability of } \\
\text { SiC failure }\end{array}$ & $\begin{array}{l}\text { Probability of } \\
\text { IPyC cracking }\end{array}$ \\
\hline \multirow{7}{*}{1} & 0.2 & $2.48 \times 10^{-1}$ & $9.99 \times 10^{-1}$ \\
\hline & 0.33 & $5.07 \times 10^{-2}$ & $9.99 \times 10^{-1}$ \\
\hline & 0.5 & $1.01 \times 10^{-2}$ & $9.99 \times 10^{-1}$ \\
\hline & 1 (nominal) & $4.03 \times 10^{-4}$ & $8.94 \times 10^{-1}$ \\
\hline & 2 & $1.49 \times 10^{-7}$ & $1.06 \times 10^{-2}$ \\
\hline & 3 & $5.35 \times 10^{-10}$ & $3.50 \times 10^{-4}$ \\
\hline & 5 & $3.35 \times 10^{-13}$ & $3.99 \times 10^{-6}$ \\
\hline \multirow{7}{*}{2} & 0.2 & $5.57 \times 10^{-2}$ & $9.99 \times 10^{-1}$ \\
\hline & 0.33 & $7.80 \times 10^{-3}$ & $9.99 \times 10^{-1}$ \\
\hline & 0.5 & $1.24 \times 10^{-3}$ & $9.99 \times 10^{-1}$ \\
\hline & 1 (nominal) & $2.52 \times 10^{-6}$ & $5.48 \times 10^{-2}$ \\
\hline & 2 & $1.76 \times 10^{-10}$ & $1.57 \times 10^{-4}$ \\
\hline & 3 & $4.96 \times 10^{-13}$ & $4.32 \times 10^{-6}$ \\
\hline & 5 & $2.52 \times 10^{-16}$ & $4.22 \times 10^{-8}$ \\
\hline \multirow{7}{*}{3} & 0.2 & $7.50 \times 10^{-3}$ & $9.99 \times 10^{-1}$ \\
\hline & 0.33 & $7.00 \times 10^{-4}$ & $9.98 \times 10^{-1}$ \\
\hline & 0.5 & $2.43 \times 10^{-5}$ & $2.73 \times 10^{-1}$ \\
\hline & 1 (nominal) & $2.21 \times 10^{-9}$ & $1.16 \times 10^{-3}$ \\
\hline & 2 & $2.88 \times 10^{-8}$ & $3.04 \times 10^{-6}$ \\
\hline & 3 & $2.98 \times 10^{-7}$ & $8.34 \times 10^{-8}$ \\
\hline & 5 & $1.30 \times 10^{-6}$ & $8.12 \times 10^{-10}$ \\
\hline
\end{tabular}

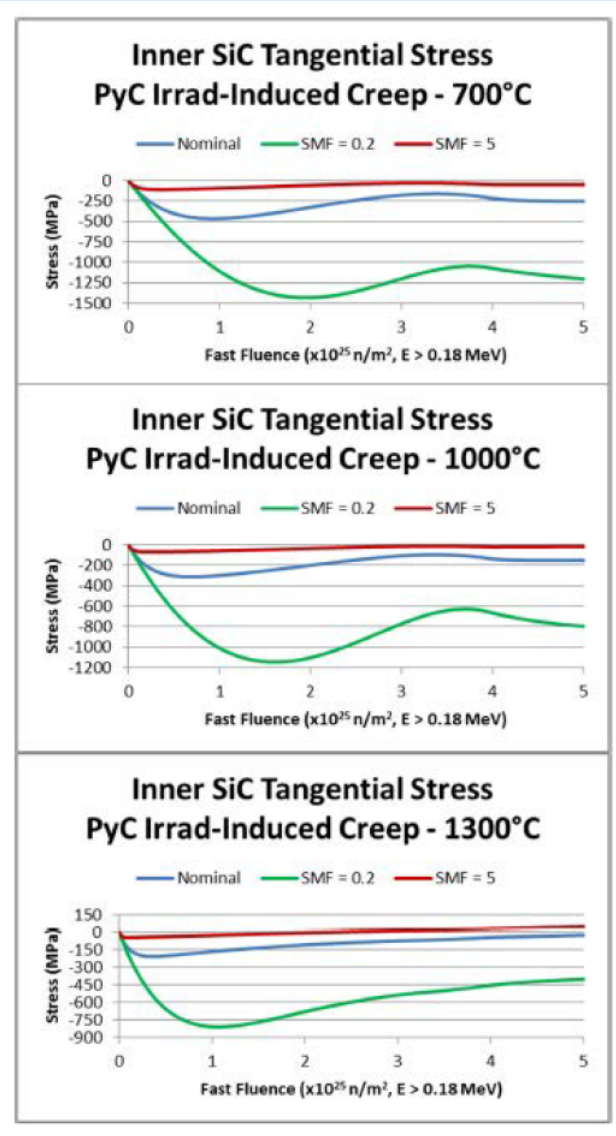

PARFUME Results for PyC Irradiation-induced creep

PARFUME uses these PyC

layer material properties:

- Elastic moduli

- Poisson's ratio

- Thermal conductivity and expansion

- Irradiation-induced creep*

- Poisson's ratio in creep*

- Strain rates*

- Weibull strength and modulus*

* These parameters have significant impact on SiC failure probability

Skerjank, W., B. Collin,

INL/EXT-18-44631,

Rev. 0, Aug. 2018. 
Importance of TRISO Fuel Materials Properties for Irradiated Fuel Performance Analysis

\section{Summary of maximum impact of material properties on SiC failure probability}

\begin{tabular}{|c|c|c|c|c|}
\hline Material Property & $\begin{array}{l}\text { Sensitivity } \\
\text { Multiplication Factor or } \\
\text { Material Property Value }\end{array}$ & $\begin{array}{c}\text { Irradiation } \\
\text { Temperature }\left({ }^{\circ} \mathrm{C}\right)\end{array}$ & $\begin{array}{l}\text { Increase in } \\
\text { SiC failure } \\
\text { probability }\end{array}$ & $\begin{array}{l}\mathrm{SiC} \text { failure } \\
\text { probability }\end{array}$ \\
\hline \multirow{3}{*}{ PyC elastic moduli } & \multirow{3}{*}{ 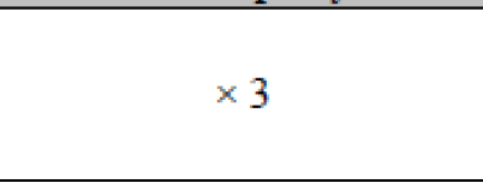 } & 700 & 1.6 & $6.54 \times 10^{-4}$ \\
\hline & & 1000 & 2.7 & $6.84 \times 10^{-6}$ \\
\hline & & 1300 & 2.0 & $4.47 \times 10^{-9}$ \\
\hline \multirow{3}{*}{ PyC Poisson's ratio } & \multirow{3}{*}{0.5} & 700 & 1.3 & $5.04 \times 10^{-4}$ \\
\hline & & 1000 & 1.6 & $3.96 \times 10^{-6}$ \\
\hline & & 1300 & 1.4 & $3.03 \times 10^{-9}$ \\
\hline \multirow{3}{*}{$\begin{array}{l}\text { PyC irradiation- } \\
\text { induced creep }\end{array}$} & \multirow{3}{*}{$\times 0.2$} & 700 & 1.1 & $2.48 \times 10^{-1}$ \\
\hline & & 1000 & $2.2 \times 10^{4}$ & $5.57 \times 10^{-2}$ \\
\hline & & 1300 & $3.4 \times 10^{6}$ & $7.50 \times 10^{-3}$ \\
\hline $\begin{array}{l}\text { PyC Poisson's ratio in } \\
\text { creep }\end{array}$ & \multicolumn{4}{|c|}{ Failure probability is maximum at nominal Poisson's ratio in creep } \\
\hline
\end{tabular}

Skerjank, W., B. Collin, INL/EXT-18-44631, Rev. 0, Aug. 2018. ${ }^{10}$ 
Importance of TRISO Fuel Materials Properties for Irradiated Fuel Performance Analysis

\section{Summary of maximum impact of material properties on SiC failure probability (cont.)}

\begin{tabular}{|c|c|c|c|c|}
\hline Material Property & $\begin{array}{c}\text { Sensitivity } \\
\text { Multiplication Factor or } \\
\text { Material Propertv Value }\end{array}$ & $\begin{array}{c}\text { Irradiation } \\
\text { Temperature }\left({ }^{\circ} \mathrm{C}\right)\end{array}$ & $\begin{array}{l}\text { Increase in } \\
\mathrm{SiC} \text { failure } \\
\text { probability }\end{array}$ & $\begin{array}{l}\text { SiC failure } \\
\text { probability }\end{array}$ \\
\hline \multirow{3}{*}{$\begin{array}{l}\text { PyC irradiation- } \\
\text { induced dimensional } \\
\text { change }\end{array}$} & \multirow[t]{3}{*}{ - } & 700 & $2.4 \times 10^{3}$ & $9.68 \times 10^{-1}$ \\
\hline & & 1000 & $1.7 \times 10^{5}$ & $4.21 \times 10^{-1}$ \\
\hline & & 1300 & $1.1 \times 10^{7}$ & $2.48 \times 10^{-2}$ \\
\hline \multirow{3}{*}{$\begin{array}{l}\text { PyC Weibull } \\
\text { parameters } \\
\left(\mathrm{m} / \sigma_{0}\right)\end{array}$} & \multirow{3}{*}{$8 / 10.0$} & 700 & 1.04 & $4.20 \times 10^{-4}$ \\
\hline & & 1000 & 2.1 & $5.37 \times 10^{-5}$ \\
\hline & & 1300 & 4.1 & $9.02 \times 10^{-9}$ \\
\hline \multirow{3}{*}{$\mathrm{SiC}$ elastic modulus } & \multirow{3}{*}{$\times 5$} & 700 & 1.6 & $6.45 \times 10^{-4}$ \\
\hline & & 1000 & 1.7 & $4.21 \times 10^{-6}$ \\
\hline & & 1300 & 1.4 & $3.01 \times 10^{-9}$ \\
\hline \multirow{3}{*}{ SiC Poisson's ratio } & \multirow{3}{*}{0.5} & 700 & 2.6 & $1.03 \times 10^{-3}$ \\
\hline & & 1000 & 2.7 & $6.79 \times 10^{-6}$ \\
\hline & & 1300 & 2.6 & $5.67 \times 10^{-9}$ \\
\hline \multirow{3}{*}{$\begin{array}{l}\text { SiC Weibull } \\
\text { parameters }\end{array}$} & \multirow{3}{*}{$4 / 0.76$} & 700 & 12.4 & $4.99 \times 10^{-3}$ \\
\hline & & 1000 & 26.5 & $4.03 \times 10^{-4}$ \\
\hline & & 1300 & 76.3 & $1.01 \times 10^{-5}$ \\
\hline
\end{tabular}




\section{Importance of TRISO Fuel Materials Properties for Irradiated Fuel Performance Analysis}

TRISO PyC Materials Properties with Significant Impact on SiC Layer Failure Probability:

- PyC irradiation-induced creep

- PyC irradiation-induced strain (dimensional change)

TRISO SiC Properties with Major Impact on SiC Layer Failure Probability:

\section{- SiC Weibull modulus, $\mathrm{m}$}

\section{- Sic Weibull characteristic strength, $\sigma_{0}$}

Shrinkage (strain) of the PyC layers puts them into tension and the SiC layer into compression but the irradiation creep relieves that tensile stress and reduces $\mathrm{SiC}$ layer compression.

An increase of the irradiation-induced PyC strain or a decrease of the irradiationinduced PyC creep creates additional tensile stress in the $\mathrm{SiC}$ layer, increasing the $\mathrm{SiC}$ layer probability of failure.
TRISO Materials Properties with No Significant Impact:

- Kernel swelling rate

- Kernel thermal conductivity

- Buffer elastic modulus

- Buffer Poisson's ratio

- Buffer irradiation-induced creep

- Buffer Poisson's ratio in creep

- Buffer irradiation-induced dimensional change

- Buffer thermal conductivity

- Buffer thermal expansion

- $\quad$ PyC thermal conductivity

- PyC thermal expansion

- $\quad$ SiC thermal conductivity

- SiC thermal expansion. 


\section{Summary and Conclusions}

- PARFUME TRISO particle modeling involves 20+ materials properties.

- Parameter sensitivity studies combined with the use of sensitivity multiplication factors (SMF) varied around nominal property values can identify which parameters are most important.

- TRISO material properties exhibit a large variability according to published historical data.

- Determining which properties are most important can help prioritize the generation of new properties data when historical materials property data is not available or deemed adequate.

- Determining TRISO materials properties as a function of temperature, neutron irradiation fluence or damage (dpa) is difficult, involves thin coating layer samples, and requires spherical geometry samples, vs. flat thin plates.

- Parameter importance ranking studies can also be used to improve modeling details when code predictions differ from well-planned experimental results. 
APPENDIX I - Energy Multiplier Module (EM²) Accelerated Fuel Qualification Strategy 


\section{Energy Multiplier Module (EM ${ }^{2}$ ) Accelerated Fuel Qualification Strategy}

By John Bolin

Nuclear Technologies and Materials General Atomics

January 16, 2020

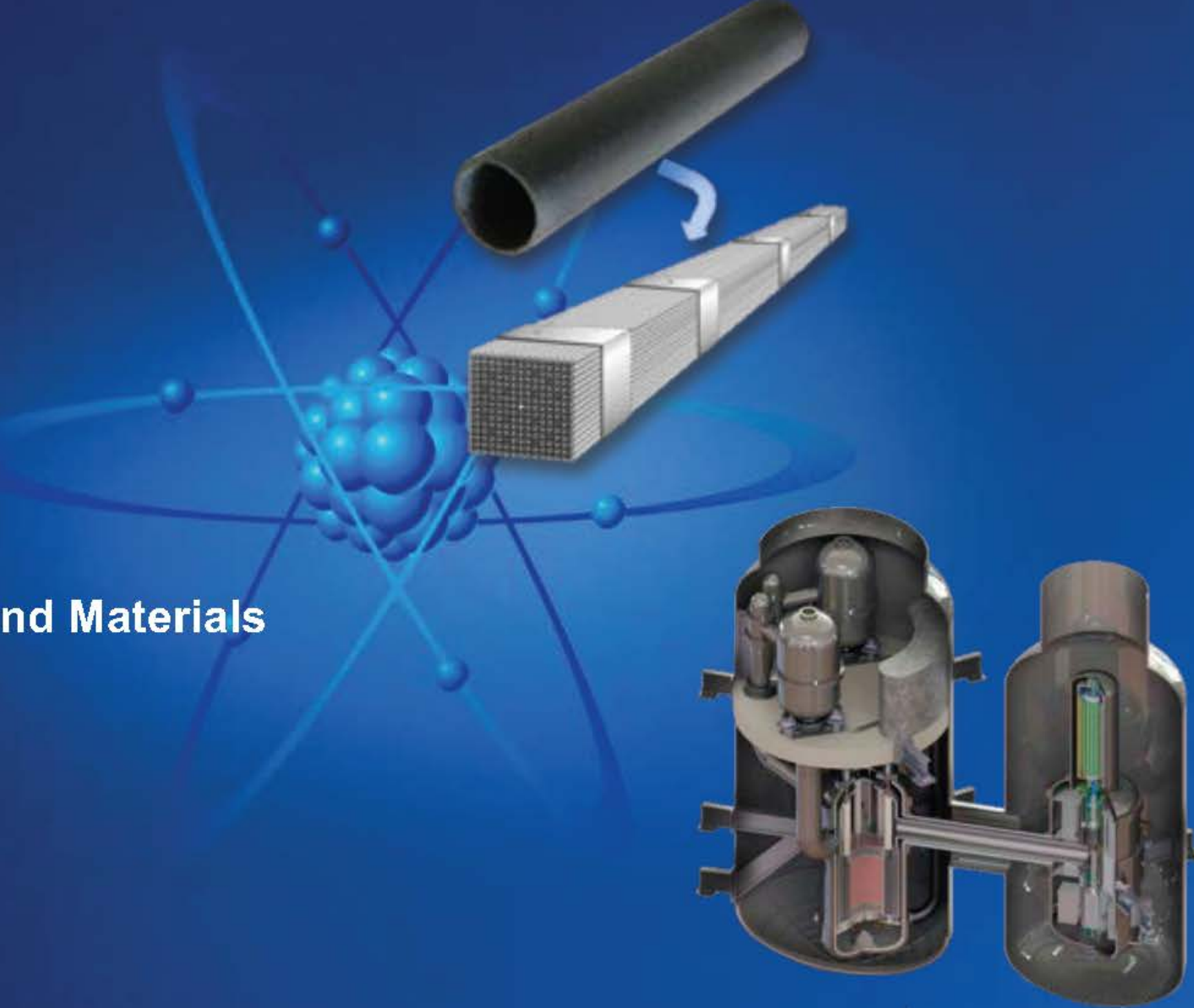




\section{EM² AFQ Strategy White Paper NRC Pre-Application License Review}

Contents include:

- Description of EM²

- Fuel design bases and criteria

- Analysis methods and material properties

- Performance evaluation

- Legacy approach to fuel qualification

- Strategy for accelerated qualification 


\section{EM² Fuel Design Driven by Top Level Goals}

\section{Innovative $\mathrm{EM}^{2}$ fuel design driven by:}

- Lower generation cost

- Fuel cycle flexibility

- Improved safety performance

- Higher net efficiency

- Higher fuel utilization

- Much less high-level waste

- Proliferation-resistant fuel cycle features

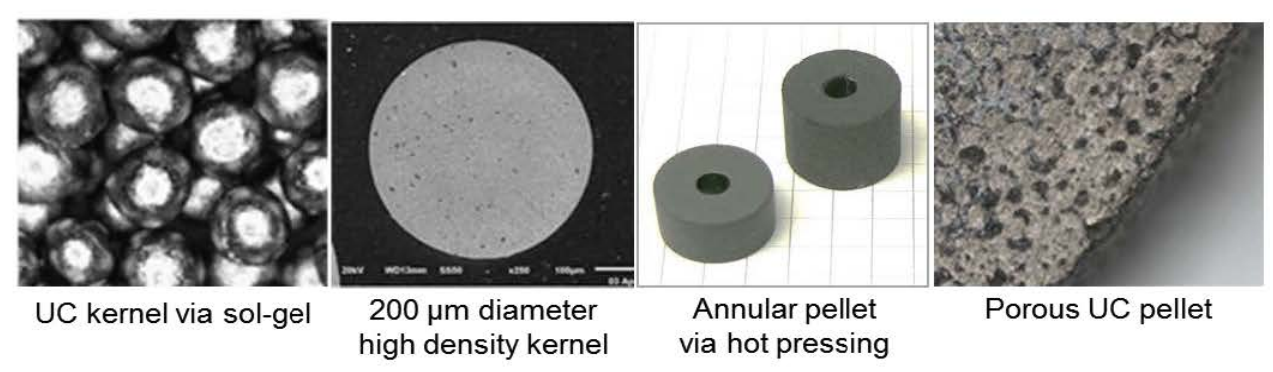




\section{$E^{2}$ is a Modular, Gas-Cooled, Convert-and-Burn, Fast Reactor}

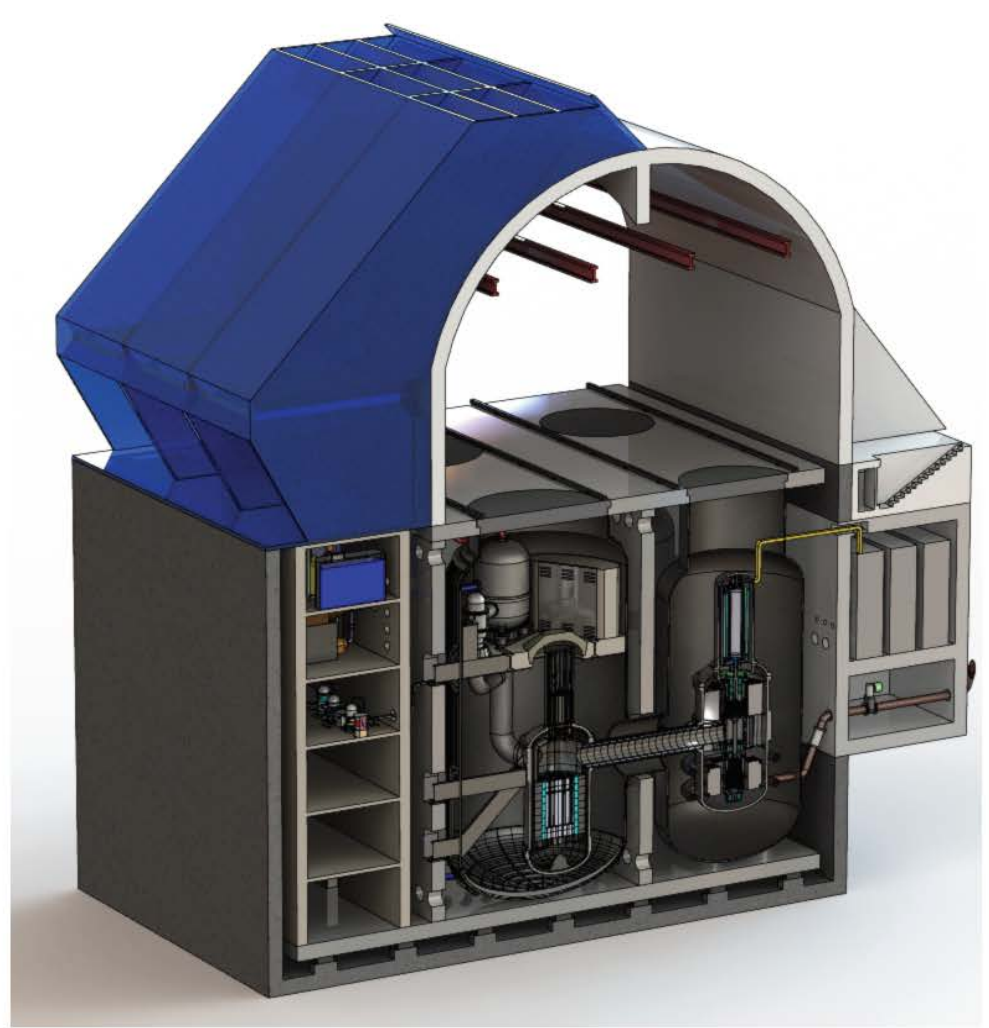

- 265/240 MWe per reactor for water/dry cooling

- $500 \mathrm{MW}_{\mathrm{t}}$ reactor power

- 4 modules per standard plant

- 60 year plant life; 30 year core life

- 60 year dry fuel storage

- $14 \%$ average fuel burnup

- Multi-fuel capable 


\section{Performance Evaluation Normal Operation}

- FRAPCON-4.0GA modified for UC fuel and SiGA SiC composite cladding

- Baseline calculation uses restrained swelling model

- Restructured annular pellet includes fuel swelling into open pores

- Restructured solid pellet has increased pellet porosity (17\% increasing to $26.8 \%$ )
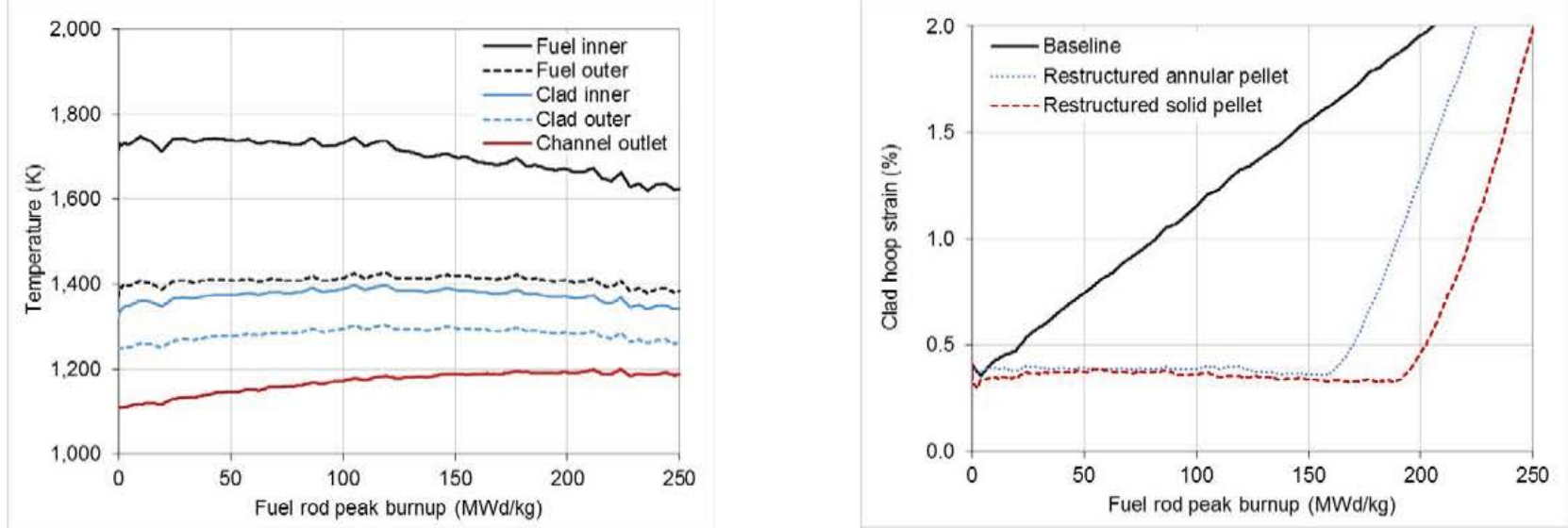


\section{Performance Evaluation Accident Conditions}

- Uncontrolled control rod withdrawal at middle-of-life conditions

- Reactor trips at $109 \%$ at $31 \mathrm{~s}$

- Peak fuel temperature of $1789 \mathrm{~K}$ well below melting point of $2705 \mathrm{~K}$

- Cladding circumferential strain $0.59 \%$ close to design limit of $0.62 \%$

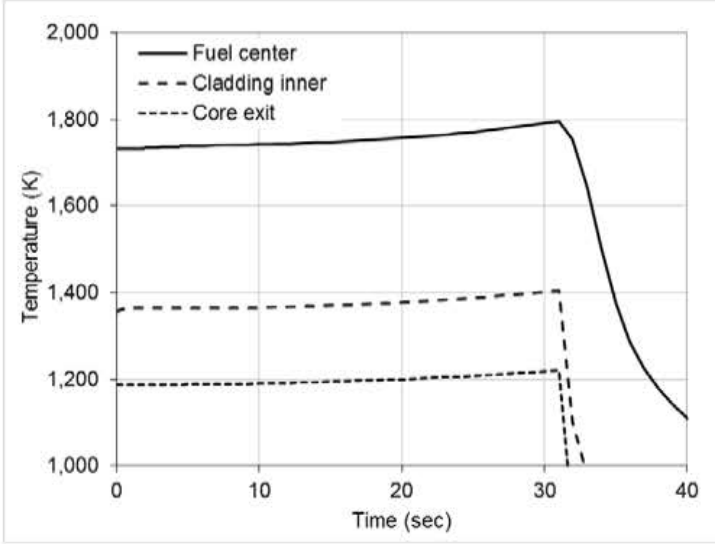

- Loss of Flow Accident (LOFA) with trip of Power Conversion System

- Small Break LOCA of $10 \mathrm{~cm}^{2}$

- Large Break LOCA of $400 \mathrm{~cm}^{2}$

- All transients assume only one of two passive cooling trains are operational

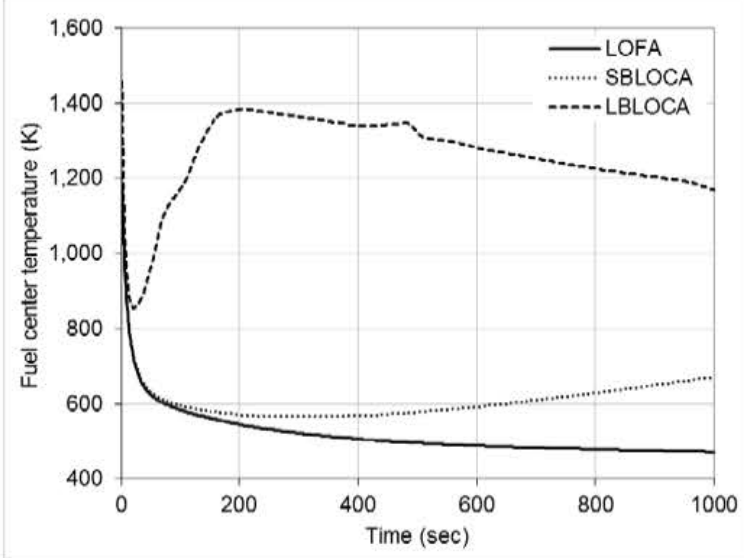




\section{Step-Wise AFQ Methodology Advanced M\&S Reduces Design Iterations}

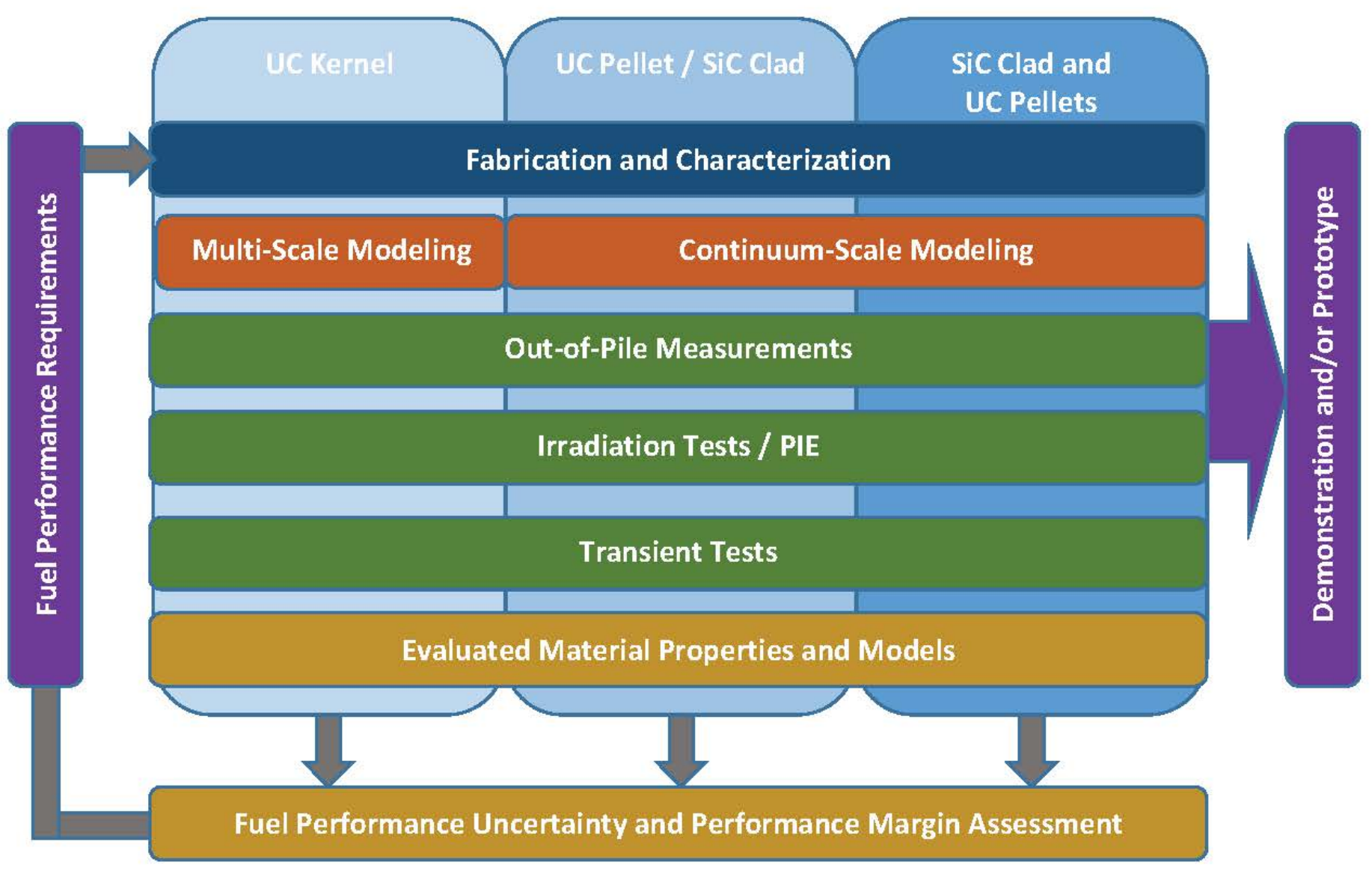




\section{Mini-Fuel Irradiation of UC Kernels at HFIR}

- HFIR irradiation delayed due to shutdown in 2019

- XCT of kernels before and after to determine fuel swelling

- Capsules will be assembled and inserted into HFIR in first quarter of 2020
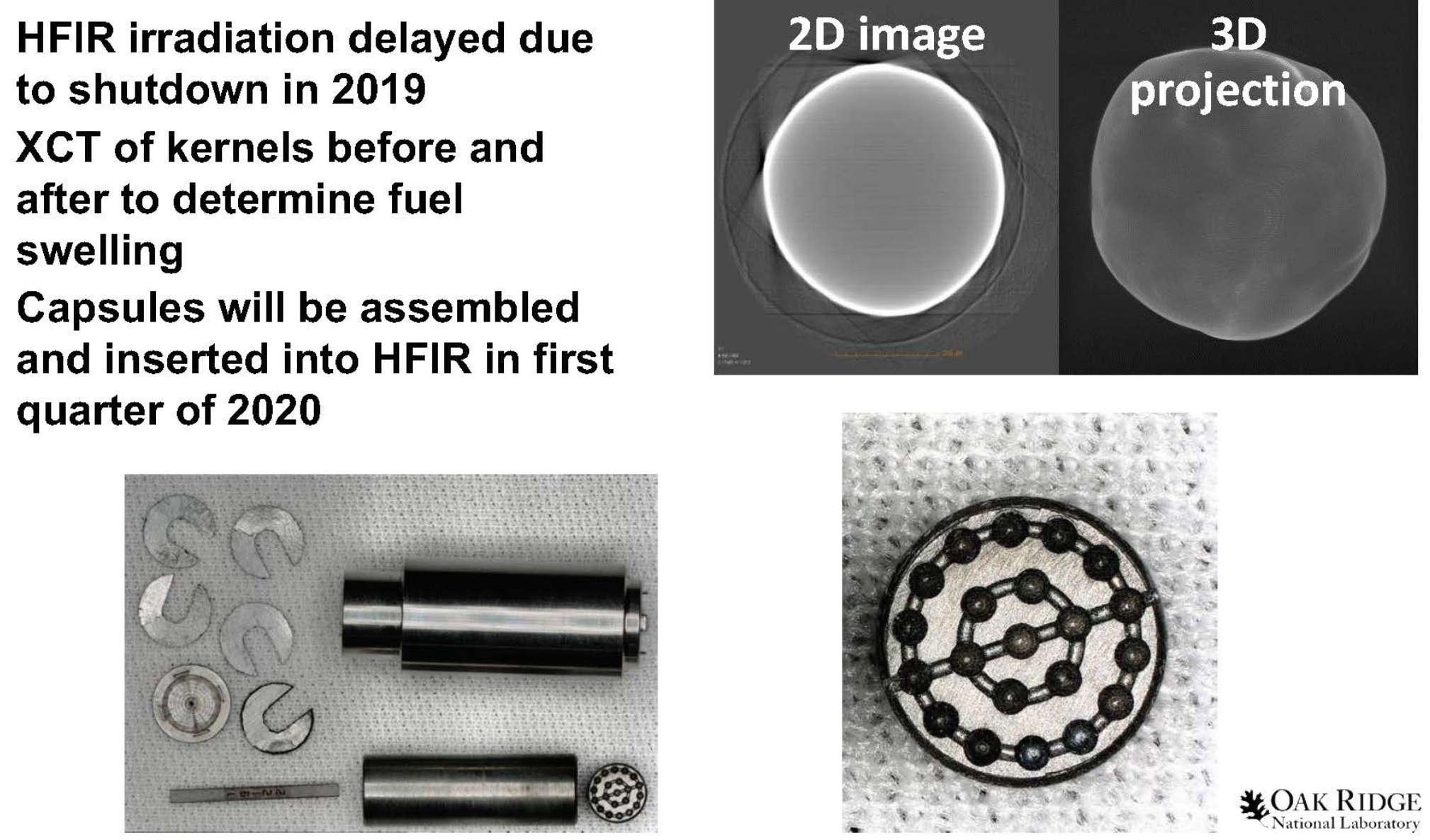


\section{Multi-Scale Modeling Progress}

- Ab-initio electronic structure modeling of Xe behavior, diffusion and clustering in UC

- Density functional theory calculations of vacancy and $X e$ clustering

- Preparing parameterization of Xolotl calculations of bubble populations
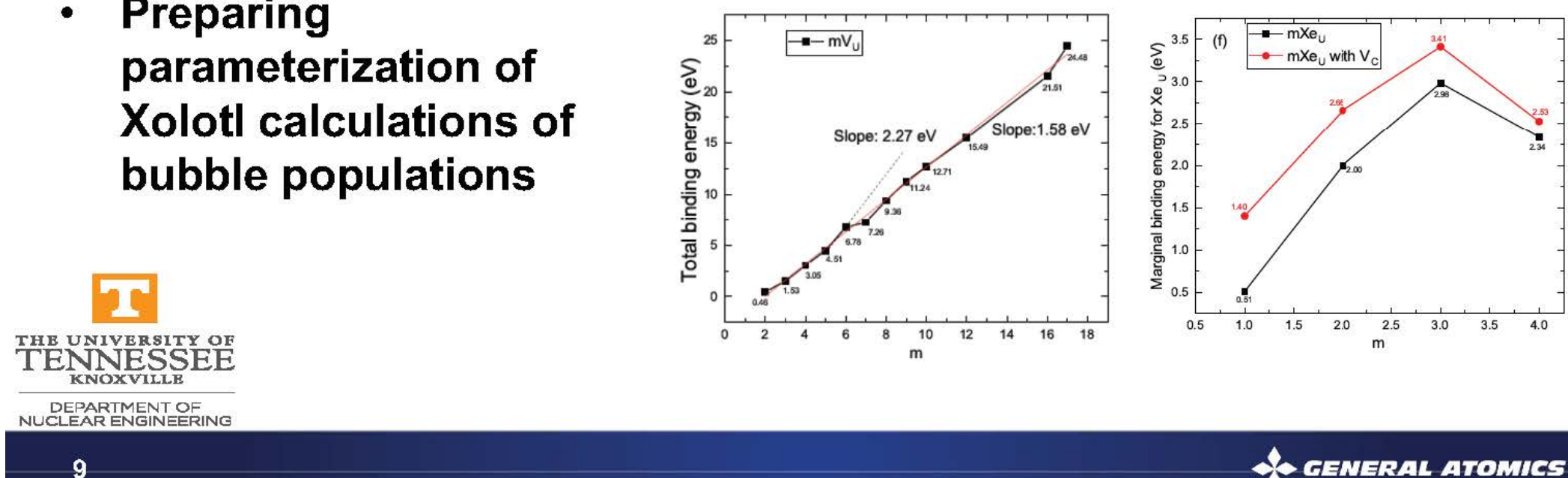


\section{Pre- and Post-Irradiation Analysis and Testing Planned and Proposed}

- XCT to quantify kernel swelling

- Fission gas release from capsules

- Preliminary fuel performance analysis using BISON

- Post-irradiation heating tests proposed to measure fission gas release at elevated temperature
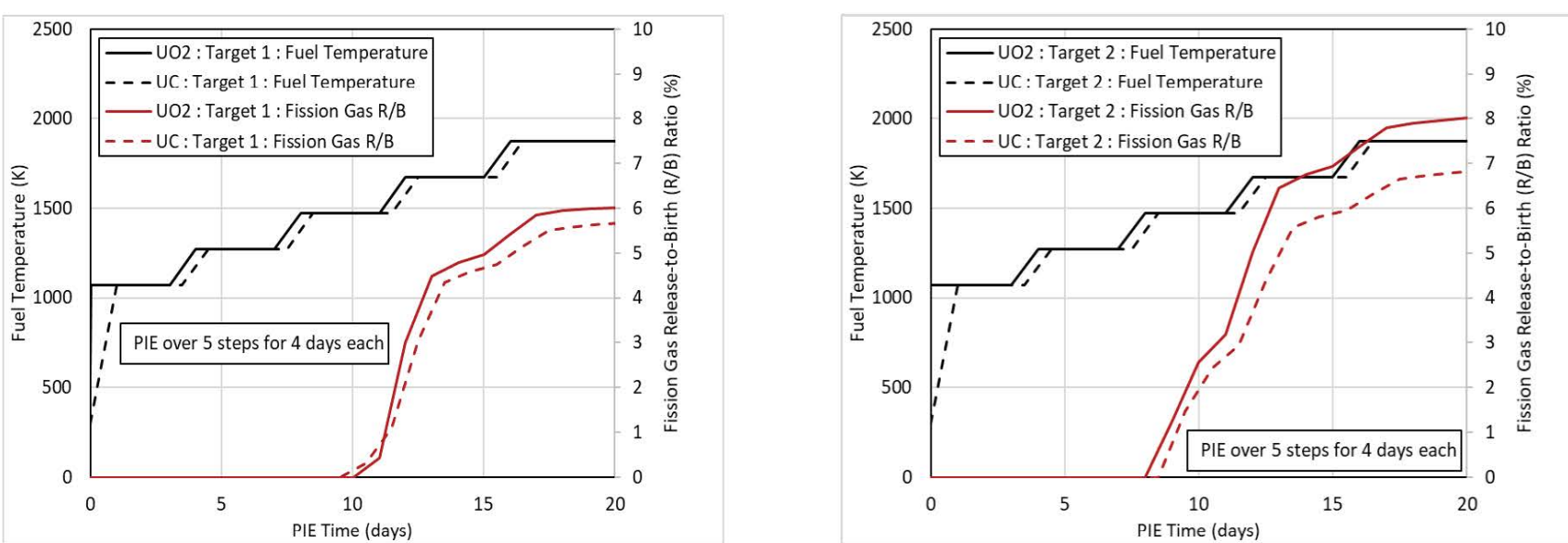


\section{Accelerated Irradiation at INL Advanced Test Reactor}

- Accelerated irradiation of UC pellets using INL Fission Accelerated Steady-state Testing (FAST) capsule design and approach

- Reduction in pellet diameter and increase in enrichment result in higher fission density and accelerated burnup with similar peak fuel temperatures

- Initial capsule design, scaling relationships, and fabrication for $\mathrm{EM}^{2} \mathrm{UC}$ pellets is supported by GA under a recent three-year INL Laboratory-Directed Research and Development project

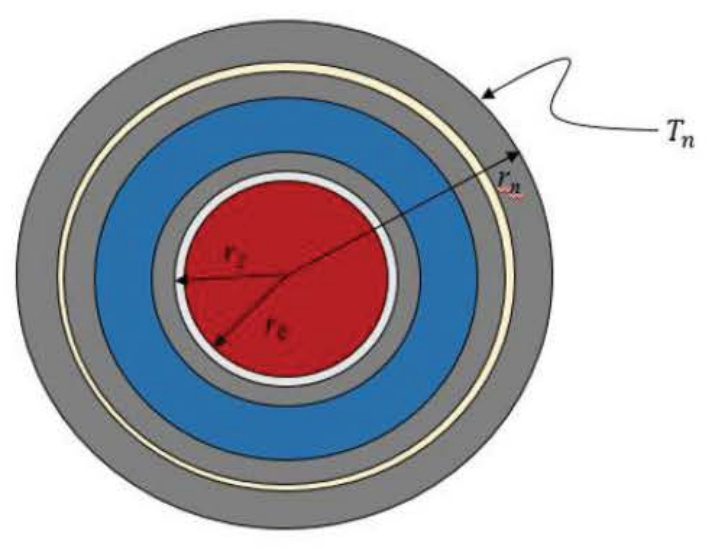




\section{Reduced Size UC Pellet Irradiation}

Key objectives

- Fission gas release

- Fuel swelling

- Creep

- PIE and post-irradiation testing

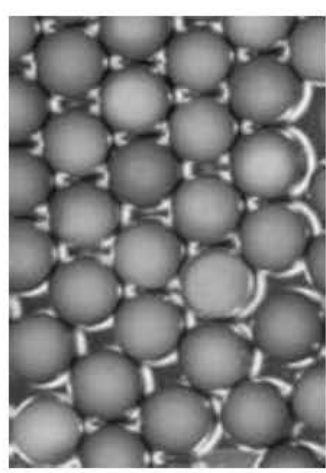

- Validate science-based models

Proposed irradiation facilities

- Mini-pellet discs in HFIR

- Reduced-size pellets in ATR using FAST approach

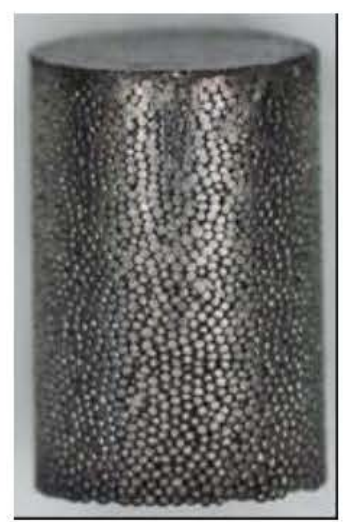




\section{Pellet-Clad Interaction Integral Fuel Testing}

- Swelling, creep and fission gas release interrelationships

- Validate advanced modeling and simulation

- Initial testing in ATR using on-line FGR monitoring used in AGR Fuel testing of TRISO compacts

- Prototypical testing in gas cartridge loop in Versatile Test Reactor
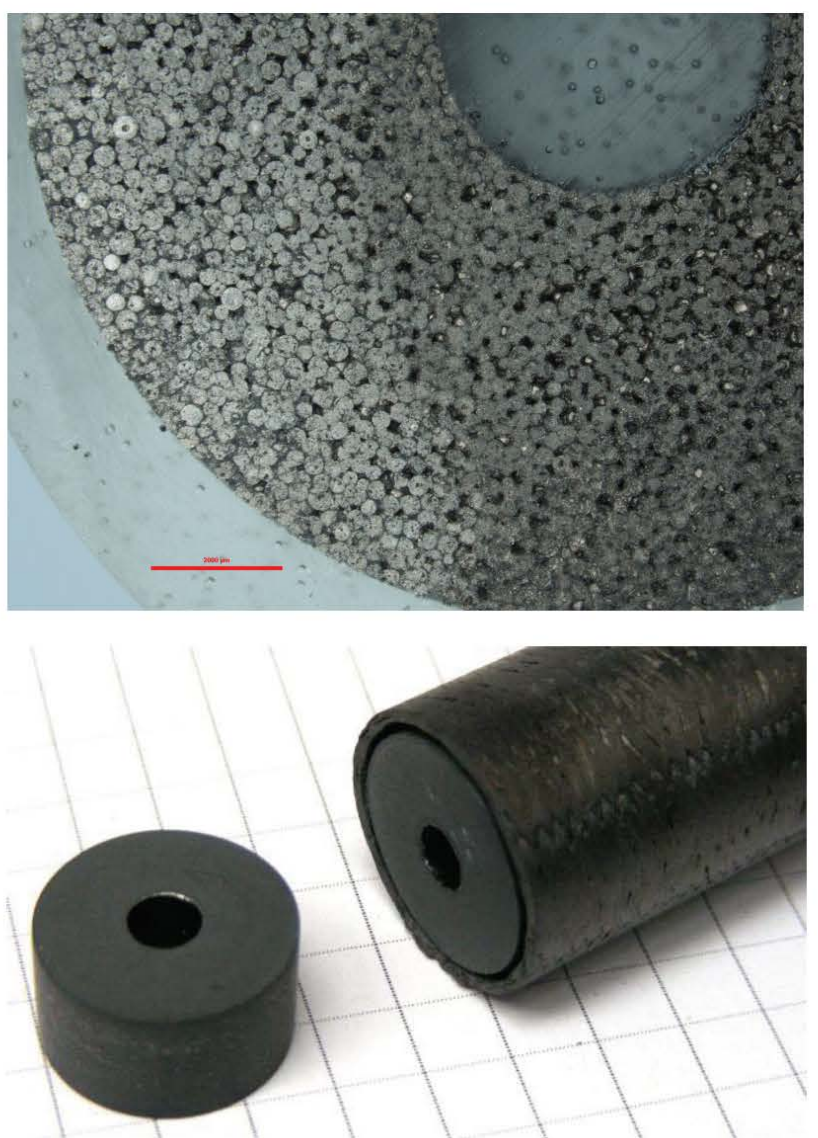


\section{Demonstration / Prototype Reactor Fuel Surveillance and Operating License Conditions}

- Safety case established from science-based modeling validated by testing

- Fuel qualification for full burnup conditional on periodic fuel surveillance and testing to reduce performance uncertainties and risk

- Fuel qualification risk reduction similar to reactor vessel material surveillance and life extension measures in current fleet
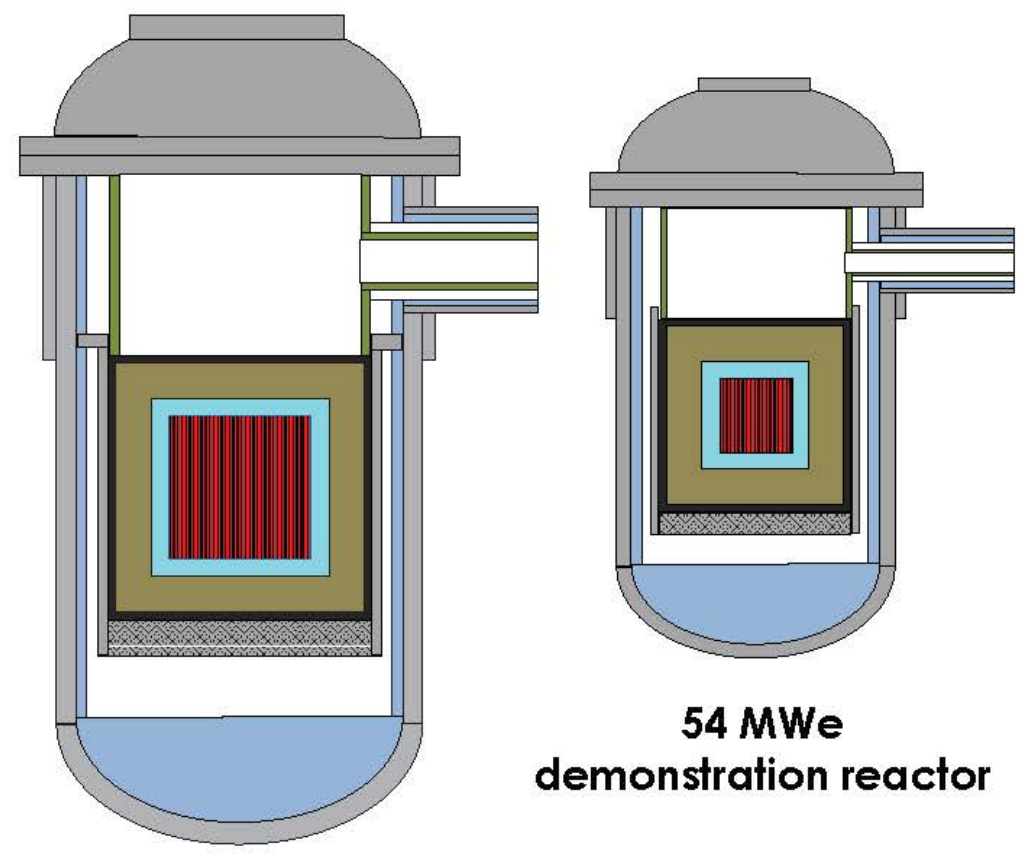

demonstration reactor

$250 \mathrm{MWe}$

commercial reactor 


\section{Key Objectives of $\mathrm{EM}^{2}$ AFQ Strategy}

- Science-based approach to predictive performance of nuclear fuel can fulfill some integral test requirements

- Accelerated fuel irradiations as part of sciencebased approach can be substituted for integral fuel irradiations

- Fuel surveillance and conditional operating license is appropriate for $\mathrm{EM}^{2}$ long life core as substitute for full burnup fuel testing under prototypical conditions 


\section{Thank You}

\section{ACKNOWLEDGEMENT}

This material is based upon work supported by the Department of Energy under Award Number DE-NE0008831.

\section{DISCLAIMER}

This report was prepared as an account of work sponsored by an agency of the United States Government. Neither the United States Government nor any agency thereof, nor any of their employees, makes any warranty, express or implied, or assumes any legal liability or responsibility for the accuracy, completeness, or usefulness of any information, apparatus, product, or process disclosed, or represents that its use would not infringe privately owned rights. Reference herein to any specific commercial product, process, or service by trade name, trademark, manufacturer, or otherwise does not necessarily constitute or imply its endorsement, recommendation, or favoring by the United States Government or any agency thereof. The views and opinions of authors expressed herein do not necessarily state or reflect those of the United States Government or any agency thereof. 
APPENDIX J - Advanced Fuel Qualification Methodology Report

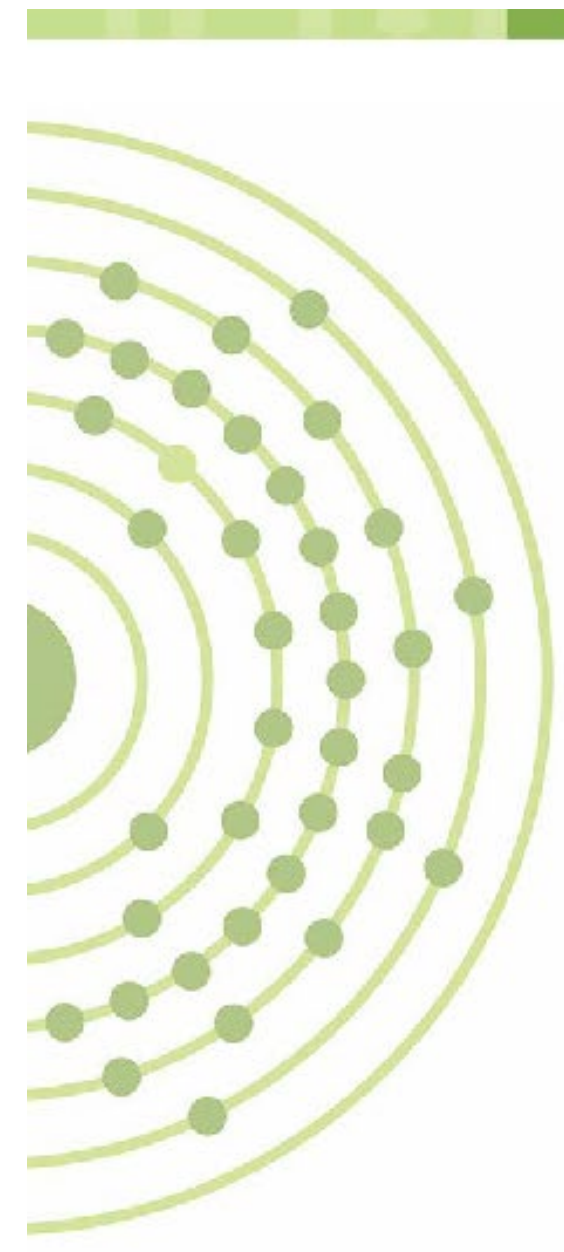

\section{TerraPower}

\section{Advanced Fuel Qualification Methodology Report}

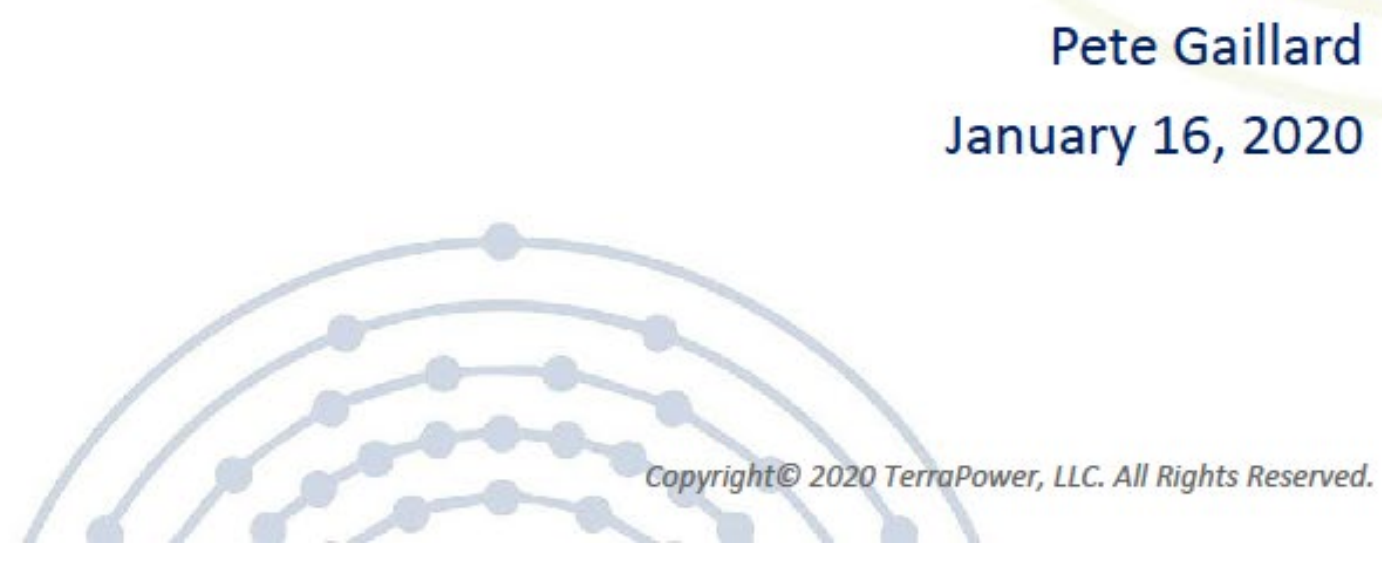




\section{Overview}

- TerraPower was notified in September 2019 of an award to develop the Advanced Fuel Qualification Methodology Report for metallic fuel in a sodium fast reactor environment

- The Report will provide a methodology addressing the qualification of advanced reactor fuel

- The Report will describe a process to evaluate regulatory deficiencies or gaps faced by advanced reactor designs for fuel qualification 


\section{Goals}

Implementing the methodology will result in:

- Development of a process to identify and develop regulatory requirements and design criteria for advanced reactor fuel

- Identification and development of specific regulatory requirements applicable for metallic fuel - but the process may be used for other advanced reactor developers)

- A method for development of Regulatory Acceptance Criteria (RAC) to ensure compliance with regulatory requirements and design criteria 


\section{Initial Steps}

- Identify and describe the aspects of the fuel system design to be addressed

- Identify applicable regulatory requirements

- The regulatory requirements are expected to be similar to requirements described in NUREG-0800, Section 4.2, Fuel System Design

- Modify or remove requirements that are not applicable 


\section{Regulatory Acceptance Criteria (RAC)}

- The RAC will be analogous to SRP AC but are expected to differ due to inherent differences between SFR and LWR technology

- SRP - Stress, strain, or loading limits for spacer grids, guide tubes, thimbles, fuel rods, control rods, channel boxes and other fuel system structural members should be provided

- RAC - Stress, strain, or loading limits for all fuel system components shall be established

- The RAC will be used to establish functional and performance design requirements 


\section{Additional Information}

- Additional information included in the report may specify design, analysis, programmatic, testing, documentation, or other types of requirements necessary to ensure the plant design complies with applicable regulatory requirements and expectations

- The Report will describe approaches (acceptance criteria and compliance methods) that may be used to demonstrate compliance with the regulatory requirements addressed in a specific SAR section. 


\section{Other Information}

Additional information to demonstrate compliance may include:

- Specification of design requirements (directly or by reference to codes and standards)

- Identification of required design and safety analyses

- Identification of design, construction, or operation procedural control programs 


\section{Expected Results}

- Expected results after the process is developed and implemented are descriptions of requirements for fuel system design necessary to ensure:

o The fuel system is not damaged during any condition of normal operation, including the effects of anticipated operational occurrences (AOOs)

- The number of fuel pin failures predicted for postulated accidents is not underestimated

- Fuel coolability will be maintained during postulated accidents

- Fuel system damage during postulated accidents will not prevent reactivity control/standby rod insertion when required 


\section{Summary}

The Advanced Fuel Qualification Methodology Report will describe a method which when implemented will result in:

- Identification of specific regulatory requirements applicable for metallic fuel that will need to be addressed in the Safety Analysis Report (SAR)

- Descriptions of requirements for fuel system design including acceptance criteria and compliance approaches

The NRC will review and evaluate the report 


\section{APPENDIX K - Fuel Qualification, NRC Perspectives}




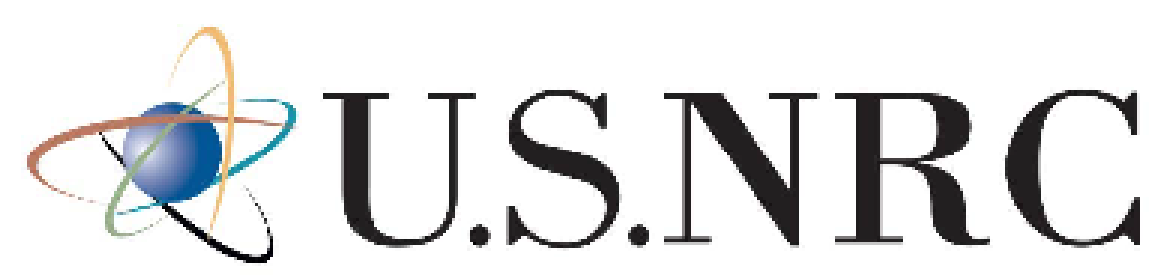

United States Nuclear Regulatory Commission

Protecting People and the Environment

\section{Fuel Qualification NRC Perspectives}

Accelerated Fuel Qualification Workshop

January 16, 2020 


\section{Topics}

- NRC fuel qualification obligations under NEIMA

- Advanced reactor fuel qualification strategy options

- Open discussion for path forward 


\section{NRC Fuel Qualification Obligations Under NEIMA}

The Nuclear Energy Innovation and Modernization Act (NEIMA) directs the NRC to modernize its approach to nuclear energy regulation.

https://www.congress.gov/bill/115th-congress/senate-bill/512/text

SEC. 103. of NEIMA covers "Advanced nuclear reactor program" and addresses fuel qualification in three subparts:

(b) Report To Establish Stages in the Commercial Advanced Nuclear Reactor Licensing Process.-(4) Required evaluations. --Consistent with the role of the Commission in protecting public health and safety and common defense and security, the report shall evaluate--

(A)(ii) strategies for the qualification of advanced nuclear reactor fuel, including the use of computer modeling and simulation and experimental validation... 


\section{NRC Fuel Qualification Obligations Under NEIMA (cont.)}

(c) Report to Increase the Use of Risk-Informed and Performance-Based Evaluation Techniques and Regulatory Guidance --

(4) Required evaluations. --Consistent with the role of the Commission in protecting public health and safety and common defense and security, the report shall evaluate--

(A) the ability of the Commission to develop and implement, where appropriate, riskinformed and performance-based licensing evaluation techniques and guidance for commercial advanced nuclear reactors within existing regulatory frameworks not later than 2 years after the date of enactment of this Act, including policies and guidance for the resolution of-

(i)(V) issues relating to the qualification of advanced nuclear reactor fuel; and...

(e) Report To Complete a Rulemaking To Establish a Technology-Inclusive Regulatory Framework for Optional Use by Commercial Advanced Nuclear Reactor Technologies in New Reactor License Applications and To Enhance Commission Expertise Relating to Advanced Nuclear Reactor Technologies.--

(1) Report required. -Not later than $\mathbf{3 0}$ months after the date of enactment of this Act, the Commission shall submit to the appropriate congressional committees a report... for--

(B) ensuring that the Commission has adequate expertise, modeling, and simulation capabilities, or access to those capabilities, to support the evaluation of commercial advanced reactor license applications, including the qualification of advanced nuclear reactor fuel. 


\section{Strategies to Meet Fuel Qualification Obligations Under NEIMA}

Internally, the staff has developed a strategy regarding the qualification of advanced nuclear reactor fuel as required by NEIMA Sec. 103(c)(4)(A)(i)(V):

(1) Staff will issue technology-neutral guidance as white paper, which will turn into RG.

(2) Staff to complete review of TRISO fuel performance topical report.

(3) Staff to complete review of topical report for metal fuels legacy data QA program.

(4) Contract with ORNL to produce a draft letter report describing regulatory policy guidance on the acceptability of an MSR fuel property measurement approach to fuel salt qualification and the technical basis for MSR fuel qualification and regulatory guidance documentation, which may be used to produce a formal NRC guidance document.

(5) Several vendors/designers have indicated plans to submit a topical report requesting NRC review and approval of its proposed fuel qualification methodology. 


\section{Options for Technology-Neutral Guidance}

The staff has committed to identifying (and beginning to implement) a technology-neutral guidance document by January 2021. This could take various forms:

1. White paper or NUREG, which leads to a future Regulatory Guide

2. Approval of a generic industry topical report

3. NRC participation in an industry-led report which leads to a future Regulatory Guide endorsing (in part or whole) the industry-led report

Thoughts/comments? 


\section{Content Ideas for Advanced Reactor Fuel Qualification Guidance}

- Provide definition of fuel qualification

- Explain the design role within fuel qualification vs. licensing role

- Description of various license options (e.g. Part 52, prototype, etc) and impacts on licensing basis requirements

- Introduce the concept of graduated fuel qualification for license applications

- Licensing oversight would be tied to the safety significance of the fuel for a given reactor design

- Fuel code verification and validation discussion

- Other topics? 
APPENDIX L - Lower Length Scale Modeling Examples 


\section{Lower Length Scale Modeling Examples}

Antoine Claisse, Denise Adorno Lopes, Kallie Metzger January 16, 2020

(W.) Westinghouse 


\section{Advanced Modeling Applications}

- Assist in understanding experimental results

- Interpolation and extrapolation of experimental data points

- Help to derive FRD models (to be validated on experiments)

- Materials screening and development

- Prediction of material behavior

- Rare or not yet commercially available materials accessible

- Combining with experiments to get deeper understanding

- Design of experiments

- Ensure selected conditions will highlight phenomena of interest

- Evaluate behaviors in extreme conditions (i.e. high burn up)

(W. Westinghouse 


\section{Example of application: understanding experimental}

\section{results}

- Xe diffusion in UN

- Large experimental discrepencies

- Modeling shows that a probable cause is the amount of vacancies in the material, varying too much and making comparison hard

Claisse, A., Schuler, T., Lopes, D. A., \& Olsson, P. (2016).

Transport properties in dilute UN $(X)$ solid solutions $(X=X e, K r)$. Physical Review B, 94(17), 174302.

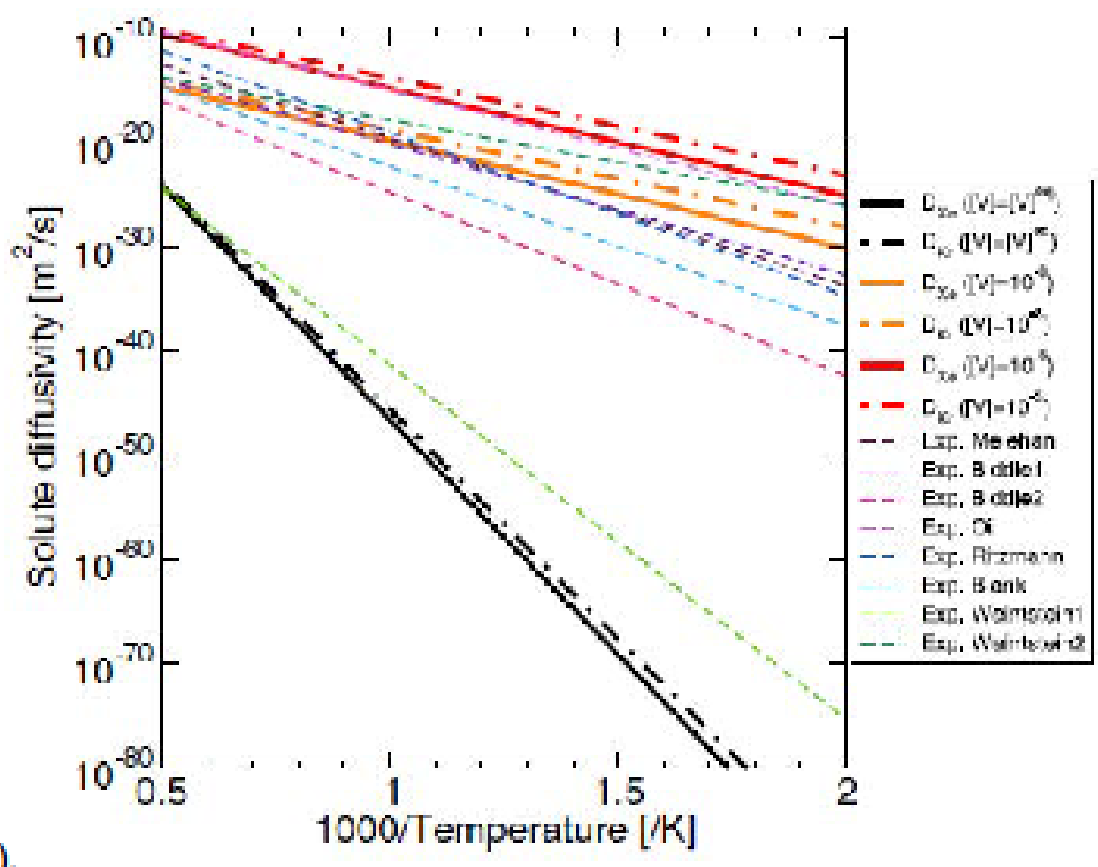

Atomistic modeling offers an explanation for apparently inconsistent

experimental results

We Westinghouse 


\section{Example of application: extrapolation/cliff behaviors}

- Xe diffusion in UN

- By understanding the diffusion mechanisms, we can

- Know the diffusion path

- Estimate if it will change with temperature

- Predict if there will be a sudden behavior change

Claisse, A., Schuler, T., Lopes, D. A., \& Olsson, P. (2016).

Transport properties in dilute UN $(X)$ solid solutions $(X=X e, K r)$.

Physical Review B, 94(17), 174302.

W. Westinghouse
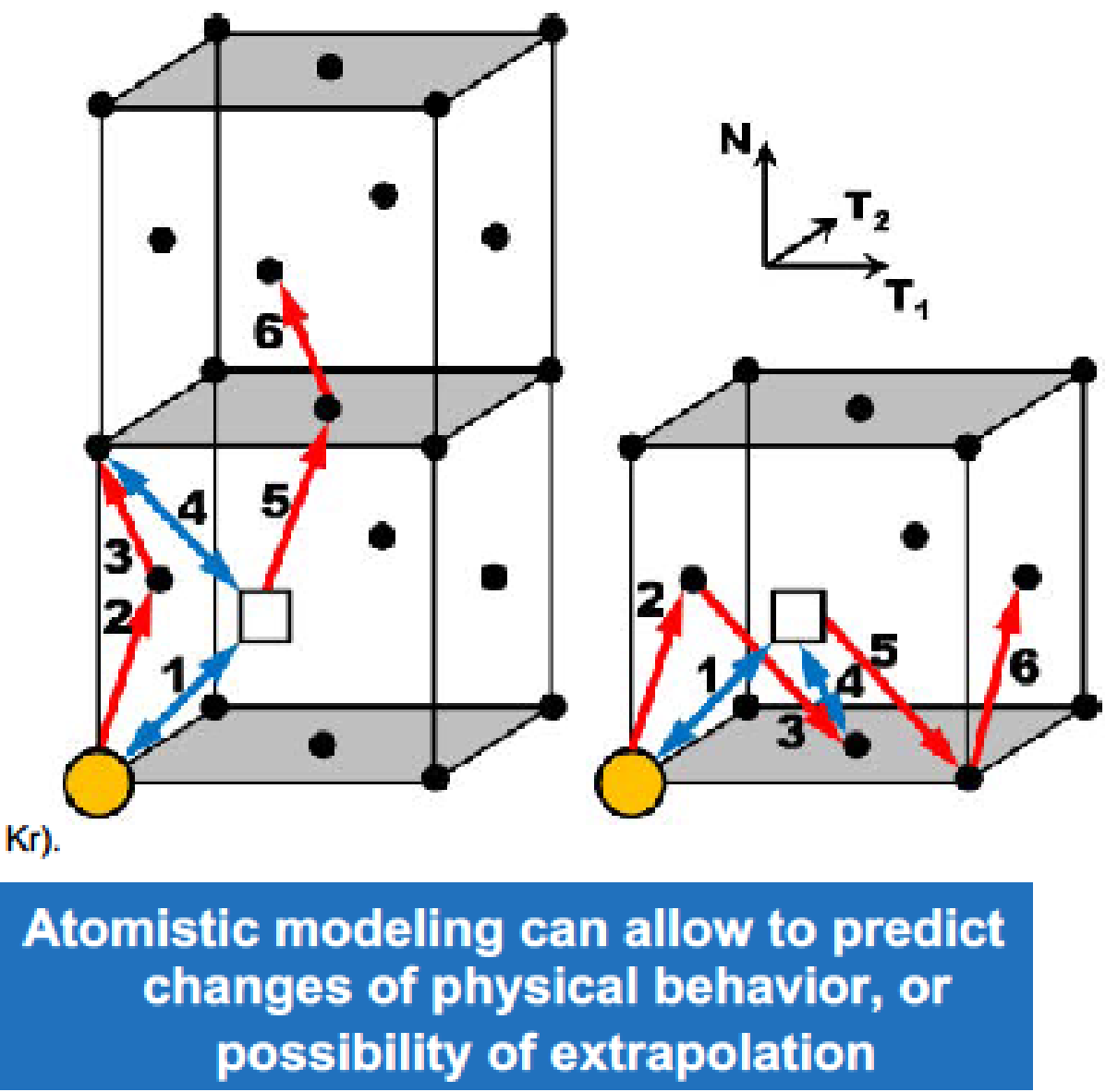


\section{Example of application: support to find equilibrium phases}

- Work mostly carried out by our partners at USC

- Combining SERPENT results (Fp concentration at a given $B U)$, CALPHAD modeling and small-scale modeling allowed to predict the phase of $\mathrm{FPs}$ in $\mathrm{U}_{3} \mathrm{Si}_{2}$

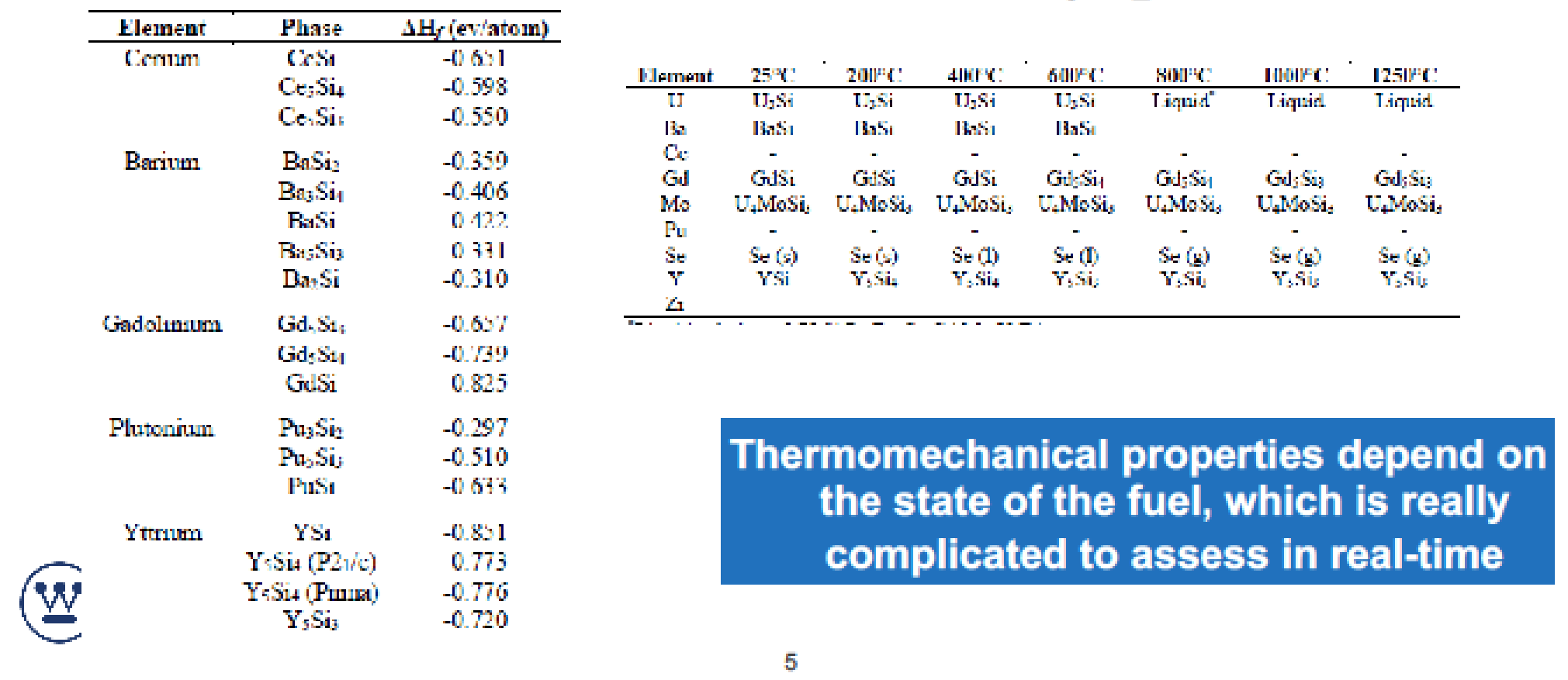




\section{APPENDIX M - Participants}


AFQ WORKSHOP II PARTICIPANTS-JANUARY 16, 2020

\begin{tabular}{|c|c|c|}
\hline AFFILIATION & NAME & EMAIL \\
\hline \multicolumn{3}{|c|}{ The Aerospace Corporation } \\
\hline & Pat Maloney & patricia.a.maloney@aero.org \\
\hline \multicolumn{3}{|c|}{ Analytical Mechanics Associates } \\
\hline & Samantha Rawlins & Samantha.b.rawlins@ama-inc.com \\
\hline \multicolumn{3}{|c|}{ Argonne National Lab } \\
\hline & Abdellatif (Latif) Yacout & yacout@anl.gov \\
\hline \multicolumn{3}{|c|}{ Department of Energy } \\
\hline & Madeline Feltus & madeline.feltus@nuclear.energy_gov \\
\hline & Mary Gillespie & mary_gillespie@nuclear.energy_gov \\
\hline & Andy Griffith & andrew.griffith@nuclear.energy_gov \\
\hline & David Henderson & david.henderson@nuclear.energy.gov \\
\hline & Diana Li & diana.li@nuclear.energy_gov \\
\hline & Bill McCaughey & bill.mccaughey@nuclear.energy.gov \\
\hline \multicolumn{3}{|l|}{ Framatome } \\
\hline & Joshua Parker & josh.parker@framatome.com \\
\hline \multicolumn{3}{|c|}{ General Atomics } \\
\hline & Mark Adams & Mark.adams@ga.com \\
\hline & Christina Back & Christina.Back@ga.com \\
\hline & John Bolin & John.Bolin@ga.com \\
\hline & Ron Faibish & Ron.Faibish@ga.com \\
\hline \multicolumn{3}{|c|}{ Idaho National Lab } \\
\hline & Steve Hayes & steven.hayes@inl.gov \\
\hline & Matthew Kerr & Matthew.Kerr@inl.gov \\
\hline \multicolumn{3}{|c|}{ Lightbridge Corporation } \\
\hline & Aaron Totemeier & Atotemeier@ltbridge.com \\
\hline
\end{tabular}




\begin{tabular}{l|l|l} 
AFFIUATION & NAME & EMAIL \\
\hline Los Alamos National Lab & & \\
\hline & David Andersson & andersson@lanl.gov \\
\hline Nuclear Regulatory Commission & & \\
\hline & Tim Drzewiecki & tim.drzewiecki@nrc.gov \\
\hline & Ray Furstenau & Ravmond.furstenau@nrc.gov \\
\hline & Jordan Hoellman & Jordan.hoellman2@nrc.gov \\
\hline & Lucas Kyriazidis & Lucas.Kvriazidis@nrc.gov \\
\hline & Kim Webber & Kimberly.webber@nrc.gov \\
\hline & Chris Van Wert & Christopher.VanWert@nrc.gov \\
\hline Oak Ridge National Lab & & \\
\hline TerraPower & Kurt Terrani & terranika@ornl.gov \\
\hline & & \\
\hline Walsh Engineering & Pete Gaillard & pgaillard@terrapower.com \\
\hline & James Vollmer & ivollmer@terrapower.com \\
\hline Westinghouse & & \\
\hline & Jim Wemer & Jim.wemer@walshengr.com \\
\hline & & \\
\hline & Kathryn Metzger & metzgeke@westinghouse.com
\end{tabular}


- GENERAL ATOMICS

P.O. BOX 85608 SAN DIEGO, CA 92186-5608 (858) 455-3000 